ROMANIAN ACADEMY

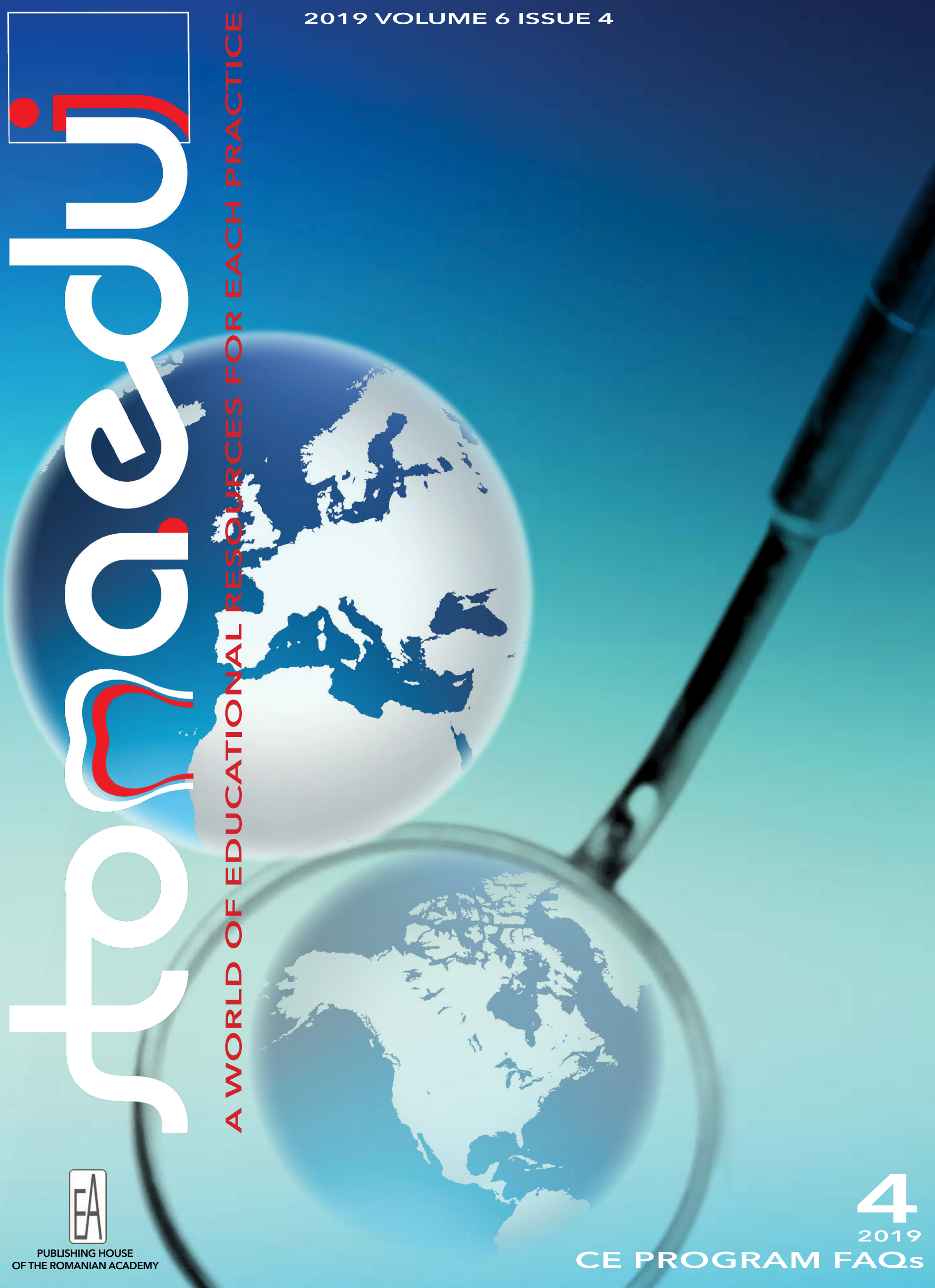




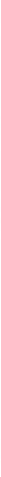

\section{Hofident $Q_{10}$}

Product presentation: Solution for oral hygiene.

Composition (INCI): aqua/water, alcohol, Capsella Bursa Pastoris extract, Plantago Lanceolata extract, Chamomilla Recutita extract, Achillea Millefolium extract, Aesculus Hippocastanum extract, Mentha Piperita extract, Ubiquinone.

Action: The product has antiseptic, healing, hemostatic, anti-inflammatory aєtion, it acts as a antioxidant, detoxifier, deodorant. It is strongly recommended in gingivitis, stomatitis, thrush, compression pain causedby dental prostheses, after tooth extraction, in case of nipple lesion, bleeding gums, mouth and gum ulcers.

Recommendations: It delays dental plaque formation, it prevents bad odour and provides daily mouth hygiene.

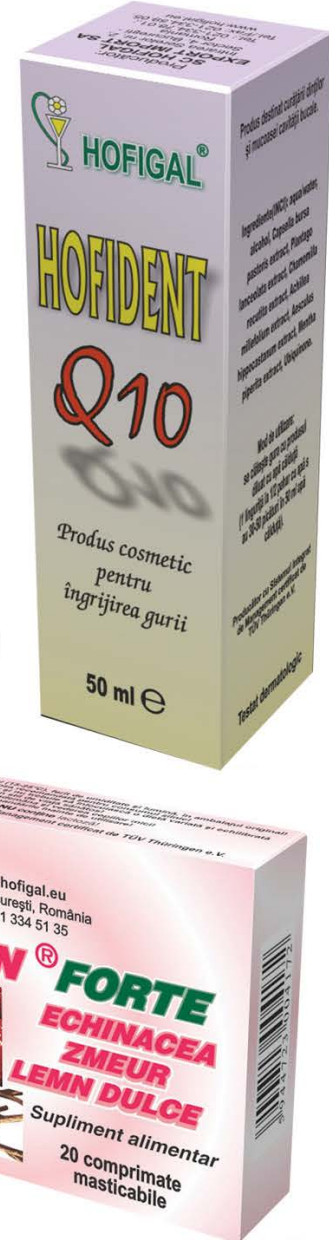

\section{Hoflmun ${ }^{\oplus}$ FORTE}

Product presentation:

Chewable tablets to stimulate the immune system

Composition: Each chewable tablet contains raspberry fruit extract (Rubii idaei fructus), Echinacea extract (Echinacea purpurea), concentrated extract of licorice root (Glycyrrhiza radix), magnesium ascorbate and excipients.

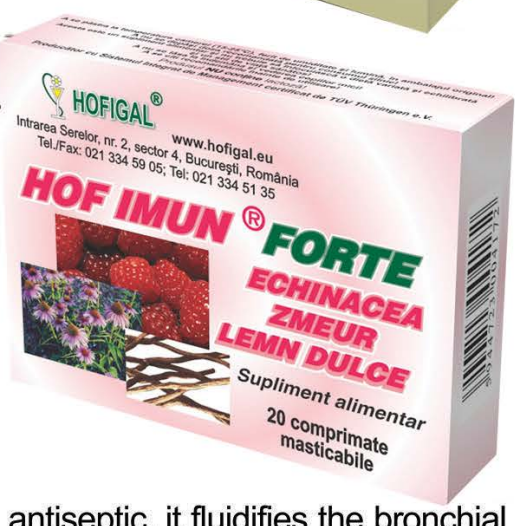

Action:It stimulates the immune system, it is antiinflammatory, antiviral, antiseptic, it fluidifies the bronchial and pharyngeal secretions, antioxidant, cardioprotective, vasoprotective, it has antineoplastic antileukimic action, (due to the ellagic acid), it contributes to wound healing, fortifies and remineralizes (it regulates the potassium balance), it has antiulcer effects and is an overall body tonic.

Recommendations: to supplement the diet with nutrients and bioactive substances in: acute and chronic infections of the upper airways (angina, pharyngitis, laryngitis, bronchitis), prophylactic during periods with increased risk of infection with influenza viruses, it has sweating effects in fever, in recurrent herpes episodes of mucocutaneous rash, frequent urinary tract infections, inflammatory urogenital processes; immunodepression after radiotherapy or chemotherapy, bacterial skin infections, psoriasis, neurodermitis, chronic cardiovascular diseases associated with hypercholesterolemia, adjuvant in the diet indicated in the treatment of gastroduodenal ulcers, tonic during periods of physical and mental strain, exhaustion.

\section{Bucoprotect gel}

Product presentation: Gel for oral hygiene.

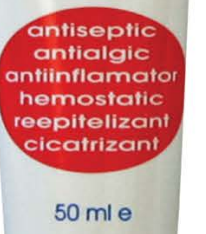

Composition (INCI): aqua, capsella bursa pastoris, calendula officinalis, achillea milefolium, hippophae rhamnoides, olea europea, hypericum perforatum, carbomer triethanolamine, collagen, foeniculum vulgare, mentha piperita, citrus amara.

Action: Antiseptic, anti-inflammatory, healing, stimulates the inside lining of the mouth and gums trophicity, reduces pain caused by specific oral diseases (gingivitis, stomatitis, lesions of the prosthesis, thrush, periodontitis). Recommendations: Fights against bad breath (halitositive nets). 


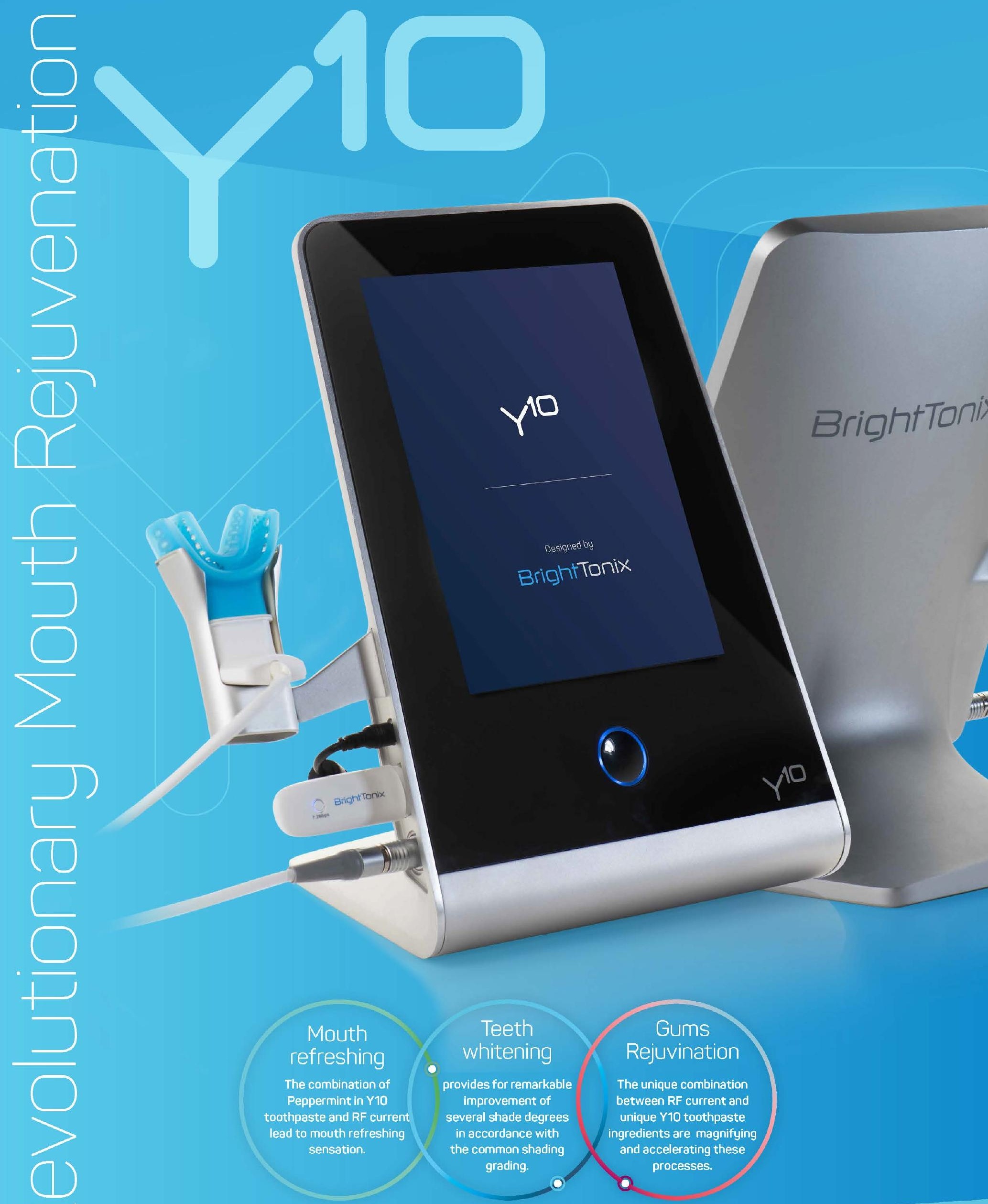




\section{EDITORIAL}

215 We need tough teachers!

\section{LETTERS}

217 Laudation in Celebration of our Mentor on his $55^{\text {th }}$ birthday,

Fawad Javed, Rafael Delgado-Ruiz

\section{CONTINUING EDUCATION ONLINE}

219 JADA CE Online

\section{ORIGINAL ARTICLES}

221 RESTORATIVE DENTISTRY: Effects of acidic/alcoholic beverages on the surface Günçe Ozan, Meltem Mert Eren, Sevda Ozel Yildiz, Hande Șar Sancakli, Esra Yildiz

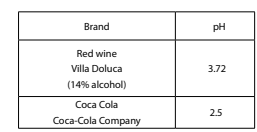

CARIOLOGY:The influence of saliva contamination on universal adhesive bonding to enamel and dentin

Simona Stoleriu, Gianina Iovan, Irina Nica, Galina Pancu, Sorin Andrian

ORAL MEDICINE: Smoking and recurrent aphthous stomatitis

237 Radmila Radisa Obradović, Marija L J Igic, Aleksandar D Mitic, Ana S Pejcic, Kosta M Todorovic, Zana Popovic

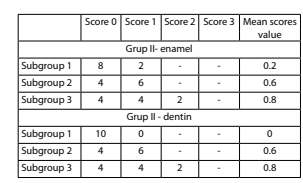

ORTHODONTICS: Evaluation of bone mineral density using cone beam

241 computed tomography

Mohammad Sadegh Nazari, Ahmad Reza Tallaeipoor, Ludovica Nucci,

Amir Ali Karamifar, Abdolreza Jamilian, Letizia Perillo

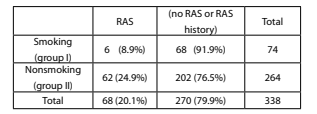

\section{REVIEW ARTICLES}

ORAL IMPLANTOLOGY: Role of the maxillary tuberosity in periodontology and implant dentistry - a review

Nicholas Montanaro, José Carlos Martins da Rosa, Luis Antonio Violin Pereira, Georgios E. Romanos

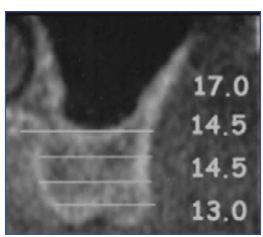

\section{CASE REPORTS}

AESTHETIC DENTISTRY: Digital workflow for virtually designing and pressing ultra-thin lithium-disilicate veneers for esthetic rehabilitation of fractured maxillary incisors - a case report

Mariann Dankó, Attila Böröczky, Zoltán Imre Kovács, Judit Borbély, Péter Hermann

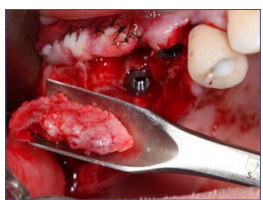




\section{DENTISTRY CONFERENCES}

272 Dentistry Conferences

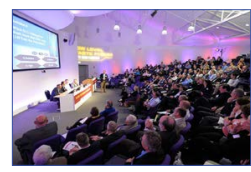

\section{PRODUCT NEWS}

Gold standard in occlusion control - OccluSense ${ }^{\oplus}$

275 by Dr. Jean Bausch GmbH \& Co. KG

Florin - Eugen Constantinescu

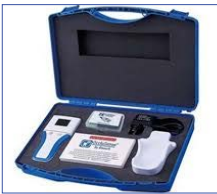

\section{BOOK REVIEWS}

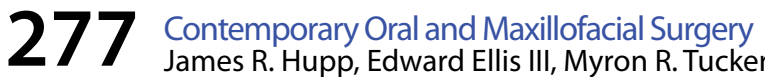

278 Dislocation of the Temporomandibular Joint - A Guide to Diagnosis and Management Nigel Shaun Matthews

279 Textbook and Color Atlas of Traumatic Injuries to the Teeth

281 Temporomandibular Joint and Airway Disorders - A Translational Perspective

\section{INSTRUCTIONS FOR AUTHORS}

284 Instructions for authors 
Editors-in-Chief

Jean-François Roulet

DDS, Habil, Prof hc, Dr hc, Professor

University of Florida, Gainesville, FL, USA

MD, DMD, PhD Professor and Chairman em.

Medical University of Vienna, Vienna, Austria

Marian-Vladimir Constantinescu

DDS, MSC, PhD, Professor

17. "Carol Davila" University of Medicine and Pharmacy, Bucharest, Romania

Co-Editors-in-Chief (Americas)

(a) Hom-Lay Wang

DDS, MSD, PhD, Professo

University of Michigan, Ann Arbor, MI, USA

- Mauro Marincola

MD, DDS, Clinical Professor

State University of Cartagena, Cartagena, Colombia

George E. Romanos

DDS, PhD, DMD, Professor

Stony Brook University, Stony Brook, NY, USA

Co-Editors-in-Chief (Asia-Pacific)

Lakshman Perera Samaranayake

Hon DSC, FDSRCS (Edin), FDS RCPS (Glas), FRACDS, FRCPath (UK), BDS, DDS (Glas)

FHKCPath FCDSHK FHKAM (Patholog), FHKAM (Dental Surgery), Professor

University of Sharjah, Sharjah, United Arab Emirates

\section{Hiroshi Ogawa}

DDS, MDSC, PhD, Associate Professor

Niigata University, Niigata, Japan

Mahesh Verma

BDS, MDS, MBA, FAMS, FDSRCS (England), FDSRCPSG (Glasgow), FDSRCS (Edinburgh)

PhD (HC), Professor

Maulana Azad Institute of Dental Sciences, New Delhi, India

Emeritus Editors-in-Chief

Peter E. Dawson

DDS, Founder Emeritus of The Dawson Academy

Saint Petersburg, FL, USA

\section{Birte Melsen}

DDS, Dr Odont, Professor

Aarhus University, Aarhus, Denmark

Alexandre Mersel

DDS, PhD, Professor, Director of Studies

Geneva Institute of Medical Dentistry (GIMD), Versoix, Switzerland

1.1

Associate Editors-in-Chief

Vasile Iulian Antoniac, Eng, PhD, Professor, Habil

Vice Dean, University “Politehnica” of Bucharest, Bucharest

Romania

Noemí Bordoni, DDS, PhD, Director

Public Health Research Institute, University of Buenos Aire

Buenos Aires, Argentina

Radu Septimiu Câmpian, DMD, MD, Professor

Dean, "Iuliu Hațieganu" University of Medicine and Pharmacy

Cluj-Napoca, Cluj-Napoca, Romania

Sergiu Ciobanu, DDS, PhD, Professor, Dean

"Nicolae Testemitananu"State Medical and Pharmaceutical

University Chişinău, Chişinău, Moldova

Francois Duret, DDS, DSO, PhD, MS, MD, PhD, Professor

Acad (ANCD) University of Montpellier, Montpellier, France

Michael Frank, DDS, PhD

ERO President, President Dental Chamber Hesse

Frankfurt am Main, Germany

Luigi M Gallo, PhD, Dr Eng, MEng

Professor and Chairman, University of Zürich, Zürich, Switzerland

Klaus Gotfredsen, DDS, PhD, Dr Odont

University of Copenhagen, Copenhagen, Denmark
Maria Greabu, MD, PhD

"Carol Davila" University of Medicine and Pharmacy Bucharest Bucharest, Romania

Peter Hermann, DMD, MSc, PhD, Professor and Head

Vice-Rector, Semmelweis University Budapest, Hungary

Ecaterina lonescu, DDS, PhD, Professor, Vice-Rector

"Carol Davila"University of Medicine and Pharmacy Bucharest

Bucharest, Romania

Amid I Ismail, BDS, MPH, MBA, Dr Ph, Dean

Temple University, Philadelphia, PA, USA

Vjekoslav Jerolimov, DDS, PhD, Acad (CASA)

University of Zagreb, Zagreb, Croatia

Veronica Mercuț, DMD, PhD, Professor, Dean

University of Medicine and Pharmacy Craiova, Dolj, Romania

Georg B. Meyer DMD PhD, Dr hc Professor and Chairman

Ernst-Moritz-Arndt University, Greifswald, Germany

Takahiro Ono, DDS, PhD, Chief Professor

Niigata University, Niigata, Japan

Poul Erik Petersen, DDS, Dr Odont, BA, MSc, Professor

WHO Senior Consultant, University of Copenhagen

Copenhagen,Denmark
Deputy Editors-in-Chief

Adrian Bejan

Eng, PhD, J.A. Jones Distinguished Professor, Acad (AR)

Duke University, Durham, NC, USA

Constantin lonescu-Târgoviste

MD, PhD, Professor, Acad (AR)

abriel Octavian Lazăr

CPhys, PhD, Professor

"Vasile Alecsandri" University of Bacău, Bacău, România

Co-Editors-in-Chief (Europe)

Nicoleta llie

Dipl-Eng, PhD, Professor

Ludwig-Maximilians-Universität München, München, Germany

Hande Şar Sancak

DDS, PhD, Associate Professo

FDI Regional CE Director Europe, Geneva-Cointrin, Switzerland

Constantinus Politis

MD, DDS, MM, MHA, PhD, Professor and Chairperson University of Leuven, Leuven, Belgium

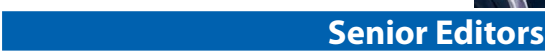

Senior Editors

Bruce Robert Donof

DMD, MD, Professor, Dean

Medicine Harvard University, Boston, MA, USA

Adrian Podolean

Eng, PhD, Professor FInstP, FOSA, FSPIE, Professor University of Kent, Canterbury, Kent, UK

Kasturi Warnakulasuriya FOP(RCPA), FICD FIL

FMedSci, Professor

King's College London, London, UK

Emeritus Editors-in-Chief

Prathip Phantumvanit

DDS, MS, FRCDT, Professo

Thammasat University, Bangkok, Thailand

Rudolf Slavice

MD, DMD, Professo

Medical University of Vienna, Vienna, Austria

David Wray

Professor Emeritus, Professor

University of Glasgow, Glasgow, UK

Mariano Alonso Sanz, DDS, MSD, PhD, Professor

Complutense University of Madrid, Madrid, Spain

Gottfried Schmalz, DDS, PhD, Drhc Professor

Acad (Leopoldina), University of Regensburg

Regensburg, Germany

Anton Sculean, DMD, Drhc, MS, Professor

University of Bern, Bern, Switzerland

Igor Alexandrovici Shugailov, MD, PhD, Professor

Vice-Rector, "A.I. Evdokimov" Moscow State University of

Medicine and Stomatology, Moscow, Russia

Adam Stabholz, DDS, PhD, Professor, Head

The Hebrew University-Hadassah, Jerusalem, Israel

Zrinka Tarle, DMD, PhD, Professor, Dean

University of Zagreb, Zagreb, Croatia

Douglas A. Terry, DDS, PhD, Clinical Assistant Professor

University of Texas, Houston, TX, USA

Jacques Vanobbergen, MDS, PhD, Professor Em. Professor

and Chairman

Gent University, Gent, Belgium

Yongsheng Zhou, DDS, PhD, Chair and Professor Associate

Dean, Peking University, Beijing, China
The Stomatology Edu Journal (Stoma Edu J)

ISSN (printed) 2360-2406, ISSN (on-line) 2502-0285,

ISSN-L 2360-2406, is a scientific magazine of the Romanian Association of Oral Rehabilitation and Posturotherapy - ROPOSTURO a partner of the FDI regular member, the Romanian Society of Stomatology - RSS (founded in 1923) under the aegis of The Romanian Academy.

\section{Editor Office}

Stomatology Edu Journal, 102-104 Mihai Eminescu st., $2^{\text {nd }}$ District, R0-020082 Bucharest, ROMANIA, Tel/Fax: +40314327930, e-mail:stomatology.edu@gmail.com,wwwstomaeduj.com Editors-in-Chief

Jean-François Roulet, Rolf Ewers, Marian-Vladimir Constantinescu Managing Editor

Florin-Eugen Constantinescu

\section{ROPOSTURO}

Romanian Association of Oral Rehabilitation and Posturotherapy, 10, Ionel Perlea St., 1 st District, R0-010209 Bucharest, Romania, Tel: +4021314 1062, Fax: +4021 3121357

e-mail: roposturo@gmail.com; www.roposturo.ro

Technical Editors

Gabriel Octavian Lazar, Valentin Miroiu, Edgar Moraru

Project Editor

Irina-Adriana Beuran

Design Editor

Dragoș Georgian Guțoi

Cover by

Arch. Florin Adamescu

DTP \& Web Designe

Valentin Miroiu

\section{Publisher Office}

Romanian Academy Publishing House, 13, Calea 13 Septembrie, $5^{\text {th }}$ District, R0-050711 Bucharest, Romania, Tel: +40213188146, 40213188106, Fax: +40213182444

e-mail: edacad@ear.ro,www.ear.ro

Technical Editor

Doina Argeșanu

Editorial Assistant

Monica Stanciu

Computer Editing

Iolanda Povară

All the original content published is the sole responsibility of the authors. All the interviewed persons are responsible for their declaration and the advertisers are responsible for the information included in their commercials. 


\section{Associate Editors}

Rafael Benoliel, DDS, PhD, BDS, Professor, Associate Dean The State University of New Jersey Newark, NJ, USA Dana Cristina Bodnar, DDS, PhD, Professor

"Carol Davila" University of Medicine and Pharmacy Bucharest, Bucharest, Romania

Romeo Călărașu, MD, PhD, Professor, Acad (ASM) "Carol Davila" University of Medicine and Pharmacy Bucharest, Bucharest, Romania

Asja Čelebić, DDS, MSc, PhD, Professor

University of Zagreb, Zagreb, Croatia

Lola Giusti, DDS, CERT, Associate Professor

University of the Pacific, San Francisco, CA, USA

Galip Gürel, DDS, MS

Dentis Dental Clinic, Istanbul, Turkiye

Fawad Javed, BDS, PhD

University of Rochester, NY, USA

Joannis Katsoulis, DMD, PhD, MAS, Professor

University of Bern, Bern, Switzerland

Anastassia E Kossioni, DDS, PhD, Associate Professor

University of Athens, Athens, Greece

Luca Levrini, DDS, PhD, Professo

University of Insubria, Varese, Italy

Giorgio Lombardo, MD, DDS, Professo

University of Verona, Verona, Italy

Armelle Maniere-Ezvan, DDS, PhD, Professor

Nice Sophia-Antipolis University, Nice, France

Domenico Massironi, DDS, PhD

MSC Massironi Study Club, Melegnano (MI), Italy

Noshir R. Mehta, DMD, MDS, MS, Professor, Assoc. Dean

Tufts University, Boston, MA, USA

Marian Neguț, MD, PhD, Professor, Acad (ASM)

"Carol Davila" University of Medicine and Pharmacy

Bucharest, Bucharest, Romania

Jean-Daniel Orthlieb, DDS, PhD, Professor, Vice-Dean

Aix Marseille University, Marseille, France

Letizia Perillo, MD, MS, PhD, Professor, Head, Dea

University of Campania Luigi Vanvitelli, Naples, Italy

Paula Perlea, DDS, PhD, Professor, Dean

"Carol Davila" University of Medicine and Pharmacy

Bucharest, Bucharest, Romania

Chiarella Sforza, MD, PhD, Professor

University of Milan, Milan, Italy

Roman Šmucler, MD, PhD, Professor

Charles University Prague, Prague, Czech Republic

Roberto Carlo Spreafico, DM, DMD

Busto-Arsizio (MI), Italy

Jon B Suzuki, DDS, PhD, MBA, Professor, Associate Dean

Temple University, Philadelphia, PA, USA

\section{Editors}

Sorin Andrian, DDS, PhD, Professor and Chairman

"Gr. T. Popa" University of Medicine and Pharmacy lassi

lasi, Romania

Vasile Astărăstoae, MD, PhD, Professor

"Gr. T. Popa" University of Medicine and Pharmacy lași

lași, Romania

Gabriela Băncescu, MD, PhD, Professor

"Carol Davila"University of Medicine and Pharmacy Bucharest Bucharest, Romania

Alexandru Dumitru Brezoescu, DDS, Chairma

Dentists'College, Bucharest, Bucharest, Romania

Octavian Buda, MD, PhD, Professor

"Carol Davila" University of Medicine and Pharmacy Bucharest Bucharest, Romania

Arnaldo Castellucci, DDS, PhD

Florence, Italy

Ingrida Čêma, DDS, PhD, Professor

Riga Stradins University, Riga, Latvia

Gabi Chaushu, DMD, MD Professor

Gabi Chaushu, DMD, MD, Professor

Rayleigh Ping-Ying Chiang, MD, MMS

Rayleigh Ping-Ying Chiang, MD, MMS

Taipei Veterans General Hospital, Taipe
Ioan Dănilă, DDS, PhD, Professor

"Gr. T. Popa" University of Medicine and Pharmacy lași
"Lan Danila, DDS, PhD, Professor

"Gr. T. Popa" Unive

lassi, Romania
Yuri Dekhtyar, Eng, Dr phys, Professor

Riga Technical University, Riga, Latvia

Valeriu Fala, DDS, PhD, MSc, Associate Professo

„Nicolae Testemițanu" State University of Medicine and Pharma

"Chişinău, Chişinău, Republic of Moldova

Daniela Aparecida Godoi Gonçalves, DDS, PhD, Professor

UNESP - Univ Est Paulista, Araraquara, Brazi

Martin D Gross, BDS, LDS, MSC, Associate Clinical Professor

Tel Aviv University, Tel Aviv, Israel

Emilian Hutu, DDS, PhD, Professor

"Carol Davila" University of Medicine and Pharmacy Bucharest

Bucharest, Romania

Andrei Cristian lonescu, DDS, PhD

University of Milan, Milan, Italy

Abdolreza Jamilian, DDS, PhD, Professor

Islamic Azad University, Tehran, Iran

Joanna Kempler, DDS, PhD, Associate Professor

University of Maryland, Baltimore, MD, USA

Amar Hassan Khamis, PhD, DEA, MSC, BSc, Professor

Mohammed Bin Rashid University of Medicine and Healt

Sciences (MBRU), Dubai, UAE

Henriette Lerner, DDS, PhD

Baden-Baden, Germany

Paulo Ribeiro de Melo, DDS, PhD, Professor

University of Porto, Porto, Portugal
Annalisa Monaco, DDS, MSc, Associate Professor

University of L'Aquila, L'Aquila, Italy

Nina Mussurlieva, DDS, PhD, Professor

Medical University of Plovdiv, Plovdiv, Bulgaria

Radmila R. Obradović, DDS, PhD, Associate Professor

University of Nišs, Niš, Serbia

Sever Toma Popa, DDS, PhD, Professor

"Iuliu Hațieganu" University of Medicine and Pharmacy Cluj-Napoca Cluj-Napoca, Romania

Mihaela Răescu, DDS, PhD, Professor

"Titu Maiorescu" University, Bucharest, Romania

lulia Romanova, DMS, PhD, Professor

Odessa National Medical University "ONMedU", Odessa, Ukrain

Mare Saag, DDS, PhD, Professor

University of Tartu, Tartu, Estonia

Fabio Savastano, MD, MOrth, Professor

University Jaume I Castellon, Castellon, Spain

Luc De Visschere, DDS, PhD, Professor

Gent University, Gent, Belgium

Constantin Marian Vârlan, DDS, PhD, Professor

"Carol Davila" University of Medicine and Pharmacy Bucharest

Bucharest, Romania

Irina Nicoleta Zetu, DDS, PhD, Professor

"Gr. T. Popa"University of Medicine and Pharmacy lași, lași, Romania Editorial Advisory Board

Marcus Oliver Ahlers, DDS, PD

Department of Operative Dentistry and Preventive Dentistry

University Medical Center Hamburg-Eppendorf,

Hamburg University Eppendorf, Hamburg, Germany

Cristina Maria Bortun, DDS, PhD, Professor and Head

Prosthetic Dentistry Téchnology Department

Faculty of Dental Medicine, "Victor Babeș"University of Medicine

and Pharmacy Timișoara, Timișoara, Romania

Bogdan Calenic, DDS, PhD, Associate Professor

Biochemistry Department, Faculty of Dental Medicine

"Carol Davila" University of Medicine and Pharmacy Bucharest

Bucharest, Romania

Nardi Casap-Caspi, DMD, MD, Professor and Head

Oral and Maxillofacial Surgery Department

Hadassah School of Dental Medicine

Hebrew University Hadassah Jerusalem, Jerusalem, Israel

Paulo G. Coelho, DDS, PhD, Professor

Hansjorg Wyss Department of Plastic Surgery

NYU Langone Health, NYU School of Medicine, New York University New York NY, USA

Daniel Edelhoff, CDT, DMD, PhD, Professor and Head

Department of Prosthodontics, Faculty of Medicine

Ludwig-Maximilians - München University, München, German

Claudia Maria de Felicio, MD, PhD, Professor

Orofacial Motricity Unit, Department of Ophthalmology and

Otolaryngology, School of Medicine, Universidade de São Paulo (USP) Ribeirão Preto, Brazil

Dorjan Hysi, DMD, MsC, PhD, Associate Professor, Chair

Conservative Dental Department, Faculty of Dental Medicine Tiran

University of Medicine Tirana, Tirana, Albania

Heinz Kniha DDS, MD, PhD, Associate Professor

Oral and Maxillofacial Surgery Department, Faculty of Medicin

Ludwig-Maximilians- München University, München, Germany

Rodica Luca, DDS, PhD, Professor

Pedodontics Department, Faculty of Dental Medicine

"Carol Davila" University of Medicine and Pharmacy Bucharest

Bucharest, Romania

Mariam Margvelashvili-Malament, DDS, MSc, PhD, Professor

Department of Prosthodontics and Operative Dentistry, School of

Dental Medicine, Tufts University, Boston, MA, USA

Domenico Massironi, DDS

MEG - Master Educational Group, Melegnano (MI), Italy

Rodolfo Isaac Miralles Lozano, MD, PhD, Professor

Physiology and Biophysics Department, Institute of Biomedical

Sciences, Faculty of Medicine, University of Chile, Santiago, Chile

Mutlu Özan, DDS, PhD, Professor, Head

Dental Biomaterials Unit, Clinic of Fixed and Removable

Prosthodontics and Dental Material Science, Center of Dent

Medicine (ZZM), University of Zürich, Zürich, Switzerland

Mariana Păcurar, DDS, PhD, Professor and Head,

Orthodontics and DentoFacial Orthopedics Department, Faculty of

Dental Medicine, University of Medicine and Pharmacy Târgu Mures Târgu Mureș, Romania

Alexandru Eugen Petre, DDS, PhD, Professor

Department of Fixed Prosthodontics and Occlusolog

"Carol Davila" University of Medicine and Pharmacy Bucharest

Bucharest, Romania

Sanda Mihaela Popescu, DDS, PhD, Professor and Head

Dental Rehabilitation and Medical Surgery Emergencies

Department, Faculty of Dental Medicine, University of Medicine and

Pharmacy of Craiova, Dolj, Romania

Elena Preoteasa, DDS, PhD, Professor and Head

Complete Denture Department, Faculty of Dental Medicine

"Carol Davila" University of Medicine and Pharmacy Bucharest Bucharest, Romania

Alina Pürienè, $B S$, PhD, Dr habil, Professor

Periodontics Department, Institute of Odontology

Faculty of Medicine, Vilnius University, Vilnius, Lithuani

Lucien Reclaru, Eng, PhD, Biomaterials Consultant

University of Geneva, Geneva, Switzerland

Stephen F. Rosenstiel, BDS, MSD, Professor and Chai

Restorative and Prosthetic Dentistry, College of Dentistry

The Ohio State University Columbus, Columbus, OH, USA

Martina Schmid-Schwap, DDS, PhD, Professor

Department of Prosthodontics, Bernhard Gottlieb

University of Dentistry, Medical University of Vienna, Vienna, Austria
Gregor Slavicek, DDS, PhD, Professor,

Steinbeis Transfer Institute of Biotechnology in Interdisciplinary

Dentistry, Steinbeis University Berlin, Berlin, Germany

Marius Steigmann, DDS, PhD, Professor

Steigmann Implant Institute, Neckargemund, Germany

Gianluca Martino Tartaglia, DDS, PhD, Associate Professor

Laboratory of Functional Anatomy of the Stomatognathic Apparatus,

Depart of Biom

University of Milan Milan Ialy

Bernard Touati, DDS, PhD, Assistant Professor

Prosthodontics Department, Faculty of Odontology, Paris V

University, Paris, France

Tamara Tserakhava, DDS, PhD, Professor and Chair

Department of Pediatric Dentistry, Dental Faculty, Belarusian State

Medical University Minsk, Belarus

Sorin Uram-Tuculescu, DDS, PhD, Assistant Professor

Prosthodontics Department School of Dentistry

Virginia Commonwealth University Richmond, Richmond, VA, USA

\section{Reviewers-in-Chief}

Stephen F. Rosenstiel, BDS, MSD, Professor Emeritus The Ohio State University Columbus, Columbus, OH, USA Mihaela Rodica Păuna, DDS, PhD, Professor

"Carol Davila" University of Medicine and Pharmacy Bucharest Bucharest, Romania

Nissan Joseph, DMD, Associate Professor

Tel Aviv University, Tel Aviv, Israel

\section{Reviewers}

Petr Bartak, Prague, Czech Republic

Cristian Niky Cumpătă, Bucharest, Romania

Andrezza Lauria de Moura, São Paulo, Brazil

Nikolay Ishkitiev, Sofia, Bulgaria

Barbara Janssens, Gent, Belgium

John Kois, Seattle, WA, USA

Cinel Malița, Bucharest, Romania

Enrico Manca, Cagliari, Italy

Vlademir Margvelashvili, Tbilisi, Georgia

Costin Marinescu, München, Germany

Marina Melescanu-Imre, Bucharest, Romania

Joel Motta Junior, Manaus, AM, Brazil

Hazem Mourad Oassim, Saudi Arabia

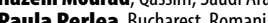

aula Perlea, Bucharest, Romani

Preoteasa, Bucharest, Romania

Robert Sabiniu Serban, Bucharest, Romania

Elina Teodorescu, Bucharest, Romania

Mei-Qing Wang, Xi'an, China

English Language Editor-in-Chief

Roxana-Cristina Petcu, Phil, PhD, Professor

Faculty of Foreign Languages, University of Bucharest

Bucharest, Romania

English Language Editors

Valeria Clucerescu, Biol.

Niculina Smaranda Ion, Phil.

Honorary Statistical Advisers

Radu Burlacu, PhD, Bucharest, Romania

loan Opriș, PhD, Associate Scientist, Miami, USA

Book Reviewers

Iulia Ciolachi, DMD, Bucharest, Romania

Florin-Eugen Constantinescu, DMD, PhD Student

Bucharest, Romania

Project Editor

Irina-Adriana Beuran, DMD, PhD

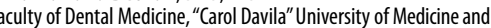

Pharmacy Bucharest, Bucharest, Romania

Indexing Databases

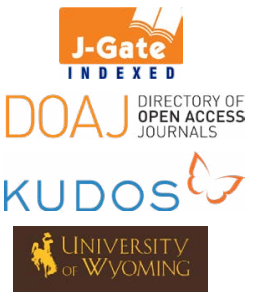

7imensions

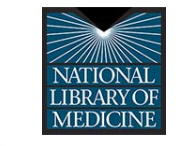

infoBASE INDEX

Crossref

(5) WorldCat"

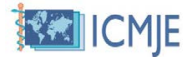

SHERPA

ROMEO

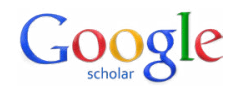

$R=$

$\mathrm{R} \partial \mathrm{AD}=$

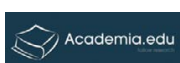


125

\section{million US \$}

Invest in R\&D

each year

1 Billion

patients

treated with

Dentsply Sirona

products evaly year

Locations

in more than

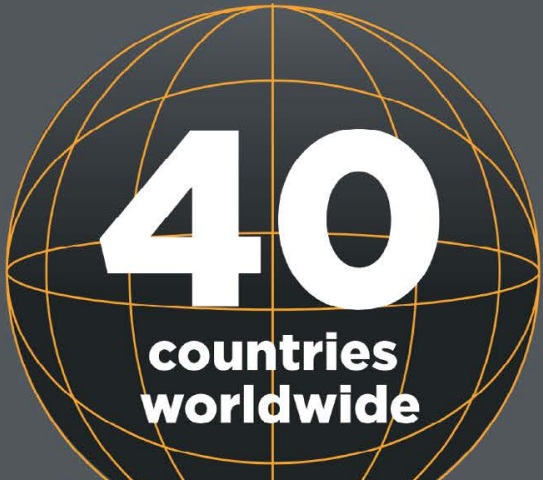

sales presence

in more than

120 countries

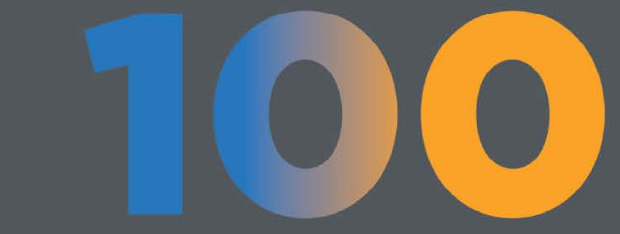

16,000

enthusiastic employees

worldwide

Dentsply

Sirona Academy educates over

\section{0,000}

professionals

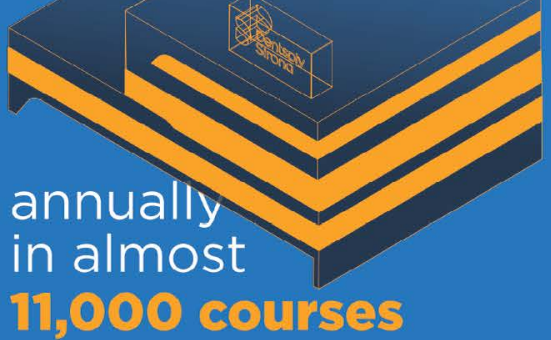

Dentsply Sirona world wide

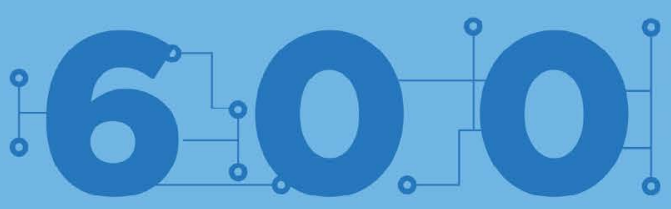

Scientists and

Engineers

the biggest platform for R\&D in the dental industry

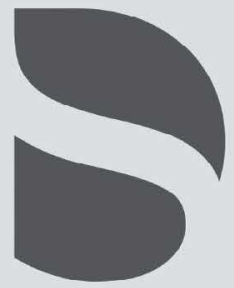




\section{We need tough teachers!}

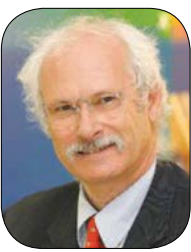

Jean-François ROULET

DDS, Habil, Prof hc, Dr hc, Professor

Editor-in-Chief

Dear Readers,

Following the classical set up of a university according to Humboldt, a University Professor should teach, perform research and service (in practically oriented professions). Teaching is divided in the undergraduate level and graduate level. Both are academic categories of education with the inherent objective that an academic should have the knowledge of his/her profession to be able to participate in the profession's development in the future. This is why in many nations, especially for the so called liberal professions (Physicians, Pharmacists, Lawyers, Architects and Engineers) professional organizations are allowed to participate or even to create and enforce their own professional laws. At graduate level the objective is to train future professors. If no one else, then they should be the ones with the deep knowledge to guide the profession into the future based on the results of their research.

My peers tell me that we are teaching the millennials or the generation $X$, which are different. They are not used to being criticized and do not have an attention span longer than 10 minutes. I am told that teachers must adapt to this, be nice to the students and avoid criticism. The unfortunate result of such an attitude is that we always tell the students what to do. The worse result is that the students ask us what to do, which yields to the situation that students are full of knowledge, pass the boards (multiple choice questions) with flying colours, but are unable to analyze a clinical situation or a research paper by applying their knowledge and "connecting the dots", in other words, they do not have the ability of critical thinking. I have experienced students on the clinical floor that do not know what materials they are using, how they work, which light curing unit they use, what it's irradiation is and which radiant exposure is needed to cure the composite they are using. The same when it comes to prevention. In discussions I literally have to beat out of them the relevant facts they have learned a few years ago and explain the clinical relevance to them. The same in the class I am teaching about learning from the literature.

So what shall we do in this situation? Let the profession degrade to a profession based on vocational training, where the dentist maybe knows what to do, but has no clue why? Shall we allow the information source for the students once they have graduated become the sales representatives, who have only one objective: sell the product that brings them the highest gain, that is converted into their bonus? Leave the future of our profession to be determined by politicians, where quite often the major aim is to be reelected? Shall we close our eyes, when looking at a health care system driven by financial politics and ignore that people die because they cannot afford health care services?

Of course not! And this is the reason why we need tough teachers. In the past, many years ago, I was feared because I was demanding to the undergraduate students. I used to teach concepts and their clinical applications, which is difficult for both the teacher and the student. Therefore the students did not like me, however it happened on numerous occasions that former students, who had become dentists in the meantime, approached me and thanked me for the great concepts and knowledge they got in their "scientific dental package". I was told that they realized only later how much better they were prepared to run their office than their peers. Today, I have completely changed my teaching style on the clinical floor. I do not give instructions any more. If the student asks me what to do, I tell him or her: "I will not tell you! You tell me what you want to do and then we can discuss it". This is the way it should go, because once they have graduated, there is no teacher anymore to tell them (see above). With this, again I am not a much liked teacher and I get poor evaluations from the students. Well I have to live with this, since I am a University Professor and not a trade school teacher!

Sincerely yours,

J.-F. Roulet

Editor-in-Chief 

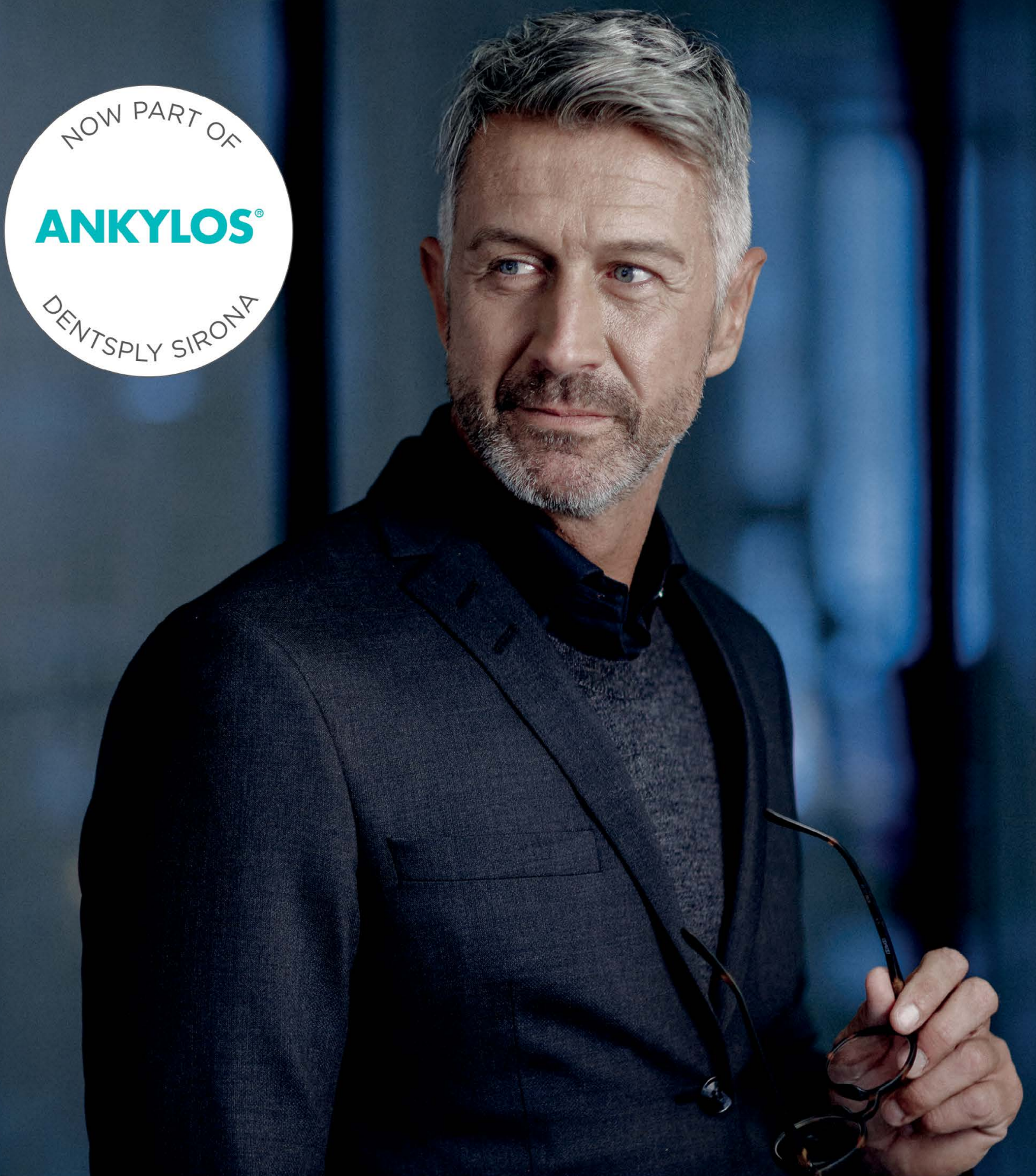

Ankylos $^{\oplus}$

Excellence

without exception

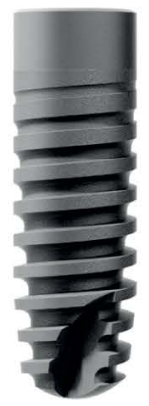

Dentsply - Sirona 


\section{Laudation in Celebration \\ of our Mentor on his $55^{\text {th }}$ birthday, Professor Georgios E. Romanos}

Professor Romanos is a fascinating personality, globally renowned for his qualifications and skills in Periodontology, Oral Surgery, Implant Dentistry, Prosthodontics and Laser dentistry. He is an example of an internationally oriented leader in clinical dental sciences and related research.

He got his DDS degree in Greece (1987); he then joined the Free University of Berlin, for advanced training in Periodontology and completion of his Doctoral degree (magna cum laude) on the distribution of collagen types in the healthy periodontal tissues of rats and monkeys (Marmoset).

After his successful training in Periodontology, Professor Romanos attended the Albert Ludwigs-University, Freiburg, (advanced training in Prosthodontics) and later the Johann Wolfgang Goethe University, Frankfurt (training in Oral Surgery and Implant Dentistry). His extensive training and professional dedication made

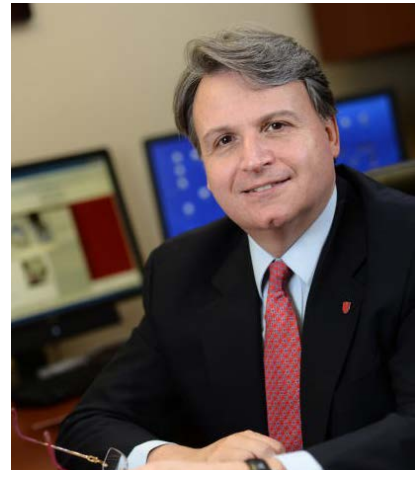
him a recognized and board-certified Oral Surgeon in Germany.

He completed his postdoc (Dr habil) and became an Associate Professor at the University of Frankfurt, Department of Oral Surgery and Implant Dentistry. In addition, he developed an interest for Laser Dentistry, and Laser Applications in Oral Surgery and Periodontology.

He moved to New York (2004) as a Clinical Professor at the New York University College of Dentistry where he worked and mentored national and international dentists. He also became Director of Laser Sciences for the New York University and later on Professor of Clinical Dentistry at the University of Rochester working and promoting research at the Eastman Institute of Oral Health $(\mathrm{EIOH})$.

Despite his heavy schedule (patients and academic activities), Professor Romanos completed the Advanced Education in General Dentistry (Eastman Institute for Oral Health, University of Rochester, NY) and became Diplomate of the American Board of Periodontology.

He was hired by the Stony Brook University School of Dental Medicine (2012) as an Associate Dean for Clinical Affairs, and also tenured Professor. He is the Founder of the Laboratory of Periodontal-, Implant-, Phototherapy (La-PIP), promoting research on bone-implant interface, peri-implantitis, implant macro-design, and also phototherapy to improve wound healing and evaluating innovative techniques in dentistry.

He has more than 400 scientific publications and book chapters and is one of the primary authors of five scientific books. His contributions have been cited in innumerable occasions, as reference for other authors, have been verified in posterior studies, and his work is utilized in multiple predoctoral and postgraduate programs as reference study. He is an energetic source of inspiration given his love for dentistry and academia. He is recognized for his high productivity and active participation in scientific organizations and for his vision for innovative research, as he includes young clinicians and professionals without borders and distinction of gender, origin, race, religion and educational background.

He has supervised multiple Master and PhD students with original works that have significantly shaped the practice of periodontology and implant dentistry. Professor Romanos has provided worldwide mentorship, and many of his mentees are now in academia conducting active research. Not only students but also colleagues have received his guidance, like ourselves or other academics and clinicians that have received his guidance and who are now in leading positions in the dental field.

Professor Romanos is a Fellow of several renowned dental organizations, which include the American Dental Education Association (ADEA) Leadership Institute, American Academy of Periodontology, American Association for Dental Research (AADR), International College of Oral Implantologists (ICOI), American Society for Laser Medicine and Surgery, Great of New York Academy of Prosthodontics and Academy of Osseointegration. Recently, he received the T.H. Maiman Research Award for Excellence in Clinical Research from the Academy of Laser 
Dentistry (ALD). Professor Romanos is a multifaceted professional, as well as a leader building a supportive culture of teaching and learning to educate and inspire students, help them discover their talents and explore their future in dental sciences and research.

His original ideas and unique concepts (immediate loading, one abutment at a time, laser therapy, medically compromised patients, risk factors in implant therapy) expanded the possibilities of the implant therapy. He is a team-player as shown by his vast global collaborations reflected in his lectures and scientific activities.

Learning from Professor Romanos has been a pleasure and his eagerness to further excel in academia and research will help him reach further milestones in his career.

For many of us, Professor Romanos is a model of scientific, mentorship, and commitment qualities. He is also a friend that encourages us to be better and follow the correct path.

\section{Professor Romanos has inspired us, and we wish him all the best!}

Fawad Javed, BDS, PhD

Assistant Professor

Eastman Institute for Oral Health

Rochester, NY, US
Rafael Delgado-Ruiz, DDS, MSc, PhD

Associate Professor

Stony Brook University

Stony Brook, NY, US

DOI: https://doi.org.10.25241/stomaeduj.2019.6(4).letter.1 


\section{stonaeduj}

Stoma Edu J. 2019;6(4):219

From The Journal of the American Dental Association

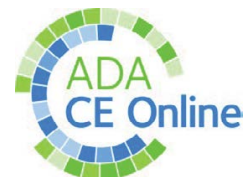

\section{JADA ONHINE CE EXAMS}

http://jada.ada.org/ce/home

http://jada.ada.org/ceworksheets

December 2019

Jevae L. Nelson, Erinne N. Kennedy, Muath Aldosari, Israel Agaku, Constantine Vardavas

PATIENT-REPORTED RECEIPT OF ORAL CANCER SCREENINGS AND SMOKING CESSATION COUNSELING FROM US ORAL HEALTH CARE PROVIDERS

National Health and Nutrition Examination Survey, 2015-2016

J Am Dent Assoc. 2019 Dec; 150 (12): 995-1003. Doi: 10.1016/ j.adaj.2019.07.017

https://jada.ada.org/article/S0002-8177(19)30506-9/fulltext

This article has an accompanying online continuing education activity available at: http://jada.ada.org/ce/home. 


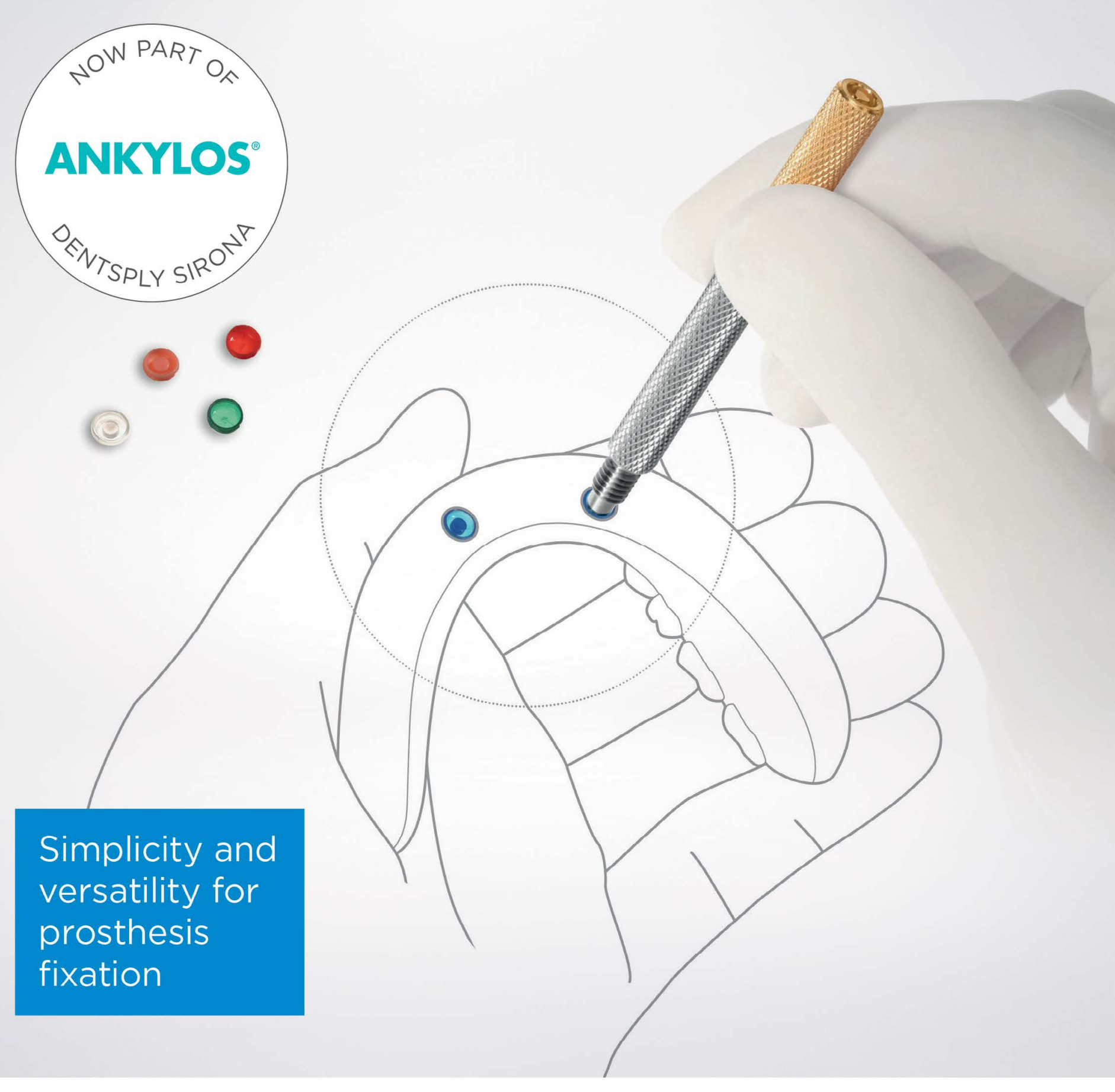

Ankylos ${ }^{\circledR}$

\section{The Locator ${ }^{\circledR}$ concept}




\title{
EFFECTS OF ACIDIC/ALCOHOLIC BEVERAGES ON THE SURFACE ROUGHNESS OF COMPOSITE RESINS LIGHT-CURED FOR TWO DIFFERENT PERIODS OF TIME
}

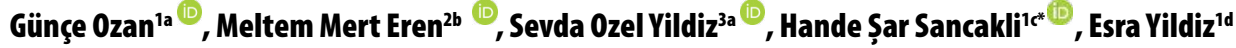 \\ 'Department of Restorative Dentistry Faculty of Dentistry, Istanbul University, TR-34390 Fatih / Istanbul, Turkey \\ 2Department of Restorative Dentistry, Faculty of Dentistry, Altınbaș University, TR-34218 Bakirkoy / İstanbul, Turkey \\ ${ }^{3}$ Department of Biostatistics, Faculty of Medicine, Istanbul University, TR-34093 Fatih / Istanbul, Turkey
}

${ }^{a} D D S, P h D$, Research Assistant

${ }^{b} D D S$, PhD, Assistant Professor

'DDS, PhD, Associate Professor

${ }^{d} D D S$, PhD, Professor

Introduction: The purpose of this study was to evaluate the surface roughness values of various resin-based composites (RBC) regarding exposure time and immersion in alcoholic and acidic beverages.

Methodology: A total of 240 disc-shaped specimens ( $8 \mathrm{~mm} \times 2 \mathrm{~mm}$ ) were prepared from two microhybrid, one nanofilled and one nanohybrid RBC. Specimens were divided into two groups, according to the exposure time; 20 or 40 seconds and immersed for $10 \mathrm{~min} /$ day during one month in either non-alcoholic (Coca Cola), alcoholic (red wine) beverages, or distilled water $(n=10)$. Surface roughness was measured after 24 hours, one week, and one month. Results were analyzed statistically using parametric and nonparametric test.

Results: The roughness values $(\mathrm{Ra})$ measured at 1-month immersion were significantly higher than those measured at 24 hours. There was no statistically significant difference due to exposure time (20 or 40 seconds) ( $p>0.05$ ). Structure of RBC, and presence of alcohol, and phosphoric acid in the immersion solutions caused a statistically significant difference among baseline and 1-month immersion intervals $(p<0.05)$. Among all RBCs, lowest Ra was observed in the microhybrid RBC Charisma Classic group.

Conclusion: Immersion in both acidic and alcoholic beverages altered the surfaces of all RBCs and generated significant surface roughness changes. All analyzed RBCs showed unacceptable changes in surface roughness.

Keywords: Resin-based composites; Exposure time; Surface roughness; Aging.

\section{Introduction}

Resin-based composits (RBC) are successfully used for the direct restoration of anterior and posterior teeth due to their simplified adhesive protocols, improved esthetic and adequate physical properties. Moreover, patients' priorities have shifted to highly esthetic restorations in both the anterior and posterior region. Considering that the posterior region has its own characteristics regarding the masticatory loads, chewing forces and possible parafunctional habits, RBCs challenge certain shortcuts when used in the posterior region. However, with the highlighted improvements in resin and filler technology, various types of RBCs have become available allowing for a clinically successful placement also in the posterior areas [1,2].

The mostly used RBC categories placed in the posterior areas include microhybrid [3], nanohybrid [4] and nano [5] RBCs [4]. To increase the esthetic aspect, progressively smaller particles have been incorporated in the monomer matrix leading to higher surface quality and superior polish retention $[4,8]$, associated with low wear rates and increased wear resistance. Besides the filler, the degree of cure of the monomer matrix may also affect the polish ability of a RBC [9]. Under ideal polymerization conditions, less residual monomers are evidenced and consequently a lower monomer release.

On the contrary, monomers that were not involved in the polymerization reactions are able to alter the restorative material, due to a softening effect of the polymer matrix, thus making the RBC prone to wear and negatively affecting the surface qualities. Therefore, the curing units used for polymerization as well the exposure time and distance may have a direct effect on the properties of the RBCs and their surface. Apart from an improvement in the filler system, modifications in the chemical composition of the monomer system are identified as well in modern RBCs. Besides traditional monomers such 
Table 1. Composition of the analyzed RBCs.

\begin{tabular}{|c|c|c|c|c|c|}
\hline Name & Brand & Type & Shade & $\begin{array}{l}\text { Lot/Ref. } \\
\text { Number }\end{array}$ & Content \\
\hline $\begin{array}{c}\text { Aelite } \\
\text { Aesthetic } \\
\text { Enamel }\end{array}$ & Bisco & Nanohybrid & A2 & $\mathrm{H}-852 \mathrm{~A} 2$ & $\begin{array}{l}\text { Bis-EMA, TEGDMA, Bis-GMA, Glass filler, } \\
\text { silica-glass filers }(0.04-5.0 \mu \mathrm{m})(73 \mathrm{wt} \%)\end{array}$ \\
\hline $\begin{array}{l}\text { Filtek } \\
\text { Ultimate } \\
\text { Body }\end{array}$ & $3 \mathrm{M}$ & Nanofilled & A2 & N441522 & $\begin{array}{l}\text { Bis-GMA, UDMA, Bis-EMA, TEGMA, silica } \\
\text { filler (20 nm), non-agglomerated/ non- } \\
\text { aggragated zirconia filler (4-11 nm) and } \\
\text { aggragated zirconia/silica cluster filler } \\
(0.6-10 \mu \mathrm{m})(78.5 \mathrm{wt} \%, 63.3 \text { vol\%) }\end{array}$ \\
\hline G-aenial & GC & Microhybrid & A2 & 1405161 & $\begin{array}{l}\text { UDMA, prepolymerized fillers containing } \\
\text { strontium and lanthan, prepolymerized } \\
\text { fillers containing silica }(16-17 \mu \mathrm{m}), \\
\text { pyrogenic silica }(<100 \mathrm{~nm})(81 \mathrm{wt} \%)\end{array}$ \\
\hline $\begin{array}{l}\text { Charisma } \\
\text { Classic }\end{array}$ & Kulzer & Microhybrid & A2 & $010718 \mathrm{~A}$ & $\begin{array}{c}\text { Bis-GMA, TEGMA, Ba-Al-B-F-Si-Glass fillers } \\
(0.7-2 \mu \mathrm{m}), \text { pyrogenic silica }(0.01-0.07 \mu \mathrm{m}) \\
\text { (78 wt } \%, 68 \text { vol\%) }\end{array}$ \\
\hline
\end{tabular}

Abbreviations: Bis-GMA = Bisphenol A glycidylmethacrylate $; U D M A=$ Urethane-dimethacrylate; $T E G D M A=$ Triethylene glycol dimethacrylate $;$ Bis-EMA = Ethoxylated bisphenol A dimethacrylate .

Table 2. Properties of the beverages used in the study.

\begin{tabular}{|c|c|}
\hline Brand & pH \\
\hline $\begin{array}{c}\text { Red wine } \\
\text { Villa Doluca } \\
(14 \% \text { alcohol })\end{array}$ & 3.72 \\
\hline $\begin{array}{c}\text { Coca Cola } \\
\text { Coca-Cola Company }\end{array}$ & 2.5 \\
\hline
\end{tabular}

as Bisphenol A glycidylmethacrylate (Bis-GMA), Urethane-dimethacrylate (UDMA), or Triethylene glycol dimethacrylate (TEGDMA), novel monomers such as modified aromatic (AUDMA = aromatic urethane dimethacrylate) and aliphatic (Bis-EMA $=$ ethoxylated bisphenol $\mathrm{A}$ glycol dimethacrylate) methacrylates have been included in organic matrices $[10,11]$ to reduce viscosity [11], water sorption, and solubility [10], thus preventing resin matrices from being softened and degraded [5]. Apart from the content of the resins, the surfaces of RBCs are expected to degrade according to the dynamics of the oral environment [12]. Excessive surface degradation by means of oral conditions may not only lower the physical properties of RBCs but also cause plaque accumulation, discoloration, and secondary caries [13]. Therefore, maintaining a smooth surface is important to the long-term success of restorations. Consuming certain types of beverages may change the surface texture of RBC restorations. The chemical properties of beverages, such as their acidity, may affect the surface properties leading to wear, softening, severe degradation, and staining [14]. Likewise, ethanol (present in alcoholic beverages) has the potential to plasticize the organic matrix of RBCs, thus lowering the physical and mechanical properties [15]. Thus, the effects of alcoholic and acidic beverages on the surface properties of RBCs need to be analyzed. The purpose of this study was to evaluate the surface roughness values of various $\mathrm{RBCs}$ as a function of the exposure time and the immersion in alcoholic and acidic beverages.

The null hypotheses were that (1) the exposure time would not affect the surface roughness of the various analyzed RBCs and (2) the analyzed RBCs would have 
similar surface properties after exposure to alcoholic and acidic beverages.

\section{Materials and methods}

240 disc-shaped samples (8 $\mathrm{mm}$ in diameter and $2 \mathrm{~mm}$ in thickness) from four RBCs were prepared with a custom made stainless steel mold: the microhybrid Charisma Classic (Kulzer, Wehrheim, Germany), the microhybrid G-eanial (GC, Tokyo, Japan), the nanohybrid Aelite Aesthetic Enamel (BISCO Dental Products, Schaumburg, IL, USA) and the nanofilled RBC Filtek Ultimate (3M, St. Paul, MN, USA). The composition of the materials is shown in Table 1.

\subsection{Specimen Preparation}

Specimens were prepared by inserting materials in one increment into a mold and placing a glass plate on the top and bottom of the mold, with a Mylar strip in between. A constant pressure (with $1 \mathrm{~kg}$ weight) was applied on the glass plate for 15 seconds to allow the excess material to escape, thus obtaining a flat specimen surface without bubbles. Sixty specimens were prepared for each of the four $\mathrm{RBCs}$. After removal of the weight and the glass plate, the specimens were polymerized with a LED (Light Emitted Diode) LCU (Light curing unit, SmartLite Max, Dentsply, Pennsylvania, USA, $1600 \mathrm{~mW} / \mathrm{cm}^{2}$ ) for 20 seconds and 40 seconds. The LCU's tip was positioned perpendicularly to specimens' surfaces and the distance between the tip and specimen was standardized using a glass microscope slide $(1 \mathrm{~mm}$ thickness).

All specimens were stored in distilled water at $37 \pm 1^{\circ} \mathrm{C}$ for 24 hours to allow for post-polymerization. The top surface of each specimen was polished with flexible aluminum oxide discs (Sof-Lex; 3M) under running water for 30 seconds. Polishing was performed by one operator to eliminate operatordependent variability, and the discs were renewed after their 5th use.

\subsection{Exposure to alcoholic and acidic beverages}

Specimens from each group $(n=10)$ were stored for $10 \mathrm{~min} /$ day during one month in one of the following media: alcoholic (red wine-RW), acidic non-alcoholic (Coca Cola-CC), and distilled water (DW) as control (Table 2). All of the beverages were used at room temperature and were renewed during every period. The specimens were kept immersed in distilled water at $37 \pm 1^{\circ} \mathrm{C}$ between cycles.

\subsection{Surface Roughness Measurements}

The roughness values for each specimen were measured with three consecutive readings, and mean $\mathrm{Ra}$ values were calculated. Before the measurement, the top surface of each specimen was blotted dry using tissue paper, and the contact guide of a surface profilometer (Taylor Hobson Surtronic 3+, Taylor Hubson, Leicester, UK) was positioned at the center of the specimen surface. The profilometer, which was calibrated against a standard after each measurement, was set to a cutoff value of $0.8 \mathrm{~mm}$, a transverse length of $0.8 \mathrm{~mm}$ and a stylus speed of $0.1 \mathrm{~mm} / \mathrm{s}$. Measurements were taken directly after polishing the specimens (baseline) as well as after one week and one month.

\subsection{Statistical Analysis}

Statistical analysis was performed using Statistical Package for Social Sciences (SPSS) for Windows 21.0. The normal distribution of the values was verified by Shapiro-Wilks tests. Acording to data distribution, both parametric (repeated measures) and non-parametric (Friedmann) tests were used for statistical analysis. A percentage roughness increase (\%) after one month of immersion was calculated using following formula:

Percentage roughness increase $=$

( $\mathrm{R}$ - one month a - R-Baseline a )/ R-Baseline a

With $\mathrm{a}=$ exposure time (20 or 40 seconds);

$\mathrm{R}=$ Roughness,

$p$ values less than 0.05 were considered statistically significant.

\section{Results}

The mean values of the surface roughness (Ra) of the RBCs cured for 20 or 40 seconds and immersed in varied beverages are shown in Table 3.

\subsection{Comparisons of alterations in Ra values of $R B C$ s by time and beverages.}

Table 3 shows that the groups exhibit higher roughness values $(\mathrm{Ra})$ after one week immersion compared to the baseline, except for the nanohybrid RBC (Aelite - 20 seconds polymerization) immersed in distilled water and the microhybrid RBC (Charisma Classic - 40 seconds polymerization) immersed in red wine. The mentioned specimens of the nanohybrid RBC show no surface roughness change during storage, and the microhybrid specimens showed smoother surfaces after one - week of immersion in red wine.

Regarding the one month results, except for the groups microhybrid (G-aenial - 20 seconds polymerization), microhybrid (Charisma Classic - 40 seconds polymerization) and nanohybrid (Aelite - 20 seconds polymerization) RBCs, all other groups exhibit highest roughness ( $\mathrm{Ra}$ ) values. Microhybrid (G-aenial) specimens immersed in distilled water showed no changes in surface roughness and microhybrid specimens had a slightly rougher surface after one month immersion in distilled water. Microhybrid specimens immersed in red wine had higher roughness values compared to the one week evaluation, but still showed better surfaces than the baseline. In addition, regarding the change of $\mathrm{Ra}$ values of the RBCs overall, there are no statistically significant differences between 20 or 40 seconds of 
Table 3. Mean and standard deviations of Ra values of all RBCs polymerized with different curing times and immersed in various beverages*.

\begin{tabular}{|c|c|c|c|c|c|c|c|}
\hline & & \multicolumn{3}{|c|}{$\begin{array}{c}20 \text { seconds } \\
\text { polymerization }\end{array}$} & \multirow[b]{2}{*}{ Base } & \multicolumn{2}{|c|}{$\begin{array}{c}40 \text { seconds } \\
\text { polymerization }\end{array}$} \\
\hline & & Base & 1-week & 1-month & & 1-week & 1-month \\
\hline \multirow{2}{*}{ Coca Cola } & Bisco & $0.28 \pm 0.05^{\mathrm{a}}$ & $0.34 \pm 0.05^{b}$ & $0.38 \pm 0.06^{c}$ & $0.38 \pm 0.13^{A}$ & $0.48 \pm 0.09^{\mathrm{B}}$ & $0.62 \pm 0.14^{\mathrm{B}}$ \\
\hline & $3 M$ & $0.42 \pm 0.11^{\mathrm{a}}$ & $0.48 \pm 0.13^{b}$ & $0.64 \pm 0.14^{c}$ & $0.41 \pm 0.20^{A}$ & $0.57 \pm 0.16^{B}$ & $0.72 \pm 0.19^{B}$ \\
\hline \multirow{2}{*}{ (CC) } & GC & $0.53 \pm 0.20^{\mathrm{a}}$ & $0.61 \pm 0.17^{a}$ & $0.73 \pm 0.26^{b}$ & $0.43 \pm 0.07^{A}$ & $0.50 \pm 0.08^{\mathrm{B}}$ & $0.57 \pm 0.08^{C}$ \\
\hline & Kulzer & $0.33 \pm 0.03^{a}$ & $0.36 \pm 0.03^{b}$ & $0.44 \pm 0.09^{c}$ & $0.29 \pm 0.04^{A}$ & $0.33 \pm 0.02^{\mathrm{A}}$ & $0.44 \pm 0.21^{\mathrm{B}}$ \\
\hline \multirow{2}{*}{ Red } & Bisco & $0.44 \pm 0.11^{\mathrm{a}}$ & $0.52 \pm 0.12^{\mathrm{b}}$ & $0.68 \pm 0.21^{c}$ & $0.38 \pm 0.07^{A}$ & $0.47 \pm 0.13^{\mathrm{B}}$ & $0.58 \pm 0.18^{B}$ \\
\hline & $3 M$ & $0.43 \pm 0.09^{a}$ & $0.50 \pm 0.08^{a}$ & $0.58 \pm 0.06^{b}$ & $0.26 \pm 0.09^{A}$ & $0.35 \pm 0.09^{B}$ & $0.45 \pm 0.11^{c}$ \\
\hline \multirow{2}{*}{ Wine (RW) } & GC & $0.54 \pm 0.12^{\mathrm{a}}$ & $0.64 \pm 0.09^{\mathrm{a}}$ & $0.87 \pm 0.23^{b}$ & $0.51 \pm 0.13^{\mathrm{A}}$ & $0.63 \pm 0.10^{A}$ & $0.73 \pm 0.15^{\mathrm{B}}$ \\
\hline & Kulzer & $0.31 \pm 0.09^{a}$ & $0.35 \pm 0.10^{a}$ & $0.45 \pm 0.17^{b}$ & $0.39 \pm 0.08^{A}$ & $0.28 \pm 0.04^{\mathrm{B}}$ & $0.36 \pm 0.08^{A}$ \\
\hline \multirow{2}{*}{ Distilled } & Bisco & $0.56 \pm 0.18^{a}$ & $0.56 \pm 0.18^{\mathrm{a}}$ & $0.57 \pm 0.18$ & $0.62 \pm 0.38^{A}$ & $0.64 \pm 0.37^{B}$ & $0.66 \pm 0.36^{c}$ \\
\hline & $3 M$ & $0.32 \pm 0.14^{\mathrm{a}}$ & $0.35 \pm 0.13^{a}$ & $0.38 \pm 0.10^{b}$ & $0.39 \pm 0.26^{A}$ & $0.41 \pm 0.26^{A}$ & $0.44 \pm 0.25^{B}$ \\
\hline \multirow{2}{*}{ Water (DW) } & $\mathrm{GC}$ & $0.48 \pm 0.19^{a}$ & $0.49 \pm 0.18^{b}$ & $0.48 \pm 0.19^{c}$ & $0.46 \pm 0.14^{\mathrm{A}}$ & $0.47 \pm 0.14^{B}$ & $0.50 \pm 0.14^{c}$ \\
\hline & Kulzer & $0.37 \pm 0.07^{a}$ & $0.38 \pm 0.07^{a}$ & $0.40 \pm 0.08^{b}$ & $0.35 \pm 0.08^{A}$ & $0.37 \pm 0.08^{A}$ & $0.38 \pm 0.08^{B}$ \\
\hline
\end{tabular}

${ }^{*}$ Different letters in the same line show statististically significant difference $(p<0.05)$. Groups polymerized for 40 seconds showed in capital letters and groups polymerized for 20 seconds showed in lower cases.

curing ( $p>0.05)$. Statistically significant differences between Ra values measured after one month immersion in different beverages are shown in Table 4 and Table 5. The tables indicated that the RBCs cured for 20 seconds and immersed in Coca Cola exhibit all statistical similar roughness. Likewise, specimens of the microhybrid RBC (Charisma Classic - 40 seconds polymerization) immersed in red wine had statistically significant lower roughness change than the nanofilled (Filtek Ultimate) and the nanohybrid RBCs (Aelite). After immesion in distilled water, specimens of microhybrid RBC (G-aenial) had hardly changed their surface roughness values. Therefore, specimens of microhybrid (Charisma Classic) and nanofilled (Filtek Ultimate) RBCs showed statistically higher roughness than the microhybrid RBC (G-aenial). All of the RBC were affected by immersion in distilled water but the specimens had statistically significant lower roughness changes compared to immersion in Coca Cola and red wine.

\section{Discussion}

The surface quality of the RBC materials is dependent on the physical characteristics of the materials as well as the techniques used for finishing and polishing them. The application of nanotechnology in dental materials enables the incorporation of smaller particles with increased filler loading and results in lower polymerization shrinkage and better physical and mechanical properties [4]. The polishability is also correlated, besides filler, to the polymerization quality [9]. The parameters affecting the quality of curing, such as the exposure time, the exposure distance or the curing characteristics of the used curing unit (radiant emittance, spectral distribution etc) may directly be related to the polishability. The effects of the polishing systems on the surface quality has already been analysed $[7,18,19]$, however without involving the exposure time. Prolonged curing time may increase the degree of conversion, lower the residual monomers, and improving thus the surface quality of RBCs [20]. In order to obtain sufficient curing, the type of the curing unit used, either LED or QTH (Quartz Tungsten Halogen), was proved to have no direct influence on the surface roughness of the RBCs [16]. This must also be the case for the curing conditions in the present study, since no significant difference in surface roughness was identified in any of the analysed materials when increasing the exposure time from 20 seconds to 40 seconds. Therefore, the first null hypothesis is accepted. Regardless of the curing time, the various types of RBCs analyzed in the present study reacted differently to storage in beverages with regard to their surface quality. This confirms the results of previous studies published for the same materials [16]. The RBCs tested in the present study were selected due to their specific filler properties. Regarding the differences in the filler content and size of the RBC that affect the physical characteristics, polymerization quality and surface roughness values were assumed to be different. Moreover, microfilled RBCs have adequate polishability, thus they could mimic the surface smoothess of enamel greatly. However, these types of RBCs had lower mechanical strength, so they are recommended for low-stress regions [3]. On the contrary, microhybrid RBCs had higher mechanical strength but lower 
Table 4. Roughness increase (\%) and significance of RBCs cured for 20 seconds after one month immersion in different beverages*.

\begin{tabular}{|c|c|c|c|c|}
\hline & $\begin{array}{c}\text { Charisma Classic } \\
\text { (Microhybrid) }\end{array}$ & $\begin{array}{c}\text { Filtek Ultimate } \\
\text { (Nanofilled) }\end{array}$ & $\begin{array}{c}\text { G-aenial } \\
\text { (Microhybrid) }\end{array}$ & $\begin{array}{c}\text { Aelite } \\
\text { (Nanohybrid) }\end{array}$ \\
\cline { 2 - 5 } & $\begin{array}{c}\mathbf{2 0} \text { seconds } \\
\text { of curing }\end{array}$ & $\begin{array}{c}\mathbf{2 0} \text { seconds } \\
\text { of curing }\end{array}$ & $\begin{array}{c}\mathbf{2 0} \text { seconds } \\
\text { of curing }\end{array}$ & $\begin{array}{c}\mathbf{2 0} \text { seconds } \\
\text { of curing }\end{array}$ \\
\hline Coca Cola & $33.3^{\mathrm{A}, \mathrm{a}}$ & $52.4^{\mathrm{C} . \mathrm{a}}$ & $32.5^{\mathrm{D}, \mathrm{a}}$ & $35.7^{\mathrm{F}, \mathrm{a}}$ \\
\hline Red Wine & $45.1^{\mathrm{A} . \mathrm{b}}$ & $34.9^{\mathrm{c} . \mathrm{b}}$ & $61.1^{\mathrm{D}, \mathrm{b}}$ & $54.4^{\mathrm{F}, \mathrm{b}}$ \\
\hline $\begin{array}{c}\text { Distilled } \\
\text { Water }\end{array}$ & $8.1^{\mathrm{B}, \mathrm{c}}$ & $18.7^{\mathrm{c} . \mathrm{c}}$ & $0^{\mathrm{E}, \mathrm{d}}$ & $1.8^{\mathrm{G}, \mathrm{c,d}}$ \\
\hline
\end{tabular}

${ }^{*}$ Different uppercase letters in each RBC column indicate a statistically significant difference between the roughness values caused by beverages. Different lowercase letters in the rows indicate a statistically significant difference between the RBCs $(p<0.05)$.

polishability [19]. Apart for the above mentioned $\mathrm{RBC}$ categories, nano RBCs could be developed with not only excellent polishability but also with better mechanical and physical properties, including resistance to different media. This general remarks stay in contradiction to the results of the present study, since the analyzed microhybrid RBC, Charisma Classic, showed smo-other, while the nanohybrid $\mathrm{RBC}$, rougher surfaces. Thus, the second hypothesis was rejected.

The present study was intended to ensure standardization by selecting the ideal pair of materials and methods. For instance, the size of specimens was designated with a diameter of $8 \mathrm{~mm}$ to match the tip of the curing unit to use the lightcuring unit only once and eliminate the tip location from being a polymerization variable. All of the RBCs were chosen in the same shade to avoid different curing time requirements. Varying particle sizes were also enrolled to evaluate the different resistance and responses to acidic/alcoholic beverages effects in terms of surface roughness. Physical, thermal, and chemical factors in the oral environment play fundamental roles in the degradation process of RBC surfaces. The influence of these processes reflects a change in the surface roughness values [21]. In the present study, lower Ra values were reached not only by aging specimens in acidic and alcoholic beverages but also in distilled water. According to the results, all of the groups and subgroups were similarly affected by distilled water. Exposure to water could result in the hydrolytic degradation of fillers' silane coating, loss of chemical bonding between fillers and plasticizing and swelling of resin matrices $[22,23]$. Consequently, fillers may be pulled out from the specimen's surface after the organic matrix absorbs water, which could increase the surface roughness [23]. In this context, RBCs containing TEGDMA, a hydrophilic monomer, are more susceptible to water degradation following water uptake [24]. In the present study, all of the RBCs except the microhybrid (G-aenial) contain TEGDMA in their organic matrix. The RBC G-eanial is advertised as a microfilled RBC, but according to its particle sizes, it needs to be classified as a microhybrid RBC. In the present study it showed the significantly lowest surface changes among the analysed RBCs when cured for 20 seconds (Table 4). Evaluating the acidic (CC) and alcoholic (RW) beverages, the ethanol concentration of red wine and the phosphoric acid in Coca Cola may lead to surface degradation. Additionally, ethanol could penetrate the organic matrix, alter the polymeric structure [12], and eventually affect the mechanical and physical properties of the RBCs. The effects of ethanol are thought to be more significant than the prolonged exposure to water [25]. In the present study, there is no significant difference among RBCs cured for 20 seconds. However, after 40 seconds of curing, the nanofilled and nanohybrid RBCs showed significantly rougher surfaces than the microhybrid RBCs. This could be attributed to the higher amount (68 vol\%) of smaller fillers $(0.01-0.07 \mu \mathrm{m})$ in the microhybrid RBC. The present data confirmed thus the study of Tantanuch et al [23] which found out that nanofilled RBCs showed better surface properties than nanohybrid RBCs after being immersed in red wine. Furthermore, the acidity of the immersing solution may have a direct effect on softening resin matrices, allowing filler to be pulled out and creating thus voids over the surface, that may enhance roughness [23]. Red wine contains not only ethanol but may also act as an acidic solution. Both analysed beverages are characterized by a low $\mathrm{pH}$; however, in the present study, regardless of the curing time, there were not statistically significant differences between the roughness values of RBCs after immersion in Coca Cola and red wine. On the other hand, Ra scores above $0.2 \mu \mathrm{m}$ have been reported to increase the biofilm formation [26]. Ra values higher than $0.3 \mu \mathrm{m}$ can be physically perceived by patients, which could lead to patient's dissatisfaction and an extra clinic sessions for polishing the restoration's surface [27]. Although all of the specimens were polished with discs (Sof-Lex), described as one of the best protocols to create low roughness scores in resin materials 
Table 5. Roughness increase (\%) and significance of 40 seconds cured RBCs after one month immersion in different beverages*.

\begin{tabular}{|c|c|c|c|c|}
\hline & $\begin{array}{c}\text { Charisma Classic } \\
\text { (Microhybrid) }\end{array}$ & $\begin{array}{c}\text { Filtek Ultimate } \\
\text { (Nanofilled) }\end{array}$ & $\begin{array}{c}\text { G-aenial } \\
\text { (Microhybrid) }\end{array}$ & $\begin{array}{c}\text { Aelite } \\
\text { (Nanohybrid) }\end{array}$ \\
\cline { 2 - 5 } & $\begin{array}{c}\mathbf{4 0} \text { seconds } \\
\text { of curing }\end{array}$ & $\begin{array}{c}\mathbf{4 0} \text { seconds of } \\
\text { curing }\end{array}$ & $\begin{array}{c}\text { 40 seconds of } \\
\text { curing }\end{array}$ & $\begin{array}{c}\mathbf{4 0} \text { seconds of } \\
\text { curing }\end{array}$ \\
\hline Coca Cola & $51.2^{\mathrm{A}, \mathrm{a}}$ & $75.6^{\mathrm{B}, \mathrm{a}}$ & $37.8^{\mathrm{D}, \mathrm{a}}$ & $63.1^{\mathrm{F}, \mathrm{a}}$ \\
\hline Red Wine & $-7.8^{\mathrm{A} . \mathrm{b}}$ & $73.1^{\mathrm{B}, \mathrm{c}}$ & $43.1^{\mathrm{D}, \mathrm{b}, \mathrm{c}}$ & $52,6^{\mathrm{F}, \mathrm{c}}$ \\
\hline $\begin{array}{c}\text { Distilled } \\
\text { Water }\end{array}$ & $8.6^{\mathrm{A}, \mathrm{d}}$ & $12.8^{\mathrm{C} . \mathrm{d}}$ & $8.7^{\mathrm{E}, \mathrm{d}}$ & $6.4^{\mathrm{G}, \mathrm{d}}$ \\
\hline
\end{tabular}

*Different uppercase letters in each RBC column indicate a statistically significant difference between the roughness values caused by beverages. Different lowercase letters in the rows indicate a statistically significant difference between the RBCs $(p<0.05)$.

[28], even at the baseline results, all of the RBCs showed surface roughness values higher as the mentioned thresholds. The possible reasons could be related to the inner characteristics, such as polishing responses of the materials. RBCs made of finer filler particles exhibit lower interspacing, less filler pullout and thus, smoother surfaces [29]. Research has shown that nanohybrid RBCs in particular create smaller voids after finishing and polishing procedures $[23,29]$. However, in the present study, the specimens cured for 40 seconds consisting of a nanofilled (Filtek Ultimate) and a nanohybrid (Aelite Aesthetic Enamel) RBC showed statistically significant rougher surfaces than the microhybrid RBC (Charisma Classic) after immersion in all beverages. Moreover, after 20 seconds curing and immersion in red wine, Charisma Classic showed smoother surfaces as compared to the nano-RBCs. These results could be attributed to the type, size, number and distribution of fillers, which all have a significant impact on the mechanical and physical characteristics of the RBCs [29]. There is clear evidence that the size and irregularity of fillers is directly proportional to the surface roughness of a RBC [30]. Smaller fillers were thought to be less prominent on the surface; thus, they were more resistant to wear because of their homogeneity in the resin matrices [22]. Small fillers could reduce the spacing that provides resistance and protects the resin matrix [13]. In the present study, the microhybrid RBC (G-aenial) and the nanofilled RBC (Filtek Ultimate) had the largest fillers (16-17 $\mu \mathrm{m}$ and 0.6-10 $\mu \mathrm{m}$, respectively) among the tested RBCs. That could be one of the reasons for those RBCs having the highest roughness scores of almost all groups. Besides filler size, a low inorganic content compromises the surface smoothness [4]. The nanofilled RBC had the highest filler amount ( 63.3 vol\%), which could be one of the reasons it has smoother surfaces than microhybrid (G-eanial) and nanohybrid RBCs, even having the largest filler particles overall. In general, the influence of the size and type of fillers on the surface quality has been thoroughly presented in the literature. Magdy et al [20] found that the RBC s with barium glass fillers showed higher surface roughness. In the present study, the microhybrid RBC was the only material containing Ba glass fillers, and results were not consistent with the above-mentioned study. It is reasonable to have conflicting results over fillers because the filler type may have an effect on surface roughness however, it is clearly not the only parameter. Besides size, amount and distribution of the fillers, their chemical composition may indirectly affect the roughness, since it determines the refractive index and thus may have an effect on the degree of conversion of the polymer matrix. At a lower refractive index mismatch between filler and matrix, less scattering occurs and the degree of conversion of the organic matrix may be increased. Marovic et al. [31] showed that Ba fillers could increase the degree of conversion of the organic matrix, while silica fillers may decrease it. However, it must be considered that scattering is not only dependent on the refractive index mismatch between filler and matrix but essentially also on the filler size and its relation to the wavelength used for curing a RBC. In the present study, the tested RBCs contained differently formulated filler particles and sizes, so the effect of the chemical composition and size on the Ra values cannot be properly discussed. The nanofilled RBC contains zirconia/silica clusters, the microhybrid RBC pyrogenic made silica, the microhybrid (Charisma Classic), RBC contains besides pyrogenic silica also prepolymerized filler based on silica while the nanohybrid RBC contains silica - glass particles. One study [4] found that, even though nano particles create smaller gaps after polishing, nanoclustered particles are not pulled out from the resin matrices neither. Among the tested RBCs, only the nanofilled RBC (Filtek Ultimate) had nanoclustered particles, which could explain the superior Ra results of the nanofilled RBC. The monomer type is one of the main component of the RBCs affecting surface quality, and it was demonstrated that the chemical composition of monomers is related to preserve surface smoothness against the tough oral 
conditions over time [22]. Bis-GMA and UDMA are the most common monomers used in RBCs. Monomers, such as Bis-EMA, have been developed to improve viscosity, lower the polymerization shrinkage and toughening the resin matrix. Bis-EMA has fewer carbon-carbon double bonds that lead to a softer, less cross-linked organic matrix that could be affected by acidic or alcoholic beverages [4]. The nanofilled and nanohybrid RBCs analyzed in the present study contain Bis-EMA and tended to be rougher than microhybrid RBCs based on Bis-GMA and TEGDMA. Another monomer with a hydrophilic character, TEGDMA, tends to degrade more quickly [4]. In the analyzed RBCs (nanohybrid and nanofilled), both TEGDMA and Bis EMA were used, thus inferior results of those RBCs could also be attributed to the softer matrices which might be degraded by acidic intake or water uptake. On the other hand, the nanofilled (Filtek Ultimate) and microhybrid (G-aenial) RBCs containe UDMA in their resin matrices. UDMA has lower water sorption and solubility than TEGDMA, Bis-GMA and Bis-EMA [4]. The microhybrid (G-aenial) contains only UDMA in the resin matrix that may lower the water uptake and may be responsible for the less changes in roughness when immersed in distilled water after 20 seconds of curing.

\section{References}

1. Manhart J, Hickel R. Bulk-fill-composites. Modern application technique of direct composites for posterior teeth. Swiss Dent J. 2014;124(1):19-37.

[PubMed] Google Scholar Scopus

2. Gönülol N, Yilmaz F. The effects of finishing and polishing techniques on surface roughness and color stability of nanocomposites. J Dent. 2012;40(2):e64-e70.

[Full text links] [CrossRef] [PubMed] Google Scholar Scopus

3. Lainović $T$, Vilotić $M$, Blažić $L$, et al. Determination of surface roughness and topography of dental resin-based nanocomposites using AFM analysis. Bosn J Basic Med Sci. 2013;13(1):34.

[Full text links] [Free PMC Article][CrossRef] [PubMed] Google Scholar Scopus

4. Yadav RD, Raisingani D, Jindal D, Mathur R. A comparative analysis of different finishing and polishing devices on nanofilled, microfilled, and hybrid composite: a scanning electron microscopy and profilometric study. Int J Clin Pediatr Dent. 2016;9(3):201-208. [Full text links] [CrossRef] [PubMed] Google Scholar

5. de Alencar e Silva Leite ML, da Cunha Medeiros e Silva FD, Meireles SS, et al. The effect of drinks on color stability and surface roughness of nanocomposites. Eur J Dent. 2014;8(3):330-336. [Full text links] [CrossRef] [PubMed] Google Scholar

6. Moda MD, Godas AGDL, Fernandes JC, et al. Comparison of different polishing methods on the surface roughness of microhybrid, microfill, and nanofill composite resins. J Investig Clin Dent. 2018;9(1):e12287.

[Full text links] [CrossRef] [PubMed] Google Scholar Scopus

7. Erdemir U, Yildiz E, Eren MM, et al. Effects of polishing systems on the surface roughness of tooth-colored materials. J Dent Sci. 2013;8(2):160-169.

[CrossRef] Google Scholar Scopus

8. Attar N. The effect of finishing and polishing procedures on the surface roughness of composite resin materials. J Contemp Dent Pract. 2007;8(1):27-35.

[CrossRef] [PubMed] Google Scholar Scopus

9. Topcu FT, Erdemir U, Sahinkesen G, et al. Evaluation of microhardness, surface roughness, and wear behavior of different types of resin composites polymerized with two different light sources. J Biomed Mater Res B Appl Biomater. 2010;92(2):470-478. [Full text links] [CrossRef] [PubMed] Google Scholar Scopus

\section{Conclusion}

Nanofilled and nanohybrid RBCs (Aelite, Filtek Ultimate) as well as one of the analyzed microhybrid RBC (Charisma Classic) showed similar surface roughness after curing for 20 seconds. Charisma Classic showed better surface quality than Aelite and Filtek Ultimate after 40 seconds of curing. Despite varying filler types and chemical composition of the monomer matrix, prolonged curing time had no significant effect on the surface roughness. Yet, immersion in both acidic and alcoholic beverages affected the surfaces of all RBCs and generated significant surface roughness changes. Thus, regardless of the curing time, all analyzed RBCs showed unacceptable changes in surface roughness.

\section{Author Contributions}

GO: had the idea of the hypothesis and MME designed the study. GO: collected the data and performed the experimental period with MME.

SOY: prepared the statistical analysis. HSS: revised the manuscript and corrected the language.

EY: editted the whole manuscript.

\section{Acknowledgment}

There is no conflict of interest.

10. Kerby RE, Knobloch LA, Schricker S, Gregg B. Synthesis and evaluation of modified urethane dimethacrylate resins with reduced water sorption and solubility. Dent Mater. 2009;25(3):302-313. [Full text links] [CrossRef] [PubMed] Google Scholar Scopus 11. Moszner N, Fischer UK, Angermann J, Rheinberger V. A partially aromatic urethane dimethacrylate as a new substitute for Bis-GMA in restorative composites. Dent Mater. 2008;24(5):694-699. [Full text links] [CrossRef] [PubMed] Google Scholar Scopus

12. Erdemir U, Tiryaki M, Saygi G, et al. Effects of different kinds of beers on the surface roughness of glazed and polished methacrylate and Silorane-based composites: a 1-month study. Ann Stomato (Roma). 2017;8(1):23-28.

[Full text links] [CrossRef] [PubMed] Google Scholar

13. Rajan VV, Ganapathy D, Sheeba PS, Kanniappan N. Effects of tooth brushing on wear, surface roughness, and color stability of composite resins-A review. J Pharm Res. 2018;12(1):95-102.

14. Bansal K, Acharya SR, Saraswathi V. Effect of alcoholic and nonalcoholic beverages on color stability and surface roughness of resin composites: An in vitro study. J Conserv Dent. 2012;15(3):283-288. [Full text links] [Free PMC Article] [CrossRef] [PubMed] Google $\underline{\text { Scholar }} \underline{\text { Scopus }}$

15. Kumavat V, Raghvendra SS, Vyavahare N, et al. Effect of alcoholic and non-alcoholic beverages on color stability, surface roughness and fracture toughness of resin composites: an in vitro study. IIOAB J. 2016;7(6):48-54.

Google Scholar -

16. Eren MM, Saygi G, Yildirim Z, et al. Surface hardness change of composite resins immersed in beverages with/without alcohol (Abstract). TDA 23th International Congress; September 21-24, 2017; Izmir, Turkey.

17. Tabatabaei $\mathrm{MH}$, Arami S, Farahat F. Effect of mechanical loads and surface roughness on wear of silorane and methacrylate-based posterior composites. J Dent (Tehran). 2016;13(6):407-414.

[Full text links] [PubMed] Google Scholar

18. Sadeghi M, Deljoo Z, Bagheri R. The influence of surface polish and beverages on the roughness of nanohybrid and microhybrid resin composite. J Dent Biomater. 2016;3(1):177-185.

Google Scholar

19. Kritzinger D, Brandt PD, De Wet FA. The effect of different polishing systems on the surface roughness of a nanocomposite and a microhybrid composite. SADJ. 2017;72(6):249-257.

[CrossRef] Google Scholar 
20. Magdy NM, Kola MZ, Alqahtani $\mathrm{HH}$, et al. Evaluation of surface roughness of different direct resin-based composites. J Int Soc Prev Community Dent. 2017;7(3):104-109.

[Full text links] [Free PMC Article] [PubMed] Google Scholar Scopus 21. Da Silva MA, Vitti RP, Sinhoreti MA, et al. Effect of alcoholic beverages on surface roughness and microhardness of dental composites. Dent Mater J. 2016;35(4):621-626.

[Full text links] [CrossRef] [PubMed] Google Scholar Scopus

22. Dos Santos PH, Catelan A, Albuquerque Guedes AP, et al. Effect of thermocycling on roughness of nanofill, microfill and microhybrid composites. Acta Odontol Scand. 2015;73(3):176-181.

[Full text links] [CrossRef] [PubMed] Google Scholar Scopus

23. Tantanuch S, Kukiattrakoon B, Peerasukprasert T, et al. Surface roughness and erosion of nanohybrid and nanofilled resin composites after immersion in red and white wine. J Conserv Dent. 2016;19(1):51-55

[Full text links] [Free PMC Article] [CrossRef] [PubMed] Google Scholar Scopus

24. Gonçalves F, Kawano $Y$, Pfeifer $C$, et al. Influence of BisGMA TEGDMA, and BisEMA contents on viscosity, conversion, and flexural strength of experimental resins and composites. Eur J Oral Sci. 2009;117(4):442-446.

[Full text links] [CrossRef] [PubMed] Google Scholar Scopus

25. Benetti AR, Ribeiro de Jesus VC, Martinelli NL, et al. Colour stability, staining and roughness of silorane after prolonged chemical challenges. J Dent. 2013;41(12):1229-1235.

[Full text links] [CrossRef] [PubMed] Google Scholar Scopus

26. Da Silva EM, De Sá Rodrigues CUF, Dias DA, et al. Effect of toothbrushing-mouthrinse-cycling on surface roughness and topography of nanofilled, microfilled, and microhybrid resin composites. Oper Dent. 2014;39(5):521-529.

[Full text links] [CrossRef] [PubMed] Google Scholar Scopus
27. de Queiroz MMV, Nishitani Shibasaki PA, Pimenta Lima MJ, et al. Effect of erosion and methods for its control on the surface roughness of composite resin. Rev Odonto Cienc. 2017;32(2):88-93. [CrossRef] Google Scholar Scopus

28. Karaman E, Tuncer D, Firat E, et al. Influence of different staining beverages on color stability, surface roughness and microhardness of silorane and methacrylate-based composite resins. J Contemp Dent Pract. 2014;15(3):319-325.

[PubMed] Google Scholar Scopus

29. Tavangar M, Bagheri R, Kwon TY, et al. Influence of beverages and surface roughness on the color change of resin composites. $J$ Investig Clin Dent. 2018;9(3):e12333.

[Full text links] [CrossRef] [PubMed] Google Scholar Scopus

30. Marghalani HY. Effect of finishing/polishing systems on the surface roughness of novel posterior composites. J Esthet Restor Dent. 2010;22(2):127-138.

[Full text links] [CrossRef] [PubMed] Google Scholar Scopus

31. Marović D, Šariri K, Demoli N, et al. Remineralizing amorphous calcium phosphate based composite resins: the influence of inert fillers on monomer conversion, polymerization shrinkage, and microhardness. Croat Med J. 2016;57(5):465-473.

[Full text links] [Free PMC Article] [CrossRef] [PubMed] Google Scholar Scopus

32. Ameri F, Abdotabrizi M, Ghasemi A, et al. Color stability of two bulk-fill composite resins. J Dent Sch. 2015;33(4):238-244.

[CrossRef] Google Scholar

\section{Günçe OZAN \\ DDS, PhD, Research Assistant Department of Restorative Dentistry Faculty of Dentistry, Istanbul University Istanbul, Turkey}

Günçe Ozan received her DDS degree in 2011 from the Faculty of Dentistry at Istanbul University, Istanbul, Turkey. She immediately started her PhD at the Restorative Dentistry Department of the same university. After studying dental erosion and preventive dentistry, she had her PhD degree in 2017. She worked at the Young Dentists' Commission of the Turkish Dental Association for 2 years. She is now continuing her career at the Istanbul University as a Research Assistant. 


\section{Orestions}

\section{Why are the novel monomers such as BIS-EMA, AUDMA developed? To reduce composites'...}

Da. Viscosity;

口b. Water sorption;

ac. Solubility;

d. All of the properties above.

\section{Choose the most hydrophilic monomer above}
口a. UDMA;
b. AUDMA;
口c. TEGDMA;
口d. BIS-GMA

3. Composites with smaller fillers show lower surface roughness values. Because...

$\square$ a. They are less prominent when they are plugged out;

b. They have low modulus of elasticity;

$\square c$. They are highly soluble;

$\square$ d. All of the statements above.

\section{How could an acidic or alcoholic beverage affect composite resin? It could cause...}

口a. Organic matrix plasticizing;

ab. Organic matrix softening;

$\square c$. Wear and degradation;

$\square$ d. All of the statements above.

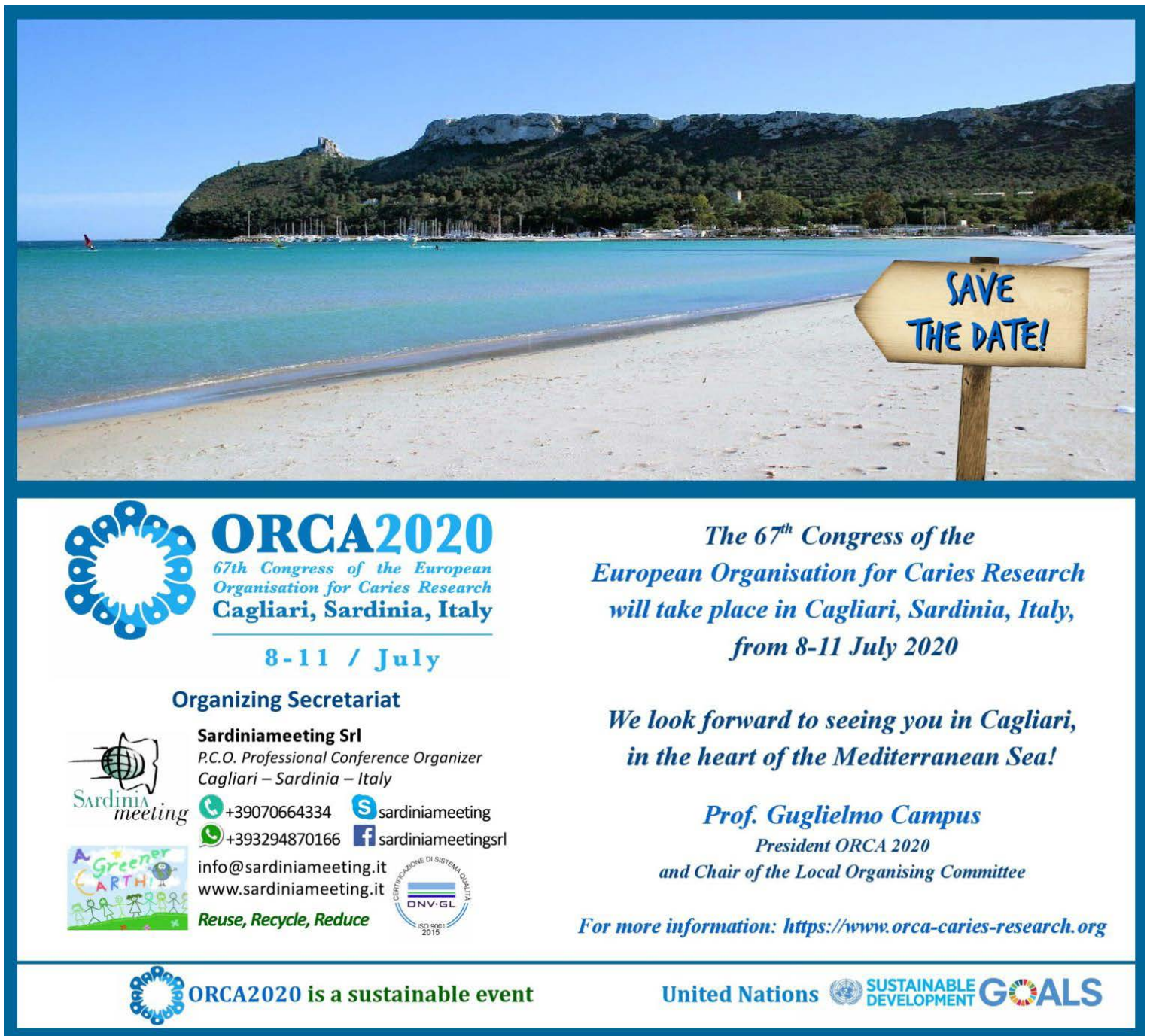




\title{
THE INFLUENCE OF SALIVA CONTAMINATION ON UNIVERSAL ADHESIVE BONDING TOENAMEL AND DENTIN
}

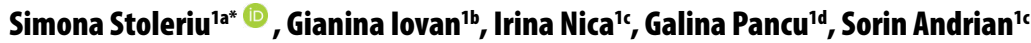 \\ 'Odontology-Periodontology and Fixed Prosthesis Department, Faculty of Dental Medicine „, Grigore T. Popa" University of Medicine and Pharmacy lași, \\ Iași, Romania
}

aDMD, PhD, Associate Professor

${ }^{b} \mathrm{DMD}, \mathrm{PhD}$, Professor

'DMD, PhD, Assistant Professor

${ }^{\mathrm{D} D M D}, \mathrm{PhD}$, Lecturer

'DMD, PhD, Professor

\section{ABSTRACT \\ DOI: https://doi.org/10.25241/stomaeduj.2019.6(4).art.2}

Introduction: The aims of the study were to investigate the enamel and dentin marginal seal of a universal adhesive system applied with etch and rinse and selfetch strategy and to evaluate the enamel and dentin marginal microleakage in case of saliva contamination on different steps of the adhesive application by dye penetration assessment.

Methodology: Thirty class $V$ cavities were prepared on the buccal face (group I- etch and rinse application of universal adhesive system) and the lingual face (group II- self-etch application of universal adhesive system) of molars and bicuspids. In each group 3 subgroups were created according to the moment of the saliva contamination: subgroup 1- no contamination, subgroup 2-contamination before light curing the adhesive, subgroup 3-contamination after light curing the adhesive. The dye penetration at the adhesive interface was evaluated according to a 4-score scale.

Results: In both groups increased enamel and dentin microleakage was recorded in subgroups 2 and 3 when comparing to subgroup 1. In group I saliva contamination before and after light curing the adhesive resin led to similar mean value of dentin microleakage. Increased values of microleakage were recorded in group II when comparing to group I in the subgroups where contamination with saliva was done before light curing the adhesive resin.

Conclusions: Saliva contamination of the adhesive system after light curing increased enamel microleakage only when the adhesive system was applied with etch and rinse strategy. Increased dentin microleakage after contamination was recorded with both strategies of universal adhesive system application.

Keywords: Universal Adhesive System; Adhesion; Saliva Contamination;

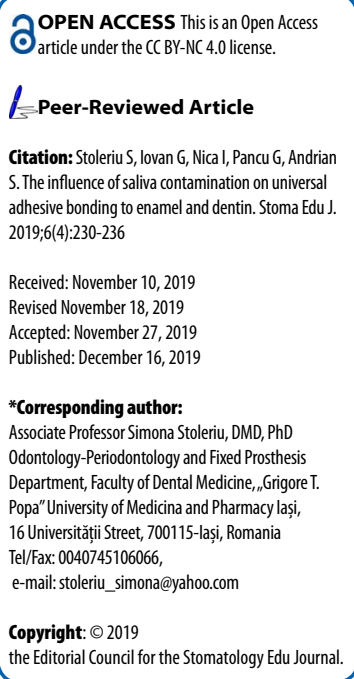

Copyright: $\odot 2019$

the Editorial Council for the Stomatology Edu Journal. Etch and Rinse; Self-Etch.

\section{Introduction}

Adhesion is the attraction of two different surfaces placed into direct tight contact determined by intermolecular forces that act at a relatively low distance [1]. The name adhesive indicates a material, most frequently a viscous fluid that joins (bonds) together two substrates and favours the transfer of forces from one surface to another [2]. There are many mechanisms implicated in the bonding process, four mechanisms being implicated in bonding to the tooth structure: 1. mechanical adhesion (resin penetration into the dental structure and resin tags formation); 2 . adhesion by sorption (chemical adhesion to the inorganic part of the tooth structure - hydroxyapatite - or to the organic part - mostly to type I collagen by Van der Waals or dipol-dipol forces, by hydrogen or covalent bonds); 3. adhesion by diffusion (substances precipitation on the tooth surface to which resin monomers can bond mechanically or chemically); 4. combination of the three mechanisms mentioned above $[3,4]$. The adhesion mechanism of bonding systems represents the replacement of removed tooth minerals with resin monomers in order that the polymers could be micromechanically integrated into the dental structure $[5,6]$. There are some conditions to obtain a good adhesion: the surface substrate should be clean, the adhesive should perfectly wet the substrate, there should be a good intimal adaptation of the adhesive to the adherent, and the bond strength should be high enough to resist to debonding forces [7]. Acid etching was recommended more than sixty 
Table 1. Details regarding the restoration protocol in sugroups 1-5 of groups I and II.

\begin{tabular}{|c|c|}
\hline \multicolumn{2}{|r|}{ Group I } \\
\hline $\begin{array}{l}\text { Subgroup } 1 \\
\text { (control) }\end{array}$ & $\begin{array}{l}\text { Phosphoric acid application for } 15 \text { seconds on enamel and dentin; washing } \\
\text { with water; drying with a brush applicator; scrubbing the surface with } \\
\text { adhesive resin for } 20 \text { seconds, air drying for } 5 \text { seconds, lightcure for } 20 \\
\text { seconds; composite resin restoration }\end{array}$ \\
\hline Subgroup 2 & $\begin{array}{l}\text { Phosphoric acid application for } 15 \text { seconds on enamel and dentin; washing } \\
\text { with water; drying with a brush applicator; scrubbing the surface with } \\
\text { adhesive resinfor } 20 \text { seconds; saliva contamination for } 5 \text { seconds, air drying } \\
\text { for } 5 \text { seconds, lightcure for } 20 \text { seconds; composite resin restoration }\end{array}$ \\
\hline Subgroup 3 & $\begin{array}{l}\text { Phosphoric acid application for } 15 \text { seconds on enamel and dentin; washing } \\
\text { with water; drying with a brush applicator; scrubbing the surface with } \\
\text { adhesive resin for } 20 \text { seconds; air drying for } 5 \text { seconds; lightcure for } 20 \\
\text { seconds; saliva contamination for } 5 \text { seconds; air drying for } 5 \text { seconds, } \\
\text { composite resin restoration }\end{array}$ \\
\hline \multicolumn{2}{|r|}{ Group II } \\
\hline Subgroup 1 & $\begin{array}{l}\text { Scrubbing the surface with the adhesive resin for } 20 \text { seconds; air drying for } 5 \\
\text { seconds; lightcure for } 20 \text { seconds; composite resin restoration }\end{array}$ \\
\hline Subgroup 2 & $\begin{array}{l}\text { Scrubbing the surface with the adhesive resin for } 20 \text { seconds; saliva } \\
\text { contamination for } 5 \text { seconds; air drying for } 5 \text { seconds; lightcure for } 20 \\
\text { seconds; composite resin restoration }\end{array}$ \\
\hline Subgroup 3 & $\begin{array}{l}\text { Scrubbing the surface with the adhesive resin for } 20 \text { seconds; air drying for } \\
5 \text { seconds; lightcure for } 20 \text { seconds; saliva contamination for } 5 \text { seconds; air } \\
\text { drying for } 5 \text { seconds; composite resin restoration }\end{array}$ \\
\hline
\end{tabular}

years ago by Buonocuore to facilitate the adhesion of composite resin to the enamel [8]. By etching the smooth surface of enamel is changed into an irregular surface and the surface energy increases. The resin will penetrate the rough surface by capillary action and resin tags will result. This is the fundamental mechanism of bonding to enamel [9]. Bonding to dentin relies mostly on monomer's penetration within the collagen fibers exposed after acid etching. The presence of dentin fluid on the cut dentin surface and the smear layer formation by fragments of hydroxyapatite crystals and denatured collagen might complicate the adhesion to dentin [10]. Optimal adhesion is obtained by completely removing the smear layer (etch and rinse strategy) or incorporating it into the adhesive layer (self-etch strategy) [11]. The technique of restoration using composite resins is very sensitive to moisture, so good isolation of the operating field is mandatory to obtain a good adhesion. The clean and high energy state of the surface is mandatory to obtain strong bonding. In some particular clinical situation ideal isolation cannot be achieved and oral biofilms, saliva, other oral fluids, and organic debris might contaminate the tooth surface prepared for adhesion [12].

An acid conditioned enamel surface rapidly absorbs salivary components, which decreases the surface energy and impairs the surface for adhesion [13]. A review of the literature regarding the influence of saliva contamination on adhesive dentistry has shown that $77 \%$ of the three-step adhesive systems, $46 \%$ of the two-step adhesive systems, $81.5 \%$ of the two-step self-etch adhesives and $73.3 \%$ of the onestep self-etch adhesives may be adversely influenced in their bond quality [14]. Universal adhesive systems are the latest class of bonding agents released on the market. Here are some of their characteristics: they can be used for direct and indirect restorations, they can react with different substrates, they can be used with etch and rinse, self-etch or selective etch strategy according to the clinical situation and the personal preference of the practitioner [15]. They should be hydrophilic in order to wet the dentin surface well, they should be hydrophobic not to allow water sorption and hydrolysis after polymerization, they should be acidic enough to etch well, but not so acidic in order not to destroy some of the initiators [7]. There are only few data in the literature regarding the bonding of universal adhesive systems in case of substrate contamination $[16,17]$. The aims of the study were to investigate the enamel and dentin marginal seal of a universal adhesive system applied in etch and rinse and self-etch strategy, to evaluate the enamel and dentin marginal microleakage in case of saliva contamination on different steps of the adhesive application by dye penetration assessment.

\section{Materials and methods}

Thirty molars and bicuspids having no caries lesions buccal and lingual on the cervical third of the crown no wear lesions or other defects after the extraction were chosen for this study. Class $V$ cavities having a depth of $3 \mathrm{~mm}$ and the cervical margin placed $2 \mathrm{~mm}$ apically of the enamel-cementum junction 
Table 2. Microleakage scores on enamel and dentin margins in group I.

\begin{tabular}{|c|c|c|c|c|c|}
\hline & Score 0 & Score 1 & Score 2 & Score 3 & $\begin{array}{l}\text { Mean scores } \\
\text { value }\end{array}$ \\
\hline \multicolumn{6}{|c|}{$\begin{array}{l}\text { Grup I - enamel (Statisticaly significant results-uppercase, No statisticaly significant results-lowercase } \\
\text { subgroup 1-subgroup 2: A,a; subgroup 1-subgroup 3: B,b; subgroup 2-subgroup 3: C,c) }\end{array}$} \\
\hline Subgroup 1 & 10 & - & - & - & $0(\mathrm{aB})$ \\
\hline Subgroup 2 & 8 & 2 & - & - & $0.2(\mathrm{a}, \mathrm{c})$ \\
\hline Subgroup 3 & 6 & 4 & - & - & $0.4(B, C)$ \\
\hline \multicolumn{6}{|c|}{$\begin{array}{l}\text { Grup I - dentin (Statisticaly significant results-uppercase, No statisticaly significant results-lowercase, } \\
\text { subgroup 1-subgroup 2: D,d; subgroup 1-subgroup 3: E,e; subgroup 2-subgroup 3: F,f) }\end{array}$} \\
\hline Subgroup 1 & 10 & - & - & - & $0(D, E)$ \\
\hline Subgroup 2 & 6 & 2 & 2 & - & $0.6(D, f)$ \\
\hline Subgroup 3 & 6 & 2 & 2 & - & $0.6(E, f)$ \\
\hline
\end{tabular}

were prepared on these areas. The buccal cavities were included in group I and the lingual cavities in group II. All the cavities were restored using the same composite resin (Ceram $X$ sphere TEC one, Dentsply Sirona - batch number 0894) and a universal adhesive system (Prime and Bond Active, Dentsply Sirona - batch number 1810000151) applied with two different strategies: etch and rinse (group I) and self-etch (group II). In each group 3 subgroups were created according to the moment of saliva contamination during the adhesive system application (table 1).

Human stimulated saliva was used for contamination. The saliva was collected from a single person in two different days, at the same hour, after a diet break of 5 hours. The same quantity of saliva $(0.1 \mathrm{~mL})$ was applied in contamination session using a syringe. The composite resin used for the restoration was applied in two layers of $1.5 \mathrm{~mm}$, each one being polymerized using a LED lamp (LED B, Guilin Woodpecker Medical Instrument Co., Ltd., Guilin, China) with a wavelength of $420-480 \mathrm{~nm}$. A constant light intensity of $1000 \mathrm{~mW} /$ $\mathrm{cm}^{2}$ was used during the experiment and the light intensity was tested before the beginning of the test using a Demetron ${ }^{\circledast}$ LED radiometer (Kerr Dental, Bioggio, Switzerland). After restoration the teeth were submersed in distilled water for 24 hours, then the external surfaces of the buccal and lingual tooth faces were covered with water resistant varnish, except a $1 \mathrm{~mm}$ area around the restorations, then they were submersed in methylene blue solution $2 \%$ $(\mathrm{pH}=7)$ for 24 hours. The teeth were sectioned in a buccal-lingual direction using diamond disks at low speed, under water cooling (Komet Dental, Brasseler $\mathrm{GmbH} \&$ Co., Lemgo, Germany). The tooth sections were evaluated using an optical microscope (CarlZeiss AXIO Imager A1m) at 10X magnification and the dye penetration at the enamel (occlusal) and dentin (cervical) margins of the cavity was assessed using a 4-score scale: 0 - no dye penetration; 1 - dye penetration less than half of the wall; 2 - dye penetration more than half but less than the entire wall; 3 - complete dye penetration on the wall until the axial wall of the cavity. The Mann-Whitney statistical test was used to compare the results in groups and subgroups.

\section{Results}

The scores of dye penetration in subgroups 1-3 of groups I and II are presented in tables 2 and 3. In both groups increased enamel microleakage was recorded in subgroups 2 and 3 when comparing to subgroup 1. Group I contamination with saliva after polymerization of the adhesive resin led to the highest microleakage mean value. Significantly statistic result was obtained when comparing enamel microleakage in subgroups 1 and 3 from group I $(p=0.029<0.05)$, but no statistically significant results were obtained when comparing enamel microleakage in subgroups 1 and $2(p=0.145>0.05)$. In group II statistically significant results were obtained when comparing enamel microleakage in subgroups 2 and 3 when comparing to subgroup $1(p=0.030<0.05$ and $p=0.005<0.05)$. In group II no statistically significant differences of values of microleakage were recorded in all subgroups when comparing to group I $(p=1.000>0.05)$.

At the dentin margins increased values of microleakage were recorded in subgroups 2 and 3 when comparing to control in both groups $(p=0.030<0.05$, $p=0.030<0.05, \quad p=0.004<0.05$, and $p=0.005<0.05$ respectively). In group I saliva contamination before and after light curing the adhesive resin led to similar mean values of microleakage. Increased values of microleakage were recorded in group II when comparing to group I in the subgroups where contamination with saliva of the adhesive resin was done before light curing. Irrespective of the moment of saliva contamination, the microleakage values at the dentin margins in etch and rinse strategy of 
Table 3. Microleakage scores on enamel and dentin margins in group II.

\begin{tabular}{|l|c|c|c|c|c|}
\hline & Score 0 & Score 1 & Score 2 & Score 3 & $\begin{array}{c}\text { Mean scores } \\
\text { value }\end{array}$ \\
\hline $\begin{array}{l}\text { Grup II- enamel (Statisticaly significant results-uppercase, No statisticaly significant results-lowercase; } \\
\text { subgroup 1-subgroup 2: A,a; subgroup 1-subgroup 3: B,b; subgroup 2-subgroup 3: C,c) }\end{array}$ & -2 & - & $0.2(A, B)$ \\
\hline Subgroup 1 & 8 & 2 & - & - & $0.6(A, c)$ \\
\hline Subgroup 2 & 4 & 6 & 2 & - & $0.8(B, c)$ \\
\hline Subgroup 3 & 4 & 4 & - & - & $0(D, E)$ \\
\hline $\begin{array}{l}\text { Grup II - dentin (Statisticaly significant results-uppercase, No statisticaly significant results-lowercase; } \\
\text { subgroup 1-subgroup 2: D,d; subgroup 1-subgroup 3: E,e; subgroup 2-subgroup 3: F,f) }\end{array}$ \\
\hline Subgroup 1
\end{tabular}

adhesive application were not higher than those at enamel margins (subgroup $2 \mathrm{p}=0.260>0.05$, subgroup $3 \mathrm{p}=0.342>0.05)$. In the self-etch strategy of the adhesive application similar values of microleakage were recorded at enamel and dentin margins. (in all subgroups $p$ value was $1.00>0.05$ )

\section{Discussion}

Composite resins are the most frequently used materials for direct restorations due to their mechanical and optical properties and to the conservative preparation of the teeth needed [18]. A lot of factors can contribute to the marginal leakage of composite resins into the oral cavity: the size and the shape of the cavity, the type of the dental substrate, the type and the placement of the prepared cavity margins, and the technique of restoration [19]. Marginal adaptation of the adhesive system to the tooth structure should prevent the microleakage onset and future caries lesion adjacent to the restoration, saliva infiltration, pulp irritation or fracture of the restoration $[20,21]$. Progress was made in time to improve the composite resins bonding to enamel and dentin. Phosphoric acid was the first acid used for tooth etching, but the newer generations of bonding agents contain acidic primers that etch and prime simultaneously. Simplifying the clinical steps of bonding application led to the release of all-in-one adhesive systems that can etch, prime and bond in just one step. Unfortunately, one-step self-adhesive systems do not etch the enamel as efficiently as etch and rinse systems and as a consequence the marginal seal might be incomplete. For multiple steps etch and rinse adhesive systems increase risk for dentin dehydration because after drying subsequent collapse of the collagen fibers might occur. Also, residual unremoved acid after an incorrect washing might lead to prolonged demineralization of the dentin and a possible closure of the spaces between the collagen fibers with reactive products [22].
The bond strength of the newer adhesive systems has been permanently improved, so the mild twostep self-etching systems are a viable alternative to the three or two-step etch and rinse systems [23]. This performance relies on their $\mathrm{pH}$ of 2 , acidic monomers being capable to create enough microretention in enamel. Regarding dentin, the self-etch adhesive systems have also demonstrated similar adhesion to the total etch systems [24]. Unfortunately onestep self-etch adhesive systems did not show the same good adhesion to enamel when comparing to total etch adhesive systems and additional step of selective etching is needed to improve enamel bonding [25-27]. One of the advantages of universal bonding systems is their possibility of application with etch and rinse and self-etch strategies, but the major goal of them being introduced into the market was the one-step self-etch application. Functional monomers, like the 10-MDP (10-methacryloyl oxide decyl hydrogenphosphate) molecule that chemically bond to hydroxyapatite simultaneously with the etching and adhesive resin penetration into the tooth structure are responsible for this particular behavior [25,27-29].

Studies have shown a similar bonding performance of universal adhesives when comparing to the selfetch adhesives and etch and rinse adhesives [16]. In the present study, the universal adhesive system application led to similar microleakage at enamel and dentin margins irrespective of the strategy of application. Some previous studies have shown increased dentin microleakage when comparing to enamel for etch and rinse and self-etch adhesive systems [30,31]. Due to increased mineral content and to a more homogenous structure, a better adhesion and a lower marginal leakage to enamel are achieved when comparing to dentin. Dentin has a lower mineral content and the organic part is mainly composed of a dense network of type I collagen fibers and it has dentin tubules. Branches 
of these tubules are denser on root dentin than on crown dentin. Etching with phosphoric acid or with acidic primers changes the surface morphology and chemical composition.Moreover, the tubules orientation can change the hybrid layer formation [32]. The results of some other studies also showed that the enamel marginal leakage was similar when universal bonding systems were used with the etch and rinse or self-etch strategy which led to the conclusion that an additional step of selective enamel etching is not necessary [16]. The same study showed similar bonding to dentin for the universal bonding systems applied in both strategies. That might be explained by the particular chemical composition of the bonding agent that was tested in the study (Scotchbond Universal Adhesive, 3M, St. Paul, MN, USA). The10-MDP molecule creates stable chemical bond and VitreBond copolymer ensures the long-term adhesion on wet or dry dentin $[25,28]$. Studies that investigated the adhesion of a universal bonding system used in class $\mathrm{V}$ cavities restoration showed similar values of microleakage irrespective of the strategy of application [27]. In class $V$ restorations were the gingival margin is located apically of the enamel-dentin junction the moisture control is difficult to achieve. Sulcular fluid and saliva (when a proper isolation is not possible) can contaminate the surface. The multiple step adhesive systems are more prone to failure due to high risk of substrate contamination when comparing to simplified adhesive systems. The adhesion of some self-etch bonding systems seems to be less efficient in dentin due to moisture that blocks the complete diffusion of the adhesive resin in the collagen network. Water sorption also leads to phase separation between hydrophobic resins and hydrophilic primers in the chemical composition of the bonding agent. Saliva glycoproteins adsorbed into the unpolymerized adhesive layer may act as a barrier that lowers the humectant character of the resin [27]. Also, water incorporation in incompletly polymerized resin might interfere with future co-polimerization with the next resin layer. In a literature review of the adverse effects of contamination in adhesive dentistry the authors

\section{References}

1. ASTM D907. Standard Terminology of Adhesives. West Conshohocken, PA, US: ASTM International (ASTM); 2015.

2. Ritter AV, Boushell LW, Walter R. Sturdevant's Art and Science of Operative Dentistry. Seventh ed. St. Louis, Ml: Elsevier; 2019.

3. Van Meerbeek B, Vargas $M$, Inoue $S$, et al. Adhesives and cements to promote preservation dentistry. Oper Dent. 2001;26(Suppl 6):119-144. Google Scholar

4. Yoshida Y, Nagakane K, Fukuda R, et al. Comparative study on adhesive performance of functional monomers. J Dent Res. 2004;83(6):454-458.

[Full text links] [CrossRef] [PubMed] Google Scholar Scopus

5. Hilton TJ. Can modern restorative procedure and material reliably seal cavities? In vitro investigations. Part 1. Am J Dent. 2002;15(3):198-210. [CrossRef] [PubMed] reported that contamination had a deleterious effect on $73.3 \%$ of the 30 evaluated one-step self-etch adhesive systems. The negative effects occurred either when contamination was simulated before and after the adhesive polymerization; it always affected the enamel and in $66.6 \%$ of the cases it affected the dentin [17]. Nair et al. reported different results than our study, but in their paper both $7^{\text {th }}$ generation of adhesives and the universal adhesives were included in the category of one-step self-etch adhesives, so it is not known for sure how many of the investigated adhesive systems were really universal adhesive systems. The limitations of our study are represented by the low number of the samples, the microleakage evaluation immediately after restoration, and the standardized time for contamination (which is relevant only in fewer clinical situations). The present study simulated clinical conditions that are likely to rarely appear.

\section{Conclusions}

Given the conditions of this study, saliva contamination after the adhesive system light curing increased the enamel microleakage only when the adhesive system was applied in etch and rinse strategy, but increased the microleakage in dentin with etch and rinse and self-etch strategies.

Contamination with saliva before the adhesive system light cure did not change the enamel microleakage irrespective of the strategy of adhesive application, but increased the dentin microleakage in both strategies.

\section{Author Contributions}

SS: concept, experimental design, data gathering and analysis, manuscript writing, Gl: concept, analysis and interpretation of the results, IN: protocol, data collection, analysis and interpretation of the results, PG: experimental design, data gathering and analysis, SA: interpretation of the results, manuscript proofreading.

\section{Acknowledgments}

Not applicable. The study was self-funded.

6. Breschi L, Mazzoni A, Ruggeri A, et al. Dental adhesion review: aging and stability of the bonded interface. Dent Mater. 2008;24(1):90-101. [Full text links] [CrossRef] [PubMed] Google Scholar Scopus

7. Alex G. Universal adhesives: the next evolution in adhesive dentistry? Compend Contin Educ Dent. 2015;36(1):15-26; quiz 28, 40. [PubMed] Google Scholar

8. Buonocore MG. A simple method of increasing the adhesion of acrylic filling to enamel surfaces. J Dent Res. 1955;34(6):849-853.

[Full text links] [PubMed] Google Scholar Scopus

9. Suppa P, Breschi L, Ruggeri A, et al. Nanoleakage within the hybrid layer: a correlative FEISEM/TEM investigation. J Biomed Mater Res B Appl Biomater. 2005;73(1):7-14.

[Full text links] [CrossRef] [PubMed] Google Scholar Scopus

10. Bowen RL, Eick JD, Henderson DA, Anderson DW. Smear layer: removal and bonding 
considerations. Oper Dent. 1984;9(Suppl3):30-34. [PubMed] Google Scholar Scopus

11. Pashley $\mathrm{DH}$, Carvalho RM. Dentin permeability and dentin adhesion. J Dent. 1997;25(5):355-372. [Full text links] [CrossRef] [PubMed] Google Scholar Scopus

12. Price RB, Dérand T, Andreou P, Murphy D. The effect of two configuration factors, time, and thermal cycling on resin to dentin bond strengths. Biomaterials. 2003;24(6):1013-1021. [Full text links] [CrossRef] [PubMed] Google Scholar Scopus

13. Buonocore MG. Caries prevention in pits and fissures sealed with an adhesive resin polymerized by ultraviolet light: a two-year study of a single adhesive application. J Am Dent Assoc. 1971;82(5):1090-1093. [Full text links] [CrossRef] [PubMed] Google Scholar Scopus

14. Marshal SJ, Bayne SC, Baier R, et al. A review of adhesion science. Dent Mater. 2010;26(2):e11-e16. Google Scholar

15. Suh BI, Feng L, Pashley DH, Tay FR. Factors contributing to the incompatibility between simplified-step adhesives and chemically-cured or dual-cured composites. Part III. Effect of acidic resin monomers. J Adhes Dent. 2003;5(4):267-282. [PubMed] Google Scholar Scopus

16. Motevaselian $F$, Yassine $E$, Mirzaee $M$, et al. In vitro microleakage of class $V$ composite restorations in use of three adhesive systems. J Islam Dent Assoc Iran. 2016;28(1):14-19. Google Scholar

17. Nair P, Hickel R, llie N. Adverse effects of salivary contamination for adhesives in restorative dentistry.

18. A literature review. Am J Dent. 2017;30(3):156-164. [PubMed] Google Scholar Scopus

19. Ferracane JL. Resin composite--state of the art. Dent Mater. 2011;27(1):29-38.

[Full text links] [CrossRef] [PubMed] Google Scholar Scopus

20. Araujo FO, Vieira LCC, Monteiro Junior S. Influence of resin composite shade and location of the gingival margin on the microleakage of posterior restorations. Oper Dent. 2006;31(5):556-561. [Full text links] [CrossRef] [PubMed] Google Scholar Scopus

21. FrancoEB, Gonzaga Lopes L, Lia MondelliRF, et al.Effect of the cavity configuration factor on the marginal microleakage of esthetic restorative materials. Am JDent. 2003;16(3):211-214. [PubMed] Google Scholar Scopus

22. Hilton TJ, Ferracane JL, Brome JC. Summitt's fundamentals of operative dentistry: a contemporary approach. Fourth ed. Hanover Park, IL, US: Quintessence Publishing Co Inc; 2013.

23. Nakabayashy N, Pashley D. Hybridzation of dental hard tissues. First ed. Chicago, IL, US: Publishing Co Inc; 1998. Google Scholar
24. Giannini M, Makishi P, Ayres AP, et al. Self-etch adhesive systems: a literature review. Braz Dent J. 2015;26(1):3-10. [Full text links] [CrossRef] [PubMed] Google Scholar Scopus

25. Gupta A, Tavane P, Gupta PK, et al. Evaluation of microleakage with total etch, self etch and universal adhesive system in class $V$ restoration: an in vitro study. J Clin Diagn Res. 2017;1(4):ZC53-ZC56. [Full text links] [PubMed] Google Scholar Scopus

26. Peumans $\mathrm{M}$, De Munck J, Van Landuyt $\mathrm{KL}$, et al. Eight-year clinical evaluation of a 2-step selfetch adhesive with and without selective ename etching. Dent Mater. 2010;26(12):1176-1184. [Full text links] [CrossRef] [PubMed] Google Scholar Scopus

27. Arami S, Shahabi S, Tabatabaie M, et al. Assessing microleakage of composite restorations in class $\mathrm{V}$ cavities prepared by Er:YAG laser irradiation or diamond bur.

28. J Conserv Dent. 2014;17(3):216-219. Google Scholar Scopus

29. Perdigão J, Kose C, Mena-Serrano AP, et al. A new universal simplified adhesive: 18-month clinical evaluation. Oper Dent. 2014;39(2):113-127. [Full text links] [CrossRef] [PubMed] Google Scholar Scopus

30. Mena-Serrano A, Kose C, De Paula EA, et al. A new universal simplified adhesive: 6-month clinical evaluation. J Esthet Restor Dent. 2013; 25(1):55-69. [Full text links] [CrossRef] [PubMed] Google Scholar Scopus

31. Muñoz MA, Luque-Martinez I, Malaquias $P$, et al. In Vitro longevity of bonding properties of universal adhesives to dentin. Oper Dent 2015:40(3):282-292. [Full text links] [CrossRef] [PubMed] Google Scholar Scopus

32. Koliniotou-Koumpia E, Dionysopoulos $P$, Koumpia $E$. In vivo evaluation of microleakage from composites with new dentin adhesives. J Oral Rehabil. 2004;31(10):1014-1022. [Full text links] [CrossRef] [PubMed] Google Scholar Scopus

33. Alavi AA Kianimanesh N. Microleakage of direct and indirect composite restorations with three dentin bonding agents. Oper Dent. 2002;27(1):19-24. [PubMed] Google Scholar Scopus

34. Tuncer D, Celik C, Cehreli SB, Arhun N. Comparison of microleakage of a multi-mode adhesive system with contemporary adhesives in class II resin restorations. J Adhes Sci Technol. 2014;28(13):1288-1297. [CrossRef] Google Scholar Scopus

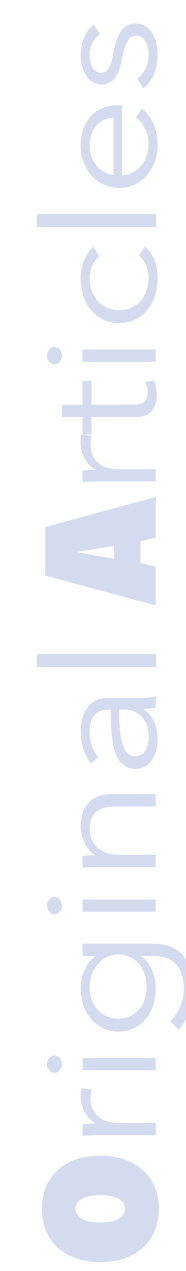

Simona STOLERIU

DMD, PhD, Associate Professor Odontology-Periodontology and Fixed Prosthesis Department Faculty of Dental Medicine "Grigore T. Popa" University of Medicine and Pharmacy laşi Iaşi, Romania

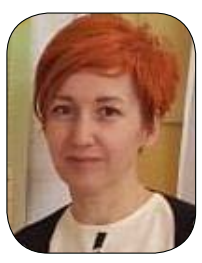

\section{cVI}

Simona Stoleriu graduated from the Faculty of Dental Medicine, "Grigore T. Popa" University of Medicine and Pharmacy laşi, laşi, Romania in 1997. Since 1999 to present she has been assistant professor, lecturer and now associated professor teaching Cariology, at the Department of Odontology, Periodontology and Fixed Prosthodontics, Faculty of Dental Medicine, "Grigore T. Popa" University of Medicine and Pharmacy laşi, laşi Romania. As of 1998 she has been a dentist in a private practice. Major research interests: 1. restorative materials behavior in oral environment; 2 . clinical and in vitro studies regarding the etiology, and the preventive and restorative treatment of tooth wear lesions; 3 . dental hard tissues remineralization of carious lesions and erosive wear. 


\section{Ouestions}

\section{The mechanisms implicated in bonding to the tooth structure include three mechanisms, with ONE EXCEPTION:}

$\square$ a. Mechanical adhesion;

b. Adhesion by sorption;

ac. Electrostatic bonding;

$\square d$. Adhesion by diffusion.

\section{A review of the literature regarding the influence of saliva contamination on adhesive dentistry has shown that:}

口a. $17 \%$ of three-step adhesive systems adversely influence their bond quality;

bb. $26 \%$ of two-step adhesive systems adversely influence their bond quality;

ac. $81.5 \%$ of two-step self-etch adhesives adversely influence their bond quality;

ad. 3.3\% of one-step self-etch adhesives adversely influence their bond quality.

\section{The results of the present study demonstrated that:}

$\square$ a. Saliva contamination after adhesive system lightcure increased enamel microleakage only when the adhesive system was applied in etch and rinse strategy;

b. Saliva contamination after adhesive system lightcure increased enamel microleakage only when the adhesive system was applied in self-etch strategy;

口. Saliva contamination after adhesive system lightcure increased enamel microleakage only when the adhesive system was applied in selective etch strategy;

口d. Saliva contamination after adhesive system lightcure increased enamel microleakage both etch and rinse and self-etch strategies.

\section{Irrespective of the strategy of universal bonding application saliva contamination significantly increased the microleakage in:}

口a. Enamel;

b. Dentin;

ac. Enamel and dentin;

$\square d$. None of the answers are correct.

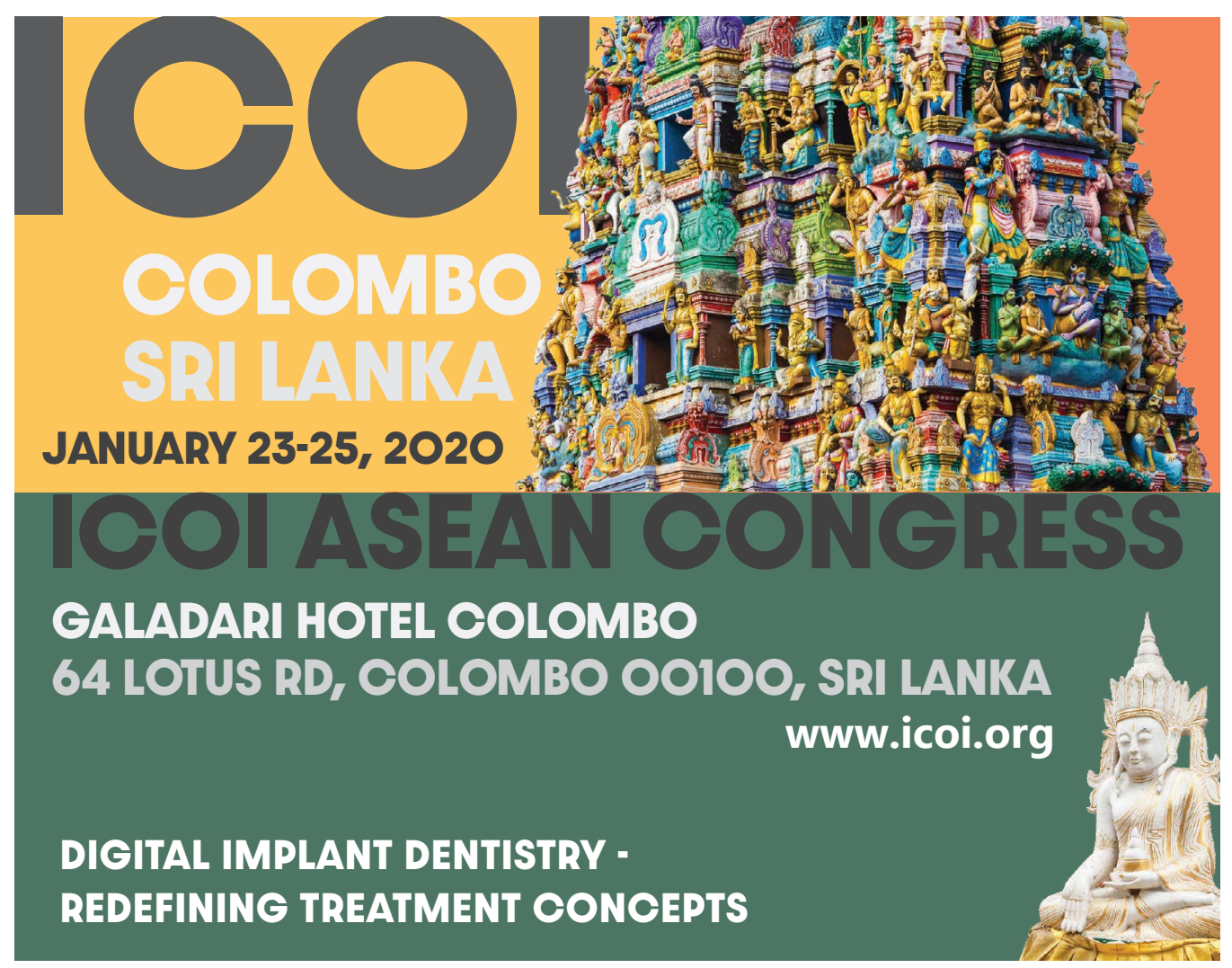




\title{
SMOKING AND RECURRENT APHTHOUSSTOMATITIS
}

\author{
Radmila Radisa Obradovic ${ }^{1 a^{*}}$ (D) ,Marija LJ Igic ${ }^{2 a}$, Aleksandar D Mitic ${ }^{3 a}$ (D) ,Ana S Pejcic ${ }^{1 a}$ (D) ,Kosta M Todorovic ${ }^{4 b}$ (D) , \\ Zana Popovic ${ }^{5 c}$
}

'Department of Periodontology and Oral Medicine, Faculty of Medicine, Niš University, Serbia 2Department of Children and Preventive Dentistry, Faculty of Medicine, Niš University, Serbia ${ }^{3}$ Department of Dental Pathology and Endodontics, Faculty of Medicine, Niš University, Serbia ${ }^{4}$ Department of Oral Surgery, Faculty of Medicine, Niš University, Serbia

${ }^{5}$ Department of Dentistry, Faculty of Medical Sciences, Kragujevac University, Serbia

${ }^{a} \mathrm{DDS}$, PhD, Professor

'DDS, Assistant

'DDS, Postdoctoral Student

\section{ABSTRACT DOI: https://doi.org/10.25241/stomaeduj.2019.6(4).art.3}

Introduction: Recurrent aphthous stomatitis (RAS) is one of the most usual inflammatory diseases of the oral mucosa. The clinical characteristics of RAS are well defined, but the exact etiology and pathogenesis of the disease are not. Several investigations have noticed cigarette smoking to have a protective effect on RAS. The aim of the study is to investigate the association between cigarette smoking and RAS in order to improve the current knowledge on this issue.

Methodology: 68 patients with RAS participated in the study. A full mouth clinical examination was performed and a medical history was taken for each patient. Data were analyzed with $x^{2}$ test.

Results: While $6(8.9 \%)$ of patients with RAS were smokers, a significantly higher percentage (24.9\%) among the subjects with RAS were not smokers (group II) (X2 $=70.4 ;$ d.f. $=2, \mathrm{P}<0.001$ ).

Conclusion: The negative association between smoking and RAS indicated by this investigation is not meant to encourage people to smoke nor to spare them from the intention to quit their habit. These conclusions should be used to clear up the cause and pathogenesis of the RAS and to identify better prevention and treatment.

Keywords: Oral Medicine; Aphthae; Recurrent Aphthous Stomatitis; Mouth; Smoking.

\section{Introduction}

Recurrent aphthous stomatitis (RAS) is a very common disease of the oral mucosa. It is called minor aphthous ulcers, herpetiform ulcers, aphthosis and many other names. Aphthous ulcers can occur alone or as part of a syndrome [1]. RAS occurs only in non-keratinized mucosa as painful, shallow round ulcers with an erythematous halo covered by a membranous layer. The clinical ulcerative period for minor aphthous ulcers may last for 2 weeks and lesions usually heal without a scar [2]. The clinical characteristics of RAS are well known, but the exact etiology and patho-genesis of the disease are not complete. The etiology of RAS includes stress, microorganisms, food hyper-sensitivity, immune dysregulation, hormonal fac-tors and a genetic predisposition, usage of the toothpaste with sodium lauryl sulfate (SLS) $[1,2]$. Current investigations have focused on a possible immunopathogenesis of RAS $[2,3]$. The epithelial cell death and the creation of ulceration probably results from the activation of a cell-mediated immune response in which Tumor
Necrosis Factor Alpha (TNFa) and other cytokines are produced [3]. Inheritance of HLA-B51 antigen, vitamin B12 deficiency, recurrent herpes labialis, Helicobacter pylori, hepatitis $C$ and hypersensitivity to nickel are involved in the development of RAS $[4,5]$. It is necessary to better understand the pathogenesis and primary cause of RAS [2]. Previously, it is thought that approximately $0.89 \%$ of the adults over 17 years of age have at least one aphthous lesion and that males (1.13\%) have almost twice the RAS than females $(0.67 \%)$. It is noticed that reported prevalence of RAS varies according to patient selection, presence of lesions at the time of investigation or during a specified period and newer literature data show that the RAS prevalence is between 5 and $60 \%$, depending on the population group studied [2].

It is estimated that tobacco use is the major cause of more than 5 million deaths every year [6]. Smoking is a common risk factor in a number of chronic diseases like lung diseases, cancer, cardiovascular diseases; and a major risk factor in the prevalence of 
Table 1. Relationship between RAS and smoking.

\begin{tabular}{|c|c|c|c|}
\hline & RAS & (no RAS or RAS history) & Total \\
\hline Smoking (group I) & $6(8.9 \%)$ & $68(91.9 \%)$ & 74 \\
\hline Nonsmoking (group II) & $62(24.9 \%)$ & $202(76.5 \%)$ & 264 \\
\hline Total & $68(20.1 \%)$ & $270(79.9 \%)$ & 338 \\
\hline
\end{tabular}

periodontal diseases [6-10]. Cigarette smoke contains approximately 4800 chemicals, with over 60 of them known to have 3 damaging effects on human cells [11]. Cigarette smoking could camouflage signs of periodontal disease like gingival bleeding or redness, by suppressing the immune response which could cause a problem in the diagnosis of the disease. Several studies have noticed cigarette smoking to have a protective effect on RAS [12-15]. It is not clear how cigarette smoking can reduce RAS prevalence but it is thought that immunological mechanisms are involved and that the cytokine (TNF) plays an important role in the pathogenesis. Nicotine has been shown to influence the immune response in inflammatory conditions $[16,17]$. It acts through the central nervous system inducing the production of glucocorticoids and activating the autonomic nervous system and consequently reducing the level of inflammation [16]. Nicotine can activate the nicotinic acetylcholine receptors on macrophages and reduce the production of TNF1and interleukins [17].

\section{The aim of the study}

The aim of the study is to investigate the association between cigarette smoking and RAS in order to increase current knowledge on this issue.

\section{Methodology}

The study was conducted on 338 patients who came at the Department of Oral Medicine and Periodontology of the Dental Clinic of Faculty of Medicine, Niš University, for one year. The Ethics Committee of the Faculty of Medicine Niš approved the study protocol (evidential number 01-2800-7). After the medical history was taken, the patients who had undergone antibiotic and corticosteroid therapy in the last three months, were not included in the study. A full mouth clinical examination was performed and the patients with active aphthous lesions and who per medical history had suffered from oral ulcers at least once within a period of 5 months were considered to suffer from RAS. The patients with other oral diseases who came at the Dental Clinic of the Medical Faculty Niš for other medical reasons were also included in this study. Out of 338 examined patients, 68 patients had RAS and 270 had no RAS or RAS history. Patients who smoked over 10 cigarettes per day (per medical history) were considered to be "smokers" and they constituted group I (74 patients). The nonsmoking patients constituted group II (264 patients).

\section{Results}

There were 68 participants with RAS, out of which 31 (46.92\%) were men and 37 (53.1\%) were women. The average age was $29.7 \pm 8.8$ years. $66(97.1 \%)$ had the minor type of the disease, $2(2.9 \%)$ had both minor and major RAS.

The relationship between RAS and smoking is shown in Table 1. While 6 (8.9\%) of patients with RAS were active smokers (group I), a significantly higher percentage $(24.9 \%)$ among the subjects with RAS were not smokers (group II) ( $22=70.4$; d. f. $=2, \mathrm{P}<$ 0.001).

\section{Discussion}

Smoking is a known risk factor in a number of chronic diseases and major risk factor of periodontal disease [2-6]. Cigarette smoking suppresses the immune host response, masks early signs of periodontal disease and has as reported by some authors a beneficial protective effect on RAS. It has also been noticed that the incidence of RAS is higher among young individuals and that adults younger than 40 years of age have more than twice higher RAS rate than those older than 40 years [12-15]. We noticed similar results in our study where the average age of the patients with RAS was $29.7 \pm 8.8$ years. It could be suspected that stress could be an aphthae provoking factor. Previously, lifestyle could induce stress and social conditions and self-management are important determinants of health. The effects of living exposed to many stress factors may cause poorer health and more frequent occurrence of RAS $[18,19]$. Literature data reveal a significant reduction of RAS in individuals who smoke. The prevalence and odds ratios for number of cigarettes smoked is significant and suggest a dose response effect $[14,15]$. A reduction in RAS prevalence with higher blood levels of nicotine is found to be significant [20]. Our study noticed a similar situation. where 8.9\% of patients with RAS were active smokers and a significantly higher percentage (24.9\%) among the subjects with RAS were not smokers (group II) (X2 $=70.4$; d. f. $=2, \mathrm{P}<0.001$ ). Kalpana [13] noticed that significant differences exist in the prevalence of RAS among cigarette smokers, which could be related to the number of cigarettes smoked per day and the duration of the habit. The "protective effect" 
on RAS was noticed only when the persons were heavy smokers or had smoked for longer periods of time. Cigarette non-smokers have far greater odds of RAS than individuals who smoked $>1$ pack per day. It was concluded that the associations of RAS with cigarette smoking and with cotinine levels were significant. Our study noticed similar results, namely that a higher number of individuals with RAS were nonsmokers (24.9\%). RAS is characterized by recurrences of short-lived lesions. The lesions are not always noticed at the time of examination and the diagnosis is often based on the patient's clinical history. The statistical evaluation of RAS is hampered because lesions cannot be evaluated by the investigator at any time and is usually based on a self-reported history of RAS. Such a diagnosis is less reliable that one based upon the observation of present lesions by a practitioner. It is to be noticed that many of the studies which found a negative correlation between RAS and smoking were based on a self-reported history of RAS [21]. Information should be carefully interpreted, especially where there is some basis to suspect response bias. The findings in this study were based on anamnesis and clinical examination conducted by an experienced practitioner and provide data on the general prevalence of RAS in smokers. There is a small number of studies in which patients were diagnosed by direct detection of present lesions by a practitioner. Queiroz et al [22] evaluated 4895 cases of recurrent aphthous ulcerations with a focus on treatment, diagnosis and etiology. Data such as sex, age, race, location, smoking habits, types of treatment, relapsing episodes, laboratory test results and clinical characteristics were collected. Regarding smoking habits, in the majority of 59 patients $(77.6 \%)$ smoking was not recorded. The investigators did not consider the percentages of

\section{References}

1. Cui RZ, Bruce AJ, Rogers RS. Recurrent aphthous stomatitis. Clin Dermatol. 2016;34(4):475-481.

2. Edgar NR, Saleh D, Miller RA. Recurrent aphthous stomatitis: a review. J Clin Aesthetic Dermatol. 2017;10(3):26-36.

$\underline{\text { Scopus }}$

3. Manthiram K, Lapidus S, Edwards K. Unraveling the pathogenesis of periodic fever, aphthous stomatitis, pharyngitis, and cervical adenitis through genetic, immunologic, and microbiologic discoveries: an update. Curr Opinion Rheumatol. 2017;29(5):493499.

[Full text links] [CrossRef] [PubMed] Google Scholar Scopus

4. Najafi S, Mohammadzadeh M, Zare Bidoki A, et al. HLA-DRB and HLA-DQB allele and haplotype frequencies in Iranian patients with recurrent aphthous stomatitis. Iran J Allergy Asthma Immunol. 15(4):289-295.

[Full text links] [PubMed] Google Scholar Scopus

5. Kuo YS, Chang JYF, Wang YP, et al. Significantly higher frequencies of hemoglobin, iron, vitamin B12, and folic acid deficiencies and of hyperhomocysteinemia in patients with Behcet's disease. $J$ Formos Med Assoc. 2018;117(10):932-938.

[Full text links] [CrossRef] [PubMed] Google Scholar Scopus 6. Britton J. Death, disease and tobacco. Lancet 2017;389(10082): 1861-1862.

[Full text links] [CrossRef] [PubMed] Google Scholar smoking notifications because they are influenced by a bias of selection of the sample. Other researchers have found a lower incidence of RAS in smokers on the basis of the disease history but not by direct detection of present lesions by a practitioner [12-14]. A similar negative correlation between smoking and RAS was noticed in our study._The treatment and, many times, the diagnosis of RAS are a challenge in the daily life of the clinician. Dental professionals and otorhinolaryngologists are usually responsible for the first contact with the patients who have RAS. These professionals should be alert to the clinical aspects of this condition since each patient will be treated in an individualized manner, because treatment is usually palliative and not curative.

\section{Conclusion}

On the basis of the aim of the study, its applied methodology and the results obtained it can be concluded that the incidence of RAS is higher among young individuals and among subjects who do not smoke. The negative association between smoking and RAS in our study is not indeed meant to encourage people to smoke nor to sway them in the decision to quit their habit. Smoking cessation is the main option to remove the harmful tobacco effects on oral tissues and to improve the quality of life.

\section{Author Contributions}

All authors (RO, MI, AM, AP, KT, and ZP) contributed in data collection and analysis, and manuscript writing. All authors agree to be accountable for the content of the work.

\section{Acknowledgment}

This research was supported by a grant from the Internal project number 11, Medical Faculty, University of Niš, Niš, Serbia.

7. Holde GE, Baker SR, Jönson B. Periodontitis and quality of life: What is the role of socioeconomic status, sense of coherence, dental service use and oral health practices? An exploratory theoryguided analysis on a Norweigan population. J Clin Periodontol. 2018;45(7):768-779.

[CrossRef] Google Scholar

8. Waziry R, Jawad M, Ballout RA, AlAkel M, Akl EA. The effects of waterpipe tobacco smoking on health outcomes: an updated systematic review and meta-analysis. Int J Epidemiol. 2017;46(1): 32-43.

[Full text links] [CrossRef] [PubMed] Google Scholar Scopus

9. Chaffee BW, Couch ET, Ryder MI. The tobacco-using periodontal patient: role of the dental practitioner in tobacco cessation and periodontal disease management. Periodontol 2000. 2016;71(1): 52-64.

[Full text links] [Free PMC Article] [CrossRef] [PubMed] Google Scholar Scopus

10. Mahmud SZ, Amin MS. Association between tobacco consumption and periodontal diseases among type 2 diabetes mellitus patients. Saudi J Oral Sci. 2016;3:90-96.

[CrossRef] Google Scholar

11. Jeong $M$, Noar SM, Zhang $D$, et al. Public understanding of cigarette smoke chemicals: Longitudional study of US adults and adolescents. Nicotine Tob Res. 2019;pii:ntz035

[Full text links] [CrossRef] [PubMed] Google Scholar 
12. Peruzzo DC, Gimenes JH, Taiete T, et al. Impact of smoking on experimental gingivitis. A clinical, microbiological and immunological prospective study. J Periodontal Res. 2016;51(6):800-811.

[Full text links] [CrossRef] [PubMed] Google Scholar Scopus

13. Kalpana R. Relation between smoking and recurrent aphthous stomatitis. Oral Maxillofac Pathol J. 2016;7(2):761-762.

Google Scholar

14. Oliveira MJ, Coimbra F, Mesquita P, Carvalho J, Pereira-Lopes $O$ Characterization of recurrent aphthous stomatitis in a young population. Rev Port Estomatol Med Dent Cir Maxilofac. 2018;59(1):10-17.

Scopus

15. Souza PRM, Doquia RP, Breunig JA, Almeida JRHL. Recurrent aphthous stomatitis in 18-year-old adolescents - Prevalence and associated factors: a population-based study. An Bras Dermatol. 2017;92(5):626-629.

[Full text links] [Free PMC Article] [CrossRef] [PubMed] Google Scholar Scopus

16. Rothbard JB, Rothbard JJ, Soares L, Fathman G, steinman L. Identification of a common immune regulatory pathaway induced by small heat shock proteins, amyloid fibrils, and nicotine. PNAS 2018;115(27):7081-7086.

[Full text links] [Free PMC Article] [CrossRef] [PubMed] Google Scholar
17. Hosseinzadeh A, Thompson PR, Segal BH, Urban CF. Nicotine induces neutrophil extracellular traps. JLB 2016;100(5):1105-1112. [Full text links] [CrossRef] [PubMed] Google Scholar Scopus

18. Chaudry A, Wimer C. Poverty is not just an indicator: The relationship between income, poverty, and child well-being. Acad Pediatr. 2016;16(3):23-29.

[CrossRef] Google Scholar Scopus

19. Ismayilova L, Karimli L, Sanson J, et al. Improving menta health among ultra-poor children: Two-year outcomes of a clusterrandomized trial in Burkina Faso. Soc Sci Med. 2018; 208:180-189. [Full text links] [CrossRef] [PubMed] Google Scholar Scopus

20. Zakaria M, El-Meshad A. Clinical efficacy of nicotine replacement therapy in the treatment of minor recurrent aphthous stomatitis. J Arab Society Medical Res. 2018;13(2):106-112.

[CrossRef] Google Scholar

21. Namrata M, Abilasha R. Recurrent aphthous stomatitis. Int $J$ Orofacial Biol. 2017;1(2):43-47.

22. Queiroz SIML, Silva MVA, Medeiros AMC, et al. Reccurrent aphthous ulceration: an epidemiological study of etiological factors, treatment and differential diagnosis. An Bras Dermatol. 2018;93(3):341-346

[Full text links] [Free PMC Article] [CrossRef] [PubMed] Google $\underline{\text { Scholar }}$

\section{Radmila Radisa OBRADOVIĆ \\ DDS, PhD, Professor \\ Department of Oral Medicine and Periodontology \\ Dental Clinic \\ Faculty of Medicine \\ Niš University \\ Niš, Serbia}

Doctor Radmila Radisa Obradović is a Professor at the Department of Oral Medicine and Periodontology, Dental Clinic, Faculty of Medicine, Niš University and at the Department of Oral Medicine and Periodontology, Faculty of Medical Sciences, Kragujevac, Serbia. She is also a member of the Niš Dental Clinic's Ethical Committee, Serbian Medical Society, Serbian Anthropological Society and Serbian Oral Laser Society (SOLAS).

She participates in national projects, and delivers many dental courses and conferences as a lecturer.

She has many scientific publications in international and Serbian medical and dental journals.

\section{Arestions}

\section{Recurrent aphthous stomatitis (RAS) is very common disease of the oral mucosa. It is called:}

$\square$ a. Minor aphthous ulcers;

ab. Herpetiform ulcers;

ac. Simple aphthosis;

$\square$ d. All of the above answers are correct.

\section{Cigarette smoking could influence signs of periodontal disease like:}

口a. Provoking bleeding;

ab. Provoking gingival redness;

ac. Camouflage gingival bleeding or redness;

$\square$ d. Provoking gingival swelling.

\section{The etiology of RAS includes:}

口a. Stress and immune dysregulation;

b. Microorganisms and food hypersensitivity;

ac. Hormonal factors and a genetic predisposition;

$\square$ d. All of the above answers are correct.

\section{The patients were divided into:}

$\square$ a. Two groups: smokers and nonsmoking patients;

b. Three groups: smokers, nonsmoking patients and patients with RAS;

ac. Two groups: smokers and patients with RAS;

$\square$ d. Two groups: nonsmoking patients and patients with RAS. 


\title{
EVALUATION OF BONE MINERAL DENSITY USING CONE BEAM COMPUTED TOMOGRAPHY
}

\author{
Mohammad Sadegh Nazari ${ }^{1 a}$, Ahmad Reza Tallaeipoor ${ }^{2 b}$, Ludovica Nuccicc, Amir Ali Karamifar ${ }^{4 d}$, Abdolreza Jamilian ${ }^{5 \mathrm{e}^{*}}$ (D) , \\ Letizia Perillo ${ }^{3 f}$ (D)
}

\begin{abstract}
'Department of Orthodontics, School of dentistry, Mashhad University of Medical Sciences, Mashhad, Iran
2Department of Oral and Maxillofacial Radiology, Cranio Maxillofacial Research Center, Faculty of Dentistry, Tehran Medical Sciences, Islamic Azad University, Tehran, Iran

${ }^{3}$ Multidisciplinary Department of Medical-Surgical and Dental Specialties, Dental School, University of Campania Luigi Vanvitelli, Naples, Italy ${ }^{4}$ Department of Orthodontics, School of Dentistry, Semnan University of Medical Sciences, Semnan, Iran

5Department of Orthodontics, Cranio Maxillofacial Research Center, Faculty of Dentistry, Tehran Medical Sciences, Islamic Azad University, Tehran, Iran
\end{abstract}

\author{
aPostgraduate Dental Student \\ ${ }^{\mathrm{b}}$ DDS, PhD, Professor \\ 'Undergraduate Dental Student \\ ${ }^{\mathrm{D} D D S}, \mathrm{MSC}$ \\ ${ }^{e} D D S$, PhD, Professor \\ ${ }^{\mathrm{f} D D S}$, PhD, Professor
}

\section{ABSTRACT DOI: https://doi.org/10.25241/stomaeduj.2019.6(4).art.4}

Introduction: Bone mineral density (BMD) is an important factor in the use of anchorage device. This study assessed the amount of bone density in the areas from 2.5 and $8.11 \mathrm{~mm}$ from maxillary alveolar to basal bone in Hounsfield units. Methodology: The samples included 30 unilateral cleft palate (15 males and 15 females) with the mean age of $14.23 \pm 2.5$ years and 30 non-clefts ( 15 males and 15 females) with the mean age of $14 \pm 2.59$ years. CBCT was used to estimate the values of bone density in Hounsfield units in the cleft and noncleft patients. BMD was measured in 4 heights $(2-5-8-11 \mathrm{~mm})$ from alveolar bone to basal bone in mesio-distal and bucco-lingual slices in the upper jaw. T-test was used to analyze the bone density values between the cleft and noncleft.

Results: The highest alveolar bone density in the mesio-distal slice was 1004 $6 \mathrm{HU}$ between the right and left centrals in the upper jaw in height of $11 \mathrm{~mm}$ in non-cleft patients. The least amount of alveolar bone density in the mesio-distal slice was $259 \pm 29 \mathrm{HU}$ in tuberosity in height of $11 \mathrm{~mm}$ in cleft patients. In non-cleft patients, the most amount of bone density was found $1639 \pm 11 \mathrm{HU}$ between the centrals in height of $11 \mathrm{~mm}$ in the bucco-lingual slice.

Conclusions: Bone density in cleft patients was lower than in non-cleft patients in all areas and maxillary tuberosity showed the lowest bone density in cleft and non-cleft patients.

Keywords: Cone Beam Computed Tomography; Bone Mineral Density; Dental Implants; Single-Tooth; Orthodontics.

\section{Introduction}

The amount of bone tissue is called bone mineral density (BMD)[1]. Assessment of BMD is necessary in many clinical conditions such as oral systemic diseases, implant planning and it also has an important role for the stability of mini-implants as anchorage $[2,3]$. Computed tomography (CT) is a diagnostic method before performing dental implant. It allows accurate three-dimensional evaluation of anatomical structures of the bone. It also measures BMD which it expresses in Hounsfield units (HU) [4]. Although CT is a diagnostic tool in medical practice, this method has not been broadly used in dentistry because of its high cost, presence of artifacts in images, high dose of radiation and complexity of examination.

Recently CT has been replaced by cone-beam computed tomography (CBCT) to evaluate anatomic structuresand the directmeasurement ofmineralized tissue $[5,6]$. CBCT provides suitable image quality concomitant with a lower exposure dose. Fast scanning time, low cost and a lower number of image artifacts are the other advantages of CBCT when compared to CT [7-9]. CBCT scanning is associated with some drawbacks, such as poor soft tissue contrast, motion 

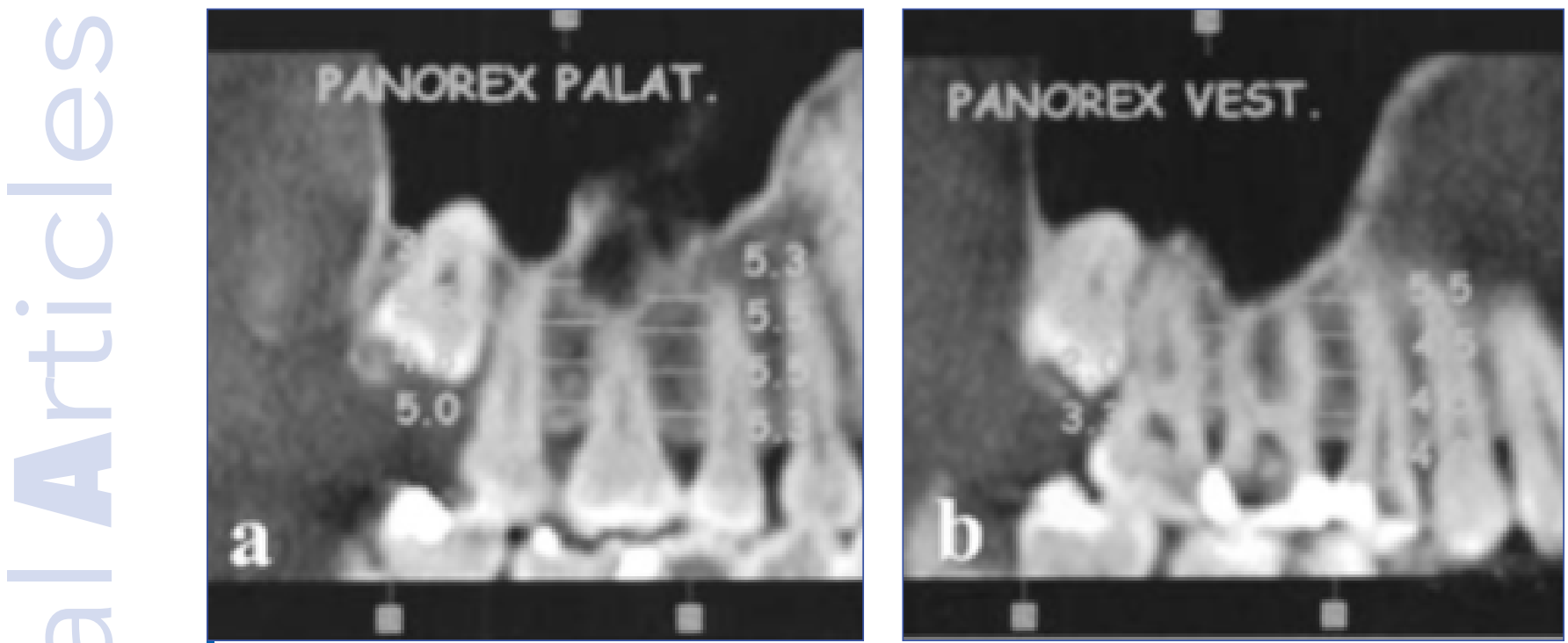

Figure 1. (a) Mesio-distal measurement on the palatal side; (b) Mesio-distal measurement on the buccal side
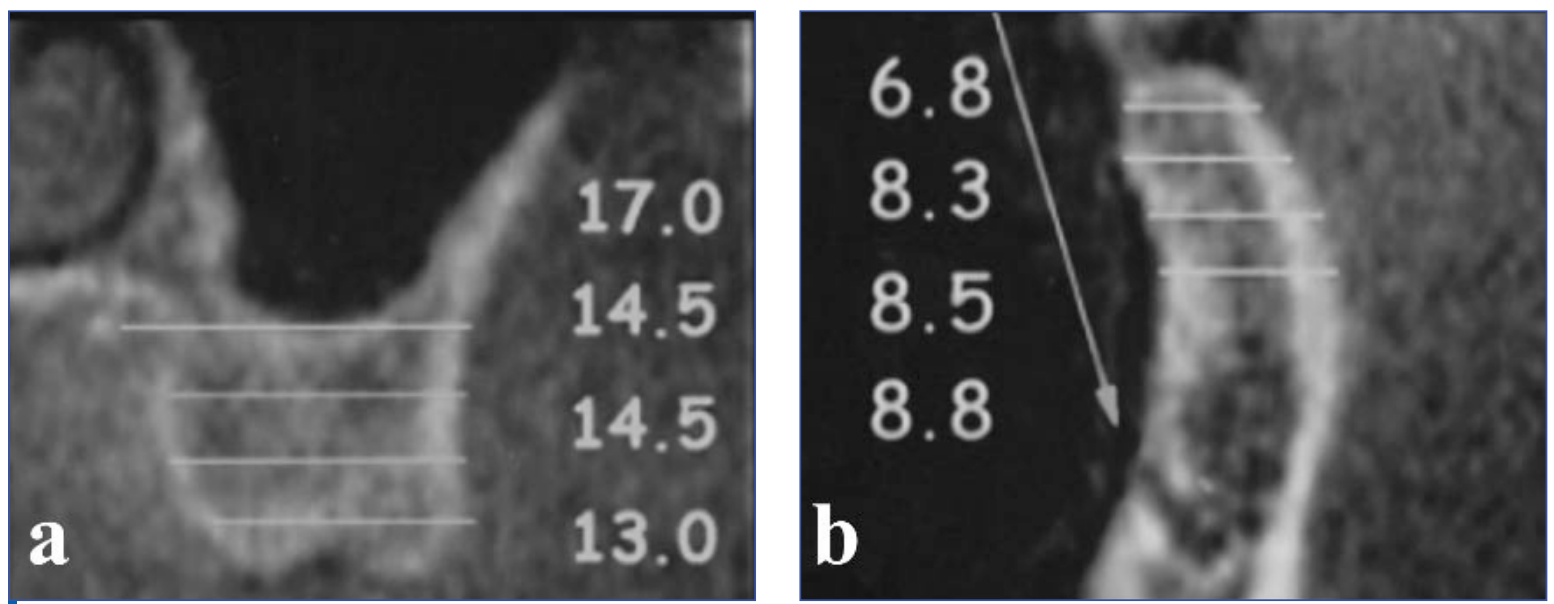

Figure 2. (a) Bucco-lingual measurement on the maxilla; (b) Bucco-lingual measurement on the mandible

artifacts and image noise. Conventional CT may distinguish $70 \%$ of root fractures, but the higher cost and high dose of radiation limit the use of this technique [10].

BMD can be recognized by Gray values acquired with $\mathrm{CBCT}$ as the $\mathrm{HU}$ values [11]. CBCT provides a three-dimensional analysis with the quantification of the mineral density of jaws in Hounsfield units (HU) [3].

CBCT is a valuable method for diagnosis and treatment planning especially in cleft lip and palate patients because it offers better data about the size and appearance of the anatomic structures affected by the cleft, the position of missing teeth, the amount of BMD, as well as the position of mini screw, dental implants and so on. To our knowledge no study compared the BMD of cleft patients with non-cleft samples.

Therefore, due to the lack of research in this area the aim of this study was to compare the BMD of interradicular distances at heights of 2, 5, 8 and $11 \mathrm{~mm}$ measured from the alveolar bone crest to basal bone in $\mathrm{HU}$ obtained by CBCT in unilateral cleft palate and non-cleft patients.

\section{Methodology}

This research protocol was approved by the Ethics Committee at the Islamic Azad University, Dental School, Protocol number 25500. The participants in this retrospective research were 30 unilateral cleft palates (15 males and 15 females) with the mean age of $14.23+2.5$ years and 30 non-cleft patients (15 males and 15 females) with the mean age of $14+2.59$ years. The criteria to select the patients were as follows: no history of serious disease affecting oral bones, no periodontal problems, no previous fracture, no history of bone grafting, no previous orthodontic therapy, none of the patients were on hormone therapy or taking calcium, vitamin $D$, fluorides, calcitonin, bisphosphonates, no palatal fistula or infection. CBCT of all the patients were taken by the same radiologist for orthodontic treatment. All unilateral cleft palate patients had palatal closure before the age of 2. The CBCT (New Tom 5G; QR, Verona, Italy) was performed to assess BMD in the cleft and noncleft regions in all patients. The images were obtained at $120 \mathrm{kV}$ and $8 \mathrm{~mA} .0 .2 \mathrm{~mm}^{3}$ voxel, $80 \mathrm{~mm}$ field of view BMD was calculated using the Xoran Cat software version 3.1.62 (Xoran Techno- 
Table 1. BMD in Hounsfield units (HU) from the mesio-distal slice in the maxillary arch between teeth and tuberosity.

\begin{tabular}{|c|c|c|c|c|c|}
\hline & Mesio-distal slice & $2 \mathrm{~mm}$ & $5 \mathrm{~mm}$ & $8 \mathrm{~mm}$ & $11 \mathrm{~mm}$ \\
\hline Region & Group & Mean \pm SD & Mean \pm SD & Mean \pm SD & Mean $\pm S D$ \\
\hline $1-1$ & $\begin{array}{c}\text { Non-cleft } \\
\text { Cleft }\end{array}$ & $\begin{array}{c}896 \pm 17^{* *} \\
884 \pm 5\end{array}$ & $\begin{array}{c}935 \pm 6 * * \\
923 \pm 7\end{array}$ & $\begin{array}{c}983 \pm 4^{* *} \\
973 \pm 5\end{array}$ & $\begin{array}{c}1004 \pm 6 * * \\
994 \pm 5\end{array}$ \\
\hline 2-1 & $\begin{array}{c}\text { Non-cleft } \\
\text { Cleft }\end{array}$ & $\begin{array}{c}874 \pm 7^{* *} \\
862 \pm 9\end{array}$ & $\begin{array}{c}916 \pm 5^{* *} \\
908 \pm 8\end{array}$ & $\begin{array}{c}953 \pm 6^{* *} \\
941 \pm 8\end{array}$ & $\begin{array}{c}994 \pm 5^{* *} \\
984 \pm 6\end{array}$ \\
\hline $3-2$ & $\begin{array}{c}\text { Non-cleft } \\
\text { Cleft }\end{array}$ & $\begin{array}{c}851 \pm 6 * * \\
842 \pm 19\end{array}$ & $\begin{array}{c}897 \pm 25 * \\
882 \pm 27\end{array}$ & $\begin{array}{c}935 \pm 77^{* *} \\
923 \pm 9\end{array}$ & $\begin{array}{c}945 \pm 5 * * \\
932 \pm 10\end{array}$ \\
\hline 4-3 & $\begin{array}{c}\text { Non-cleft } \\
\text { Cleft }\end{array}$ & $\begin{array}{c}845 \pm 25 * \\
832 \pm 26\end{array}$ & $\begin{array}{l}872 \pm 28 \\
860 \pm 29\end{array}$ & $\begin{array}{l}896 \pm 27 \\
885 \pm 27\end{array}$ & $\begin{array}{l}915 \pm 34 \\
904 \pm 34\end{array}$ \\
\hline $5-4$ & $\begin{array}{c}\text { Non-cleft } \\
\text { Cleft }\end{array}$ & $\begin{array}{l}832 \pm 34 \\
831 \pm 27\end{array}$ & $\begin{array}{l}857 \pm 26 \\
845 \pm 25\end{array}$ & $\begin{array}{l}886 \pm 22 \\
875 \pm 23\end{array}$ & $\begin{array}{l}872 \pm 24 \\
857 \pm 25\end{array}$ \\
\hline $\begin{array}{l}\text { 6-5 } \\
\text { Palatal side }\end{array}$ & $\begin{array}{c}\text { Non-cleft } \\
\text { Cleft }\end{array}$ & $\begin{array}{l}934 \pm 61 \\
913 \pm 40\end{array}$ & $\begin{array}{l}980 \pm 89 \\
951 \pm 37\end{array}$ & $\begin{array}{l}954 \pm 72 \\
927 \pm 35\end{array}$ & $\begin{array}{l}645 \pm 50 \\
634 \pm 50\end{array}$ \\
\hline $\begin{array}{c}\text { 7-6 } \\
\text { Palatal side }\end{array}$ & $\begin{array}{l}\text { Non-cleft } \\
\text { Cleft }\end{array}$ & $\begin{array}{l}899 \pm 39 \\
877 \pm 59\end{array}$ & $\begin{array}{l}934 \pm 47 \\
919 \pm 43\end{array}$ & $\begin{array}{l}880 \pm 37 \\
868 \pm 39\end{array}$ & $\begin{array}{l}542 \pm 57 \\
535 \pm 50\end{array}$ \\
\hline $\begin{array}{c}6-5 \\
\text { Buccal side }\end{array}$ & $\begin{array}{c}\text { Non-cleft } \\
\text { Cleft }\end{array}$ & $\begin{array}{l}825 \pm 42 \\
814 \pm 43\end{array}$ & $\begin{array}{l}846 \pm 38 \\
838 \pm 35\end{array}$ & $\begin{array}{l}870 \pm 41 \\
855 \pm 42\end{array}$ & $\begin{array}{l}643 \pm 47 \\
626 \pm 46\end{array}$ \\
\hline $\begin{array}{c}\text { 7-6 } \\
\text { Buccal side }\end{array}$ & $\begin{array}{c}\text { Non-cleft } \\
\text { Cleft }\end{array}$ & $\begin{array}{c}770 \pm 82 * * \\
721 \pm 63\end{array}$ & $\begin{array}{l}671 \pm 90 \\
660 \pm 88\end{array}$ & $\begin{array}{l}773 \pm 79 \\
759 \pm 77\end{array}$ & $\begin{array}{l}406 \pm 81 \\
397 \pm 79\end{array}$ \\
\hline Tuber & $\begin{array}{c}\text { Non-cleft } \\
\text { Cleft }\end{array}$ & $\begin{array}{l}650 \pm 125 \\
643 \pm 107\end{array}$ & $\begin{array}{l}566 \pm 129 \\
539 \pm 105\end{array}$ & $\begin{array}{l}408 \pm 98 \\
407 \pm 64\end{array}$ & $\begin{array}{l}265 \pm 55 \\
259 \pm 29\end{array}$ \\
\hline
\end{tabular}

**P 01/0> *P 05/0>

logies, Ann Arbor, MI, USA). This software includes an application to outline the selected bone within a defined area and to provide the average BMD in HU. Using the Xoran Cat software, version 3.1.62 the slices were made in the alveolar bone height in the range of 2-5-8- to $11 \mathrm{~mm}$ from the alveolar crest to the basal bone in mesio distal slices and in buccolingual slices on the right and left sides of the maxillary arch. In other words, BMD was measured in 4 heights $(2-5-8-11 \mathrm{~mm})$ from the alveolar bone to the basal bone in mesio distal and bucco-lingual slices in the following areas. Figures 1 and 2 show the mesiodistal and bucco-lingual measurement respectively. Between the right and left centrals ( 1 and 1); between the central and lateral incisors ( 1 and 2); between cuspids and first premolars ( 3 and 4 ); between the first and second premolars ( 4 and 5 ); between the second premolar and first molar (5 and 6); between the first and second molars ( 6 and 7 ); the region distal to second molars (7D) and tuberosity for both sides of the upper jaw. These heights were also measured on the palatal and buccal sides in mesio-distal slice only in the posterior region between the second premolar and first molar (5 and 6); between the first and second molars (6 and 7). Mean and standard deviations of BMD were measured for heights of 2-5-8 and $11 \mathrm{~mm}$ in cleft and non-cleft patients. T-test was used to analyze the bone density values between the cleft and noncleft. SPSS 18.0 (SPSS, Inc, Chicago, IL, USA) was used for statistical analysis. The differences were considered statistically significant with the $p<0.05$.

\section{Results}

The highest alveolar BMD in the mesio distal slice was $1004 \pm 6 \mathrm{HU}$ between the right and left centrals in the upper jaw in height of $11 \mathrm{~mm}$ in non-cleft patients. The least amount of alveolar BMD in the mesio-distal slice was $259 \pm 29 \mathrm{HU}$ in the tuberosity in height of 11 $\mathrm{mm}$ in cleft patients. The highest amount of BMD in the posterior region found was $980 \pm 89 \mathrm{HU}$ which was between the second premolar and the first molar in a depth of $5 \mathrm{~mm}$ from the mesio-distal view in non-cleft patients and it was $927 \pm 35 \mathrm{HU}$ in height of $8 \mathrm{~mm}$ in the same slice in cleft patients. The highest amount of BMD in the palatal side was $980 \pm 89 \mathrm{HU}$ in $5 \mathrm{~mm}$ from alveolar crest in non-clefts patients and the lowest one was $626 \pm 46 \mathrm{HU}$ in the buccal side in $11 \mathrm{~mm}$ from alveolar crest in clefts samples. Table 1 
Table 2. BMD in Hounsfield units (HU) from the bucco-palatal slice in the maxillary arch between teeth and tuberosity.

\begin{tabular}{|c|c|c|c|c|c|}
\hline & Bucco-palatal slice & $\mathbf{2} \mathbf{~ m m}$ & $\mathbf{5 m m}$ & $\mathbf{8 m m}$ & $\mathbf{1 1} \mathbf{m m}$ \\
\hline \multirow{2}{*}{ Region } & Group & Mean \pm SD & Mean \pm SD & Mean \pm SD & Mean \pm SD \\
\hline $\mathbf{1 - 1}$ & Non-cleft & $615 \pm 5^{* *}$ & $683 \pm 4^{* *}$ & $783 \pm 6^{* *}$ & $1639 \pm 11^{* *}$ \\
& Cleft & $607 \pm 5$ & $671 \pm 6$ & $772 \pm 6$ & $1582 \pm 26$ \\
\hline $\mathbf{2 - 1}$ & Non-cleft & $684 \pm 4^{* *}$ & $764 \pm 6^{* *}$ & $845 \pm 4^{* *}$ & $1447 \pm 10^{* *}$ \\
& Cleft & $673 \pm 7$ & $753 \pm 9$ & $836 \pm 6$ & $1438 \pm 10$ \\
\hline $\mathbf{3 - 2}$ & Non-cleft & $756 \pm 6^{* *}$ & $848 \pm 18^{* *}$ & $903 \pm 6^{* *}$ & $1257 \pm 10^{* *}$ \\
& Cleft & $744 \pm 7$ & $837 \pm 6$ & $894 \pm 6$ & $1248 \pm 10$ \\
\hline \multirow{2}{*}{$\mathbf{4 - 3}$} & Non-cleft & $825 \pm 5^{* *}$ & $924 \pm 5^{* *}$ & $963 \pm 4^{* *}$ & $1064 \pm 4^{* *}$ \\
& Cleft & $819 \pm 7$ & $917 \pm 7$ & $949 \pm 8$ & $1051 \pm 8$ \\
\hline $\mathbf{5 - 4}$ & Non-cleft & $934 \pm 6^{* *}$ & $993 \pm 4^{* *}$ & $1008 \pm 9^{* *}$ & $830 \pm 20$ \\
& Cleft & $921 \pm 7$ & $981 \pm 8$ & $1001 \pm 9$ & $822 \pm 19$ \\
\hline $\mathbf{6 - 5}$ & Non-cleft & $1078 \pm 18^{* *}$ & $1159 \pm 21^{* *}$ & $1030 \pm 9^{* *}$ & $674 \pm 105$ \\
& Cleft & $1064 \pm 19$ & $1146 \pm 20$ & $1018 \pm 9$ & $661 \pm 104$ \\
\hline $\mathbf{7 - 6}$ & Non-cleft & $1332 \pm 43$ & $1439 \pm 45$ & $1254 \pm 24^{* *}$ & $643 \pm 22^{*}$ \\
& Cleft & $1331 \pm 44$ & $1427 \pm 45$ & $1209 \pm 31$ & $631 \pm 19$ \\
\hline Tuber & Non-cleft & $833 \pm 34$ & $839 \pm 26$ & $365 \pm 19 *$ & $262 \pm 19 *$ \\
& Cleft & $822 \pm 32$ & $750 \pm 25$ & $354 \pm 17$ & $251 \pm 19$ \\
\hline
\end{tabular}

** $\mathrm{P} 01 / 0>\quad * \mathrm{P} 05 / 0>$

shows the means, standard deviations between the assessed areas on cleft and non-cleft patients in mesio-distal slices. The BMD of the anterior region of the maxilla in non-cleft patients was statistically higher than the cleft samples in the bucco-lingual slices in all areas. In non-cleft patients, the highest amount of BMD found was $1639 \pm 11 \mathrm{HU}$ between the centrals in height of $11 \mathrm{~mm}$ in the bucco-lingual slices in noncleft patients. The highest amount of BMD in the posterior region was found between the first and second molars in a depth of $5 \mathrm{~mm}$ from the bucco-lingual view in both cleft and non-cleft patients which was $1439 \pm 45 \mathrm{HU}$ and $1427 \pm 45 \mathrm{HU}$ respectively. There was no significant difference between the 2 groups in this area. The least amount of BMD found was $251 \pm 19 \mathrm{HU}$ in tuberosity in height of $11 \mathrm{~mm}$ in the bucco-lingual slice of cleft patients. Table 2 shows the values obtained for the means, standard deviations between the assessed areas on cleft and non-cleft patients in bucco-lingual slices.

\section{Discussion}

The result of this research can be used as additional information to select the most suitable area for anchorage devices such as mini- implants. These findings suggest that the best quality of alveolar bone density for mini implant installation from the mesiodistal view, may be in the posterior area between the second premolar and first molar in depth of $5 \mathrm{~mm}$ from the crest of the alveolar bone and also in the bucco-lingual slide, may be between the first and second molars in a depth of $5 \mathrm{~mm}$ from the crest of alveolar bone in cleft and non-cleft patients. The insertion of mini-implants in this area, considering only the highest BMD as a factor for success, would be more interesting. But one must keep in mind that this does not always occur, because other factors may contribute to loosening the mini-implants. For mini implant installation there must be adequate cortical bone thickness and also high BMD. It is considered that BMD is a key factor for the stability of mini-implants as anchorage. BMD should be such so as to favor the mechanical retention of the mini implant in a predetermined position. There are many factors for losing mini-implants as anchorage and one of these factors is poor bone density [12-15]. BMD has an important role in a successful implant. Areas of lesser bone quality have exhibited weaker stability and higher failure rates of dental implants $[16,17]$. The data which one obtained from this study will serve as guidelines for choosing the best quality of alveolar BMD for the placement of mini implants or dental implants. There was a progressive increase in BMD from cleft to non-cleft patients in all areas. This study showed that the maxillary tuberosity area had a lower BMD and also showed that BMD was greater on the palatal side than the buccal side between second premolars and the first \& second molars in both 
groups. Due to this fact anchorage devices can be applied on the palatal side. On the other hand, with respect to the aesthetic concerns of the device, and for greater mechanical control, mini implants can be inserted in the lingual side[18]. BMD can be measured in $\mathrm{HU}$ by $\mathrm{CT}$ and $\mathrm{CBCT}$ [8]. With $\mathrm{CT}$, BMD values are presented in Hounsfield Unit (HU) based on density of air $(-1,000 \mathrm{HU})$ and pure water $(0 \mathrm{HU})$.The density of cortical bone ranges from $\pm 1,000$ to $\pm 1,600 \mathrm{HU}$ values [19]. Turkyilmaz et al [20] determined that BMD ranged from 278 to $1,227 \mathrm{HU}$ in the jaws, with a mean of $751 \mathrm{HU}$. According to Turkyilmaz et al, the variability of the different amount of DBM in the literature is due to the effect of variables such as age and sex. BMD varies according the regions of the jaws and may be affected by many factors including osteoporosis, existence or absence of cleft [21-22].

Because of the high dosage of $\mathrm{CT}$ and lower dose of radiation exposure of $C B C T$, recently $C B C T$ has been widely used for craniofacial imaging [23].

Pripatnanont et al [24] found that the mean BMD after grafting in the cleft site was $426.1 \pm 120.1 \mathrm{HU}$ which was statistically lower than that in the noncleft site with the mean value of $543.9 \pm 120.2 \mathrm{HU}$. Regarding the different types of secondary alveolar bone grafting in patients with cleft lip and palate, Scalzone et al [25] in a systematic review found that the autologous bone and the rh-BMP2 graft showed a similar effectiveness in maxillary alveolar reconstruction assessing bone graft volume and height, although the rh-BMP2 grafta relative shorter shelf life. The use of BMD using CBCT required high stability and reliability of gray values and a consistent correlation between quantitative gray values and density. Various limitations are associated with the use of Hounsfield unit values in CBCT. These issues relate to the limited-field of CBCT geometry, basic radiation physics principles and the assumptions

\section{References}

1. Celenk C, Celenk P. Relationship of mandibular and cervical vertebral bone density using computed tomography. Dentomaxillofac Radiol. 2008;37(1):47-51.

[CrossRef] [PubMed] Google Scholar Scopus

2. Nackaerts $O$, Jacobs $R$, Horner $K$, et al. Bone density measurements in intra-oral radiographs. Clin Oral Investig. 2007;11(3):225-229.

[Full text links] [CrossRef] [PubMed] Google Scholar Scopus

3. Marquezan M, Lau TC, Mattos CT, et al. Bone mineral density: methods of measurement and its influence on primary stability of miniscrews. Angle Orthod. 2012;82(1):62-66. [Full text links] [CrossRef] [PubMed] Google Scholar Scopus

4. Aranyarachkul P, Caruso J, Gantes B, et al. Bone density assessments of dental implant sites: 2. Quantitative conebeam computerized tomography. Int J Oral Maxillofac Implants. 2005;20(3):416-424.

[PubMed] Google Scholar Scopus

5. Park HS, Lee YJ, Jeong SH, Kwon TG. Density of the alveolar and basal bones of the maxilla and the mandible. Am J Orthod Dentofacial Orthop. 2008;133(1):30-37. [Full text links] [CrossRef] [PubMed] Google Scholar Scopus

6. Choi JH, Park $\mathrm{CH}, \mathrm{Yi}$ SW, et al. Bone density measurement in interdental areas with simulated placement of orthodontic miniscrew implants. Am J Orthod Dentofacial Orthop. 2009;136(6):766. e1-e12; discussion 766-777.

[Full text links] [CrossRef] [PubMed] Google Scholar Scopus and limitations of currently used reconstruction algorithms [25].

\section{Conclusions}

BMD in non-cleft patients was higher than in cleft patients in all areas; however, the mean BMD in noncleft patients was significantly greater than in cleft patients from the upper left to the right canines in all areas in the medio-distal slice. Significantly higher BMD was found in the labial cortical plate between the centrals on the mesio distal direction in depth of $11 \mathrm{~mm}$ from the alveolar crest in cleft and non-cleft patients. The highest amount of BMD was found between the first and second molars on the bucco palatal area $5 \mathrm{~mm}$ from the alveolar crest in cleft and non-cleft patients and the differences between them were not statistically significant. The maxillary tuberosity showed the lowest BMD.

The amount of BMD was higher in the palatal side than the buccal side both in cleft and non-cleft patients between the second premolar and the first \& second molars.

\section{Author Contributions}

MSN: responsible for study design, administration, data interpretation, recruitment, statistical analysis, literature review. ART: responsible for data interpretation, critical revision and final approval of the article. AJ: responsible for the study concept, study design, data interpretation, critical revision, writing and revising the report and final approval of the article. $L N$ : responsible for the literature review. AAK: responsible for data gathering, LP: responsible for drafting, data interpretation, critical revision and final approval of the article.

\section{Acknowledgment}

There is no conflict of interest.

7. Miracle AC, Mukherji SK. Conebeam CT of the head and neck, part 1: physical principles. AJNR Am J Neuroradiol. 2009;30(6):1088-1095.

[Full text links] [CrossRef] [PubMed] Google Scholar Scopus

8. Lee S, Gantes B, Riggs M, Crigger M. Bone density assessments of dental implant sites: 3. Bone quality evaluation during osteotomy and implant placement. Int J Oral Maxillofac Implants. 2007;22(2):208-212. [PubMed] Google Scholar Scopus

9. Gonzalez-Garcia $\mathrm{R}$, Monje $\mathrm{F}$. The reliability of cone-beam computed tomography to assess bone density at dental implant recipient sites: a histomorphometric analysis by micro-CT. Clin Oral Implants Res. 2013;24(8):871-879.

[Full text links] [CrossRef] [PubMed] Google Scholar Scopus

10. Jain S, Choudhary K, Nagi R, et al. New evolution of conebeam computed tomography in dentistry: combining digital technologies. Imaging Sci Dent. 2019;49(3):179-190. [Full text links] [Free PMC Article] [CrossRef] [PubMed] Google Scholar

11. Katsumata A, Hirukawa A, Okumura $S$, et al. Effects of image artifacts on gray-value density in limited-volume cone-beam computerized tomography. Oral Surg Oral Med Oral Pathol Oral Radiol Endod. 2007;104(6):829-836.

[Full text links] [CrossRef] [PubMed] Google Scholar Scopus

12. Bergkvist G, Koh KJ, Sahlholm S, et al. Bone density at implant sites and its relationship to assessment of bone quality 
and treatment outcome. Int J Oral Maxillofac Implants. 2010;25(2):321-328.

[PubMed] Google Scholar Scopus

13. Perillo L, Jamilian A, Shafieyoon A, et al. Finite element analysis of miniscrew placement in mandibular alveolar bone with varied angulations. Eur J Orthod. 2015;37(1):56-59. [Full text links] [CrossRef] [PubMed] Google Scholar Scopus

14. Cozzani M, Sadri D, Nucci L, et al. The effect of Alexander, Gianelly, Roth, and MBT bracket systems on anterior retraction: a 3-dimensional finite element study. Clin Oral Investig. 2019 Jul 28

[Full text links] [CrossRef] [PubMed] Google Scholar Scopus

15. Cozzani M, Azizi A, Eslami S, et al. 3-dimensional finite element analysis of the outcomes of Alexander, Gianelly, Roth and MBT bracket prescription. Int Orthod. 2019;17(1):45-52. [Full text links] [CrossRef] [PubMed] Google Scholar Scopus

16. Merheb J, Van Assche N, Coucke W, et al. Relationship between cortical bone thickness or computerized tomography-derived bone density values and implant stability. Clin Oral Implants Res. 2010;21(6):612-617. [Full text links] [CrossRef] [PubMed] Google Scholar Scopus

17. Akdeniz BG, Oksan T, Kovanlikaya I, Genc I. Evaluation of bone height and bone density by computed tomography and panoramic radiography for implant recipient sites. J Oral Implantol. 2000;26(2):114-119.

[Full text links] [CrossRef] [PubMed] Google Scholar Scopus

18. Monnerat C, Restle L, Mucha JN. Tomographic mapping of mandibular interradicular spaces for placement of orthodontic mini-implants. Am J Orthod Dentofacial Orthop. 2009;135(4):428. e1-e9; discussion 428-429.

[Full text links] [CrossRef] [PubMed] Google Scholar Scopus

19. Norton MR, Gamble C. Bone classification: an objective scale of bone density using the computerized tomography scan. Clin Oral Implants Res. 2001;12(1):79-84.

[Full text links] [CrossRef] [PubMed] Google Scholar Scopus
20. Turkyilmaz I, Tözüm TF, Tumer C, Ozbek EN. Assessment of correlation between computerized tomography values of the bone, and maximum torque and resonance frequency values at dental implant placement. J Oral Rehabil. 2006;33(12):881-888. [Full text links] [CrossRef] [PubMed] Google Scholar Scopus

21. Lindh $\mathrm{C}$, Obrant $\mathrm{K}$, Petersson A. Maxillary bone mineral density and its relationship to the bone mineral density of the lumbar spine and hip. Oral Surg Oral Med Oral Pathol Oral Radiol Endod. 2004;98(1):102-109.

[Full text links] [CrossRef] [PubMed] Google Scholar Scopus

22. Benlidayi ME, Tatli U, Kurkcu M, et al. Comparison of bovinederived hydroxyapatite and autogenous bone for secondary alveolar bone grafting in patients with alveolar clefts. J Oral Maxillofac Surg. 2012;70(1):e95-e102.

[Full text links] [CrossRef] [PubMed] Google Scholar Scopus

23. Mah JK, Danforth RA, Bumann A, Hatcher D. Radiation absorbed in maxillofacial imaging with a new dental computed tomography device. Oral Surg Oral Med Oral Pathol Oral Radiol Endod. 2003;96(4):508-513.

[Full text links] [CrossRef] [PubMed] Google Scholar Scopus

24. Pripatnanont $\mathrm{P}$, Nuntanaranont $\mathrm{T}$, Vongvatcharanon $\mathrm{S}$ Proportion of deproteinized bovine bone and autogenous bone affects bone formation in the treatment of calvarial defects in rabbits. Int J Oral Maxillofac Surg. 2009;38(4):356362.

[Full text links] [CrossRef] [PubMed] Google Scholar Scopus

25. Pauwels R, Jacobs R, Singer SR, Mupparapu M. CBCT-based bone quality assessment: are Hounsfield units applicable? Dentomaxillofac Radiol. 2015;44(1):20140238. [Full text links] [Free PMC Article] [CrossRef] [PubMed] Google Scholar
Mohammad Sadegh NAZARI

Postgraduate Student

Department of Orthodontics

School of Dentistry

Mashhad University of Medical Sciences, Mashhad, Iran

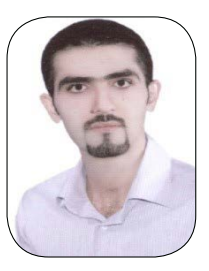

Maohammad Sadegh Nazari graduated from the Tehran Azad University of Dental School in 2017 and as a resident of orthodontics in 2018 at the Mashhad University of Medical Science. He became a top Iranian student researcher in 2016 and a national student in 2016. He has published 9 articles. He has participated in various conferences and congresses and has had several oral presentation and posters. His scientific interests are focused on orthognathic surgery patients. 


\section{Ouestions}

\section{What is the amount of bone tissue?}

Da. Hounsfield unit;

ab. Bone mineral density (BMD);

ac. Bone resorption;

$\square$ d. Bone remodeling.

2. Which one is used to evaluate anatomic structures and thr direct measurement of mineralized tissue before dental implant?

Da. CBCT;

ab. $\mathrm{HU}$;

口c. MRI;

घd. CT.

3. What is the highest alveolar bone density in the mesio distal between ... in the upper jaw in height of ... mm in ... patient?

$\square$ a. Right and left centrals, 8, non-cleft;

ab. Central and lateral, 11, non-cleft;

口c. Right and left centrals, 11, non-cleft;

ud. Central and lateral, 8, non-cleft.

\section{Which is the highest amount of bone density in the posterior region?}

$\square$ a. First and second molars;

ab. Second premolar and first molar;

$\square$ c. First and second premolars;

ad. Second and third molars.
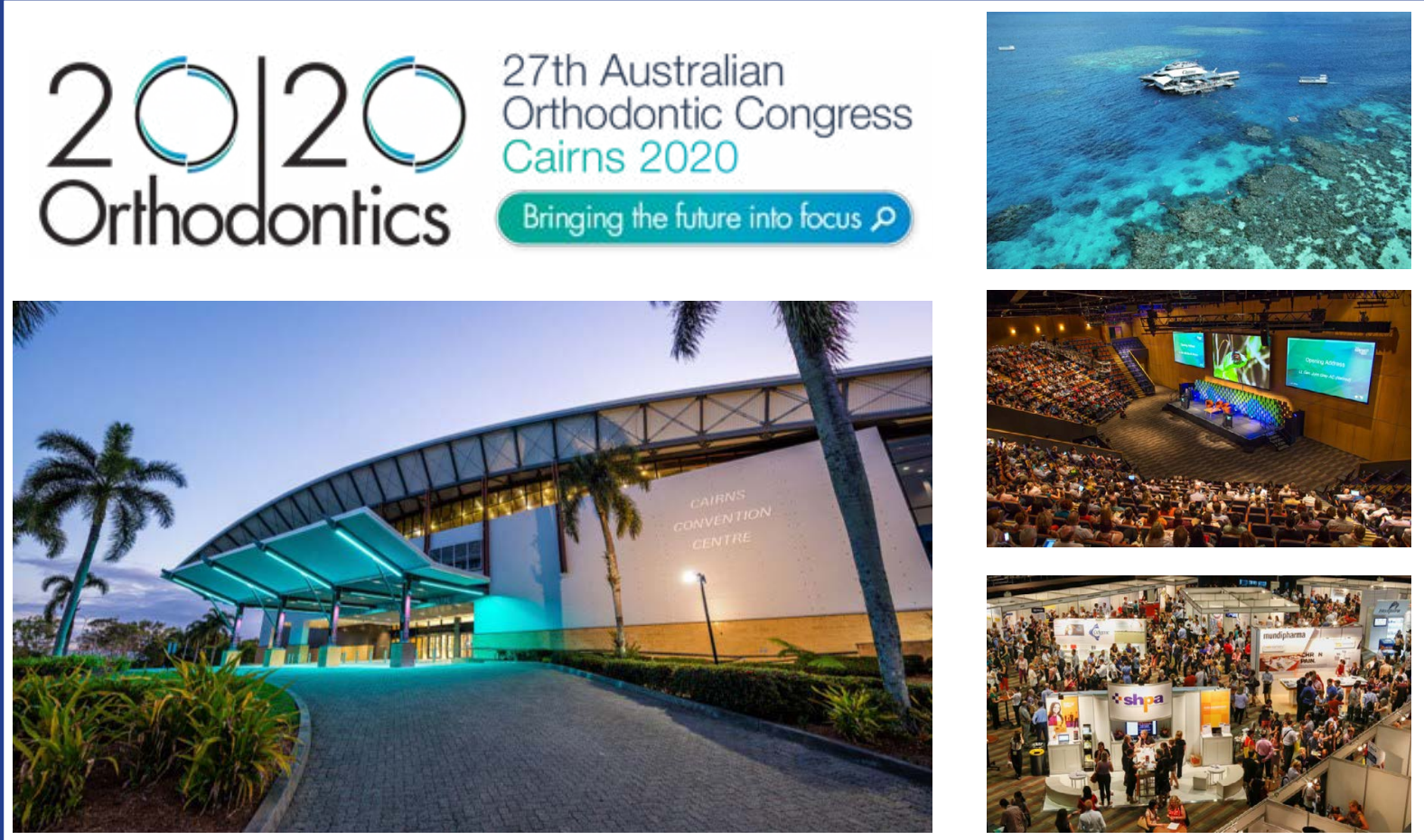

19 - 20 March 2020

Cairns Convention Centre www.aso2020cairns.com.au 

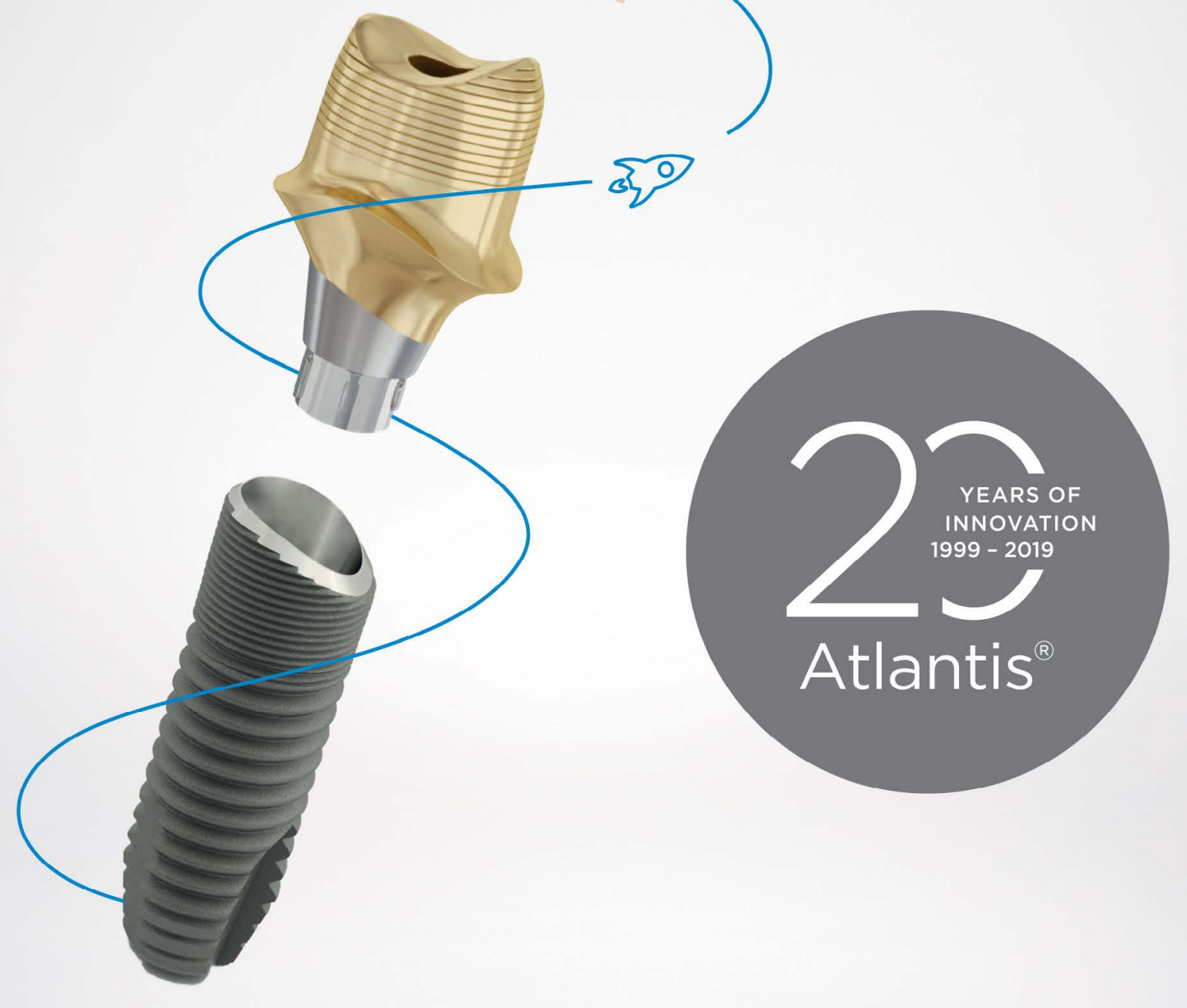

\section{Demand for dental implants is rising - are you ready?}

Changing eating habits, increasing life expectancy and the desire for a "perfect" smile, are causing the number of dental implant treatments to surge. By 2025, the global dental implants market is expected to be $\$ 6.5$ bn*. Is your dental laboratory positioned to take advantage of the increasing demand? Outsourcing parts of your production could be the key to optimizing your dental laboratory business. 


\title{
ROLE OF THE MAXILLARY TUBEROSITY IN PERIODONTOLOGY AND IMPLANT DENTISTRY-A REVIEW
}

\author{
Nicholas Montanaro ${ }^{1 \mathrm{a}}$, José Carlos Martins da Rosa ${ }^{2 \mathrm{~b}}$, Luis Antonio Violin Pereira ${ }^{3 \mathrm{c}}$, Georgios E. Romanos ${ }^{1 \mathrm{~d}^{*}}$ (i)
}

'Department of Periodontology, School of Dental Medicine, Stony Brook University, Stony Brook, NY, USA

2Department of Implantology, São Leopoldo Mandic Dental Research Center, Campinas ( SP), Brazil

${ }^{3}$ Department of Biochemistry and Tissue Biology, Institute of Biology, State University of Campinas, Campinas (SP), Brazil

${ }^{\mathrm{a} D D S}$

${ }^{b} D D S, M s C$, PhD

MDD, PhD

${ }^{d} D D S$, PhD, Prof, Dr med dent

\section{ABSTRACT DOI: https://doi.org/10.25241/stomaeduj.2019.6(4).art.5}

Background:The maxillary tuberosity in implant dentistry presents the clinical location for clinicians with respect to the periodontal, surgical, prosthetic, implantological and mechanical aspects.

Objective: The aim of this paper was to evaluate the role of the maxillary tuberosity based on the literature and to enhance the role of tilted implants placed in the maxillary tuberosity as an anchorage to the most posterior end of prostheses in order to avoid biomechanical complications from distal cantilevers.

Data Sources: Information was obtained mainly from the PubMed and MEDLINE databases, online books managed by the National Center for Biotechnology Information, and non-indexed sources. Previous studies have demonstrated more than $94 \%$ survival rates of implants placed in the maxillary tuberosity despite the usage of varied implant designs and surgical protocols. Data Extraction and Synthesis: The web search included the following keywords: bone, dental implant, dental implantation, maxillary osteotomy, osseointegration for period 1980 to 2017. Proper insertion of tapered implants with adequate bone condensation of the local cancellous bone is effective in generating the required primary stability and eventual osseointegration required for long-term success. In cases where implant placement in the maxillary tuberosity provides no immediate restorative benefit, various hard and soft tissues of the region can be harvested for autogenous grafting to address distant constraints. Usage of the maxillary tuberosity for implant placement or as a grafting source can provide increased options for clinicians to restore a patient's dentition to a higher quality without the requirement of more numerous, costlier and complicated surgical restorative procedures.

Keywords: Bone; Dental Implant; Dental Implantation; Maxillary Osteotomy; Osseointegration.

\section{Introduction}

The maxillary tuberosity (MT) is a bony region located bilaterally on the upper jaw that is posterior to the most distal molar roots. It is often characterized by its prominent rounded appearance that bulges outward from the face of the maxillary bones around the maxillary sinus. The tuber region is comprised primarily of spongy cancellous osseous tissue - specifically categorized as a combination of type III and IV bone with abundant marrow [1,2]. It is situated along the medial side of the pyramidal process of the palatine bone and forms an articular surface at this site. The posterior superior alveolar nerves and vessels pierce through the posterior surface of the MT, and this tu-

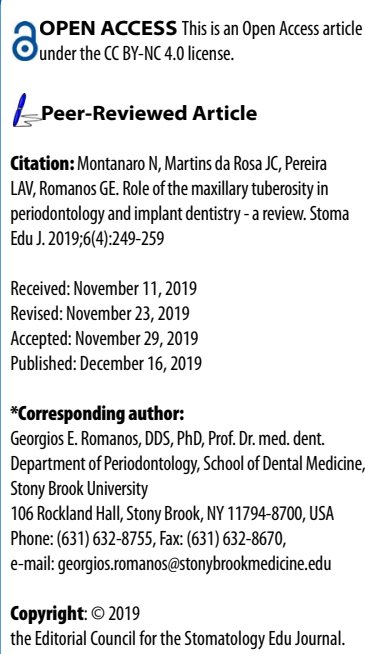

ber region also functions as an attachment point for the medial pterygoid muscles. In the past, soft and hard tissues of the MT served as excellent donor sites when these tissues were deficient elsewhere in the maxilla. It has been shown that gingival connective tissues can be harvested and grafted successfully at recipient sites for cosmetic and functional root coverage in the anterior maxilla $[3,4]$. The MT can also function as a bone source as there is frequently an abundance of untapped usable bone mass, even in patients with bone recession throughout the remainder of the maxilla. Bone harvested from the maxillary tuberosity has been used in the reconstruction of compromised sockets for immediate implantation, 


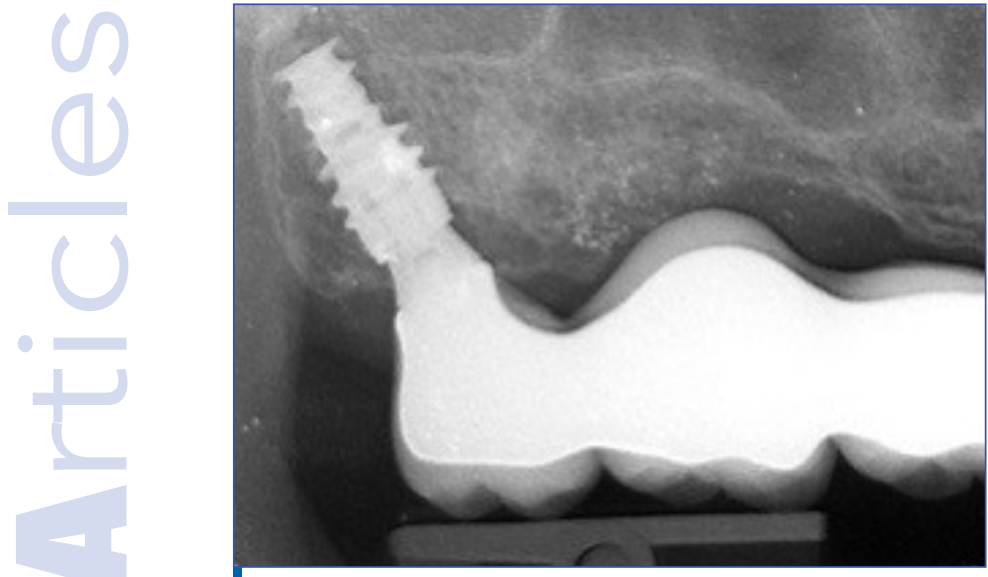

Figure 1. Maxillary tuberosity providing support for an implant-supported fixed prosthesis (courtesy: Dr. E. El-Haddad, Torino, Italy).

as well as effectively in the management of intrabony defects in mandibular molars [4,5]. Varying defects covering trauma, infection, or bone recession often result in structure changes of alveolar processes that cannot be candidates for implantation without additional grafting procedures. The usage of bone grafts harvested from the MT can provide a superb alternative source of autogenous bone to augment the alveolar ridges and sockets without the need for more invasive surgical harvesting procedures, such as when bone tissues are taken from the chin or the ramus [6]. Although the maxillary tuberosity does not naturally support teeth nor is it a traditional site for dental implants, it can provide support for some restorations in particular cases. The MT is a more permanent structure, and even with the extraction of all maxillary teeth, the MT remains with only minor resorption. It is speculated that the pterygoid medialis muscle provides loading forces during mastication which counteract disuse atrophy $[1,2]$. Bone resorption in the palatal direction and narrowing of the MT is generally only seen when tooth loss is secondary to pronounced periodontal disease. As such, the convex anatomy of MT should always be taken into consideration in traditional denture design as the medial and lateral walls resist the horizontal and torqueing forces which would move the denture base in the lateral or palatal directions [7-11]. In more recent times, the MT has been deemed as an acceptable site for implant placement, especially in cases where there is a need to avoid sinus grafting, thus providing increased stability for fixed (Fig. 1) or removable prostheses (Fig. 2). Implant placement in this posterior region is quite comparable to that of conventional implant placement elsewhere in the maxilla with only slight alterations of drilling, bone condensation procedures, and instruments in order to protect the weaker bone in the area. Several previous studies have demonstrated excellent survival rates comparable to that of implants placed throughout the remainder of the maxilla [12-21]. Successfully placed and osseointegrated implants in the tuber region can be used as abutments for implant-supported prostheses to avoid distal canti- levers and control bending moments in the posterior segments. Implant placement in the MT is a much more conservative option in treatment when there is insufficient bone mass throughout the rest of the maxilla. This allows for the circumvention of extensive surgical grafting or sinus lifting procedures that entail greater risk of complications. Implant placement in the MT becomes a more sensible choice for elderly patients, those with healing deficiencies, or those where cost for treatment is restricted.

The objective of this study was to evaluate the literature presenting implants placed in the MT region and the outcomes of the treatment and to discuss the clinical potential of this anatomical area as a donor site for soft and hard tissue in order to demonstrate the role of the tuberosity in periodontology and implant dentistry.

\section{Materials and methods}

This literature review was carried out through the utilization of PubMed.gov, an online database comprised of biomedical literature from MEDLINE, life science journals, and online books managed by the National Center for Biotechnology Information. Search criteria for scientific papers in this review were confined to the role of the maxillary tuberosity and pterygoid in implant dentistry.

This included anatomy, implant placement, removal of tissues, and surgical outcomes.

\section{Results}

A PubMed search was performed with the search criteria "maxillary tuberosity and implants", or "pterygoid and implants". This resulted in a total of 73 and 75 articles, respectively (148 total). Articles discussing use of non-dental implants in the tuberosity or pterygoid regions, or dental implants used for prostheses that do not ultimately restore teeth were excluded from our review. After exclusion criteria were applied and papers of insufficient data were removed from review, there were 10 papers of sufficient quality in which our study was based (Table 1). The tuberosity currently serves as an underutilized region of the maxilla that has the potential to be a critical area for implant placement in patients with bone deficiencies throughout the mouth. Despite its advantages, implant placement in this region is often hindered by its own anatomy; primarily the spongy bone of the maxilla is softer and more cancellous than that of the mandible, and bone density decreases posteriorly. The bone of the tuberosity contains high amount of bone marrow $[1,2,12,22,23]$. As such, any clinician planning for the placement of implants in this location must first take into consideration the relative lower density and properties of this osseous tissue to best avoid implant failure $[8,9,11,18,24]$. Generally, implants must be angulated to properly fit the tube-rosity bone structure with sufficient length. Angled (tilted) implants were seen as unfavorable to support large restorations in the past as they were 
Table 1. Survival rates of implants placed in the maxillary tuberosity across published studies[12-21].

\begin{tabular}{|c|c|c|c|c|c|c|c|c|c|c|c|}
\hline 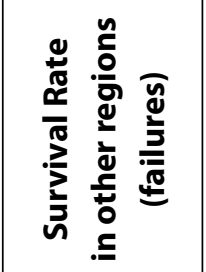 & ○े & $\begin{array}{l}\Xi \\
80 \\
0 \\
0 \\
0\end{array}$ & ○े & $\begin{array}{l}\bar{\Xi} \\
\text { ठें }\end{array}$ & ஓे & $\underset{z}{z}$ & 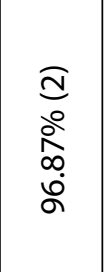 & 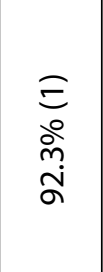 & $\frac{\Sigma}{z}$ & 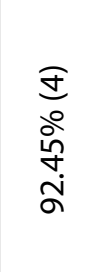 & 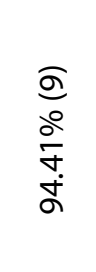 \\
\hline 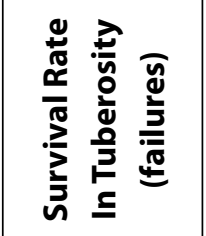 & ঃे & ஓे & ঃे & 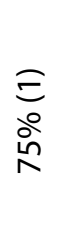 & ঃి & ঃे & ঃे & ஜे & $\begin{array}{l}\sqrt{n} \\
\stackrel{\circ}{0} \\
\text { à }\end{array}$ & 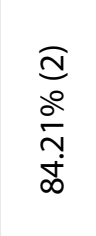 & $\begin{array}{l}\frac{\alpha}{m} \\
\hat{o} \\
\stackrel{\alpha}{\alpha}\end{array}$ \\
\hline 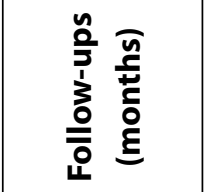 & $\stackrel{ \pm}{\sim}$ & $\stackrel{d}{\sim}$ & $\stackrel{m}{m}$ & $\stackrel{\infty}{-}$ & $\$$ & $\begin{array}{l}\stackrel{ \pm}{\infty} \\
\stackrel{0}{ } \\
\stackrel{\sim}{\simeq}\end{array}$ & 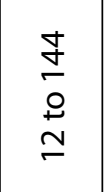 & $\begin{array}{l}\stackrel{\infty}{+} \\
\stackrel{0}{0} \\
\stackrel{0}{0}\end{array}$ & $\stackrel{+}{\sim}$ & $\begin{array}{l}8 \\
\stackrel{0}{0} \\
\stackrel{0}{0}\end{array}$ & 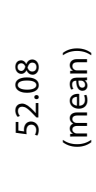 \\
\hline 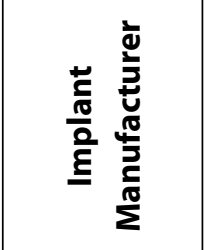 & 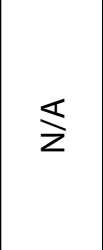 & $\frac{\mathbb{z}}{z}$ & $\frac{\Sigma}{z}$ & $\underset{z}{z}$ & $\frac{\Sigma}{z}$ & $\sum_{\mathcal{U}}$ & 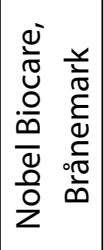 & 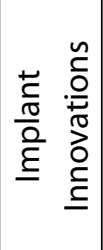 & 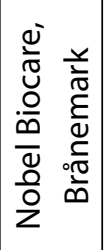 & 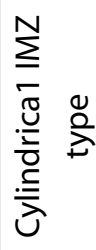 & \\
\hline 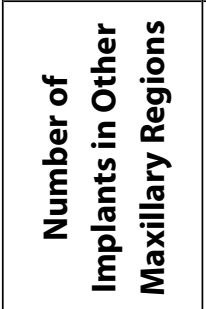 & $\nabla$ & $m$ & 0 & $N$ & 0 & $\stackrel{ }{\circ}$ & ఫ & $\stackrel{m}{-}$ & 0 & nn & $\bar{\sigma}$ \\
\hline 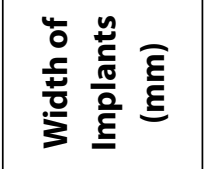 & $\stackrel{\circ}{+}$ & 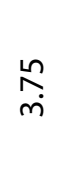 & \begin{tabular}{l}
$\infty$ \\
$\stackrel{+}{+}$ \\
$\infty$ \\
\hdashline$\dot{+}$
\end{tabular} & 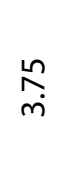 & $\$$ & $\begin{array}{l}\stackrel{\circ}{+} \\
\stackrel{+}{N} \\
\hat{m}\end{array}$ & $\begin{array}{l}\stackrel{\circ}{+} \\
\stackrel{\leftrightarrow}{N} \\
\stackrel{m}{m}\end{array}$ & $\begin{array}{l}\stackrel{\circ}{+} \\
\stackrel{+}{N} \\
\hat{m}\end{array}$ & 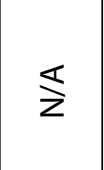 & 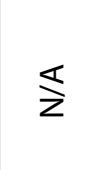 & \\
\hline 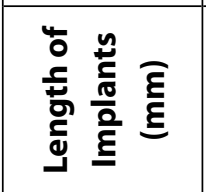 & $\stackrel{\circ}{\circ}$ & $\begin{array}{l}\stackrel{0}{m} \\
\frac{m}{\infty} \\
0 \\
\dot{0}\end{array}$ & $\stackrel{\circ}{\stackrel{+}{ \pm}}$ & $\begin{array}{l}\circ \\
\dot{m} \\
\infty \\
0 \\
0 \\
\dot{0}\end{array}$ & $\$$ & $\frac{\stackrel{n}{n}}{\stackrel{n}{\check{n}}}$ & $\begin{array}{l}\stackrel{0}{\dot{0}} \\
\text { ò } \\
\dot{m}\end{array}$ & $\begin{array}{l}0 \\
\grave{0} \\
o \\
0 \\
0\end{array}$ & 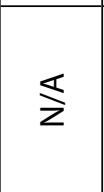 & $\frac{\Sigma}{z}$ & \\
\hline 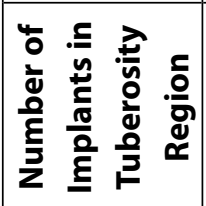 & $\sim$ & $N$ & $\sim$ & $\nabla$ & $N$ & $\lambda$ & $\approx$ & શิ & $\stackrel{N}{N}$ & $\stackrel{9}{-}$ & $\underset{\sigma}{\sigma}$ \\
\hline 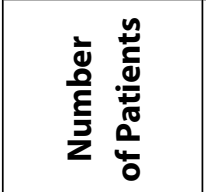 & - & - & - & - & - & $\wedge$ & $\stackrel{N}{ }$ & 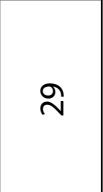 & ஜ & $\mp$ & $\underline{E}$ \\
\hline & 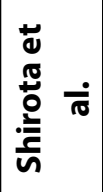 & $\begin{array}{l}\dot{\sigma} \\
\stackrel{0}{d} \\
\tilde{y} \\
\frac{\tilde{U}}{\tilde{J}}\end{array}$ & 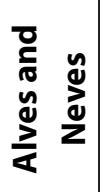 & 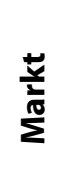 & 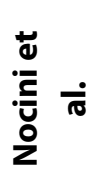 & 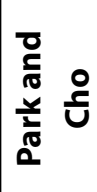 & $\begin{array}{l}\frac{\dot{\pi}}{0} \\
\frac{0}{\overline{0}} \\
\frac{0}{\alpha}\end{array}$ & 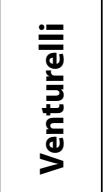 & $\begin{array}{l}\frac{\pi}{0} \\
\frac{\pi}{10} \\
\infty\end{array}$ & 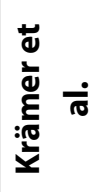 & 店 \\
\hline
\end{tabular}



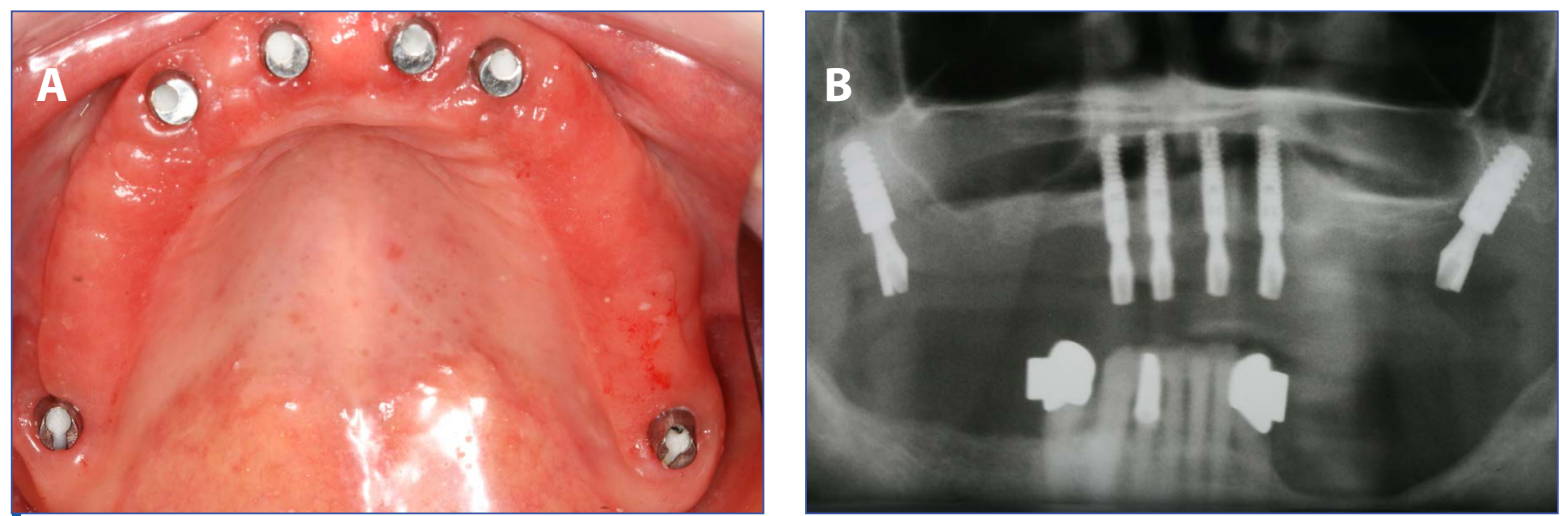

Figure 2. Clinical (A) and radiologic (B) conditions demonstrating the maxillary tuberosity providing support of tuberosity-embedded implants 10 years after functional loading of a removable implant-supported prosthesis.
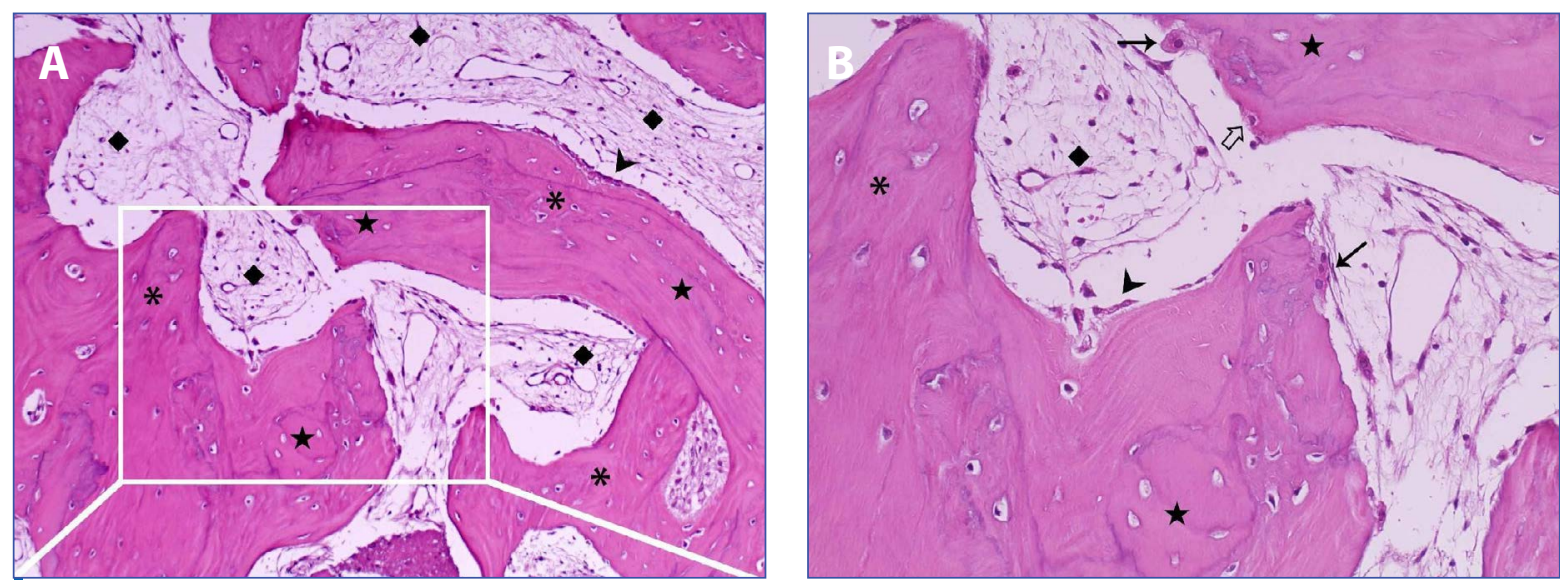

Figure 3. Representative photomicrographs of a biopsy specimens visualized by hematoxylin and eosin staining retrieved 3-months after grafting of maxillary tuberosity bone to the alveolar ridge. (A) Panoramic view (microscopic objective 10x) of well-vascularized and cell-rich marrow ( $\downarrow$ ), newly formed trabecular bone $\left(^{*}\right)$ with bone lining and/or osteoblast-like cells $(\boldsymbol{\nabla})$, and areas of non-vital bone $(\star)$ with empty lacunae. A large number of exuberant osteocytes in lacunae are associated with non-lamellar arrangement typical of newly remodeled bone. (B) At higher magnification (microscopic objective 20x), details of marrow ( $\bullet$ ), newly formed trabecular bone $(*)$, bone-lining cells or osteoblast-like cells $(>)$, osteoblasts ( $(\nabla)$, and osteoclasts $(\rightarrow)$ resorbing non-vital bone are evident. No signs of inflammatory reaction were observed.

thought to increase risk of bone resorption and implant failure, but more current studies have shown that angulated implants offer the same, if not better, long-term results when compared to their non-angulated counterparts - especially with implant lengths exceeding $13 \mathrm{~mm}$, regardless of angulation [25-27].

This may likely be due to greater primary stability imparted by the additional threads of longer implants, leading to more successful long-term outcomes.

This primary stability may have been a more critical factor to implant success than the spongy bone's lesser density support. Additional considerations for implant placement in the MT include the amount of bone available and bone height issues. As the MT is predominately lower density bone, the insufficiency of the bone tissue may inhibit a patient's candidacy for placement as ample bone volume is required for lasting results.

\subsection{Implants in the Tuber Region}

Pre-operative planning, implant design, superb osteotomy preparation using an optimal drilling procedure, and bone condensation are important factors to take into account in order to achieve long-term implant success. Detailed planning and bone ma- pping is advised on a per-patient basis to avoid surgical complications. Bone volume should be evaluated through the utilization of cone beam computed tomography (CBCT), but a combination of typical panoramic and periapical radiographs can provide adequate pre-operative bone information to substitute when CBCT is unavailable [28]. It has been suggested that a lateral window in the maxillary sinus can be made to further verify correct placement [18]. Once these considerations are taken into account, it is advised to choose a location more palatal as bone resorption is most commonly observed in the palatal direction, and distances of $35 \mathrm{~mm}$ or greater from opposing dentition are recommended to allow for surgical access [14]. More confined openings may negatively influence implant angulation or the ability for the surgeon to manipulate instruments. The use of a radiopaque marker integrated on a surgical guide or other acrylic guide can be employed along the edentulous ridge to assist in proper implant site location [12]. Several operatory procedures for implant placement in the MT have been suggested with mutual attributes yielding very similar results, and several studies have suggested that the utilization of an adapted drilling technique in sites of poor bone 

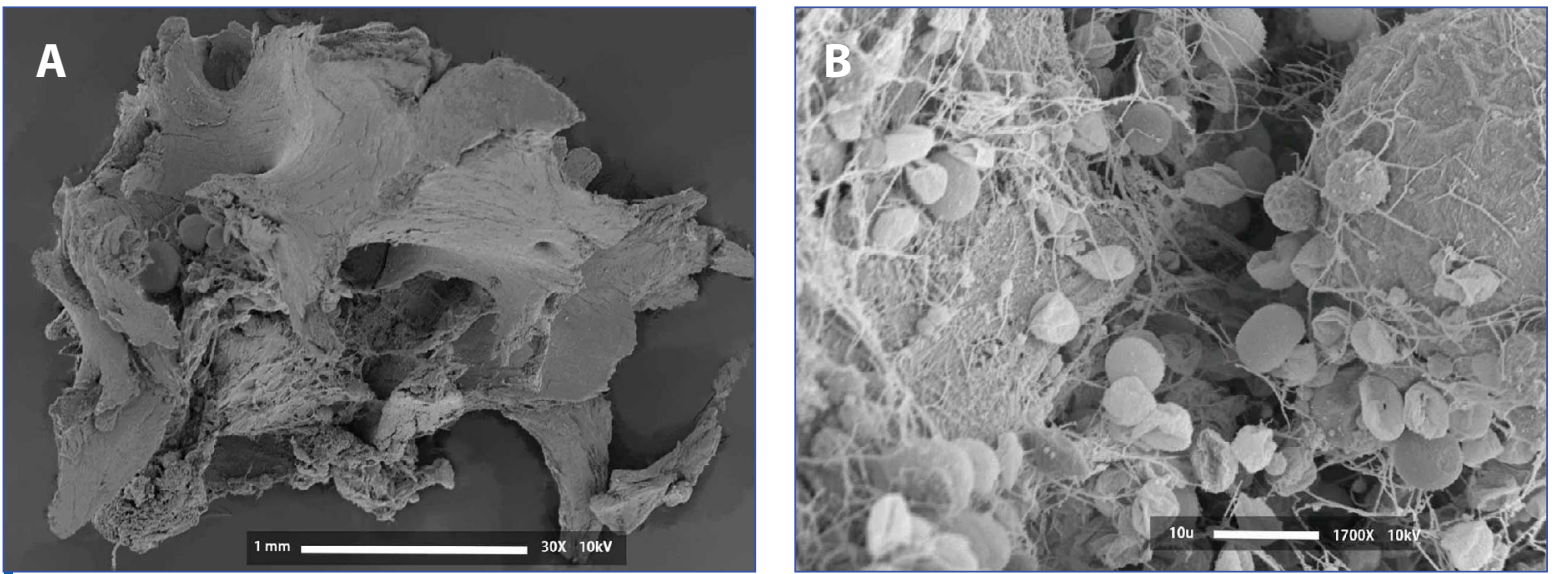

Figure 4. Representative scanning electron micrographs of a bony fragment retrieved from the maxillary tuberosity with associated particulate harvested via rongeur forcep. (A) Panoramic view of a particle with structure larger than $1 \mathrm{~mm}$ to facilitate the osseoconduction process (30x). (B) At higher magnification, details of bone matrix and fibrin network within cells are observed, which remain intact even after the particulate procedure $(1,700 x)$.

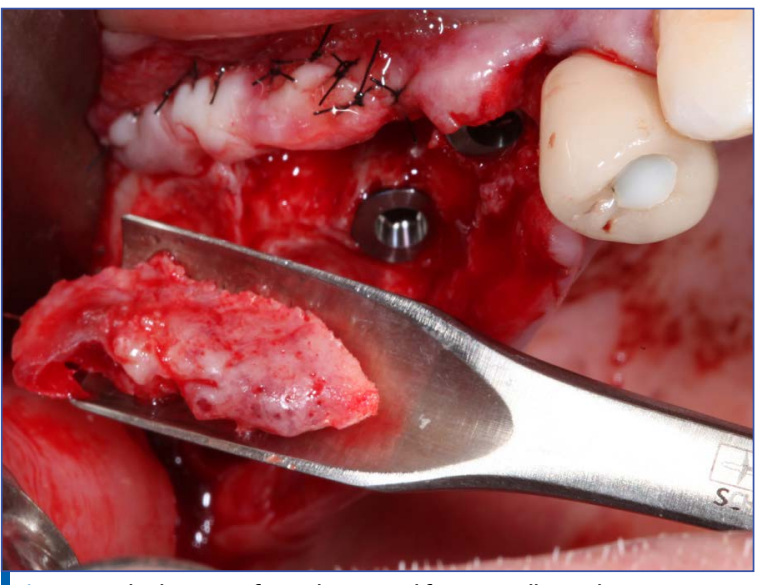

Figure 5. The bone graft was harvested from maxillary tuberosity in close proximity to the receptor site using IDR chisels. The graft was reshaped in relation to the defect configuration, and the remaining bone was crushed for use as particulate graft.

density is vastly advantageous in improving initial endosseous stability $[9,14,15,25,28-33]$. The highest success rates and greatest primary stability were observed after procedures that extensively employed under-sizing of the osteotomy, local bone condensation, osseodensification (Versah drills), or a combination of these methods as compared to that of traditional bone drilling techniques. By first under-drilling the bone with minimal countersinking and then mini-mizing the site preparation, the implant can obtain a constricted fit into the osteotomy once the fixture is eventually placed. This allows for a stronger thread engagement into the surrounding bone walls. Additionally, angulation of the implant site is critical, as the implant should maintain a $10-20^{\circ}$ mesial slant to mimic the natural angulation of the third molar $[12,34]$. A special emphasis is also placed on the bone condensation of the low quality bone. Bone condensation is obligatory in areas of reduced bone density in the posterior maxilla to attain sufficient implant stability [35]. To accomplish this condensation properly, an osteotome or modified osteotome technique or the method of osseodensification should be implemented over a conventional drilling tech- nique $[15,31,36]$. Blunt surgical osteotomes are recommended as the lack of sharpened edges, such as those found on drills, reduces the chance of cutting palatine and other maxillary arteries and nerves [15]. After bone condensation, significantly higher implant stability has been recorded immediately after surgery, as well as during the following observation periods compared to solely bone drilling techniques [33]. Procedures with the highest success rates and greatest implant stabilities consistently placed tapered implants in bone once implant sites were drilled and condensed [12-21]. The soft tissues of the maxillary tuberosity should be treated with care during surgery to avoid periosteal tears that will hinder proper blood flow and slow the healing process, and intimate wound approximation is required for optimal results. Complications at this site are minimal as bthere are no major vital structures in the immediate surgical area. Excess soft tissue over the surgical site should be trimmed to be no more than $3 \mathrm{~mm}$, allowing for adequate space for proper hygiene once the initial wound has healed [12]. Any implants placed in the tuber region should be allowed to heal for 6 months or more without loading in most cases. Premature loading would cause unwarranted stress on the surrounding low-density bone, increasing risk of failure before proper osseointegration [37]. In cases of severely weakened bone, progressive or early moderate loading protocols of the bone with implant prostheses may be used to strengthen the bone over the healing period $[38,39]$. Posterior occlusal forces can reach nearly ten times that of those in the anterior jaw, and these forces must be eliminated or adjusted to reach the desired load [12]. Loading forces can be decreased through the reduction of prosthesis occlusive contacts or through the adjustment of opposing dentition in contact with the prosthesis.

Shorter healing times (4-6 months) and more prompt integration may be plausible with implant surface modification [40]. Upon adequate healing of the implant site, fixed permanent prostheses can be fabricated and placed in a similar fashion as fixed dentures 

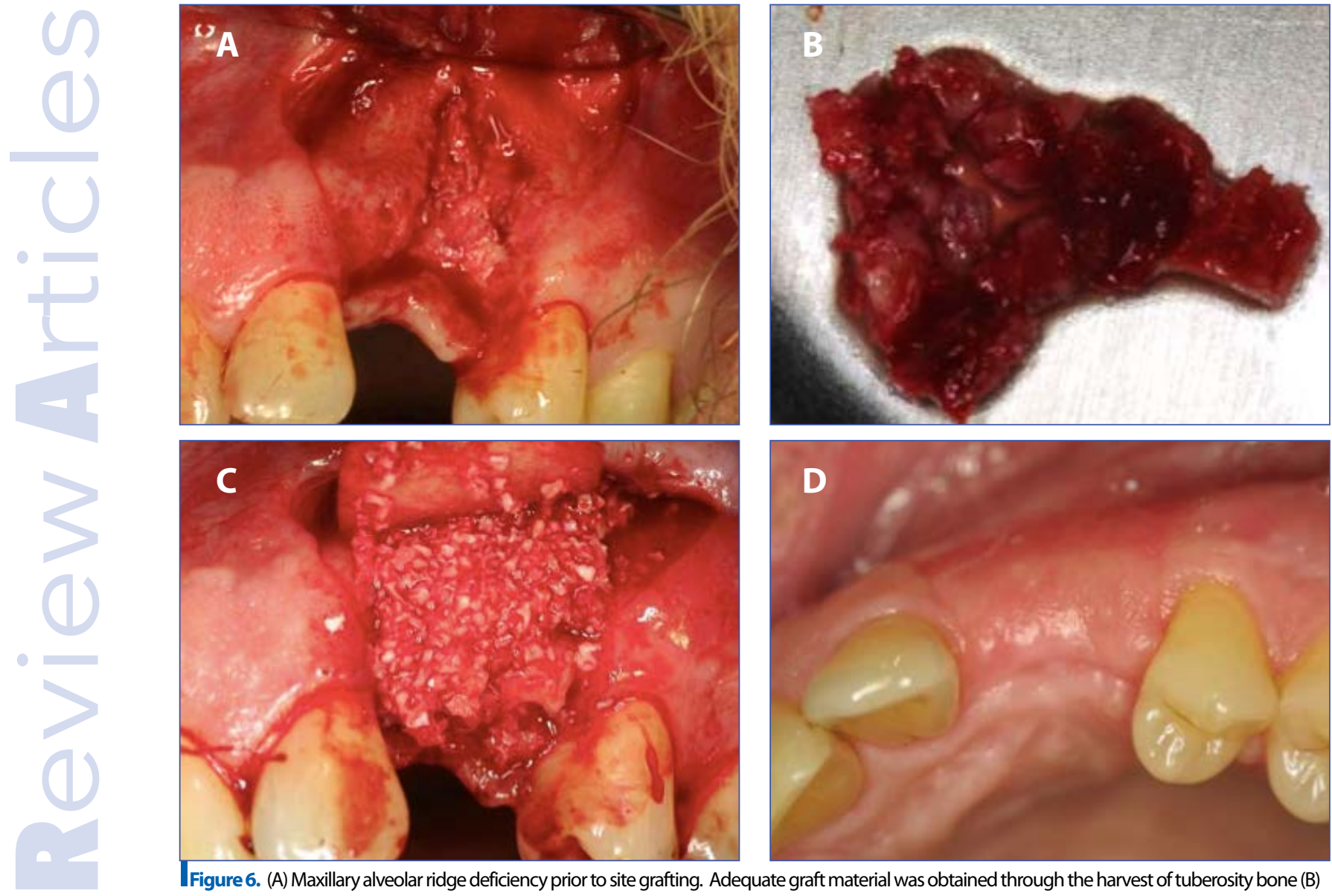

Figure 6. (A) Maxillary alveolar ridge deficiency prior to site grafting. Adequate graft material was obtained through the harvest of tuberosity bone (B) in combination with bovine osseous particulate as a composite graft (C). (D) The surgical site presented with excellent ridge contour after 3-months of healing post-operatively.

supported by implants placed in traditional maxillary positions. In fully or partially edentulous patients, posterior implants can be splinted together with anterior implants to reduce stresses in the supporting bone, as well as provide the framework for bridge or hybrid restorations that span larger proportions of the maxillary arch [41]. High survival rates of implants placed in the tuber region have been consistently shown in multiple studies [12-21,28]. Across these studies, 161 implants were placed in the maxillary tuberosity with a $95.03 \%$ survival rate over an average follow-up period of 52.08 months (Table 1). All studies demonstrated high success rates. Comparatively, 161 implants were placed in traditional regions in the maxilla with a $94.41 \%$ survival rate in the same patients over the same time interval (Table 1). Survival rates of implants in the MT and that of other maxillary implants were not significantly different from one another $(p>0.05)$. Marginal bone resorption across all studies was analogous to that of conventional implants placed throughout the maxilla despite different surgical modalities [28]. Similarities in survival rates amongst implants placed throughout the maxilla suggest tuberosity-based implants can provide a stable and predictable alternative to the traditional major rafting procedures that would other wise be required to stabilize implants in maxillary areas with bone deficiencies further anterior to the tuberosity. This provides a much more con- servative option for patients restricted financially or by medical conditions that hinder or delay healing processes. Survival rates over longer time intervals ( $>15$ years) are required to further validate this conclusion as an effective conservative alternative to major grafting or lifting procedures and to make accurate comparisons to established long-term studies of fixed prostheses. Often times, the bone volume of the maxillary tuberosity alone is insufficient for implant fixture placement. In these cases, implants have also been placed into the pterygoid plate area to overcome anatomical constraints similar to the way implants in the MT have been used in partially or completely edentulous patients [10,42-46]. The consideration of pterygoid implants was first proposed as a means of anchoring the posterior ends of fixed prostheses into as dense bone as possible in the posterior maxilla with implants longer than $15 \mathrm{~mm}$ [42]. This involves drilling through the pterygoid processes of the sphenoid, the pyramidal process of the palatine bone, as well within the MT in close proximity to the posterior wall of the sinus at approximately $35-55^{\circ}$ angulation [10]. The occlusal forces generated in the posterior maxilla far exceed those generated in anterior areas, and the bone quality of the MT is often inadequate to support fixed prostheses alone [12]. In these situations, compensation by means of fixture engagement of the pyramidal process of the cortical plate and associated pterygomaxillary 

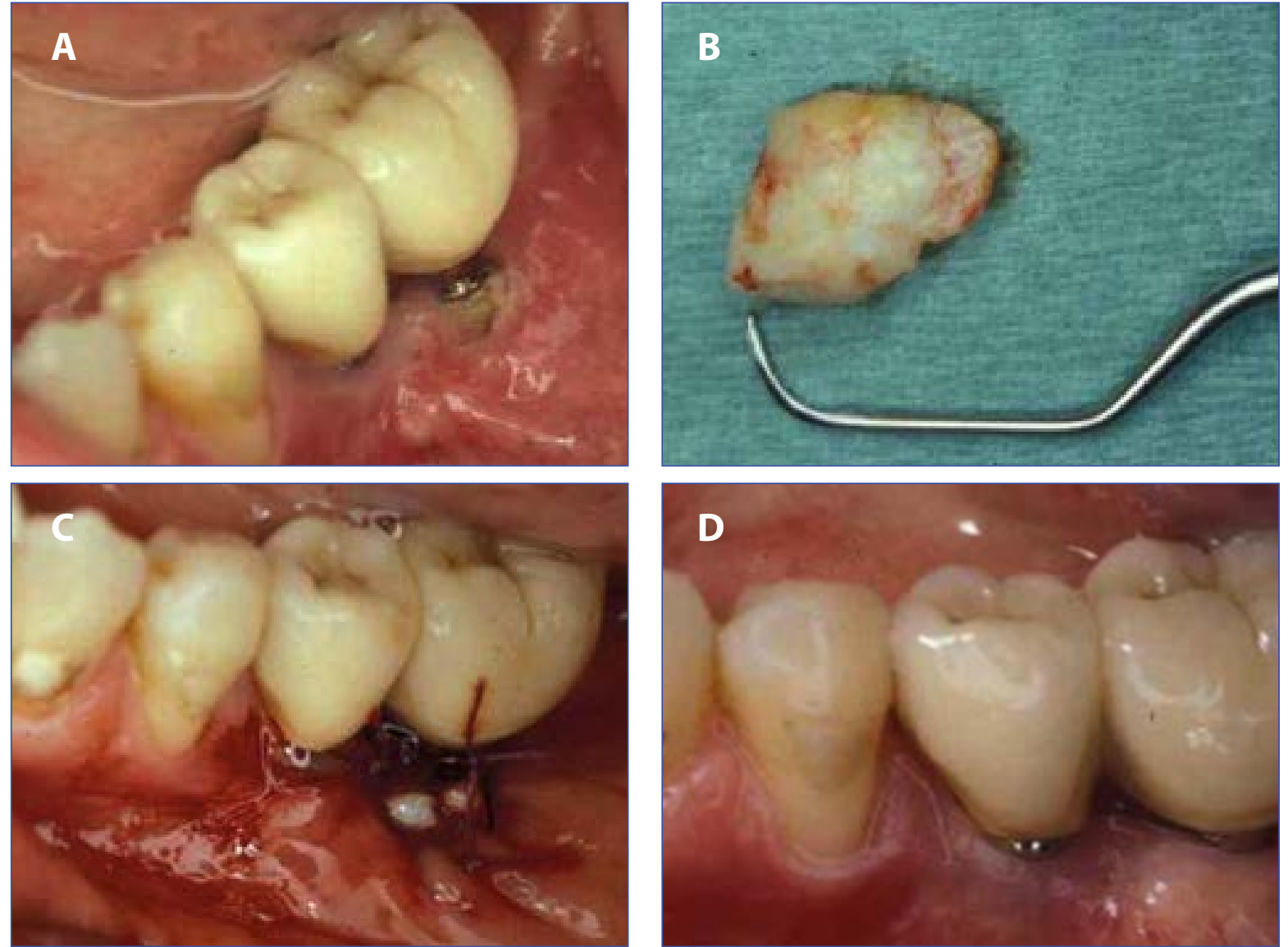

Figure 7. Peri-implant dehiscence (A) before placement of a soft tissue graft harvested from the maxillary tuberosity (B). The graft was immobilized within a pouch (C), and healing at the 2-years surgery demonstrated an outstanding soft tissue condition (D).

regions may be required [44]. Increased implant length in the pterygomaxillary region was found to lead to superior rates of osseointegration [46]. This may be a result of better implant apex engagement of the cortical bone between the medial and lateral pterygoid plates, thereby increasing stability after placement. It is important to note that although pterygoid implants utilize parts of the MT, not all MT-implants engage the area encompassing the pterygoid region. In this way, pterygoid implants and the implant restorations associated with them most frequently involve or incorporate a combination or direct connection of the pterygoid with the MT. Dental implants incorporating the pterygoid plate and accompanying areas have been shown to have high cumulative survival rates in edentulous maxillary arches ranging from $88.2 \%$ to $97.7 \%$ with similar expected bone loss as conventional implants in reported studies [10,47-50]. Implant placement into the pterygoid region poses similar difficulties as tuberosity implants: high operator learning curves, limited surgical access, and high risk of complication if arteries or their major branches are disrupted $[49,51]$. Regardless of inclusion of pterygoid engagement, these posterior maxillary implants function to support distal ends of fixed prostheses to alleviate bending and cantilever forces, as well as to provide overall denture stability. Their usage to restore missing dentition is highly viable as both a standalone procedure or in situations where they are combined with implants in the MT that serve to decrease nonaxial loads of permanent restorations.

\subsection{Bone Grafting and Harvesting from the Tuberosity}

Loss of osseous tissue from trauma, infection, or genetic resorption leads to low bone density that cannot support implants, and consequently, implantsupported restorations. Traditionally, intraoral sites of autogenous bone block grafts, such as the symphysis and ramus have been used to supplement alveolar ridges with deficiencies prior to implant placement [6]. Although the tuberosity serves as a candidate for direct implant fixation, when bone volume is abundant, this maxillary region can be manipulated with the use of various instruments to serve as an additional bone harvesting site to alleviate these deficiencies in cases of subpar bone mass for implant support. This is particularly critical as the MT frequently fails to be recognized as a bone graft source during implantation assessment. Typical CBCT scans and panoramic imaging can provide enough pre-operative assessment of the MT to determine if bone volume is appropriate for grafting $[5,52]$. Removal of bone from the MT is the least invasive alternative for intraoral grafting and would not require any extensive repair at the donor site while providing more than adequate bone volume to be used anteriorly to correct ridge deficiencies. This site has become a strong candidate as a grafting source in Immediate Dentoalveolar Restoration (IDR) of compromised sockets, 
where the cortico-cancellous graft can be shaped to the size of the distant defect and inserted to bolster bone mass [4,53]. Amongst autogenous bone sources, the greatest vertical gains are frequently seen from MT blocks compared to composite grafts in localized bone deficiencies $[7,54,55]$. The biological properties of a patient's own bone are enhanced when used as a grafting material, as the autogenous bone contains a wealth of bone marrow with great potential for angiogenesis (Figs. 3, 4). Autogenous bone is the optimal choice in larger block grafts due to its osseoinductive and osteogenic properties compared to that of xenografts, allogeneic, or alloplastic (synthetic) options [6,56-58]. Bone harvested from the MT (Fig. 5) can also be combined with other grafting materials to form composite grafts. In situations where only minimal amounts of hard tissue can be harvested from the MT, biomaterials may be used to supplement (Fig. 6). Bone substitutes, when embedded in osteoprogenitor cells of the MT, provide adequate bone formation in vivo [59]. Employment of composite grafts using biomaterials and autogenous tuber bone expands patient candidacy by reducing the total amount of patient bone required for grafting procedures, while still retaining the benefits of utilizing autogenous tissue. In this respect, the hard tissue of the MT can be manipulated in a plethora of ways to overcome the problems of bone deficiency throughout the maxilla. Different surgical alternatives for bone augmentation in post-extraction compromised sockets have been described [60]. However, some of these techniques require longer periods for rehabilitation and are usually expensive [61]. The Immediate Dento-alveolar Restoration (IDR), a one-stage technique, allows dental extraction, implantation, and provisionalization to occur in the same procedure as the flapless bone reconstruction using cortico-cancellous bone graft harvested from the maxillary tuberosity [62]. The IDR technique, aside from presenting lower overall costs and treatment time, has been shown clinically and radiographically to be effective with respect to soft and hard tissue stability in compromised sockets [63]. The advantages of IDR include: ease of tuberosity harvest, the malleability of bone fragment which allows adequate adaptation to the receptor region, and the biological membranous properties of the cortico-cancellous graft that promote effective bone and gingival healing. Furthermore, the trabecular nature of grafts harvested from the maxillary tuberosity contribute to increase revascularization capacity and to release growth factors to the receptor site [64]. Bone density at the buccal, palatal, and basal cortical maxillary tuberosity is less compared to other maxillary and mandibular bone locations. Due to the decreased thickness of its cortical bone, maxillary tuberosity grafts are easily shaped, yet its cortical structure can act as a biological barrier stabilizing the soft tissue and particulate bone graft around the implant
[65]. The total porosity and porous volume of these grafts indicate that the cortico-cancellous structure can act as a scaffold structure for cellular and vascular growth. Additionally, the maxillary tuberosity is a source of osteoprogenitor cells and growth factors [66]. Taken together, the cortical and cancellous bone from the maxillary tuberosity can be considered as an ideal structure for bone regeneration, as it is a natural scaffold filled with osteoblastic cells and growth factors [67].

\subsection{Soft Tissue Grafting and Harvesting from the Tuber Region}

The palatal area most commonly serves as the primary donor site for soft tissue grafts in cases of root coverage. This is not always the case with patients with diminished size, thickness, or rate of blood flow of the greater palatal artery which can lead to limited quantities of connective tissue available for harvest. The MT has been associated with connective tissue that can be used as an autogenous graft for soft tissue augmentation around implants (Fig. 7) simultaneously or secondarily with implant placement [4]. The gingival cuff of the MT has been shown as an excellent source of soft tissue to provide full, lasting coverage in more anterior regions of both the maxilla and mandible [3]. Transplantation of tuberosity connective tissue onto the aesthetic anterior gingival cuff demonstrated an improvement of the tissue biotype over a healing period to match the surrounding gingival tissue in texture and color [3]. Additionally, soft tissue grafting from the MT has been shown to be easier than grafting from the palatal masticatory mucosa $[3,68]$. Subepithelial connective tissue can simply be harvested from the MT and sutured within a pouch in areas of localized gingival recession with little to no complications to treat buccal soft tissue dehiscence around single implants [69-70].

This can fully or partially alleviate aesthetic exposure of implant threads due to bone loss around the fixture. Soft tissues of the MT can be employed throughout the oral cavity in a similar way as other traditional gingival grafts with similar success rates.

\section{Conclusions}

There are high success rates of dental implants placed in the MT, which can provide a stable and predictable alternative to the traditional major grafting procedures required to stabilize implants in bonedeficient maxillary areas anterior to the tuberosity. Proper placement of implants in this region with the correct surgical techniques, especially local bone condensing, can provide support of the prostheses in patients without complex grafting procedures. Bone and soft tissue harvested from the maxillary tuberosity provides many advantages and serves as an outstanding reservoir of tissue with excellent regeneration capacity. 


\section{Author Contributions}

NM and GR: wrote and edited the manuscript. JMR and LAP: provided the information about the Immediate Dento-alveolar Restoration (IDR) and supported with photographic documentation.

\section{References}

1. Lekholm U, Zarb GA. Patient selection and preparation. In: Brånemark PI, Zarb GA, Albrektsson T, eds. Tissue-integrated Prostheses: Osseointegration in Clinical Dentistry. Chicago, IL: Quintessence Publishing Co.; 1985:199-209.

2. Lekholm U, Gunne J, Henry $P$, et al. Survival of the Brånemark implant in partially edentulous jaws: a 10-year prospective multicenter study. Int J Oral Maxillofac Implants. 1999;14(5):639-645.

[PubMed] Google Scholar Scopus

3. Jung UW, Um YJ, Choi SH. Histologic observation of soft tissue acquired from maxillary tuberosity area for root coverage. J Periodontol. 2008;79(5):934-940. [Full text links] [CrossRef] [PubMed] Google Scholar Scopus

4. da Rosa JC, Rosa AC, Fadanelli MA, Sotto-Maior BS. Immediate implant placement, reconstruction of compromised sockets, and repair of gingival recession with a triple graft from the maxillary tuberosity: A variation of the immediate dentoalveolar restoration technique. J Prosth Dent. 2014;112(4):717-722.

[Full text links] [CrossRef] [PubMed] Google Scholar Scopus

5. Singh S. Management of infrabony defects in mandibular molars in a patient with generalized aggressive periodontitis using autogenous bone graft from maxillary tuberosity. $J$ Indian Soc Periodontol. 2010;14(1):53-56.

[Full text links] [CrossRef] [PubMed] Google Scholar

6. Tolstunov L. Maxillary tuberosity block bone graft: innovative technique and case report. J Oral Maxillofac Surg. 2009;67(8):1723-1729.

[Full text links] [CrossRef] [PubMed] Google Scholar Scopus

7. Jensen J, Simonsen EK, Sindet-Pedersen S. Reconstruction of the severely resorbed maxilla with bone grafting and osseointegrated implants: a preliminary report. J Oral Maxillofac Surg. 1990;48(1):27-32; discussion 33.

[Full text links] [CrossRef] [PubMed] Google Scholar Scopus

8. Jaffin RA, Berman $\mathrm{CL}$. The excessive loss of Brånemark fixtures in type IV bone: a 5-year analysis. J Periodontol. $1991 ; 62(1): 2-4$.

[Full text links] [CrossRef] [PubMed] Google Scholar Scopus

9. Krogh PH. Anatomic and surgical considerations in the use of osseointegrated implants in the posterior maxilla. Oral Maxillofac Surg Clin North Am. 1991;3(4):853-868.

10. Candel E, Peñarrocha $D$, and Peñarrocha $M$. Rehabilitation of the atrophic posterior maxilla with pterygoid implants: A Review. J Oral Implantol. 2012;38 Spec No:461-466.

[Full text links] [CrossRef] [PubMed] Google Scholar Scopus

11. Goiato MC, dos Santos DM, Santiago JF Jr, et al. Longevity of dental implants in type IV bone: a systematic review. Int J Oral Maxillofac Surg. 2014;43(9):1108-1116.

[Full text links] [CrossRef] [PubMed] Google Scholar Scopus

12. Bahat O. Osseointegrated implants in the maxillary tuberosity: report on 45 consecutive patients. Int J Oral Maxillofac Implants. 1992;7(4):459-467.

[CrossRef] [PubMed] Google Scholar Scopus

13. Krämer $A$, Weber $H$, Benzing U. Implant and prosthetic treatment of the edentulous maxilla using a bar-supported prosthesis. Int J Oral Maxillofac Implants. 1992;7(2):251-255. [CrossRef] [PubMed] Google Scholar Scopus

14. Venturelli A. A modified surgical protocol for placing implants in the maxillary tuberosity: clinical results at 36 months after loading with fixed partial dentures. Int J Oral Maxillofac Implants. 1996;11(6):743-749. [PubMed] Google Scholar Scopus

15. Nocini PF, Albanese M, Fior A, De Santis D. Implant placement in the maxillary tuberosity: the Summers' technique performed with modified osteotomes. Clin Oral Implants Res. 2000;11(3):273-278.

[Full text links] [CrossRef] [PubMed] Google Scholar Scopus

16. Markt JC. Implant prosthodontic rehabilitation of a patient with nevoid basal cell carcinoma syndrome: a clinical report. J Prosthet Dent. 2003;89(5):436-442.

[Full text links] [CrossRef] [PubMed] Google Scholar Scopus

\section{Acknowledgments}

There is no conflict of interest.
17. Alves CC, Neves M. Tapered implants: from indications to advantages. Int $J$ Periodontics Restorative Dent 2009;29(2):161-167.

[PubMed] Google Scholar Scopus

18. Ridell A, Gröndahl K, Sennerby L. Placement of Brånemark implants in the maxillary tuber region: anatomical considerations, surgical technique and long-term results. Clin Oral Implants Res. 2009;20(1):94-98.

[Full text links] [CrossRef] [PubMed] Google Scholar Scopus

19. Leles CR, Leles JL, de Paula Souza C, et al. Implant-supported obturator overdenture for extensive maxillary resection patient: a clinical report. J Prosthodont. 2010;19(3):240-244. [Full text links] [CrossRef] [PubMed] Google Scholar Scopus

20. Park YJ, Cho SA. Retrospective chart analysis on survival rate of fixtures installed at the tuberosity bone for cases with missing unilateral upper molars: a study of 7 cases. $J$ Oral Maxillofac Surg. 2010;68(6):1338-1344

[Full text links] [CrossRef] [PubMed] Google Scholar Scopus

21. Shirota T, Shimodaira O, Matsui Y, et al. Zygoma implantsupported prosthetic rehabilitation of a patient with a maxillary defect.Int JOralMaxillofac Surg. 2011;40(1):113-117. [Full text links] [CrossRef] [PubMed] Google Scholar Scopus

22. Khayat $P$, Nader $N$. The use of osseointegrated implants in the maxillary tuberosity. Pract Periodontics Aesthet Dent 1994;6(4):53-61; quiz 62 Google Scholar Scopus

23. Park HS, Lee YJ, Jeong SH, Kwon TG. Density of the alveolar and basal bones of the maxilla and the mandible. Am Orthod Dentofacial Orthop. 2008;133(1):30-37.

[Full text links] [CrossRef] [PubMed] Google Scholar Scopus

24. Yamaura T, Abe S, Tamatsu Y, et al. Anatomical study of the maxillary tuberosity in Japanese men. Bull Tokyo Dent Coll. 1998;39(4):287-292.

[PubMed] Google Scholar Scopus

25. Mattsson T, Köndell PA, Gynther GW, et al Implant treatment without bone grafting in severely resorbed edentulous maxillae. J Oral Maxillofac Surg. 1999;57(3):281-287.

[Full text links] [CrossRef] [PubMed] Google Scholar Scopus

26. Krekmanov L. Placement of posterior mandibular and maxillary implants in patients with severe bone deficiency: a clinical report of procedure. Int J Oral Maxillofac Implants. 2000:15(5):722-730.

[PubMed] Google Scholar Scopus

27. Aparicio C, Perales $P$, Rangert B. Tilted implants as an alternative to maxillary sinus grafting: a clinical, radiologic, and periotest study. Clin Implant Dent Relat Res. 2001;3(1):3949.

[Full text links] [CrossRef] [PubMed] Google Scholar Scopus

28. Lopes LF, da Silva VF, Santiago JF Jr, et al. Placement of dental implants in the maxillary tuberosity: a systematic review. Int. J Oral Maxillofac Surg. 2015;44(2):229-238.

[Full text links] [CrossRef] [PubMed] Google Scholar Scopus

29. Balshi TJ. Single, tuberosity-osseointegrated implant support for a tissue-integrated prosthesis. Int J Periodontics Restorative Dent. 1992;12(5):345-357.

[PubMed] Google Scholar Scopus

30. Alghamdi H, Anand PS, Anil S. Undersized implant site preparation to enhance primary implant stability in poor bone density: a prospective clinical study. J Oral Maxillofac Surg. 2001;69(12):e506-e512.

[Full text links] [CrossRef] [PubMed] Google Scholar Scopus

31. Blanco J, Suárez J, Novio $S$, et al. Histomorphometric assessment in human cadavers of the peri-implant bone density in maxillary tuberosity following implant placement using osteotome and conventional techniques. Clin Oral Implants Res. 2008;19(5):505-510.

[Full text links] [CrossRef] [PubMed] Google Scholar Scopus

32. Tabassum A, Meijer GJ, Wolke JG, Jansen JA. Influence of the surgical technique and surface roughness on the primary stability of an implant in artificial bone with a density equivalent to maxillary bone: a laboratory study. Clin Oral 
Implants Res. 2009;20(4):327-332.

[Full text links] [CrossRef] [PubMed] Google Scholar Scopus

33. Ahn SJ, Leesungbok R, Lee SW, et al. Differences in implant stability associated with various methods of preparation of the implant bed: an in vitro study. J Prosthet Dent. 2012;107(6):366-372.

[Full text links] [PubMed] Google Scholar Scopus

34. de Faria Almeida DA, Pellizzer EP, Verri FR, et al. Influence of tapered and external hexagon connections on bone stresses around tilted dental implants: three-dimensional finite element method with statistical analysis. J Periodontol. 2014;85(2):261-269.

[Full text links] [CrossRef] [PubMed] Google Scholar Scopus

35. Marković A, Ćalsan D, Čolić S, et al. Implant stability in posterior maxilla: bone-condensing versus bone-drilling: a clinical study. Oral Surg Oral Med Oral Pathol Oral Radiol Endod. 2011;112(5):557-563.

[Full text links] [CrossRef] [PubMed] Google Scholar Scopus

36. Huwais S, Meyer EG. A novel osseous densification approach in implant osteotomy preparation to increase biomechanical primary stability, bone mineral density, and bone-to-implant contact. Int J Oral Maxillofac Implants. 2017;32(1):27-36. [Full text links] [CrossRef] [PubMed] Google Scholar Scopus

37. Ekfeldt A, Christiansson U, Eriksson T, et al. A retrospective analysis of factors associated with multiple implant failures in maxillae. Clin Oral Implants Res. 2001;12(5):462-467.

[Full text links] [CrossRef] [PubMed] Google Scholar Scopus

38. Misch CE. Progressive loading of bone with implant prostheses. J Dent Symp. 1993;1:50-53.

[CrossRef] Google Scholar Scopus

39. Romanos GE, Grizas E, Laukart E, Nentwig GH. Effects of early moderate loading on implant stability: a retrospective investigation of 634 implants with platform switching and morse-tapered connections. Clin Implant Dent Relat Res. 2016;18(2):301-309.

[Full text links] [CrossRef] [PubMed] Google Scholar Scopus

40. Albrektsson $\mathrm{T}$, Brånemark $\mathrm{PI}$, Hansson $\mathrm{HA}$, Lindström J. Osseointegrated titanium implants. Requirements for ensuring a long-lasting, direct bone-to-implant anchorage in man. Acta Orthop Scand. 1981;52(2):155-170.

[CrossRef] [PubMed] Google Scholar Scopus

41. Bal BT, Cağlar A, Aydin C, et al. Finite element analysis of stress distribution with splinted and nonsplinted maxillary anterior fixed prostheses supported by zirconia or titanium implants. Int J Oral Maxillofac Implants. 2013;28(1):e27-e38. [CrossRef] Google Scholar Scopus

42. Tulasne JF. Osseointegrated fixtures in the pterygoid region In:Worthington P, Brånemark PI, eds. Advanced Osseointegration Surgery. Applications in the Maxillofacial Region. Chicago, IL: Quintessence Publishing Co Ltd; 1992: 182-188.

43. Graves SL. The pterygoid plate implant: a solution for restoring the posterior maxilla. Int J Periodontics Restorative Dent. 1994;14(6):512-523.

[PubMed] Google Scholar Scopus

44. Lee SP, Paik KS, Kim MK. Anatomical study of the pyramidal process of the palatine bone in relation to implant placement in the posterior maxilla. J Oral Rehabil. 2001;28(2):125-132. [Full text links] [CrossRef] [PubMed] Google Scholar Scopus

45. Rodríguez X, Méndez V, Vela X, Segalà M. Modified surgical protocol for placing implants in the pterygomaxillary region: clinical and radiologic study of 454 implants. Int J Oral Maxillofac Implants. 2012;27(6):1547-1553. [PubMed] Google Scholar Scopus

46. Balshi TJ, Wolfinger GJ, Slauch RW, Balshi SF. Brånemark system implant lengths in the pterygomaxillary region: a retrospective comparison. Implant Dent. 2013;22(6):610-612. [Full text links] [CrossRef] [PubMed] Google Scholar Scopus

47. Balshi TJ, Wolfinger GJ, Balshi SF 2nd. Analysis of 356 pterygomaxillary implants in edentulous arches for fixed prosthesis anchorage. Int J Oral Maxillofac Implants. 1999;14(3):398-406

[PubMed] Google Scholar Scopus

48. Vrielinck L, Politis C, Schepers S, et al. Image-based planning and clinical validation of zygoma and pterygoid implant placement in patients with severe bone atrophy using customized drill guides. Preliminary results from a prospective clinical follow-up study. Int J Oral Maxillofac Surg. 2003;32(1):7-14. [Full text links] [PubMed] Google Scholar Scopus

49. Curi MM, Cardoso $\mathrm{CL}$, Ribeiro Kde C. Retrospective study of pterygoid implants in the atrophic posterior maxilla: implant and prosthesis survival rates up to 3 years. Int J Oral Maxillofac Implants. 2015;30(2):378-383.

[Full text links] [CrossRef] [PubMed] Google Scholar Scopus
50. Bidra AS, Huynh-Ba G. Implants in the pterygoid region: a systematic review of the literature. Int J Oral Maxillofac Surg. 2011;40(8):773-781.

[Full text links] [CrossRef] [PubMed] Google Scholar Scopus

51. Lombardo G, Pardo A Mascellaro A et al Rehabilitation of severely resorbed maxillae with zygomatic implants: a literature review. Stoma Edu J. 2015;2(1):69-78.

52. Murakami I, Murakami Y, Kopp CD, et al. Panoramic implant notation system--a method to denote implant positions and prosthodontic modalities. J Prosthodont Res. 2012;56(1):65-69. [Full text links] [CrossRef] [PubMed] Google Scholar Scopus

53. da Rosa JC, Rosa AC, da Rosa DM, Zardo CM. Immediate Dentoalveolar Restoration of compromised sockets: a novel technique. Eur J Esthet Dent. 2013;8(3):432-443.

[Full text links] [CrossRef] [PubMed] Google Scholar Scopus

54. Gross BD, James RB, Fister J. Use of pocket inlay grafts and tuberoplasty in maxillary prosthetic construction. J Prosthet Dent. 1980;43(6):649-653.

[Full text links] [CrossRef] [PubMed] Google Scholar Scopus

55. Khojasteh A, Behnia H, Shayesteh YS, et al. Localized bone augmentation with cortical bone blocks tented over different particulate bone substitutes: a retrospective study. Int J Oral Maxillofac Implants. 2012;27(6):1481-1493. [PubMed] Google Scholar Scopus

56. KellerEE, van Roekel NB, Desjardins RP, Tolman DE Prosthetic surgical reconstruction of the severely resorbed maxilla with iliac bone grafting and tissue-integrated prostheses. Int $J$ Oral Maxillofac Implants. 1987;2(3):155-165.

[PubMed] Google Scholar

57. Kahnberg KE, Nilsson P, Rasmusson L. Le Fort I osteotomy with interpositional bone grafts and implants for rehabilitation of the severely resorbed maxilla: a 2-stage procedure. Int J Oral Maxillofac Implants. 1999;14(4):571-578.

[PubMed] Google Scholar Scopus

58. Simion M, Fontana F. Autogenous and xenogeneic bone grafts for the bone regeneration. A literature review. Minerva Stomatol. 2004;53(5):191-206. [PubMed] Google Scholar Scopus

59. Srouji $S$, Ben-David D, Funari $A$, et al. Evaluation of the osteoconductive potential of bone substitutes embedded with schneiderian membrane- or maxillary bone marrowderived osteoprogenitor cells. Clin Oral Implants Res. 2013:24(12):1288-1294.

[Full text links] [CrossRef] [PubMed] Google Scholar Scopus

60. Schneider D, Grunder U, Ender A, et al. Volume gain and stability of peri-implant tissue following bone and soft tissue augmentation: 1-year results from a prospective cohort study. Clin Oral Implants Res. 2011;22(1):28-37.

[Full text links] [CrossRef] [PubMed] Google Scholar Scopus

61. Buser D, Chappuis V, Bornstein MM, et al. Long-term stability of contour augmentation with early implant placement following single tooth extraction in the esthetic zone a prospective, cross-sectional study in 41 patients with a 5- to 9-year follow- up. J Periodontol. 2013;84(11):1517-1527. [Full text links] [CrossRef] [PubMed] Google Scholar Scopus

62. Rosa JC, Rosa AC, Rosa DM, Zardo CM. Immediate Dentoalveolar Restoration of compromised sockets: a novel technique. Eur J Esthet Dent. 2013;8(3):432-443.

[Full text links] [CrossRef] [PubMed] Google Scholar Scopus

63. Rosa JC, Rosa AC, Francischone CE, Sotto-Maior BS. Esthetic outcomes and tissue stability of implant placement in compromised sockets following immediate dentoalveolar restoration: results of a prospective case series at 58 months followup. Int J Periodontics Restorative Dent. 2014;34(2):199-208.

[Full text links] [CrossRef] [PubMed] Google Scholar Scopus

64. Rosa AC, da Rosa JC, Dias Pereira LA, et al. Guidelines for selecting the implant diameter during immediate implant placement of a fresh extraction socket: a case series. Int $J$ Periodontics Restorative Dent. 2016;36(3):401-407. [Full text links] [CrossRef] [PubMed] Google Scholar Scopus

65. da Rosa JC, Rosa AC, Fadanelli MA, Sotto-Maior BS. Immediate implant placement, reconstruction of compromised sockets, and repair of gingival recession with a triple graft from the maxillary tuberosity: a variation of the immediate dento-alveolar restoration technique. J Prosthet Dent. 2014; 112(4):717-722.

[CrossRef] Google Scholar

66. Cicconetti A, Sacchetti B, Bartoli A, et al. Human maxillary tuberosity and jaw periosteum as sources of osteoprogenitor cells for tissue engineering. Oral Surg Oral Med Oral Pathol Oral Radiol Endod. 2007; 104(5):618.e1-e12.

[Full text links] [CrossRef] [PubMed] Google Scholar Scopus

67. Rosa JC, Rosa AC, Francischone CE, Sotto-Maior BS. Esthetic outcomes and tissue stability of implant placement in 
compromised sockets following immediate dento-alveolar restoration: results of a prospective case series at 58 months follow-up. Int J Periodontics Restorative Dent. 2014;34(2):199-208. [CrossRef] Google Scholar

68. de Molon RS, de Avila ED, de Barros-Filho LA, et al. Reconstruction of the alveolar buccal bone plate in compromised fresh socket after immediate implant placement followed by immediate provisionalization. J Esthet Restor Dent. 2015;27(3):122-135.

[Full text links] [CrossRef] [PubMed] Google Scholar Scopus
69. Nizam N, Akcalı A. Vestibular unit transplantation in the coverage of gingival recession: a microsurgical approach. Int J Esthet Dent. 2014;9(4):516-524.

[PubMed] Google Scholar Scopus

70. Roccuzzo M, Gaudioso L, Bunino M, Dalmasso P. Surgical treatment of buccal soft tissue recessions around single implants: 1-year results from a prospective pilot study. Clin Oral Implants Res. 2014;25(6):641-646.

[Full text links] [CrossRef] [PubMed] Google Scholar Scopus

Nicholas MONTANARO

DDS

Department of Periodontology

School of Dental Medicine

Stony Brook University

Stony Brook, NY, USA

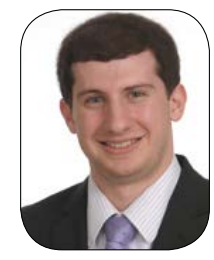

Nicholas Montanaro is an Oral and Maxillofacial Surgery resident within the Northwell Health System. He completed his undergraduate studies in Cell and Molecular Biology at the Hofstra University, Long Island, New York and later went on to earn his DDS degree from the Stony Brook University, Stony Brook, NY, USA. His current research focuses on the advancement of innovative dental implant technologies, development of regenerative biomaterials, and management of peri-implant disease.

\section{ouestions}

\section{Can maxillary tuberosity be used for implant placement?}

a. After panoramic radiographic evaluation?

ab. After occlusal radiograph?

ac. After CBCT?

$\square$ d. After periapical radiograph of the region?

\section{Tilted implants are associated with more failures and crestal bone loss:}

$\square$ a. The statement is not correct in case of supracrestal placement;

ab. The statement is not correct in case of subcrestal placement;

$\square c$. The statement is not correct in bruxers;

ad. The statement is not correct.

\section{An autogenous graft can be harvested from the}

口a. Tuberosity;

b. Chin region;

ac. Ramus;

$\square$ d. All of the above.

\section{Soft tissue augmentation as a free gingival graft from the tuberosity is recommended compared to the area of hard palate}

$\square$ a. For improvement of aesthetics;

b. To eliminate risks of bleeding;

ac. To increase thickness volume;

$\square$ d. All of the above. 


\section{Is it real, or is it Celtra?}
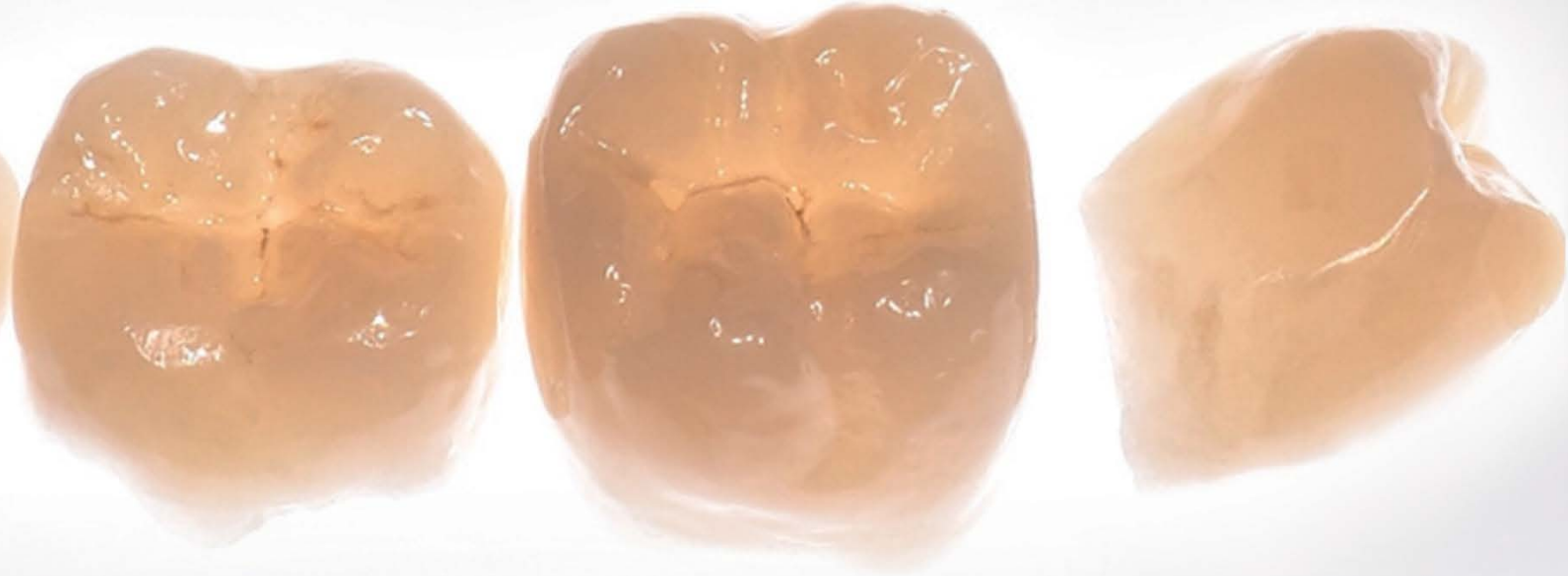

\section{Celtra}

Zirconia - Reinforced Lithium Silicate (ZLS)

A unique class of high strength glass ceramics Developed to make a difference

- Natural opalescence and translucency provides a chameleon effect that blends in seamlessly with surrounding dentition

- Exceptional margin integrity and high strength you can rely on*

- Easy to adjust and polish chairside

- Radiopacity shows sealed margins

Available for chairside milling with CEREC $^{\circledR}$, and now also at dental labs nationwide!

celtra-dentsplysirona.com

*Bending strength testing by Justus-Liebig, University of Giessen, Germany

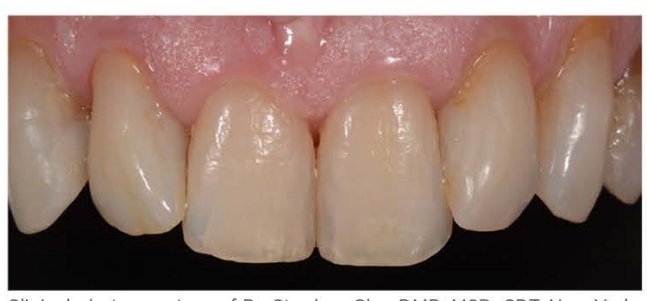

Clinical photo courtesy of Dr. Stephen Chu, DMD, MSD, CDT, New York USA. Full contour Celtra tooth \#7. Adam J. Mieleszko, CDT, SDNY (Synergistic Dentistry of New York).

Celtra Microstructure Competitive Microstructure

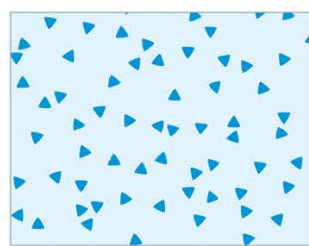

Zirconia-reinforced Lithium Silicate crystallites 500-1,400 nm

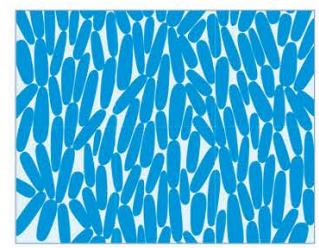

Conventional lithium disilicate crystallites 2000-4000 nm
To learn more, request a free Celtra Clinical Information Kit at Celtralnfo.com 


\title{
DIGITAL WORKFLOW FOR VIRTUALLY DESIGNING AND PRESSING ULTRA-THIN LITHIUM-DISILICATE VENEERS FOR ESTHETIC REHABILITATION OF FRACTURED MAXILLARY INCISORS - A CASE REPORT
}

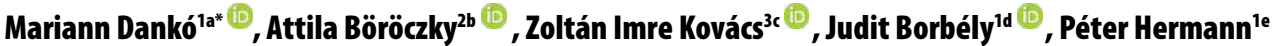

'Department of Prosthodontics, Faculty of Dentistry, Semmelweis University, Budapest, Hungary

IIndependent Óvár Dental Technology Kkt., Hungary

${ }^{3}$ Department of General Dental Preclinical Practice, Faculty of Dentistry, Semmelweis University, Budapest, Hungary

aDMD, Resident

bT

DMD

dDMD, PhD

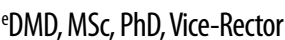

\section{ABSTRACT \\ DOI: https://doi.org/10.25241/stomaeduj.2019.6(4).art.6}

Aim: The aim of this case report is to explain the clinical and laboratory procedures for fabricating ultra-thin lithium-disilicate pressed veneers using a mixed analog/ digital workflow.

Summary: Four ultra-thin pressed lithium-disilicate veneers were produced for maxillary fractured incisors with the help of virtual smile design, digital wax-up and intraoral mock-up. With initial photos from the patient, the smile design could be performed considering the patient's individual face form. An intraoral scan was taken for the digital wax-up, which was guided by the contour line of smile design on the face photo. A printed model and template were manufactured for the mock-up. After a guided minimally invasive preparation and digital impression, the final veneers were designed as an exact copy of the mock-up. Wax pattern was designed on computer and fabricated by milling machine. Finally, lithiumdisilicate veneers were pressed, individualized and cemented using an adhesive technique.

Key learning points: 1 . digital workflow is convenient for a predictable procedure making ultra-thin lithium-disilicate pressed veneers. 2. the virtual smile design digital wax-up - intraoral mock-up scheme presents an opportunity for effective communication with the patient and laboratory. 3. smile design software recommends an ideal smile curve for the patient with the help of definitive points and reference lines on the face. 4. guided preparation through mock-up preserves the greatest amount of enamel structure, which is important with regards to adhesive cementation. 5. when pressing lithium-disilicate veneers, a mixed analog/digital workflow using CAD and a milled wax pattern results in better physical properties and marginal fit than fully digitally milled veneers.

Keywords: Smile Design; Digital Impression; Lithium-Disilicate; Veneers;

Pressed Veneers; Adhesive Cementation.

\section{Introduction}

Working with ceramic restorations in the anterior region is still a great challenge. The number and variety of ceramic materials are increasing, offering thinner wall thicknesses with better physical and optical properties and a wide range of options when a patient needs an esthetic rehabilitation of the maxillary anterior teeth and smile. On the other hand, the patients' expectations are growing regarding not only the esthetics of the restoration

\section{OOPEN ACCESS This is an Open Access article under the CC BY-NC 4.0 license. \\ IsPeer-Reviewed Article \\ Citation: Dankó M, Böröczky A, Kovács Zl, Borbély J, Hermann P. Digital workflow for virtually designing and pressing ultra-thin lithium-disilicate veneers for esthetic rehabilitation of fractured maxillary incisors - a case report. Stoma Edu J. 2019;6(4):261-270 \\ Received: November 05, 2019 Revised December 05, 2019 Accepted: December 12, 2019 Published: December 17, 2019 \\ *Corresponding author: \\ Department of Prosthodontis, Faculty of Dentistry, Semmelweis University Street 47, 1088 Budapest, Hungary el/Fax: +36703643723 e-mail: dankomariann56@gmail.com \\ Copyright: $\odot 2019$ \\ the Editorial Council for the Stomatology Edu Journal.}

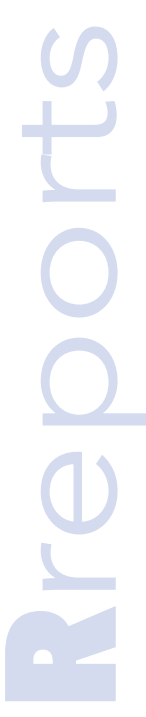




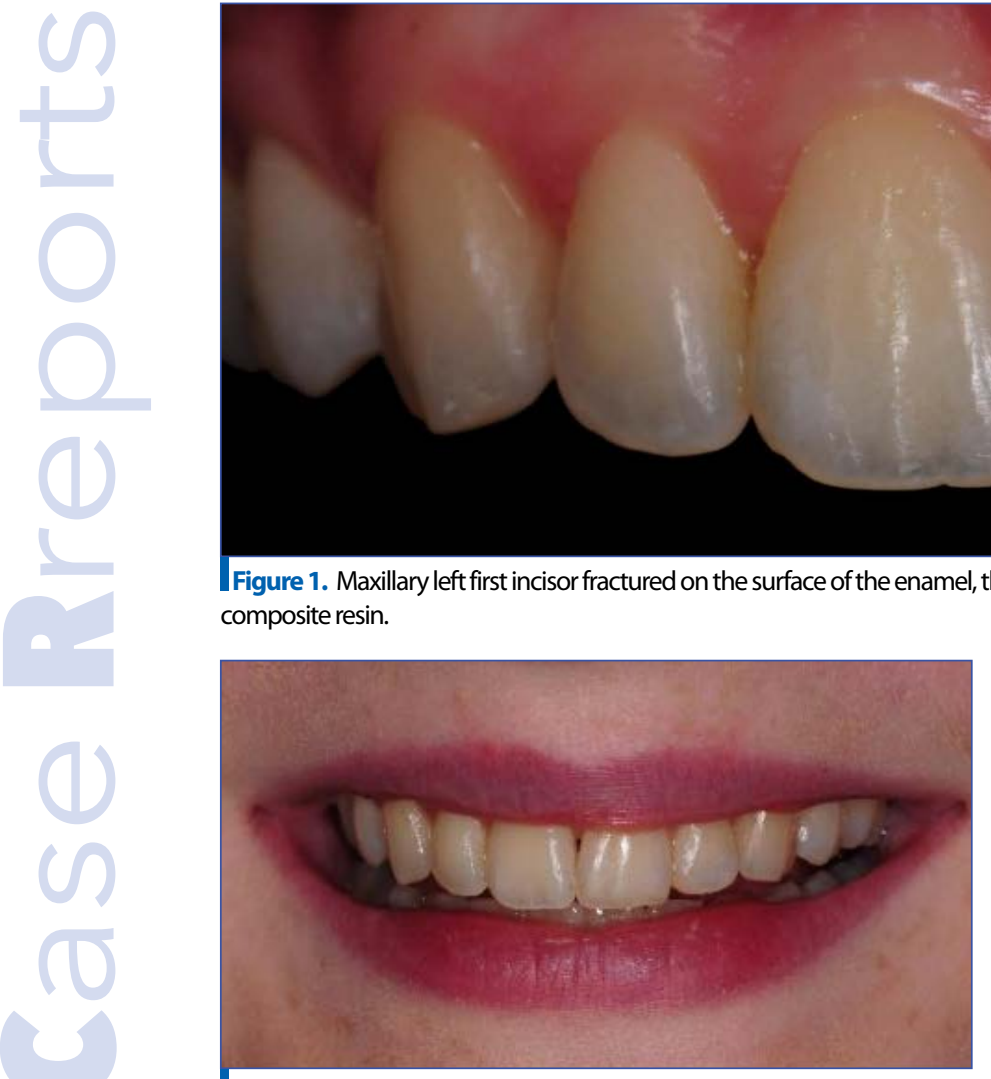

Figure 2. Initial smile photo.

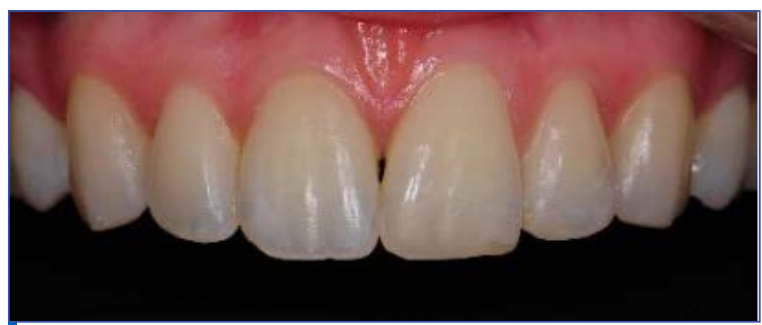

Figure 4. Bleached teeth after 6 weeks

invasive veneers $[4,5]$. The indications for these restorations include: discolored teeth after root canal treatment, tetracyclin, hypoplasia, hypercalcification or fluorosis; covering small composite restorations; closing small diastemas; completing fractured teeth or enamel chipping; altering the shape of teeth; and correcting minor orthodontic problems such as rotation [6].

A suitable material for this application is lithiumdisilicate, which can be processed either by conventional pressing or using digital milling techniques. Both are indicated for manufacturing ultra-thin veneers; however, pressed lithiumdisilicate wall thicknesses can be reduced by an extra $0.1 \mathrm{~mm}$. The minimum wall thickness for the pressed variant is $0.3 \mathrm{~mm}$ in the gingival third and $0.4 \mathrm{~mm}$ in the mid and incisal parts, while for the milled variant it is 0.4 and $0.5 \mathrm{~mm}$, respectively [7]. The Scientific Documentation by Ivoclar Vivadent $[8,9]$ and other recent studies $[10,11]$ showed that the fracture toughness of the pressed material is higher than that of the milled solution. According to Azar et al [12] the marginal fit of the pressed

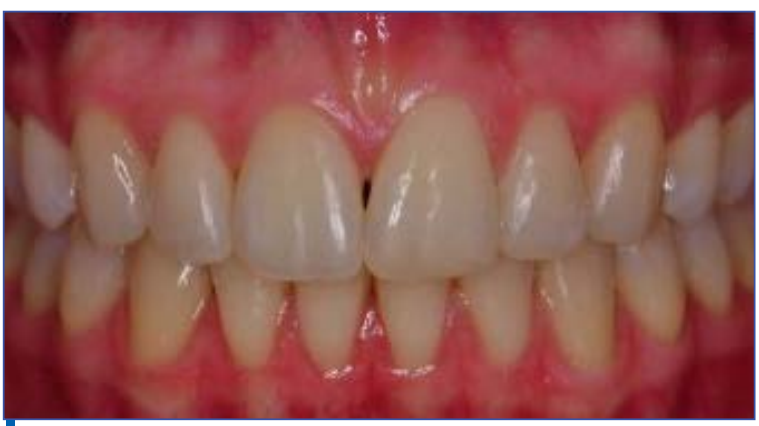

Figure 3. Initial maximal intercuspation position.

restorations is also better than milled. Overall, digital clinical and laboratory workflow is important because of the possibility it provides to design and show a new smile to the patient, and to achieve this form in the final restoration. When an impression of the prepared abutments is taken with an intraoral scanner, full digital workflow can be used with the advantage of time-efficiency, reduced discomfort for the patient, simplified clinical procedures, and better communication with the laboratory and the patient, given the trueness and precision levels comparable to conventional impressions [13].

This fully digital method to mill from a lithiumdisilicate block would be faster. Yet, despite the minimally invasive case in this study, the conventional pressing technique combined with digital workflow was preferred, because of the mentioned superior physical properties, more accurate marginal fit and mainly the reducible wall thickness of pressed lithium-disilicate restorations. This case report aims to explain the clinical and laboratory procedures for fabricating ultra-thin lithium-disilicate pressed veneers using a mixed analog/digital workflow.

\section{Case report}

2.1. Treatment plan

A 25-year-old female patient presented with a need for esthetic rehabilitation of her fractured incisors after a bicycle accident and improvement to the appearance of her smile. The mesial incisal edge of the maxillary left lateral incisor had been missing since the accident and was completed with composite 


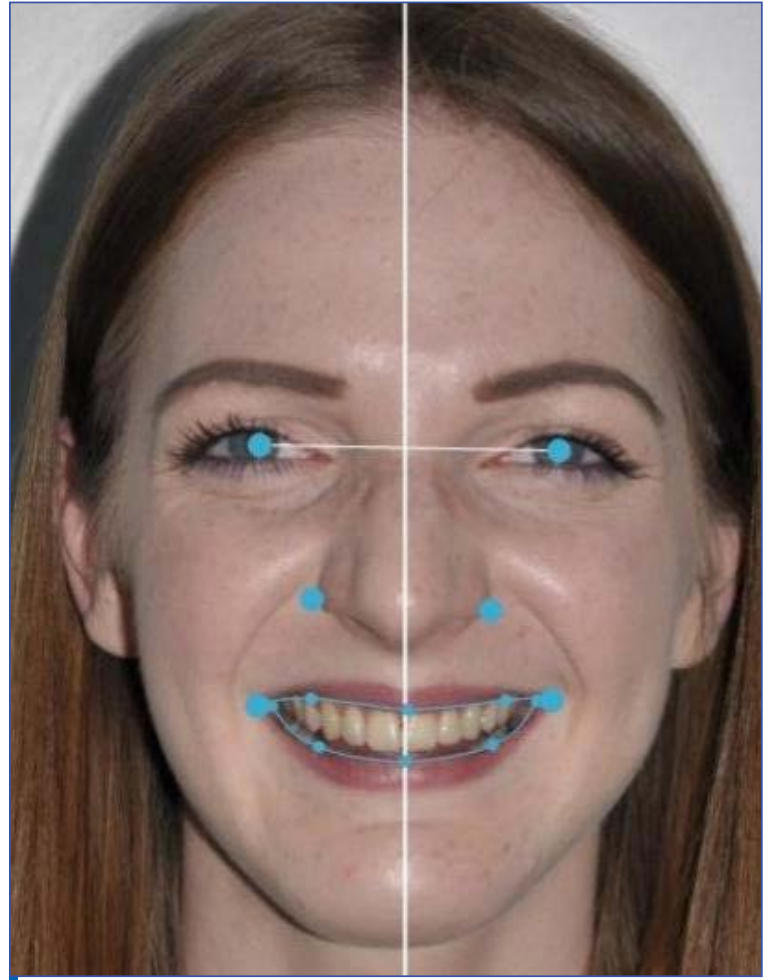

Figure 5. Imported photo and reference points in smile design program.

material as a temporary solution for 2 months. The right and left central incisors were only fractured on the surface of the enamel, but some discoloration had appeared on the left central incisor (Figs. 1-3). The treatment plan was to bleach the teeth on both arches, then to prepare her four maxillary incisors with a minimally invasive method for ultra-thin lithium-disilicate pressed veneers, which she agreed to after being informed about the benefits and risks of the treatment. The bleaching was performed by 40\% hydrogen peroxide (Opalescence Boost 40\%, Ultradent Products, South Jordan, UT, USA) and blue-light whitening accelerator lamp (Beyond Command Whitening Accelerator, Beyond European Headquarters, Zielona Gora, Poland), which resulted in B1 color (Fig. 4).

\subsection{Smile design}

A virtual smile design and an intraoral mock-up constitute the best way to show the patient the designed form of her teeth and the appearance of a new smile. It is essential that this method should give the opportunity to change and correct the form according to the patient's expectations before producing the final veneers. First, a full-face smile photo and a retracted frontal photo were needed for the smile design. After importing the photos in the smile design program (Smile Design, 3Shape, Copenhagen, Denmark), the following reference points and lines were set: pupils, nasal wings, and curve of the lips. In the next step, the two photos were aligned moving two pairs of points (Figs. 5-6). According to the reference points, the software recommended an ideal gingival and smile curve

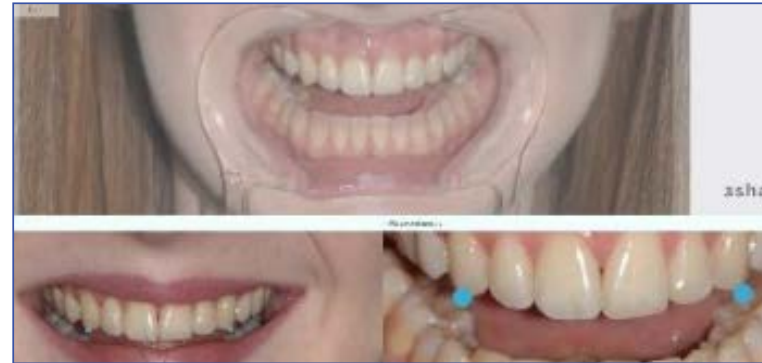

Figure 6. Aligned pictures in smile design program.

shape, which could be optionally altered. As only the incisors were planned to be altered without surgical treatment, the gingival line was replaced to the original position and the smile curve shape was repositioned to the canine-premolar line, the result being that the incisors, mainly the second are shorter than they should be (Fig. 7).

The 2D outline of the teeth was designed and the parameters (texture, color, brightness) of the smile simulation were set. The smile simulation was transferred to the patient's mobile phone through an application (my3Shape app, 3Shape, Copenhagen, Denmark), in which she could see the before and after smile situation in one picture (Fig. 8). Finally, the retracted photo with the outline of the designed teeth was exported from the software, and was used as a guide for a digital wax-up.

\subsection{Digital wax-up}

For a digital wax-up, an intraoral scan was taken from the initial status of the maxillary and mandibular arches and maximum intercuspation (Trios 3 POD, 3Shape, Copenhagen, Denmark). The intraoral scans were sent to the laboratory software (Dental System, 3Shape, Copenhagen, Denmark), in which the scans and the picture with the smile design were aligned on six pairs of points. Then the desired shape of the teeth was designed on the initial scan guided by the outline of the smile design, and a 3D printed model was produced with this design (Figs. 9-10).

\subsection{Mock-up, pre-preparation scan and preparation}

For the 3D printed model (Bego Varseo S, Bremen, Germany), a template was made and a bisacryl resin (Dental Central Crown and Bridge Material, Hannover, Germany) mock-up was fabricated intraorally (Fig. 11). The patient was satisfied with the shape and the new smile, and changes in phonetics were not noticeable. The mock-up was retained by friction and used for guided minimally invasive preparation $[4,5]$. Three calibration points were cut with round diamond burs into the incisal part for 0.4 $\mathrm{mm}$ and two calibration grooves to the vestibular surface for $0.3 \mathrm{~mm}$ reduction (Fig. 12). Then an overall reduction was performed with a chamfer diamond bur. The thickness of the mock-up was $0.1 \mathrm{~mm}$ on average, so the preparation resulted in $0.2-0.3 \mathrm{~mm}$ minimal enamel loss. The margin line was prepared first paragingivally, then by double corded sulcus 


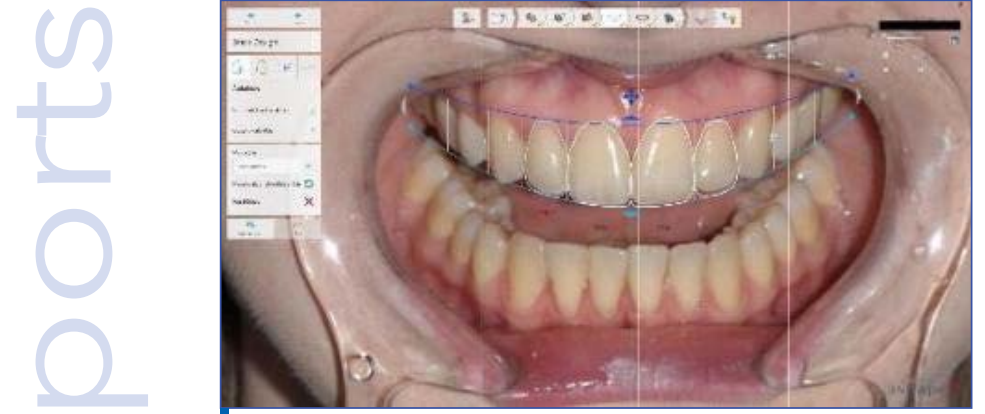

Figure 7. Ideal smile curve shape.

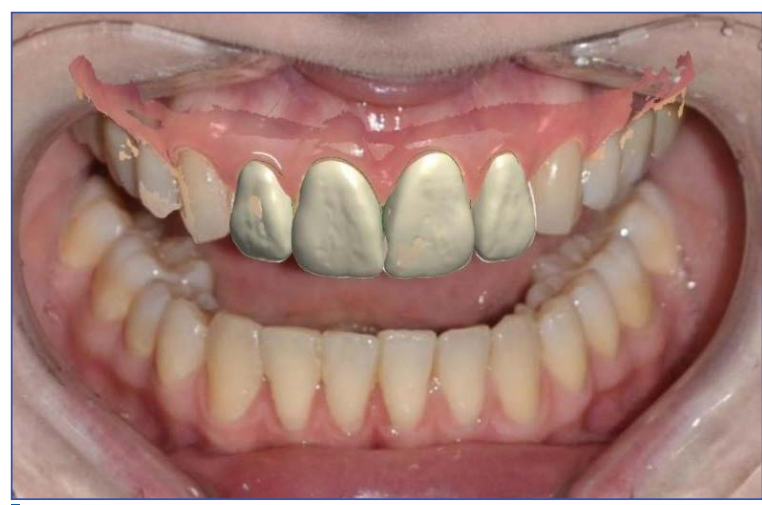

Figure 9. Digital wax-up.

retraction (Ultrapak \#00 and \#000, Ultradent, South Jordan, UT, USA) $0.5 \mathrm{~mm}$ subgingivally (Fig. 13). The enamel of the contact surfaces was reduced with the preparation of the buccal surface, however the remaining contact point was not separated directly. A new workflow was started in the software and a digital impression was made from the maxilla with a mock-up as a pre-preparation scan. For this scan, a second mock-up was fabricated for the prepared teeth (Fig. 14), because it imitated the desired thickness and marginal fit for the final veneers and resulted in a finer shape and surface so later the copy of the pre-preparation scan could perform a more accurate design for the final veneers. The second mock-up was also used as temporary veneers and retained by flow composite resin without etching and bonding.

\subsection{Digital impression}

A digital impression was taken from the prepared teeth by sulcus retraction then from the mandibular arch and maximum intercuspation. The prescription was sent to the laboratory.

\subsection{Shade measurement and material selection}

Before preparation, the right central incisor was selected as a reference tooth for shade selection. $A$ reference photo was taken with a B1 tab chosen as best match (VITA Classical shade guide, VITA Zahnfabrik, Bad Säckingen, Germany). The actual tooth shade was a bit darker than B1; the lightness level could be described with the A1 tab but with the yellow hue of a B tab (Fig. 15). After preparation, a die shade measurement was also performed; the

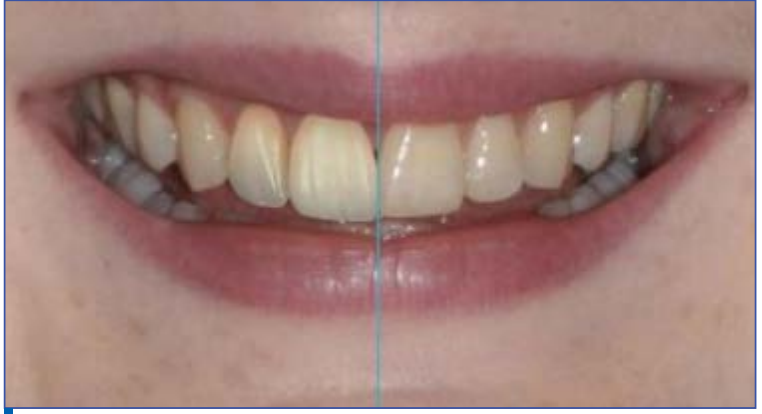

Figure 8. Smile simulation.

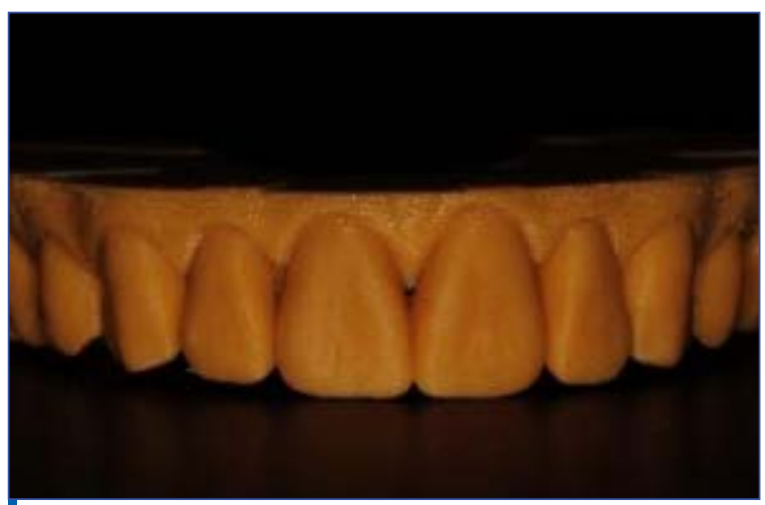

Figure 10. 3D printed model.

color was identified as ND2 (IPS Natural Die Material Shade Guide, Ivoclar Vivadent, Wien, Austria) (Fig. 16). For the $0.3 \mathrm{~mm}$ ultra-thin lithium-disilicate veneers, a medium-translucency B1 color ingot was selected (IPS e.max Press MT B1, Ivoclar Vivadent, Wien, Austria).

\subsection{Laboratory procedure}

The prescription was accepted in the laboratory design software. After margin line and insertion direction determination, the design was made by the morph to pre-preparation function of the software, which resulted in a $0.006 \mathrm{~mm}$ precise copy of the mock-up. This way, the exact same shape that the patient accepted intraorally could be transferred to the final design on the prepared teeth (Fig. 17). As we chose to produce the final restoration from pressed lithium-disilicate, the wax pattern for the pressing technique was performed by milling out the final design of the restoration from a wax block (APWhite Lemon Wax Blank, Aesthetic-Press, Düsseldorf, Germany with Zenotec Mini, Wieland Dental, Pforzheim, Germany). The wax pattern was sprued, invested (IPS PressVEST Premium, Ivoclar Vivadent, Wien, Austria) and fired out (Denkal 4B, Calory Hitech Technical Ltd., Budapest, Hungary), then pressed from the lithium disilicate block (Programat EP 3000, Ivoclar Vivadent, Wien, Austria). After checking the fit of the veneers intraorally (Fig.18), staining and glazing was made in the laboratory on 3D printed model (Fig. 19) with the patient's attendance (IPS Ivocolor Essence and Shade, Glaze Powder FLUO and Mixing Liquid Longlife, Ivoclar Vivadent, Wien, Austria). During staining, the veneers were tried in 


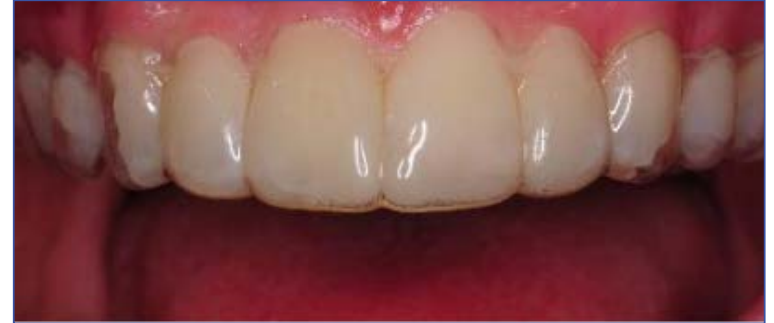

Figure 11. Template and bisacryl resin.

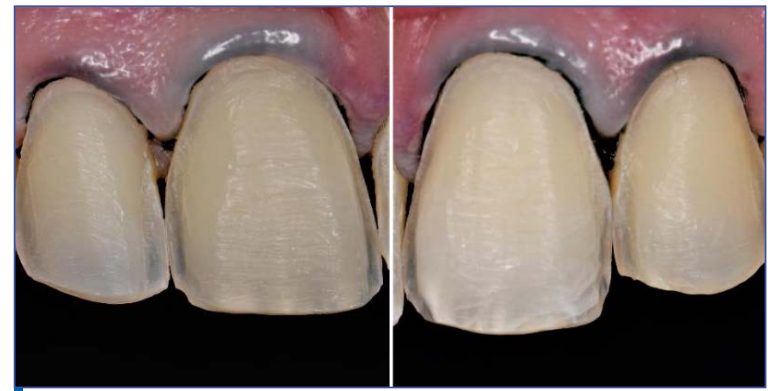

Figure 13. Prepared teeth with minimally-invasive method, sulcus retraction.

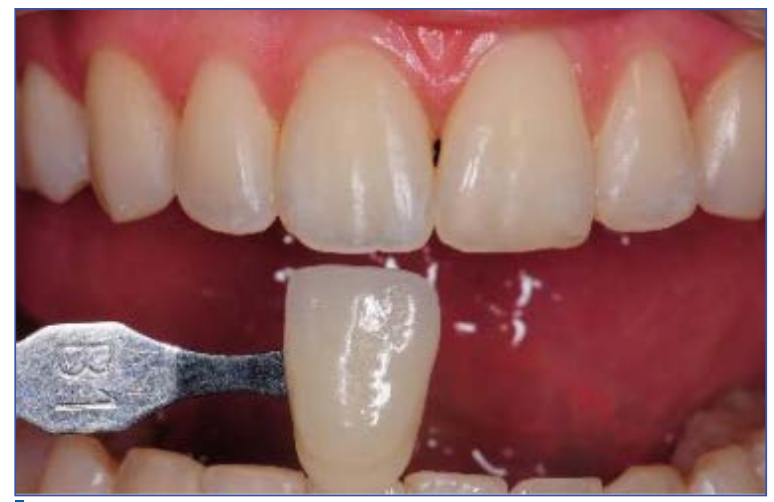

Figure 15. Shade measurement before preparation.

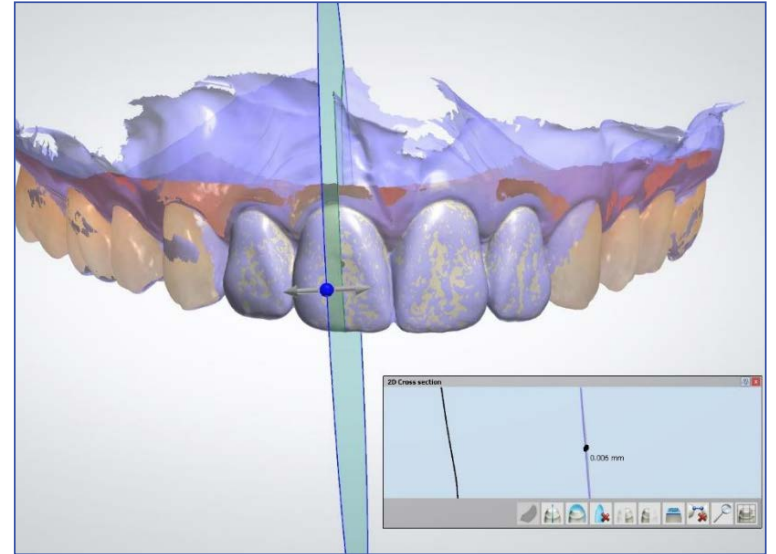

Figure 17. Virtual design of the final restoration.

with try-in paste in neutral color (Variolink Esthetic Try-In Paste Neutral, Ivoclar Vivadent, Wien, Austria)..

\subsection{Cementation}

The cementation protocol was used according to Ivoclar Vivadent's Cementation Navigation System [14]. The surfaces of the veneers were etched and silanated in one step with a primer (Monobond Etch

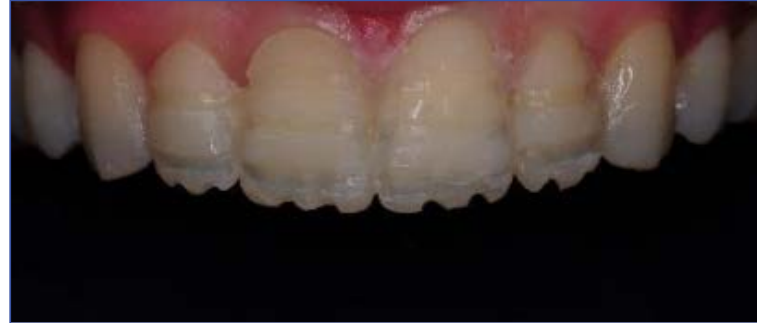

Figure 12. Calibration points and grooves.

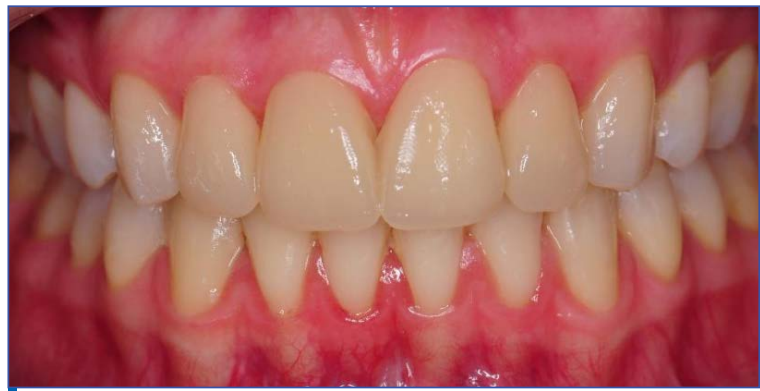

Figure 14. Intraoral mock-up after preparation.

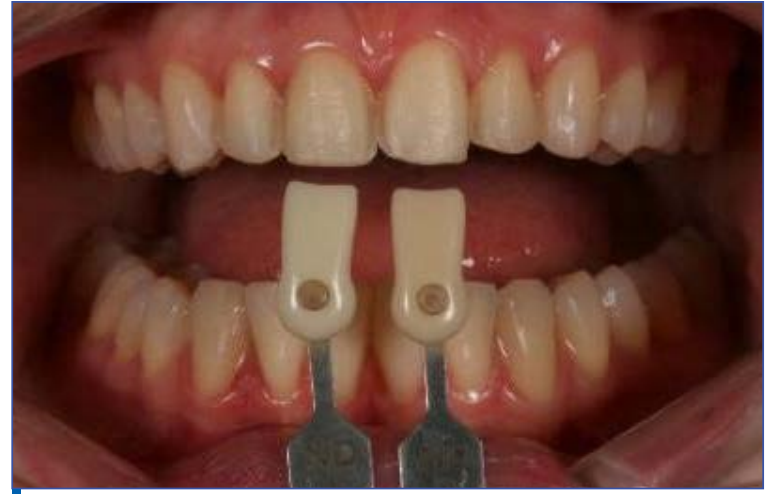

Figure 16. Die shade measurement.

\& Prime, Ivoclar Vivadent, Wien, Austria).

A sulcus retraction cord and rubber dam isolation were applied, and the teeth were prepared with the two-step total etch technique (Ultra-Etch, Ultradent Products, Cologne, Germany and $3 \mathrm{M}$ Adper Single Bond Plus Adhesive, 3M ESPE, St. Paul, MN, USA). A light-curing resin cement in the same neutral color as the try-in paste was applied for the veneers and placed in the right position (Variolink Esthetic LC Neutral, Ivoclar Vivadent, Wien, Austria). The veneers were spot-polymerized for 2 seconds for easy excess cement removal, then fully polymerized for 60 seconds on each surface [5]. The veneers were cemented one by one (Figs. 20-21). After cementation, the occlusal contact points were checked in maximal intercuspation position, by protrusion (Figs. 22-24).

\section{Discussion}

Similar case reports for smile design and ultra-thin veneers were published in the last few years $[1,4,5]$. Digital smile design was performed by designing the shape of the teeth and the gingival line in harmony with the form of the face using definite 

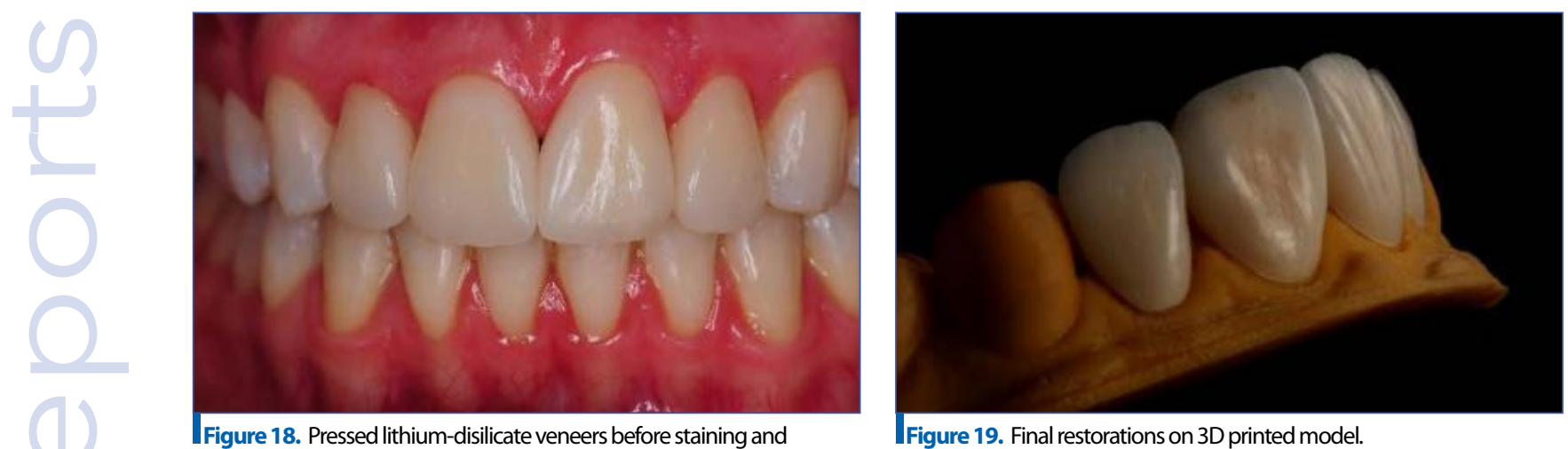

Figure 18. Pressed lithium-disilicate veneers before staining and

Figure 19. Final restorations on 3D printed model.
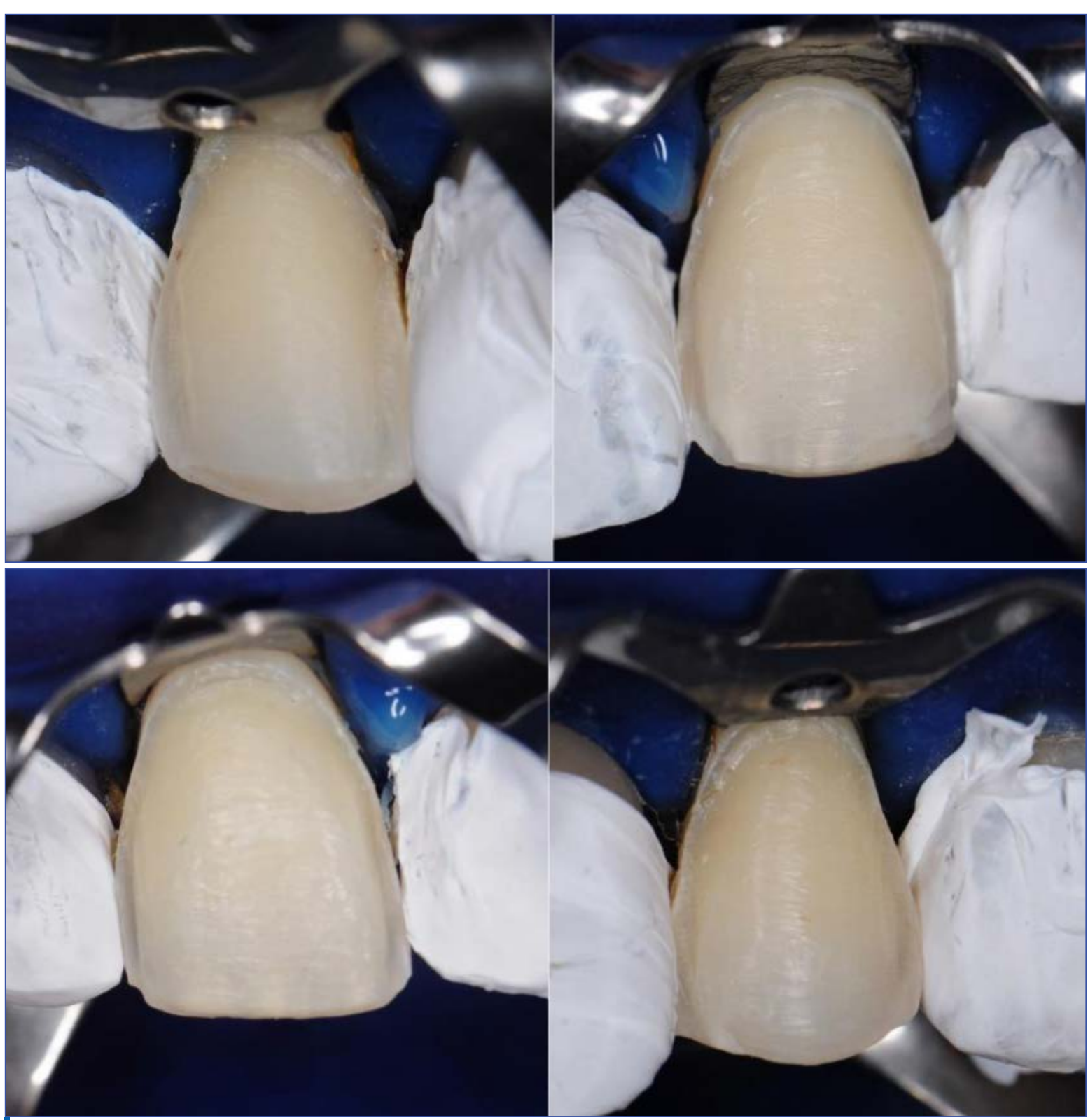

Figure 20. Cementation in absolute isolation

points and reference lines to approve the esthetics of the patient's smile. The impression was taken using the conventional method $[1,4,5]$. Hu et al [1] used the scanned mock-up form as a "ghost image" to guide the design of the final shape, albeit not to a fully anatomical form. A dentin cut-back shape was designed, milled from wax, pressed, and the incisal part was layered, which could lead to a difference between the mock-up and the final shape [1]. Stanley et al [2] described a fully digital workflow for a full-mouth rehabilitation, in which digital smile design and digital impression was performed, and 

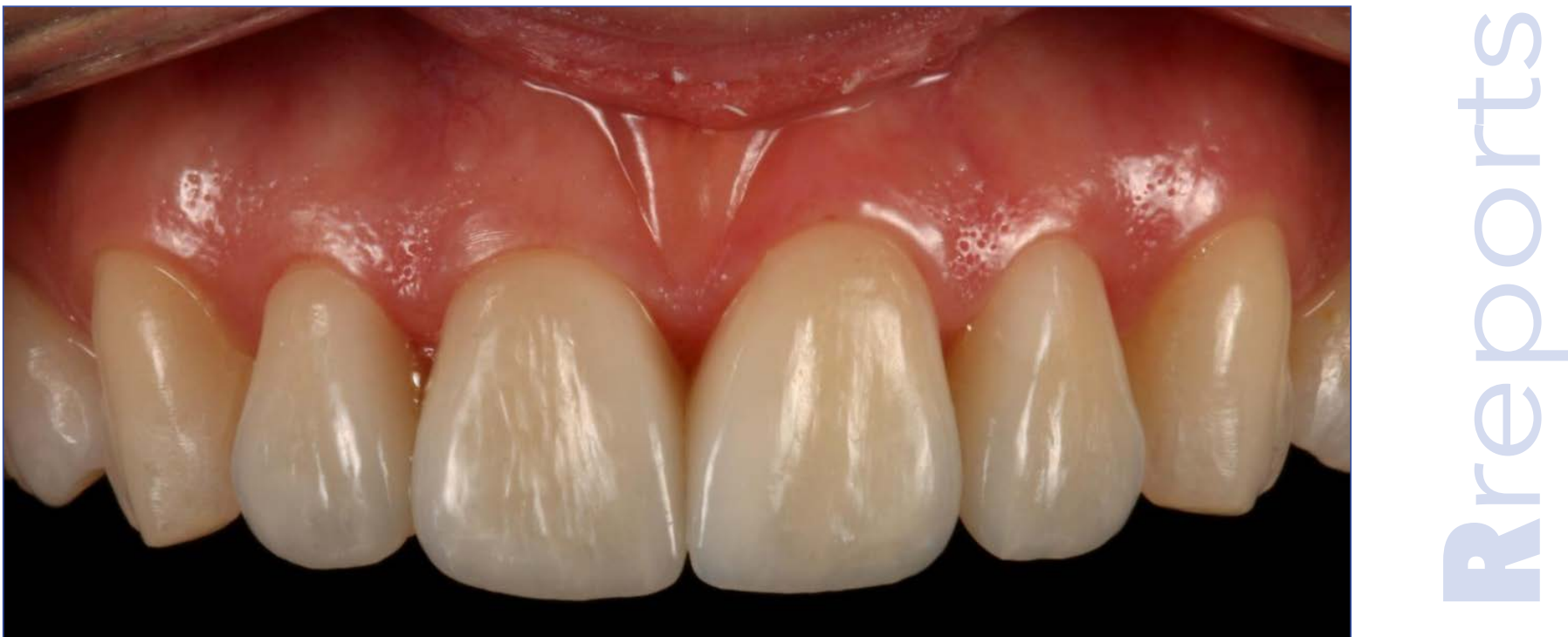

Figure 21. Cemented final restorations.
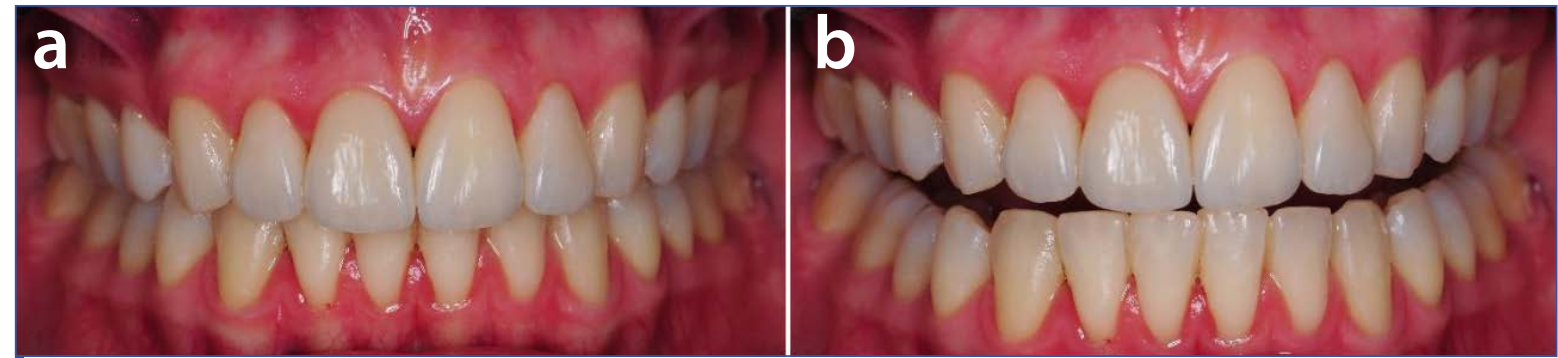

Figure 22. Maximal intercuspation position (a) and protrusion (b).

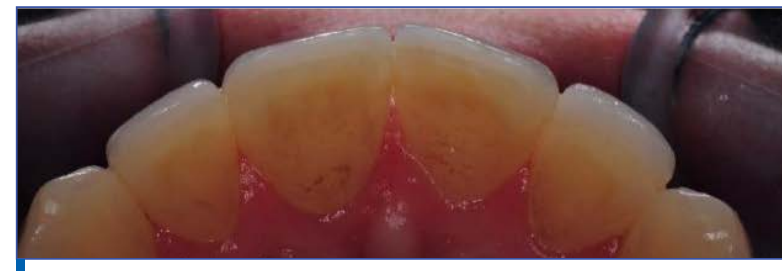

Figure 23. Incisal margin from palatal view.

the digital model of the wax-up was 3D printed. The mock-up was performed with vacuum formed matrix and bysacril; then, after a guided preparation, the definitive veneers were designed computeraided and milled from e.max CAD [2]. However, in this case report it is not mentioned how the shape of the mock-up was transformed for the final restoration. The wax-up - mock-up technique for patient motivation and guided preparation is now a well-known, long used method [5]. The aim of a mock-up driven preparation is to save as much hard tissue as possible. The preparation starts from the desired form with calibration grooves on the vestibular surface; then, with a chamfer bur, the vestibular surface is prepared uniformly in the depth of the calibration grooves. Using this method, the tooth structure is only removed from where it is needed for the final restoration [5]. Non-prep veneers are also considered as a possibility for minimally invasive treatment; however, according to Magne et al [15], the laboratory process and the handling of these veneers are extremely challenging and

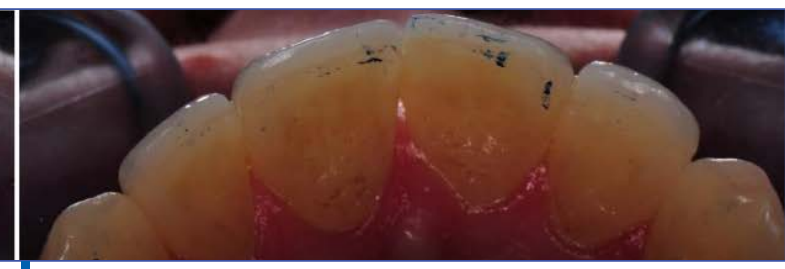

Figure 24. Anterior-guidance.

usually end-up in bulky, unsupported margins with a risk of chipping [15]. Transferring the exact shape of the mock-up to the final restoration is essential. One benefit of the mock-up is that the patient can visualize the new smile and can accept the shape, but if the copy of the shape is not exact to a hundred percent, it could result in conflicts with the patient after inserting the final restoration [5]. Another advantage why a mock-up should be prepared is the guided nature of the preparation, which means that a uniform, minimally invasive preparation and veneer wall-thickness can be achieved. If the design of the veneers is altered relative to the mock-up, a discrepancy from the desired wall-thickness and color may occur [4]. The method described in a case report by Kovács [16] is a possible method to copy the exact same shape of the mock-up to the final veneers. A pre-preparation scan is to be taken from the mock- up in the same workflow with the preparation scan from the abutments, after which the "morph to pre-preparation" function in the laboratory software results in a precise copy [16]. 


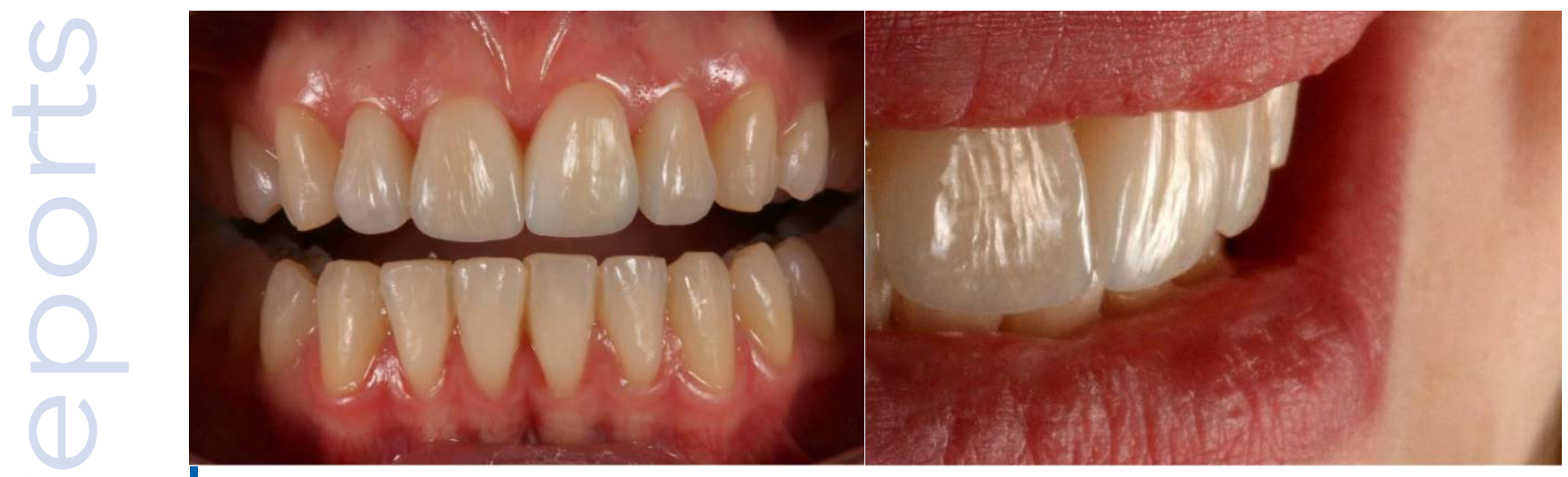

Figure 25. Final result.

The material choice in this case report was based on published in vitro studies, in which the fracture resistance and marginal fit accuracy of IPS e.max Press and CAD were examined [8-12,17]. The length of the silicate crystals in e.max Press is 3-6 $\mu \mathrm{m}[8]$ and in e.max CAD they are 0.1-1 $\mu \mathrm{m}[10]$. The proportion of the crystal phase in Press is 70\% [8]; however, in CAD in the blue phase it is $40 \%$, which will transform after sintering into $70 \%$ [9]. It is suggested that crystallization is more complete in the pressed material than in sintered CAD blocks [10]. Because of the differences in the crystal structure, the fracture toughness, flexural strength and fracture load parameters of e.max Press are greater than those of CAD $[8,9]$. Furthermore, according to Schestatsly et al [10], the milling procedure initiates a cascade of cracks in the material, which results in chipping [10]. These statements correlate with Alkadi et al [11], who describe that the fracture toughness of CAD blocks is lower because of a smaller crystal length and phase, and the fractures formed in the glossy matrix where the crystal transformation was not complete. Regarding the marginal fit of lithium disilicate crowns, those made with the press technique after making a wax pattern by hand had a significantly better accuracy of fit than crowns milled from a CAD block [12]. The reason is suggested to be an easier adaptation of the wax pattern to the dies than to the milled ceramic. According to a critical review, most of the studies comparing the pressed and milled restorations concluded that the marginal fit of e.max Press is more accurate than e.max CAD [17]. The pattern for the pressing technique can be produced by several methods depending on the impression technique and material of the pattern. According to Homsy et al [18], for conventional impressions, lithium-disilicate crowns pressed from milled wax patterns have a more precise marginal fit than those from free-hand wax patterns. In their in vitro study, six combinations of techniques were compared with the following parameters: for conventional impression and gypsum cast making, wax and resin patterns by hand; for conventional impression but digitalized stone dies, milling wax and PMMA patterns; and for digital impressions, milling wax and PMMA patterns. All inlay patterns were pressed from e.max Press lithium-disilicate. It was concluded that the accuracy of the marginal fit depends on the impression technique but is independent from the material of the pattern; however, the internal fit of the restorations depends on the pattern's material.

Overall, the most accurate method was when a wax pattern was milled after digital impression [18]. However, it must be considered that another option to produce patterns with the CAD/CAM technique is $3 \mathrm{D}$ printing. Elfar et al. and Kang et al. compared pressed restorations from free-hand, milled and 3D printed wax patterns, but concluded with different results. According to Elfar et al [19], crowns from 3D printed wax patterns were the most accurate [19]; however, Kang et al [20] reported that veneers from milled wax patterns had the best marginal fit [20]. It has to be mentioned that they produced different types of restorations and different methods to evaluate the results.

Although it is still not conclusive whether the 3D printing or the milling technique is more accurate, it is described in the two studies that both CAD/CAM techniques are more accurate than free-handed approaches, and the marginal fits of all techniques are in the clinically acceptable range $[19,20]$. The cementation of lithium-disilicate pressed veneers was performed with an adhesive technique in absolute rubber dam isolation using light curing resin cement. There are two methods mentioned for surface treatment of the veneers.

The Cementation Navigation System by Ivoclar Vivadent describes a one-component primer called Monobond Etch and Prime for preparing the surface [14]; however, the Scientific Documentation of IPS e.max Press [8] offers another option: first, 5\% hydrofluoric gel (IPS Ceramic Etching Gel), then a silanizing agent called Monobond Plus is to be applied to the surface.

In an in vitro study, pressed lithium-disilicate crowns were produced and cemented with resin cement to epoxy resin-reinforced glass fiber dies with the two different surface treatments mentioned above. The results showed that crowns treated with Monobond Etch \& Prime had greater mechanical structural reliability and higher survival rate than those treated with Monobond Plus [10]. 


\section{Conclusion}

In cases when restorations are prepared in the esthetic region, the communication between the patient and the dentist is always the first key to success. The patient has to understand the opportunities and limitations, while the dentist has to get to know the expectations of the patient. An ideal situation to communicate is when the form of the restorations can be visualized in the mouth by performing a mock-up.

Digital devices and software offer an effective way for precise, time efficient, predictable, comfortable, and individually designed rehabilitation of the patient's smile; however, in spite of the potential offered by fully digital workflows, in some cases, considering conventional laboratory procedures such as pressing lithium-disilicate produces a better outcome (Fig. 25).

\section{Author Contributions}

MD: performed clinical procedure, wrote initial manuscript, AB: performed laboratory procedure and final result photos, ZK: conception and design of the study, JB: revised the article critically for important intellectual content, $\mathrm{PH}$ : approved the final version to be submitted.

\section{Acknowledgments}

The authors thank for Dental-Trade Kft., Budapest, Hungary for producing 3D printed models.

\section{References}

1. Hu JC, Klimmek K. Minimal Veneer Intervention for Maximal Smile Transformation. J Cosmet Dent. 2018;34(3):28-37.

[Full text link] Google Scholar

2. Stanley M, Paz AG, Miguel I, Coachman C. Fully digital workflow, integrating dental scan, smile design and CAD-CAM: case report. BMC Oral Health. 2018;18(1):134. [CrossRef] [free PMC article] [PudMed] Google Scholar Scopus

3. Coachman C, Paravina RD. Digitally Enhanced Esthetic Dentistry - From Treatment Planning to Quality Control. J Esthet Restor Dent. 2016;28:S3-S4.

[CrossRef] [PubMed] Google Scholar Scopus

4. Coachman C, Gurel G, Calamita $M$, et al. The Influence of Tooth Color on Preparation Design for Laminate Veneers from a Minimally Invasive Perspective: Case Report. Int J Periodontics Restorative Dent. 2014;34(4):453-459.

[CrossRef] [PubMed] Google Scholar Scopus

5. Gürel G. Predictable and precise tooth preparation techniques for porcelain laminate veneers in complex cases. Int Dent SA. 2007;9(1):30-40.

[Full text link] Google Scholar

6. Smielak B. No-Preparation and Minimally Invasive Veneers in Clinical Practice : Part 1. Smile Dent J. 2015;10(1):12-15.

[CrossRef] Google Scholar

7. IPS e.max ${ }^{\circledR}$ Clinical Guide [Internet]. 2013 [cited 10.25.2019.] Available from: https://www.ivoclarvivadent.ru/zoolu-website/ media/document/1269/IPS+e-max+Clinical+Guide.

8. Bühler-Zemp P, Völkel T, Fischer K. IPS e.max ${ }^{\circledR}$ Press Scientific Documentation [Internet]. 2011 [updated 2011 March; cited 10.25.2019.] Available from: https://www.ivoclarvivadent.fr/ zoolu-website/media/document/9808/IPS+e-max+Press.

9. Fischer $K$, Bühler-Zemp $P$, Völkel T. IPS e.max ${ }^{\circledR}$ CAD Scientific Documentation [Internet]. 2011 [updated 2011 March; cited 10.25.2019.] Available from: https://www.ivoclarvivadent.com/ zoolu-website/media/document/9793/IPS+e-max+CAD.

10. Schestatsky R, Zucuni CP, Venturini AB, et al. CAD-CAM milled versus pressed lithium-disilicate monolithic crowns adhesively cemented after distinct surface treatments: Fatigue performance and ceramic surface characteristics. J Mech Behav Biomed Mater. 2019;94:144-154.

[CrossRef] [PubMed] Google Scholar Scopus

11. Alkadi L, Ruse ND. Fracture toughness of two lithium disilicate dental glass ceramics. J Prosthet Dent. 2016;116(4):591-596.

[CrossRef] [PudMed] Google Scholar Scopus

12. Azar B, Eckert S, Kunkela J, Ingr T, Mounajjed R. The marginal fit of lithium disilicate crowns: Press vs. CAD/CAM. Braz Oral Res. 2018;32(0).

[CrossRef] [PubMed] Google Scholar

13. Mangano F, Gandolfi A, Luongo G, Logozzo S. Intraoral scanners in dentistry: a review of the current literature. BMC Oral Health. 2017:17(1):149.

[CrossRef] [free PMC article] [PubMed] Google Scholar

14. Cementation Navigation System ${ }^{\circledR}$ Ivoclar Vivadent [Internet] 2019.http://www.cementation-navigation.com/en/a/tooth/ veneer/lithium-disilicate/variolink-esthetic/adhese-universal.pdf. 15. Magne $P$, Hannah J, Magne M. The case for moderate guided prep indirect porcelain veneers in the anterior dentition. The pendulum of porcelain veneer preparations: from almost nonprep to over-prep to non-prep. Eur J Esthet Dent. 2013;8(3):376-388. [Full text link] [PubMed] Google Scholar

16. Kovács ZI, Borbely J Schmidt P, Hermann P. CAD/CAM Monolithic Restoration in Molar Region without Occlusal Adjustment. Poster No 38 presented. In: Digital Dentistry Society Global Conference. October 3-5,2019; Baden-Baden, Germany.

17. Mounajjed R, Layton DM, Azar B. The marginal fit of E.max Press and E.max CAD lithium disilicate restorations: A critical review. Dent Mater J. 2016;35(6):835-844. [CrossRef] [PubMed] Google Scholar Scopus

18. Homsy FR, Özcan M, Khoury M, Majzoub ZAK. Comparison of fit accuracy of pressed lithium disilicate inlays fabricated from wax or resin patterns with conventional and CAD-CAM technologies. $J$ Prosthet Dent. 2018;120(4):530-536.

[CrossRef] [PubMed] Google Scholar Scopus

19. Elfar M, Korsel A, Kamel M. Marginal fit of heat pressed lithium disilicate crowns fabricated by three-dimensional printed and subtractive CAD/CAM wax patterns. Tanta Dent J. 2018;15(4):199. [CrossRef] [Full text link] Google Scholar

20. Kang S-Y, Lee H-N, Kim J-H, Kim W-C. Evaluation of marginal discrepancy of pressable ceramic veneer fabricated using CAD/ CAM system: Additive and subtractive manufacturing. J Adv Prosthodont. 2018;10(5):347.

[CrossRef] [free PMC article] [PubMed] Google Scholar Scopus 


\section{Mariann DANKÓ \\ DMD, Clinical Doctor, Resident Department of Prosthodontics Faculty of Dentistry Semmelweis University Budapest, Hungary}

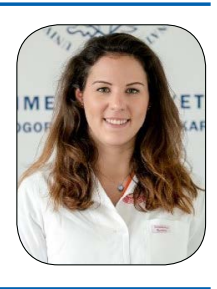

Dr. Mariann Dankó, DMD, graduated from Faculty of Dentistry, Semmelweis University, Budapest, Hungary in 2018. She is currently attending the residency program in Prosthodontics at the Department of Prosthodontics, Faculty of Dentistry, Semmelweis University, Budapest, Hungary. She participates in the Digital Dentistry, and Implant Prosthetics Working Groups. She works with digital appliances and performs digital workflows also in private practice.

\section{Ouestions}

\section{What is/are the advantage(s) of a fully digital workflow?}

口a. Time-efficiency;

b. Simplified clinical procedures;

ac. Less discomfort for the patient;

$\square$ d. All of them

\section{Which type of pattern was used to press lithium-disilicate veneers in this study?}

Da. Milled wax pattern;

ab. 3D printed wax pattern;

ac. Hand-crafted wax pattern;

$\square$ d. Hand-crafted resin pattern.

\section{Why is it considered to get back to a conventional pressing method while performing a digital workflow?}

Da. Pressed lithium-disilicate has more accurate marginal fit;

ab. Milled lithium-disilicate has better physical properties;

uc. Pressing lithium-disilicate is a faster procedure than milling;

ad. All of them.

\section{Why is it important to perform an intraoral mock-up for the initial status?}

$\square$ a. Facilitates the communication with the patient and laboratory;

ub. Possible to adjust according to patient's expectation;

uc. Offers a guided minimally invasive preparation option for preserving hard tissue;

$\square$ d. All of them.

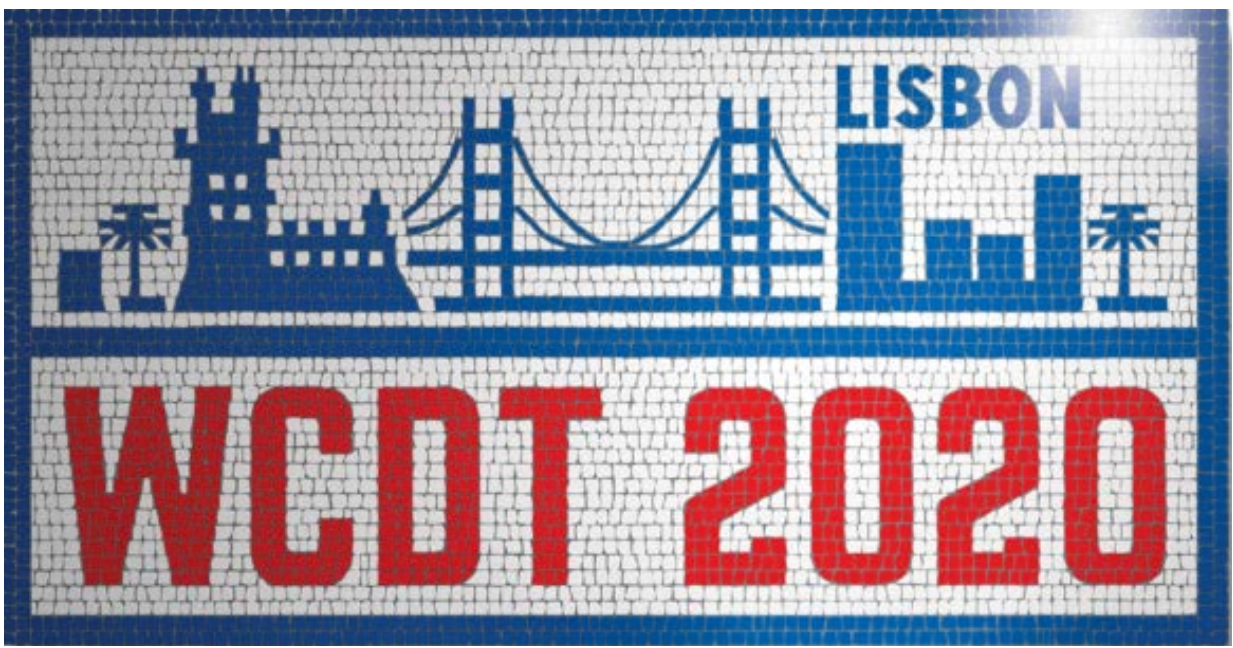

21 st

World Congress

on Dental

Traumatology

Lisbon, Portugal

17-20 th June 


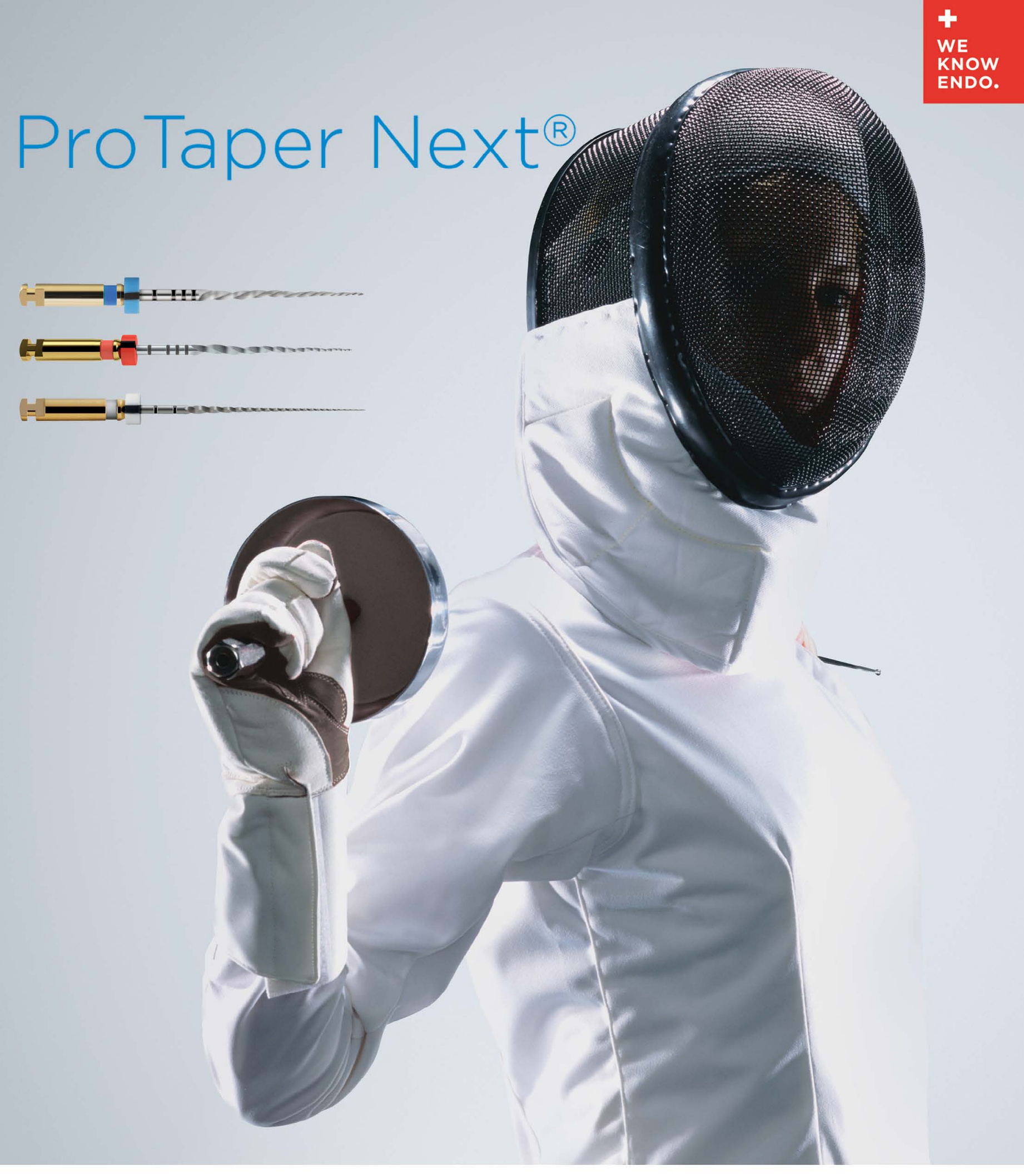

Office \& Showroom

98A Vulturilor Street, $3^{\text {rd }}$ District

RO-030857 Bucharest, Romania

Tel: +40 774074094

e-mail: office.romania@dentsplysirona.com

\section{Dentsply Sirona}


Esthetics forum $3^{\text {rd }}$ edition

Date: 13 - 14 December 2019

Location: Cluj, Romania

Event type: Conference, Exhibition, Workshops

Visit event website: https://www.sser.ro/ef3/

ICDOH 2019: $13^{\text {th }}$ International Conference on Denta and Oral Health

Date: 19 - 20 December 2019

Location: Istanbul, Turkey

Event type: Conference, Exhibition, Workshops

Visit event website: https://waset.org/dental-and-oralhealth-conference-in-december-2019-in-istanbul

$2^{\text {nd }}$ International Conference on Advanced Dentistry and Oral Health

Date: 28 - 30 December 2019

Location: Cape Town, South Africa

Event type: Conference, Exhibition, Workshops

Visit event website: https://globaldentalconferences.org

The International Conference on Dentistry (ICD-20)

Date: 05 - 06 January 2020

Location: Kiev, Ukraine

Event type: Conference, Exhibition, Workshops

Visit event website: https:/asar.net.in/event/index.php?id=1111177

Italy 2020 Dental Conference in The Snow

Date: 07 - 14 January 2020

Location: San Cassiano (BZ), Italy

Event type: Conference, Exhibition, Workshops

Visit event website: https://www.highlandspd.com.au/ courses\#italy2020

Functional Occlusion - Science Driven Management Date: 09 - 11 January 2020

Location: Seattle, WA, USA

Event type: Conference, Exhibition, Workshops

Visit event website: https://www.koiscenter.com/

courses/153-functional-occlusion-course/

Northern Lights 2020 Dental Conference

Date: 22 January - 02 February 2020

Location: Lofoten, Norway

Event type: Conference, Exhibition, Workshops

Visit event website: https://unconventional.com.au/

conference/northern-lights-2020-dental-conference/

International Digital Days 2020

Date: 23 - 25 January 2020

Location: Paris, France

Event type: Conference, Exhibition, Workshops

Visit event website: https://www.digitaldays.dental

British Academy of Aesthetic Dentistry Annual Scientific Meeting 2020

Date: 24 - 25 January 2020

Location: Stoke Poges, UK

Event type: Conference, Exhibition, Workshops

Visit event website: http://www.baad.org.uk/downloads/

BAAD-2020-Flyer.pdf
Annual Meeting of the Israeli Society of Periodontology and Osseointegration 2020

Date: 29 - 30 January 2020

Location: Tel Aviv, Israel

Event type: Conference, Exhibition, Workshops

Visit event website: https://annual2020.perio.org.il/en/

CIOSP 2020 - The $38^{\text {th }}$ Sao Paulo International Dental Meeting

Date: 29 January - 01 February 2020

Location: São Paulo, Brazil

Event type: Conference, Exhibition, Workshops

Visit event website: www.ciosp.com.br

SOCE - National Congress of the Spanish Society of Digital Dentistry and New Technologies

Date: 31 January - 01 February 2020

Location: Malaga, Spain

Event type: Conference, Exhibition, Workshops

Visit event website: https://socemalaga.com/

$40^{\text {th }}$ Annual Hawaiian Dental Forum

Date: 01 - 08 February 2020

Location: Lahaina, Hawaii, USA

Event type: Conference, Exhibition

Visit event website: https://www.dentsem.com/hawaiiandental-forum

Bones and Teeth Gordon Research Conference (GRC) 2020

Date: 02 - 07 February 2020

Location: Galveston, TX, USA

Event type: Conference, Exhibition, Workshops

Visit event website: https://www.grc.org/bones-and-

teeth-conference/2020/

AEEDC 2020 - The $24^{\text {th }}$ edition of the UAE International

Dental Conference

Date: 04 - 06 February 2020

Location: Dubai, United Arab Emirates

Event type: Conference, Exhibition

Visit event website: www.aeedc.com

Dental Expo Krasnoyarsk 2020

Date: 19 - 21 February 2020

Location: Krasnoyarsk, Russia

Event type: Conference, Exhibition, Workshops

Visit event website: www.dental-expo.com/en/kras.html

American Academy of Dental Group Practice (AADGP) Dental Expo 2020

Date: 19 - 22 February 2020

Location: Las Vegas, NV, USA

Event type: Conference, Exhibition

Visit event website: https://aadgpexpo.org

Meeting of The American Prosthodontic Society

Date: 20 - 21 February 2020

Location: Chicago, IL, USA

Event type: Conference, Exhibition, Workshops

Visit event website: https://www.prostho.org/annual_ meeting_welcome.html 
BIDEM 2020 - Bangladesh International Dental Meeting \& Exhibition

Date: 20 - 22 February 2020

Location: Dhaka, Bangladesh

Event type: Conference, Exhibition

Visit event website: www.bdmta.com

Midwinter Dental Meeting 2020

Date: 20 - 22 February 2020

Location: Chicago, IL, USA

Event type: Conference, Exhibition, Workshops

Visit event website: https://www.cds.org/meetingsevents/midwinter-meeting

Antarctica Medical \& Dental Conference 2020

Date: 25 February - 09 March 2020

Location: Antartica, South America

Event type: Conference, Exhibition, Workshops

Visit event website: https://unconventional.com.au/

conference/antarctica/

ICOI Winter Implant Symposium 2020

Date: 27 - 29 February 2020

Location: Houston, TX, USA

Event type: Conference, Exhibition, Workshops

Visit event website: www.icoi.org/meetings-and-symposia

$\mathbf{2 8}^{\text {th }}$ Euro Dentistry Congress

Date: 02 - 03 March 2020

Location: Edinburgh, UK

Event type: Conference, Exhibition, Workshops

Visit event website: https://dentistry.cmesociety.com

Pacific Dental Conference 2020

Date: 05 - 07 March 2020

Location: Vancouver, Canada

Event type: Conference, Exhibition, Workshops

Visit event website: https://www.pdconf.com/ncs2020/

Perio 2020 - National Congress

Date: 12 - 14 March 2020

Location: Rimini, Italy

Event type: Conference, Exhibition, Workshops

Visit event website: https://www.sidp.it/media/taocekp.pdf

ADX 2020 - Sydney - Australia's Premier Dental Event Date: 13 - 15 March 2020

Location: Sydney, Australia

Event type: Conference, Exhibition, Workshops

Visit event website: www.adx.org.au
ASO 2020 - The $27^{\text {th }}$ Australian Orthodontic Congress

Date: 19 - 23 March 2020

Location: Cairns, Australia

Event type: Conference, Exhibition, Workshops

Visit event website: www.aso.org.au/australian-

orthodontic-congress

$18^{\text {th }}$ International Conference on Oral and Maxillofacial Pathology 2020

Date: 23 - 24 March 2020

Location: Madrid, Spain

Event type: Conference, Exhibition, Workshops

Visit event website: https://oralpathology.

conferenceseries.com/

$39^{\text {th }}$ Asia Pacific Dental and Oral Health Congress Date: 23 - 24 March 2020

Location: Yokohama, Japan

Event type: Conference, Exhibition, Workshops

Visit event website: https://www.dentalcongress.com/ asia-pacific/

Dental-Expo Volgograd 2020

Date: 24 - 26 March 2020

Location: Volgograd, Russia

Event type: Conference, Exhibition

Visit event website: www.dental-expo.com/en/volgograd. html

Dentale Symphonie 2020

Date: 26 - 28 March 2020

Location: Salzburg, Austria

Event type: Conference, Exhibition, Workshops

Visit event website: www.colloquium.dental/dentale-

symphonie

Kazdentexpo 2020

Date: 27 - 29 March 2020

Location: Almaty, Kazakhstan

Event type: Conference, Exhibition

Visit event website: www.dental-expo.com/en/kazdent.

html

$26^{\text {th }}$ Global Dentists and Pediatric Dentistry Annual Meeting

Date: 30 - 31 March 2020

Location: London, UK

Event type: Conference, Exhibition, Workshops

Visit event website: https://dentists.dentistryconferences. com/ 


\section{Neuromuscular Dentistry Powered by Myotronics}

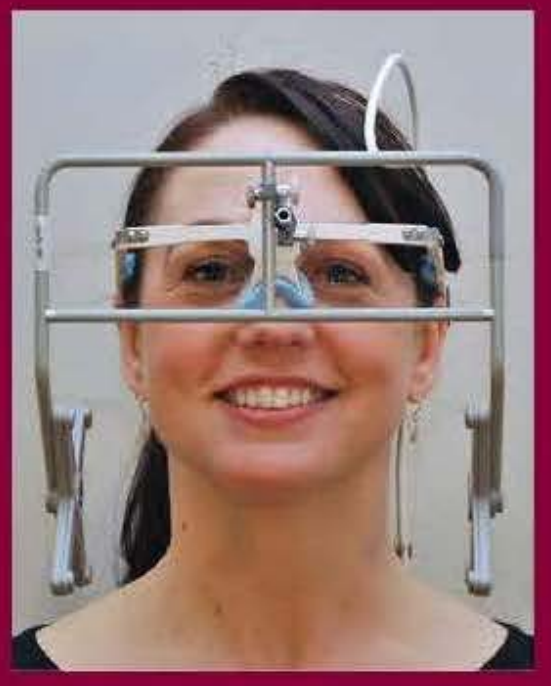

Dentists worldwide are discovering the science and the benefits of Neuromuscular Dentistry with Myotronics technology.

Evaluate and successfully treat occlusal and restorative cases with reliable, reproducible clinical data never seen before.

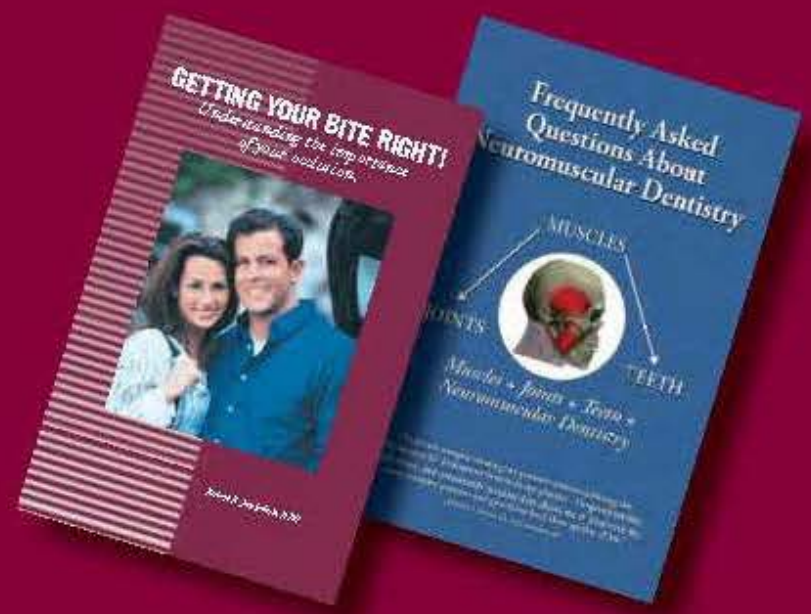

Contact Myotronics to receive information on upcoming CE courses and complimentary booklets on the benefits of Neuromuscular Dentistry. 800.426.0316 or info@myotronics.com.
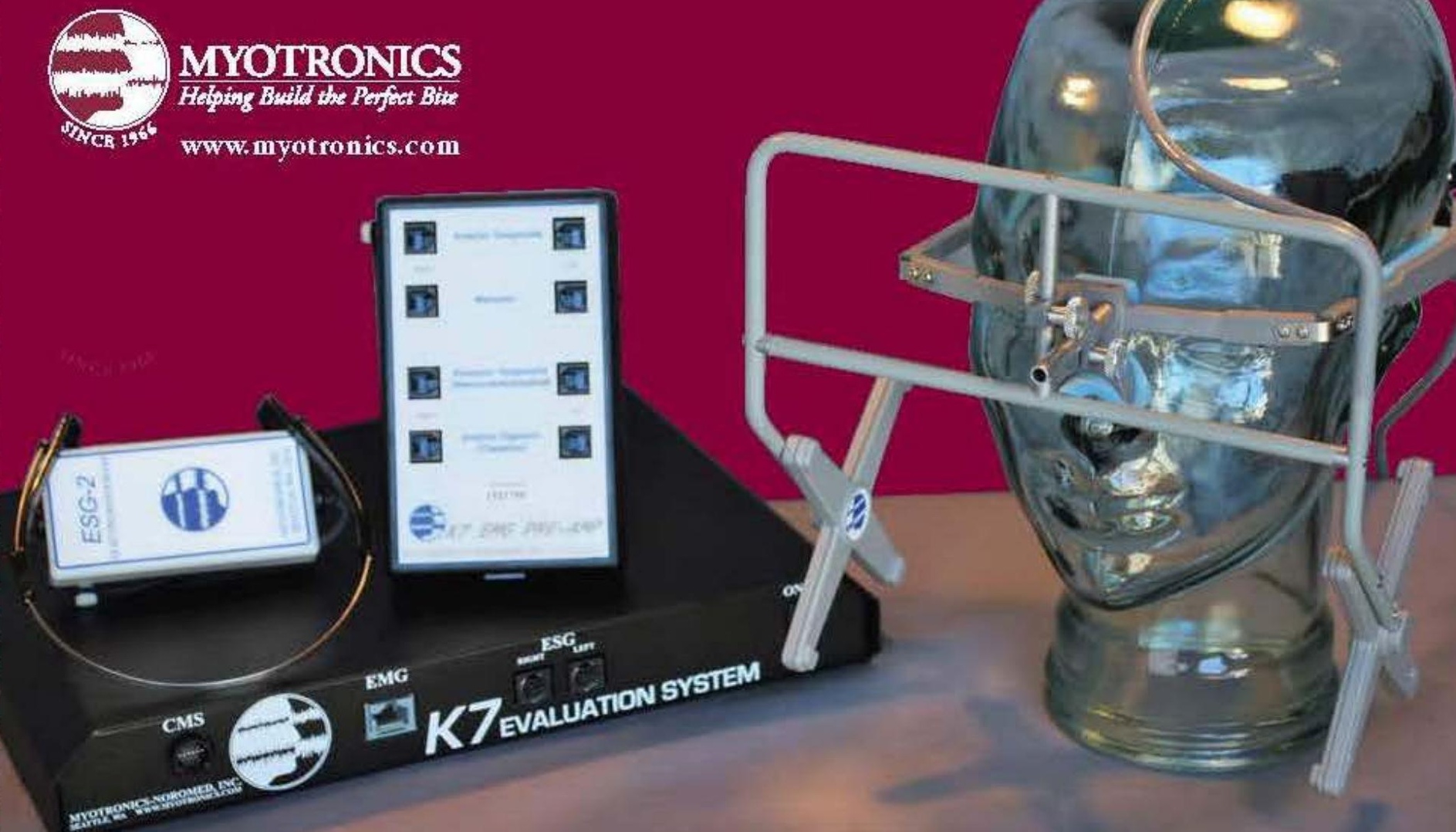


\section{Gold Standard in Occlusion Control - OccluSense ${ }^{\circledR}$ by Dr. Jean Bausch GmbH \& Co. KG}

While attending the 2019 IDS I had the opportunity to get direct knowledge of the most advanced instruments, devices and appliances for dental practice.

At the stand of Dr. Jean Bausch GmbH \& Co. KG, the owner of the company, André Bausch and his daughter, presented to me and my father the new OccluSense ${ }^{\circledast}$ BK 5000 system for instrumental occlusal analysis. The OccluSense ${ }^{\oplus}$ system combines traditional and digital recording of the distribution of masticatory forces on occlusal surfaces. Experts in printed organic electronics supported Dr. Jean Bausch GmbH \& Co. KG, manufacturer of occlusion testing materials, from the initial product idea to the final production of customized flexible sensors for each dental practice for digital occlusion control.

The September 2019 Digital Future of Dentistry Technology Expo organized at the ADA FDI World Dental Congress in San Francisco selected Bausch's OccluSense ${ }^{\circledR}$ as a winner of the Best of Class (BOC) technology awards in the Emerging Technologies category.

Compared to the well-known T-Scan (Tekscan, Inc., South Boston, MA 02127, USA) whose pressure sensor is 100 microns, the OccluSense ${ }^{\circledast}$ sensor is very flexible at only 60 microns, and is additionally covered in red. Established color transfer on occlusal surfaces facilitates the allocation of recorded data. The data can be displayed graphically $2-$ and 3-dimensional, including the distribution of the masticatory forces recorded digitally.

The OccluSense ${ }^{\circledast}$ system can be used by any dentist, because occlusion control is a routine in everyday practice. The system consists of a portable device, an inductive charger, a test sensor and a 25-sensor box presented in a storage and transport box.

The very flexible sensors on plastic substrate are only $60 \mu \mathrm{m}$ thin and allow the recording of all the masticatory forces at 256 pressure levels. The thin and flexible material allows the recording of both static and dynamic occlusion. Due to their color coverage, it is possible to assign them to the contact points on the patient's teeth.

The chewing forces are covered by the sensor and recorded by the hand-held battery-powered device that transmits the recorded data wirelessly into the OccluSense ${ }^{\circledR}$-iPad application. The inductive charger provides wireless power transfer. Fully charged batteries allow the device to be used for up to 4 hours.

The novelty of the OccluSense ${ }^{\oplus}$ System is the digital representation of the occlusal points and associated stress loads, which could cause various symptoms, such as headaches, headaches, neck pain, shoulder pain, light hypersensitivity, bruxism or swallowing difficulties.

In everyday dental practice, documentation and storage are all the more important, as we talk more and more about evidence-based dental medicine. The app saves each shot automatically so that it is easy to make comparisons.

The OccluSense ${ }^{\oplus}$ System can be used in various fields of dentistry, including functional diagnostics, dental technology and osteopathy.

Dr. Jean Bausch GmbH \& Co. KG

Oskar-Schindler-Str. 4, D-50769 Köln, Germany

https://www.occlusense.com/occlusense?lang=en

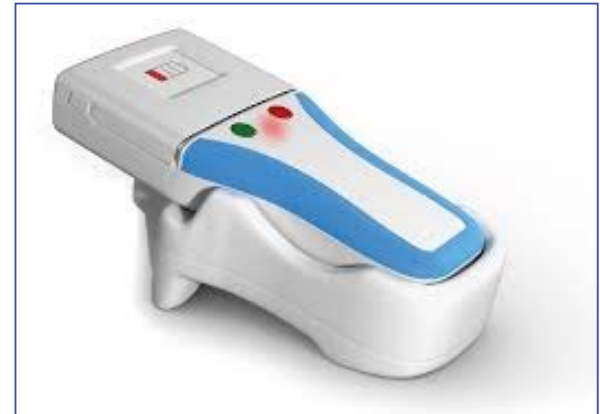

OccluSense ${ }^{\circledast}$ handheld device and inductive charger.

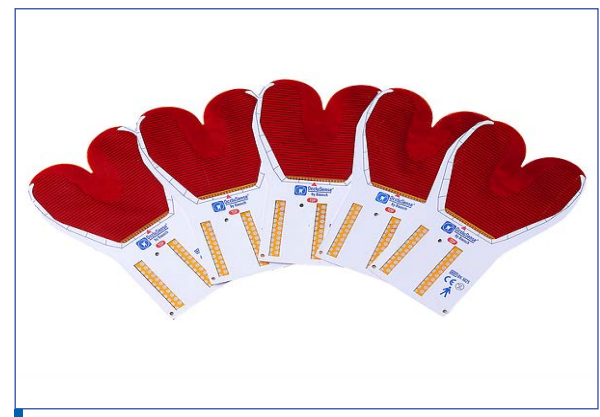

OccluSense ${ }^{\oplus}$, Electronic Pressure Sensor.

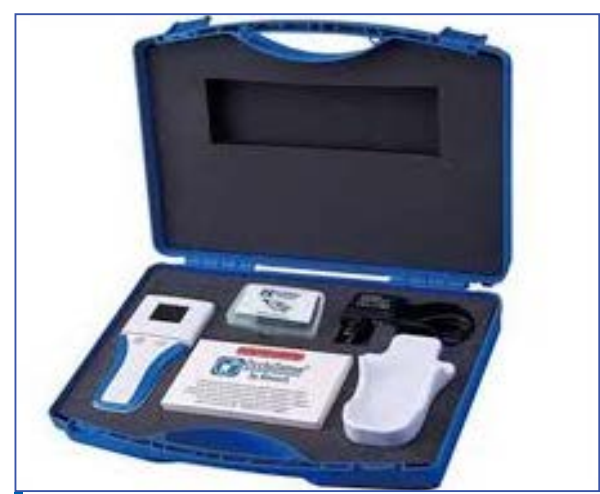

OccluSense ${ }^{\oplus}$ system with a convenient suitcase.

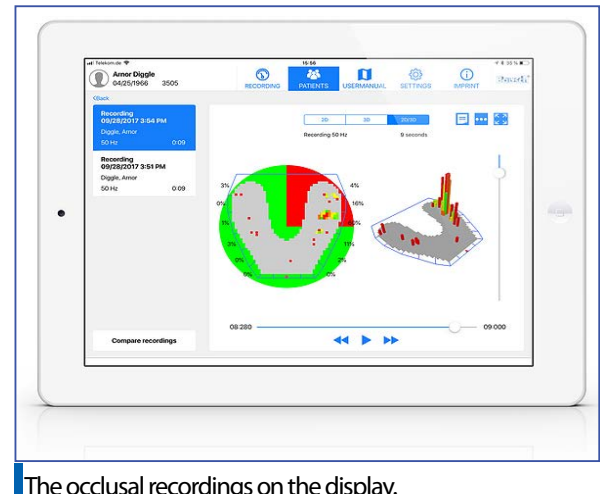

The occlusal recordings on the display.

Florin - Eugen Constantinescu DMD, PhD Student

Editorial Director, Product News 


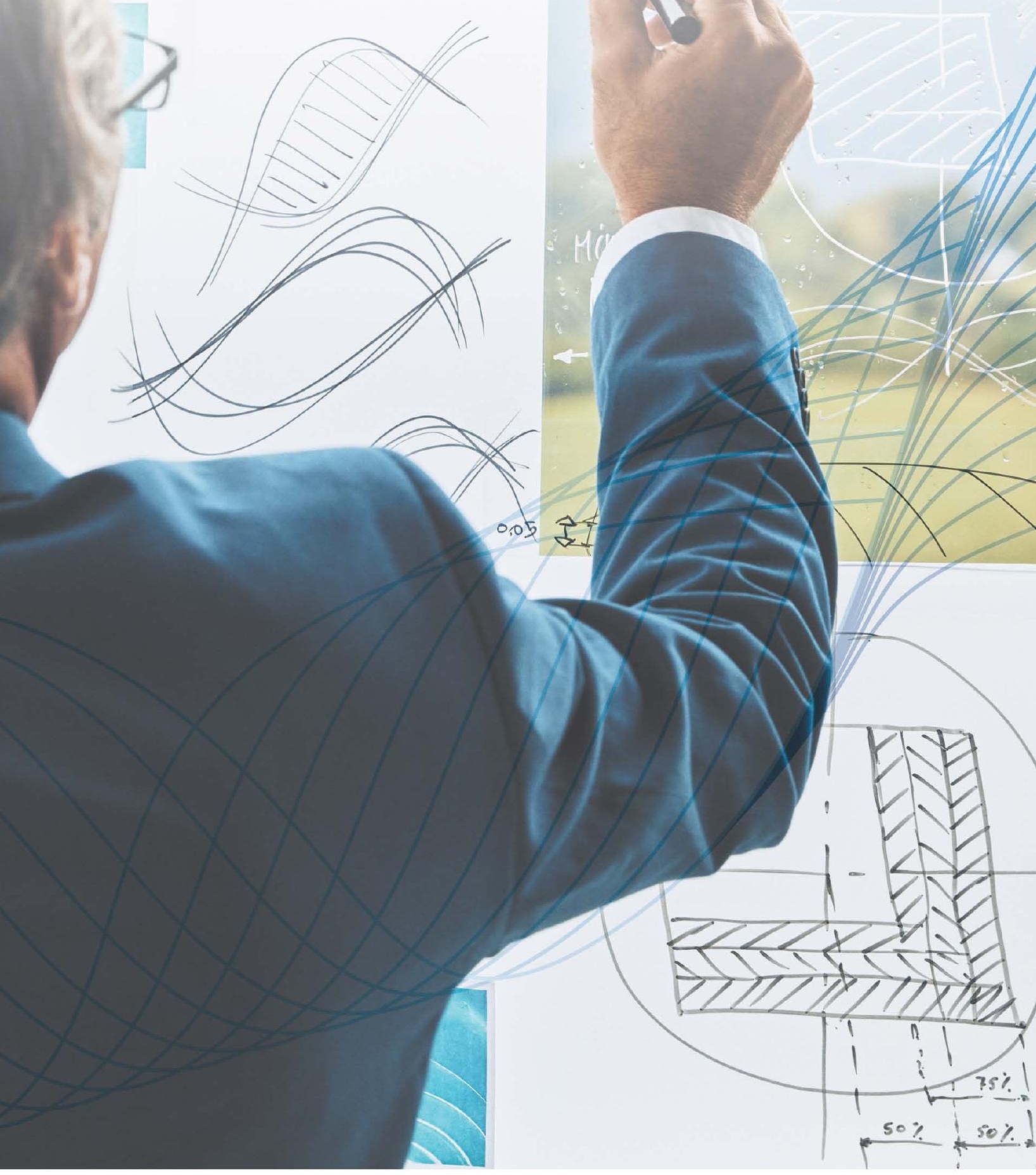

TruNatomy ${ }^{\text {TM }}$

Redefining our design process 


\section{Contemporary Oral and Maxillofacial Surgery}

Authors: James R. Hupp, Edward Ellis III,

Myron R. Tucker

Publisher: Elsevier, Inc., Philadelphia, PA, USA

Language: English

ISBN: 978-0-323-55221-9

Edition: 7/e

Year Published: 2019

Pages: 721, illustrated

Price: $104.99 €$

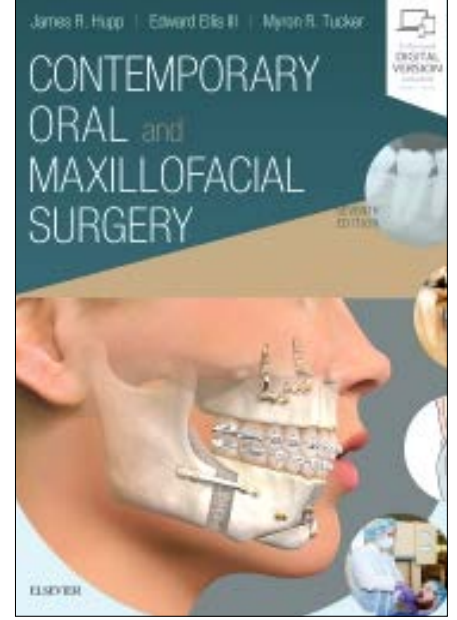

Marian-Vladimir

Constantinescu

$\mathrm{DDS}, \mathrm{MSC}, \mathrm{PhD}$

Holistic Dental \& Medical Institute

of Bucharest-ROPOSTURO,

Bucharest, Romania

-mail:

dr.vladimir.constantinescu@gmail.com

A new book has now been added to the reference literature on dental surgery, namely "Contemporary Oral and Maxillofacial Surgery", written by well-known OMS educators, James R. Hupp, Edward Ellis III and Myron R. Tucker, who present the readers with the best means of evaluation, diagnosis and treatment in head, neck and orofacial infections.

The book comprises 31 chapters, divided in 8 parts, accompanied by several appendices and an index.

Part I, "Principles of Surgery", presents the pre-operative health status evaluation, prevention and management of medical emergencies, principles of surgery, wound repair, infection control in surgical practice, pain and anxiety control in surgical practice.

Part II, instrumentation for basic oral surgery, shows principles of routine and more complex exodontia, management of impacted teeth, post-extraction patient management and medicolegal consideration are brought together in "Principles of Exodontia".

Part III, "Preprosthetic and Implant Surgery", describes pre-prosthetic surgery, basic concepts and techniques, advanced concepts and complex cases in implant treatment.

Part IV, "Infections", addresses odontogenic infections, principles of endodontic surgery, patient undergoing radiotherapy or chemotherapy, odontogenic diseases of the maxillary sinus and salivary gland disorders.

Part V, "Management of Oral Pathologic Lesions", describes principles of differential diagnosis and biopsy and surgical management of oral pathologic lesions.

Soft tissue and dentoalveolar injuries and management of facial fractures are presented in Part Vl, "Oral and Maxillofacial Trauma".

Part VII, "Dentofacial Deformities", highlights correction of dentofacial deformities, facial cosmetic surgery, patients with orofacial clefts and defects of the jaws.

Facial neuropathology and temporomandibular disorders are described in Part VIII.

The appendices include examples of operative notes, administration schedule of drugs, useful prescriptions, consent for extractions and anesthesia and antibiotics.

The book is clearly edited and is accompanied by drawings and full colored photography to make the concepts presented easy to understand.

The $7^{\text {th }}$ edition of the book "Contemporary Oral and Maxillofacial Surgery" represents a comprehensive text for understanding the most advanced procedures and technologies that help to treat patients with head, neck and orofacial area pathologies. The book is the best guide in training dentistry and dental hygiene students and improving dental postgraduates, general practitioners and OMF surgery.

The Books Review is drafted in the reviewer's sole wording and illustrates his opinions. 


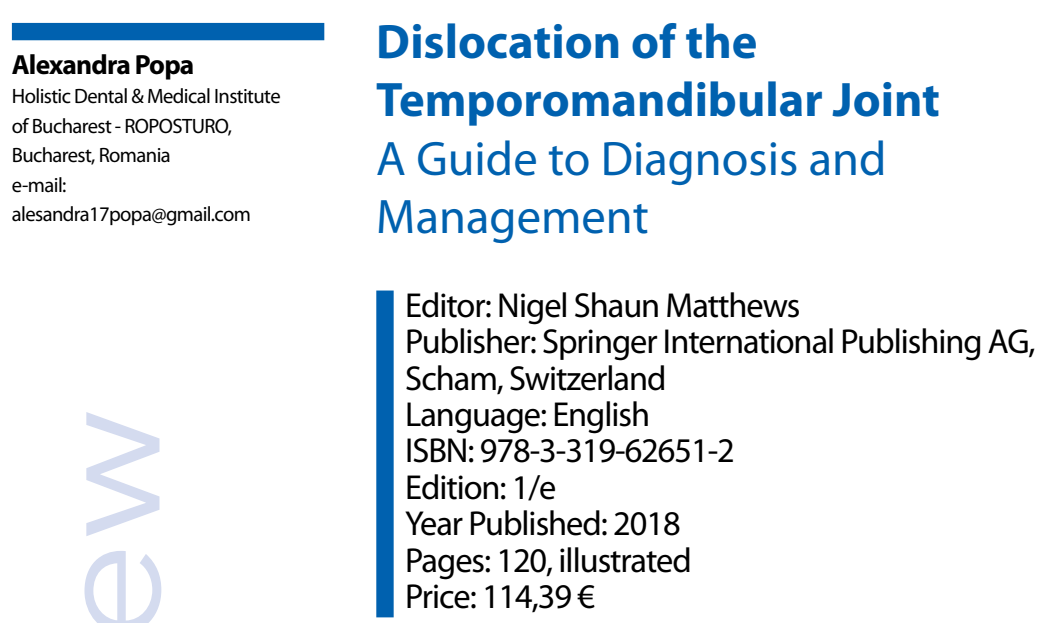

\section{Dislocation of the Temporomandibular Joint A Guide to Diagnosis and Management}

Editor: Nigel Shaun Matthews

Publisher: Springer International Publishing AG,

Scham, Switzerland

Language: English

ISBN: 978-3-319-62651-2

Edition: 1/e

Year Published: 2018

Pages: 120, illustrated

Price: $114,39 €$

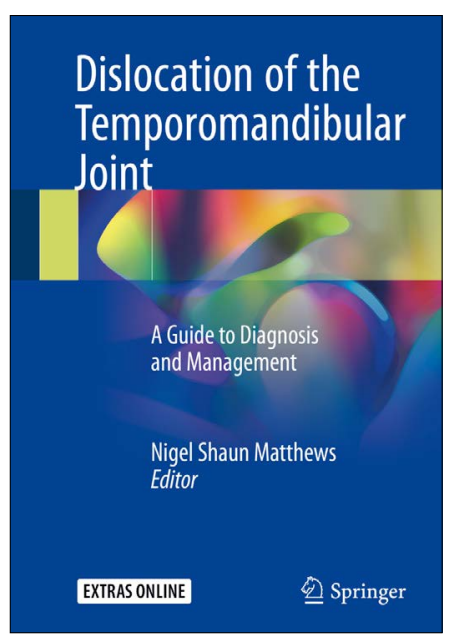

Temporomandibular joint (TMJ) dislocation affects up to $5 \%$ of the population. It is a medical emergency that the dentist must identify as quickly and efficiently as possible to prevent the need for corrective surgery.

The book entitled "Dislocation of the temporomandibular joint. A Guide to Diagnosis and Management" by Professor Nigel Shaun Matthews from the University of North Carolina is a global overview of TMJ dislocation, from issues related to etiology and diagnosis, to management.

The book comprises 9 chapters.

First, we are informed about the etiology, presentation, and diagnosis, while making a clear distinction between dislocation, subluxation, and normal mandibular translation.

The book includes images of the TMJ from conventional radiography, panoramic radiography, scanography, computed tomography (Cone Beam Computed Tomography (CBCT), Multidetector Helical CT (MDCT) and magnetic resonance imaging, with examples in normal anatomy, as well as in pathologies.

Acute TMJ dislocation and technique of manual reduction are clearly defined, classified and presented.

With respect to chronic TMJ dislocation, after the definition, etiology and diagnosis, as well as management and complications are presented.

The TMJ dislocation aspect of pathology is addressed both conservatively and surgically in separate chapters. TMJ dislocation and repositioning of the dislocated mandible is treated arthroscopically, as well as by surgical technique, using alloplastic TMJ prostheses.

The book is an update of the problematic cases of dislocation of the temporomandibular joint, constituting a useful source of information for both the general dentist and the OMF surgeon.

The Books Review is drafted in the reviewer's sole wording and illustrates his opinions. 


\section{Textbook and Color Atlas of}

\section{Traumatic Injuries to the Teeth}

Editors: Jens O. Andreasen, Frances M. Andreasen,

Lars Andersson

Publisher:Wiley-Blackwell, Oxford, UK

Language: English

ISBN: 978-1-119-16707-5

Edition: $5 / \mathrm{e}$

Year Published: 2018

Pages: 1064, illustrated

Price: $\$ 245.00$

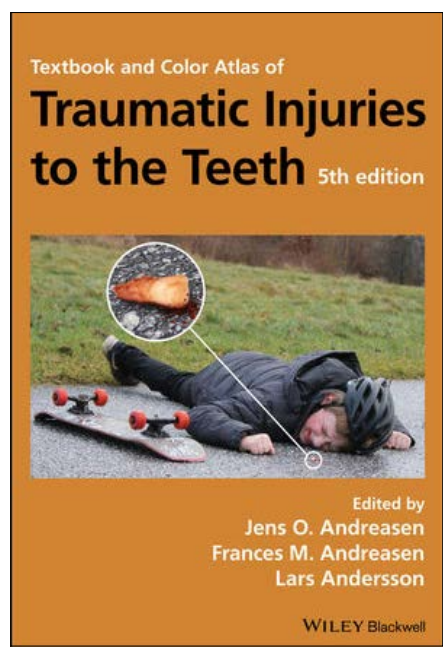

Marian-Vladimi

Constantinescu

DDS, MSc, PhD

Holistic Dental \& Medical Institute

of Bucharest-ROPOSTURO,

Bucharest, Romania

e-mail:

dr.vladimir.constantinescu@gmail.com

The $5^{\text {th }}$ edition of the book entitled "Textbook and Color Atlas of Traumatic Injuries to the Teeth" is an update of the issues presented in the previous 2007 edition; the book aims to present the dental traumatology from the perspective of an interdisciplinary treatment.

The book comprises 44 chapters, accompanied by several appendices and an index.

This book presents the nature of traumatic injuries, and then wound healing subsequent to injury, response of oral tissues to trauma, response of traumatized dental tissues to various treatment procedures and prediction and timing of healing complications.

The book tackles the characteristics of oral stem cells, the development of a bio-root and bone-resorbing osteoclasts with their role in dental tissue regeneration.

The psychological aspects of traumatic dental injuries and the different types of orofacial injuries in child physical abuse are presented, and then their classification, epidemiology and etiology are described.

Following the examination and diagnosis of dental injuries, we are informed about the different forms of traumatic injuries to the teeth, from coronary fractures, radicular fractures, dislocations, concussion and subluxation, extrusive and intrusive luxation, avulsion, injuries to the supporting bone and soft tissue, primary dentition and developing teeth.

The management of traumatic injuries to the teeth is exhaustively presented from regenerative endodontics, reinforcing endodontically, orthodontic treatment, restoration with resin composites, porcelain laminate veneers, conventional bridges, autotransplantation and implant therapy.

The restoration of the traumatized tooth is approached from several perspectives: biological, preventive and predicting the economic aspect.

Based on the experience of the Oral and Maxillofacial Surgery Department at the University Hospital in Copenhagen, Denmark, which has had over 4000 patients in more than 50 years, the Dental Trauma Guide has been complemented since 2006.

To promote best practices in dental traumatology, Scandinavian researchers have established the International Association of Dental Traumatology (IADT) and the journal Dental Traumatology.

The appendices provide us with a number of useful observation sheets, starting with an emergency record for acute dental trauma, a clinical examination form, a summary of treatment and a comparison between costs / effectiveness of different treatment solutions.

It is a comprehensive textbook, useful and necessary to undergraduate BDS, postgraduates in pediatric dentistry, oral surgery, endodontics, and general dentists that address dental trauma in a common effort to find the best treatment solutions for victims of dental trauma.

The Books Review is drafted in the reviewer's sole wording and illustrates his opinions. 


Florin-Eugen
Constantinescu
DMD, PhD Student
Holistic Dental \& Medical Institute
of Bucharest-ROPOSTURO,
Bucharest, Romania
e-mail:
dr.florin.constantinescu@gmail.com

\section{Sports Dentistry: Principles} and Practice

Editors: Peter D. Fine, Chris Louca, Albert Leung

Publisher:Wiley-Blackwell, Oxford, OX, UK

Language: English

ISBN: 978-1-119-33255-8

Edition: 1/e

Year Published: 2018

Pages: 232, illustrated

Price: $\$ 85.00$

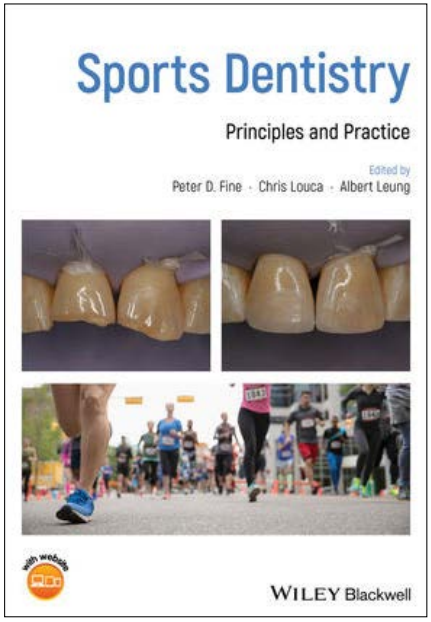

The book entitled "Sports Dentistry: Principles and Practice" offers dentists the most effective treatment methods for sports dentistry in the dental, endodontic and restorative area.

The book contains eleven chapters and an index.

First, the authors present the prevalence / incidence of dental trauma during sports, dealing with trauma caused to teeth, the role of education and the role of sports dentistry.

The book deals with dental trauma to the hard and soft tissues in the adult athlete, so injuries are classified, and then trauma to the periodontal ligament is presented root fractures, splinting techniques, ankylosis and an emergency dental kit are discussed.

Regarding trauma to the permanent dentition in pediatric patients in competitive sports, the book discusses epidemiology, preventing trauma, emergency management of soft tissue injuries, primary teeth, permanent teeth and prognosis.

It presents the restoration of teeth damaged by trauma, restorative techniques, anterior restorations with composite material, clinical sequence and minimally invasive bonded porcelain.

As to the endodontic treatment as a consequence of sports injuries, the nature of the injuries, the vitality of the dental pulp, while the treatment and recall are specified.

The treatment of dental wear in athletes is analyzed from the perspective of the types of wear, prevalence, diet, gastro-oesophageal reflux (GORD) and laryngopharyngeal (LPR), eating disorders and management The prevention of sporting dental injuries is exemplified with different devices such as: mouthguards, helmets, early intervention orthodontics, face shields and effective preventive measures.

The book discusses the role of nutrition in sports, optimal diet for athletes, hydration, supplements and eating disorders.

The analysis of dental disorders in elite athletes identifies a number of conditions: tooth surface loss, acidic challenge, dental caries, acute and chronic infections, temporomandibular joint dysfunction and barotrauma. The book is clearly written and is accompanied by explanatory diagrams and images, and a website with illustrative case studies, constituting a guide for the general practitioner and specialists in pediatric dentistry, orthodontics, endodontics, oral and maxillofacial surgery.

The Books Review is drafted in the reviewer's sole wording and illustrates his opinions. 


\section{Temporomandibular Joint and Airway Disorders A Translational Perspective}

Editors: G. Gary Demerjian, André Barkhordarian, Francesco Chiappelli

Publisher: Springer International Publishing AG, Cham, Switzerland

Language: English

ISBN: 978-3-319-76367-5

Edition: 1/e

Year Published: 2018

Pages: 140, illustrated

Price: $164,99 €$

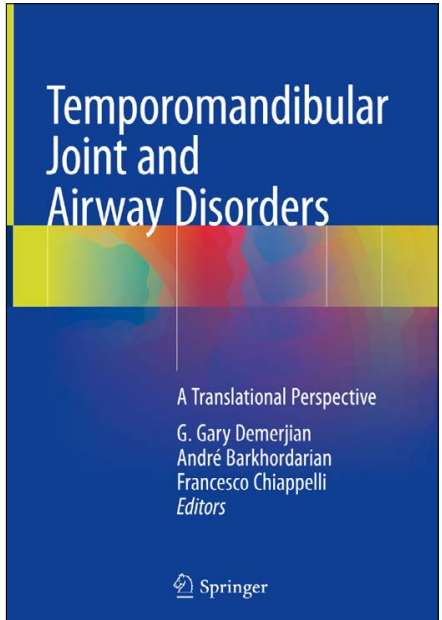

Marian-Vladimir

Constantinescu

DDS, MSc, PhD

Holistic Dental \& Medical Institute

of Bucharest-ROPOSTURO,

Bucharest, Romania

e-mail:

dr.vladimir.constantinescu@gmail.com

Lately, practitioners have increasingly come across different forms of disorders of the temporomandibular joint. The book entitled "Temporomandibular Joint and Airway Disorders" addresses the temporomandibular joint and airway disorders from a translational perspective.

The book contains 12 chapters and an index, and is divided into two parts.

Part I, Translational Research, presents detailed data on the neuroanatomy and neurophysiology of the trigeminal network system. And then we become acquainted with neuroimmune and systemic manifestations of neuroinflammation and molecular mechanism of temporomandibular joint disorders.

Part II, Translational Effectiveness, presents the head and neck manifestations, trigeminal nerve inflammation and the possibilities of biomechanical dental treatments. After deciphering the relationship between TMJ, orofacial pain and sleep apnea, the immunologic and physiologic effects of the various dental sleep appliance therapy are discussed.

The correlation of facial balance, TMD and airway for all ages from orthodontic / orthopedic perspective is presented and convincingly illustrated via a series of cases from orthodontic / orthopedic perspective. Information on the anatomical structures and the local pathology at the level of the temporomandibular articulation within the disorders at this level are exemplified with the help of the cone beam computed tomography $(C B C T)$ and magnetic resonance imaging (MRI). Research centered on the patient-related outcomes is conducted from the perspective of evidence-based medical and dental practice for patients with temporomandibular joint disorders. Finally, future avenues of translational care for patients with temporomandibular disorders are mentioned.

The book is a compelling plea for a better understanding of temporomandibular joint and airway disorders; it is a compelling guide for practitioners, residents, interns and students who want to deepen their knowledge in this area of dental practice.

The Books Review is drafted in the reviewer's sole wording and illustrates his opinions. 


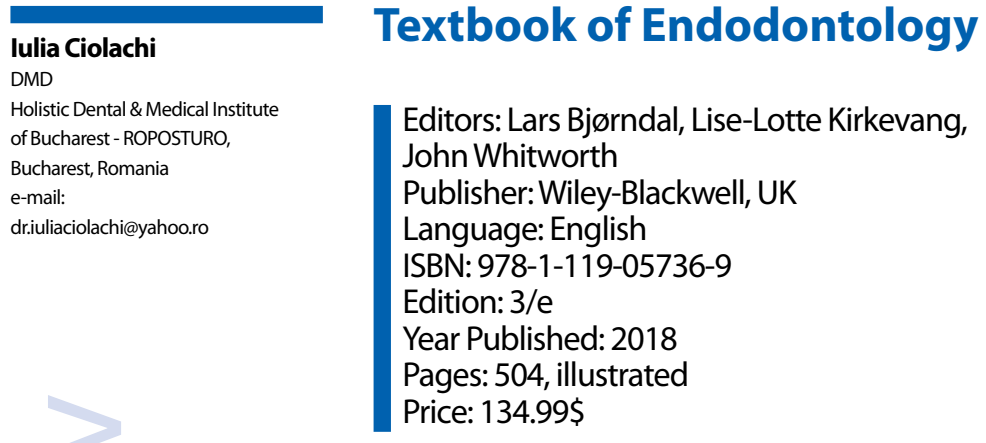

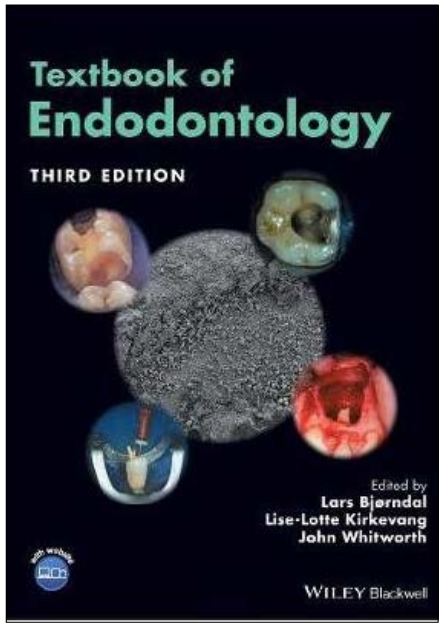

In current clinical work, endodontic therapy is also needed to solve many cases,. The editors, Lars Bjørndal, Lise-Lotte Kirkevang, and John Whitworth, and their coworkers have made substantial changes to the third edition of the "Textbook of Endodontology" by adding six new chapters. The book contains twenty-six chapters, divided into five parts, as well as an index.

The first part, "The Vital Pulp" approaches the structure and functions of the vital pulp, as well pulpal pain, diagnosis and treatment strategy.

In the second part, the authors discuss "The Infected Necrotic Pulp and Apical Periodontitis", highlighting the microbiology and clinical diagnosis of these diseases.

Endodontic emergencies, the aseptic working field, access cavity preparation, root canal instrumentation, irrigation and disinfection, root canal fillings, materials and techniques are the themes discussed in part three, "Endodontic Treatment Procedures".

The fourth part, "The Endodontically Treated Tooth", discusses the following: the root canal treated tooth in prosthodontic reconstruction, measuring endodontic disease and treatment outcome, endodontic retreatment, nonsurgical retreatment and surgical endodontics.

The last part, "Additional Considerations", brings to our attention local anesthetic considerations, complex orofacial pain conditions, endodontic complications after trauma, medicolegal considerations, emergencies in need of urgent referral and the transitions to independent practice.

The third edition of the Textbook of Endodontology is an important source of knowledge for undergraduate and postgraduate students, and dental practitioners, providing them with the latest approaches to endodontic theory and techniques necessary for everyday practice.

The Books Review is drafted in the reviewer's sole wording and illustrates his opinions. 


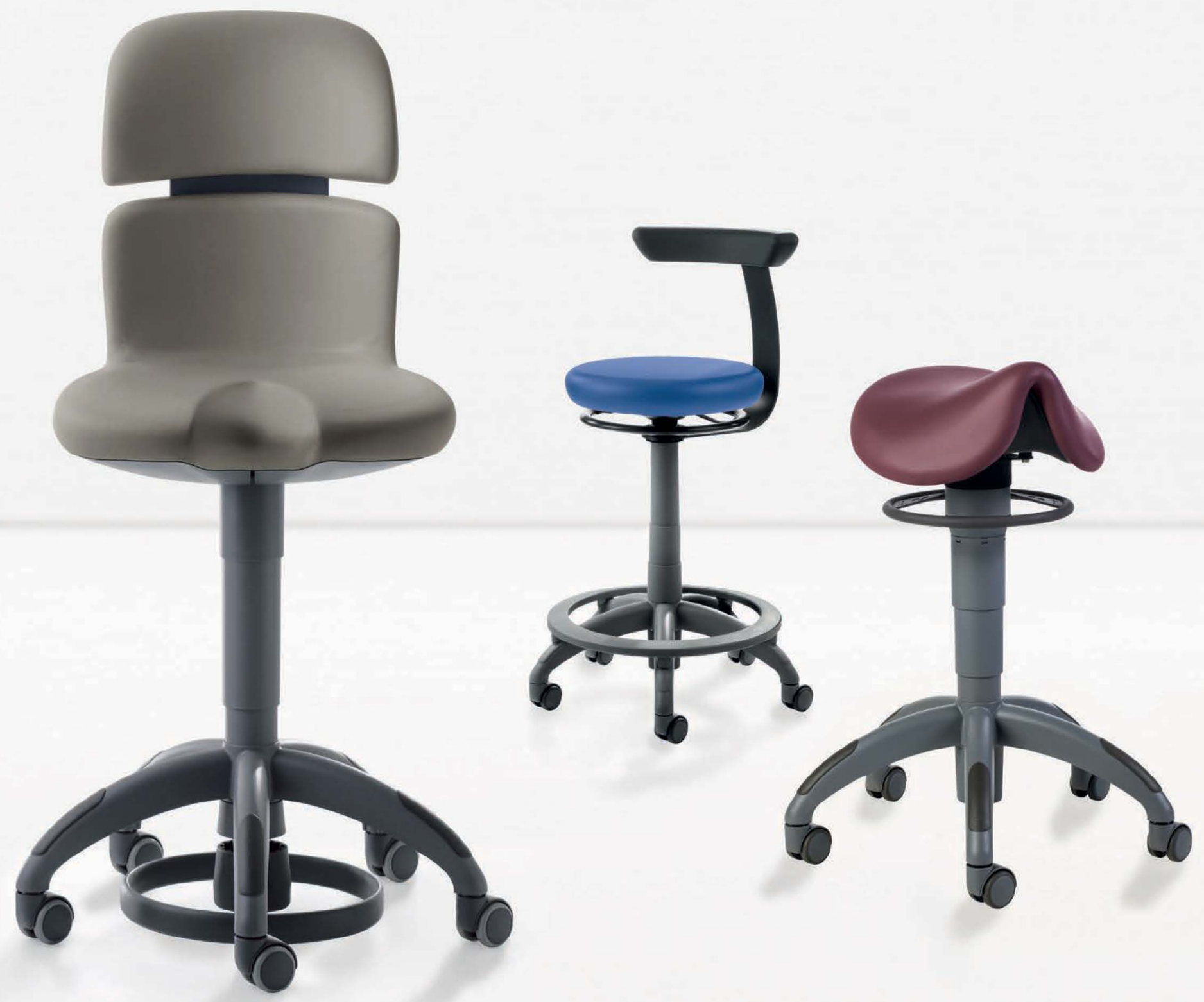

Hugo, Carl, Theo by Dentply Sirona Working Stools

It's all about keeping the balance 
The Stomatology Edu Journal (Stoma Edu J) is a quarterly international journal, double blind peer-reviewed, open access journal to be database indexed, which accepts original articles for publication in all aspects of dental development and research. It addresses those interested in oral and maxillofacial sciences including students, graduates, postgraduates, educators, researchers, dental practitioners, those involved in dental industry and policy-makers relevant to the practice of dentistry.

\section{Submission Instructions}

The Stomatology Edu Journal (Stoma Edu J) publishes articles written only in English. All articles will be accompanied by the signed copyright form which can be returned by e-mail, fax (as scanned documents). All the responsibility for the originality of the material sent belongs to the author(s) alone. Each article will be evaluated by the peer-review committee composed of two independent peer-reviewers, in a blinded fashion, according to the peer-review protocol. All manuscripts must be original and exclusive. The Stomatology Edu Journal Editor will consider only articles that are original, have not been published elsewhere and have been submitted exclusively to the Stomatology Edu Journal. The manuscripts should be submitted online at www. ManuscriptManager.net/stom.

\section{Ethics in publishing}

The Stomatology Edu Journal (Stoma Edu J) and its editoria board fully adhere and comply to the policies and principles of Committee on Publication Ethics (COPE) (https:// publicationethics.org/files/2008 Code of Conduct.pdf). Your manuscript should not contain any information that has already been published. If you include already published figures or images, please obtain the necessary permission from the copyright holder to publish under the CC-BY license. Plagiarism, data fabrication and image manipulation are not tolerated. Plagiarism is not acceptable in the Stomatology Edu Journal (Stoma Edu J) submissions. Plagiarism includes copying text, ideas, images, or data from another source, even from your own publications, without giving any credit to the original source. Reuse of text that is copied from another source must be between quotes and the original source must be cited. If a study's design or the manuscript's structure or language has been inspired by previous works, these works must be explicitly cited.

If plagiarism is detected during the peer review process, the manuscript may be rejected. If plagiarism is detected after publication, we may publish a correction or retract the paper. Image files must not be manipulated or adjusted in any way that could lead to misinterpretation of the information provided by the original image. To verify the originality of content submitted to our journals, we use iThenticate (www.ithenticate. com) to check submissions against previous publications. All submitted manuscripts will be checked for any possible duplication or plagiarism with iThenticate (www.ithenticate. com). Nevertheless, corresponding authors are responsible for any fraud, intentional or unintentional malpractice.

\section{Articles sent for publishing}

The Stomatology Edu Journal (Stoma Edu J) publishes: origina articles; reviews; case reports; technical procedures; consensus declaration coming from an association or from a group of specialists; letters to the editor. All articles must be up to 3,000 and 5,000 words for meta- analysis (the word count is for the manuscript text only). Letters to the editor must not exceed 400 words of text and have no more than 3 authors. Letters to the editor can be related to an article already published in the journal or it can represent original scientific contributions or events news/presentations etc. of interest for the reader.

\section{Permissions and Ethics}

For citations, tables, figures etc. which are not original, these must be accompanied by the written permission for their use and the full reference must be provided. Photographs of identifiable persons must be sent alongside the written permission of the person(s) and all regions that may allow the identification of the subject must be covered. The author must have obtained, for all studies including human subjects, the permission of the subjects to be part of the study whilst keeping their anonymity. By sending the article, the author declares that he obtained this permission from all his subjects. All studies must respect the Helsinki Declaration (1975). For human and animal studies, the authors must have obtained the approval of the ethics committee from the University/Institute/etc. where the study was done. Consent for publication is required for studies involving human subjects - ALL case reports, letters that describe cases and some original articles. Cohort studies are exempt; instead evidence of IRB approval (name of IRB, date of approval and approval code/reference number) must be provided.

\section{Manuscript preparation}

The article must be written in conformity with the general recommendations of the International Committee of Medical Journal Editors. http://www.icmje.org/icmjerecommendations.pdf

The Stomatology Edu Journal (Stoma Edu J) uses double-blind review, which means that both the reviewer and author name(s) are not allowed to be revealed to one another for a manuscript under review. The identities of the authors are concealed from the reviewers, and vice versa. To facilitate this, please include the following separately:

Title page (with author details): This should include the title, authors' names and affiliations, and a complete address for the corresponding author including an e-mail address, Author Contributions, Acknowledgements and Curriculum Vitae.

Blinded manuscript (no author details): The main body of the paper (including the references, figures, and tables) should not include any identifying information, such as the authors' names or affiliations.

The articles must be sent either as a Microsoft Word 2000 document $\left({ }^{*}\right.$.doc) or as a Microsoft Word 2003 document (*.docx). The article will be written using Times New Roman font, size 12 for the characters with one and half $(11 / 2)$ spaces between paragraphs. The manuscript must be sent in its final form. The pages will be numbered with the manuscript containing the following sections: title, authors, abstract, keywords, the text of article, contributions, acknowledgments, references, the figures and the tables legend.

A. The title of the manuscript will have a maximum of 100 characters without spaces, written in title case, centered capitals, and in 12 point bold Times New Roman font at the top of page. Abbreviations should be avoided within the title.

B. The author(s) will send their full name(s) and surname(s) the highest academic position, their full titles and their affiliations. All names are listed together and separated by commas. Provide exact and correct author names as these will be indexed in official archives. Affiliations should be keyed to the author's name with superscript numbers and be listed as follows: Laboratory, Department, Institute, Organization, City, State abbreviation (USA, Canada, Australia), and Country (without detailed address information such as city zip codes or street names).

The correspondent author will send his/her full name and surname, the highest academic position, his/her full title, his/ her affiliation, his/her institution address, his/ her telephone, fax and e-mail. The authors will send this information in the same format as that in the published articles.

\section{The Structured Abstract}

The abstract can have a maximum of 250 words. After the abstract, the author(s) must mention a maximum of 5 keywords. Keywords must be selected from Medline Mesh. Abbreviations are not accepted in the title or the abstract.

The abstract for Original Scientific Articles should be no more than 250 words using the following structure: Introduction; Methodology; Results; Conclusion.

The abstract for Review Articles should be no more than 250 words with the authors covering all the following information regarding the subject presented under the following subheadings: Background, Objective, Data Sources, Study Selection, Data Extraction, Data Synthesis.

The abstract for Case Reports should be no more than 250 words using the following structure: Aim, Summary and Key learning points: provide up to 5 short statements of the report The abstract for Clinical Articles should be no more than 250 words using the following structure: Aim, Methodology, Results and Conclusions. 


\section{The Article Text}

Headings and Sub-headings

Except for special names (e.g. GABAergic), capitalize only the first letter of headings and subheadings. Headings and subheadings need to be defined in Times New Roman, 12, bold. You may insert up to 5 heading levels into your manuscript (not more than for example: 3.2.2.1.2 Heading title).

For original articles:

1. Introduction - a presentation of the most important aspects in the studied domain without doing a review of the literature. The purpose of this part is to present and backup the hypothesis on which the study was based.

2. Material and Methods - this section will include all required information so that the reader can verify the validity of the study including, but not limited to, subjects, measurements, statistics and ethics. The methods used should be discussed (why the methods have been chosen, which the limitations/ advantages). A paragraph about the statistical analysis is required as well.

3. Results - the results of the study will be presented in a descending order of importance. An interpretation of the results will not be done in this section.

4. Discussion - the authors will present the way the results backup the original hypothesis, as well as the way in which the results are backed up or contradicted by the published literature. A paragraph must be dedicated to presenting the limitations of the study.

5. Conclusion - The conclusion presents the implications of this latest work. In addition, authors may consider discussing future plans or recommendations for future research etc. For all other types of articles, we recommend the use of a clear structure based on sections and sub-sections.

\section{E. Author Contributions}

The Author Contributions section is mandatory for all articles, including articles by sole authors. The Author Contributions statement must describe the contributions of individual authors and, in doing so, all authors agree to be accountable for the content of the work. Please list only 2 initials for each author, without periods, but separated by commas (e.g. AC, AS). In the case of two authors with the same initials, please use their middle initial to differentiate between them (e.g. AEC, ASC). Each author must be able to prove his active participation in the study by contributing to the concept, protocol, data gathering or analysis, their interpretation or by critically revising the manuscript.

\section{F. Acknowledgments}

Acknowledge persons who have made substantive contributions to the study. Specify grant or other financial support, citing the name of the supporting organization and grant number.

\section{G. References}

- The references will be written using the Vancouver style (https://www.imperial.ac.uk/media/imperial-college/ administration-and-support-services/library/public/vancouver. pdf). All references that are identified with DOI (Digital Object Identifier) must be mentioned.

- For each reference use active links to the full text (DOI link), free PMC article, PubMed, Google Scholar, and Scopus pages, were they exist:

- For all references identified with DOI the full-text link must be the CrossRef hyperlink

\section{Examples}

\section{Articles with DOI}

Singbartl G. Pre-operative autologous blood donation: clinical parameters and efficacy. Blood Transfus. 2011;9(1):10-18.

[CrossRef] [Free PMC Article] [PubMed] Google Scholar Scopus Articles without DOI

Mehta H, Shah S. Management of Buccal Gap and Resorption of Buccal Plate in Immediate Implant Placement: A Clinical Case Report. J Int Oral Health. 2015;7(Suppl 1):72-75.

\section{[Full text links] [PubMed] Google Scholar}

- The references will be numbered, in the order they appear in the text, in square brackets, as such: [3], [5,7-9].

- All sources found in the text must be present in the bibliography and all the papers mentioned in the bibliography must appear in the text.

- For references with more than 5 authors, list the first 3 authors followed by "et al."
- Full-page ranges should be given in expanded form (e.g.. 426429 , not 426-9).

- If non-English-language titles are translated into English, bracketed indication of the original language should follow the title.

- All journals will be abbreviated and italicized names of journals according to the style in PubMed; refer to the National Library of Medicine (NLM) Journals Database (http://www.ncbi.nlm. nih.gov/nlmcatalog/journals) if needed. Journal names will be abbreviated according to the List of Title Word Abbreviations - Information obtained from sources which are not published yet, but accepted for publishing will include at the end of the reference the mention "in print" between round parentheses.

- If the cited results have not been published yet the mention will be "personal communication" written in the text of article between round parentheses.

- Only references read by the authors of the article will be cited.

- An original article will have at most 50 references, a review will have at most 100 references, a letter to the editor 5 references, whilst all other types of articles will have the minimum number of references required.

\section{Curriculum Vitae - Ultra Short version}

Please provide a brief presentation of the first author and his contribution in the field, of maximum 130 words (with a $3.5 \times 4.5$ cm color photo).

\section{Figures, Images, Tables}

All illustrations must be numbered and cited in the text in order of appearance.

Figures and Images will be drawn professionally and sent in separate file(s) as jpeg, tiff or png files. Illustrations should preferably fill single column width $(54 \mathrm{~mm})$ after reduction, although in some cases $113 \mathrm{~mm}$ (double column) and $171 \mathrm{~mm}$ (full page) widths will be accepted. See the Image quality specifications chart for details. Image files also must be cropped as close to the actual image as possible.

In the text, each figure must be represented by a number, a title and a description. The authors will indicate where should the figure be placed in the text. All images or figures must come from the author's personal collection or the author must have rights to publish the image or figure. All images must be at or above intended display size, with the following image resolutions: Line Art $800 \mathrm{dpi}$, Combination (Line Art + Halftone) 600 dpi, Halftone 300 dpi. We do not accept images or figures taken from the Internet.

The Tooth Identification System used in manuscripts must conform to the FDI International System. Units used in manuscripts must conform to the Système Internationale d'Unités (SI).

Tables will be included in the text and each table will have a number and a short description if required.

\section{Ownership Rights}

By sending the article for publication the author(s):

- take full responsibility for the scientific content of the text and for the accuracy of the send data;

- become (co)author(s) of the manuscript (all further plagiarism accusation are addressed solely to the author(s) who signed the manuscript);

- declare they are the rightful owners of the images, figures and/or information sent for publishing and that they have the permission to publish all the materials for which they do not own the intellectual property rights;

- declare that the message/content of the manuscript is not influenced in anyway by commercial interests/previous engagements/ any sort of relations with other people or companies;

- transfer all rights for the manuscript to the Editorial Council for the Stomatology Edu Journal.

\section{Other}

Previously mentioned limitations can be ignored in special cases with the agreement of the chief-editor and/or the publisher. All published materials cannot be returned.

Not taking into consideration the recommen-dations mentioned before can lead to delay in publishing the materials or may lead to not publishing the article.

The Stomatology Edu Journal (Stoma Edu J) also helps authors measure the impact of their research through specialist partnerships with Kudos and Altmetric. 
- 1 year Subscription (4 issues of the journal) - 280 RON (72 Euro for foreign subscribers)

- 2 years Subscription (8 issues of the journal) - 540 RON (136 Euro for foreign subscribers)

- Single Issue - 80 RON (20 Euro for foreign subscribers)

Please send the filled subscription at the following e-mail: roposturo@gmail.com.

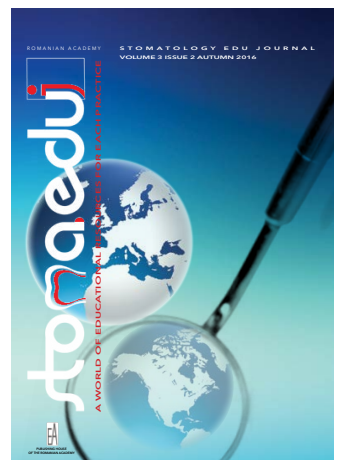

\section{PLEASE COMPLETE ALL THE SUBSCRIPTION FIELDS IN CAPITAL LETTERS!}

Name............................................. Surname

Mrs. $\square$ Mr. $\square$ Ms.

Home Address

City ..................................... Sector....

District.

Post office code.

Mobile phone.

Web

E-mail:

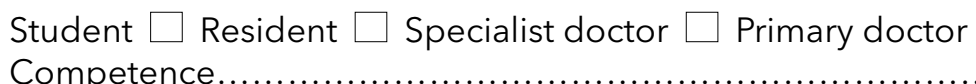

Institution

Activity domain: $\square$ Private $\square$ Public

Department.

Position

Specialty

Institution address.

City ...................................... Sector.

District.

Post office code.

Phone

E-mail:

Web.

CUI (Institution Unique Registration Code)

VAT Payer: $\square$ Yes $\square$ No

Invoice - please fill all the necessary details for invoice:

Name....

CNP (Personal Identification Number).

Or

Institution

CUI (Institution Unique Registration Code)...

Date.

Signature

After filling the subscription, please send it together with the proof of payment to:

\section{ROPOSTURO}

Romanian Association of Oral Rehabilitation and Posturotherapy

10, lonel Perlea St., $1^{\text {st }}$ District, RO-010209 Bucharest, Romania

Tel: +4021314 1062, Fax: +4021312 1357

e-mail: roposturo@gmail.com

www.roposturo.ro 


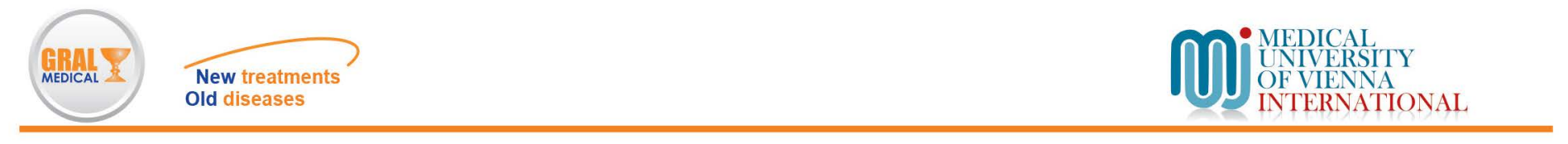

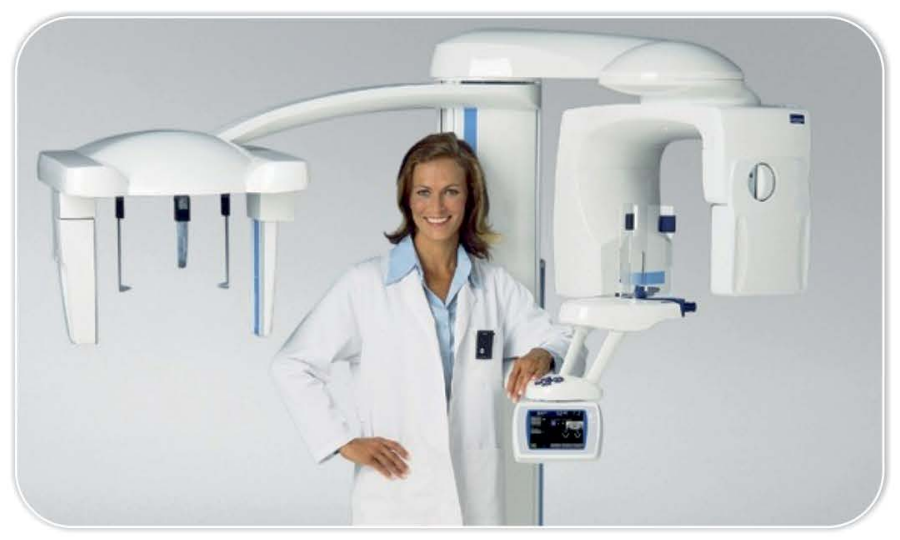

\section{ORTHODONTIC X-RAYS (RADIOGRAPHS)}

Profile (lateral) cephalometric views

Standard OPG (Orthopantomogram) for adults and children (magnification 1.3-1.6)

Orthodontic diagnostic photos

\section{X-RAYS (RADIOGRAPHS) FOR SPECIAL TREATMENTS} Standard OPG (Orthopantomogram) for adults and children (magnification 1.3-1.6)

Ortoradial orthopantogram for adults and

children (magnification 1.3-1.6)

Orthopantogram with reduced for adults and children

Combination for the same patient

(standard OPG +orthoradial+ reduced shadow)

Four-view TMJ- right to left joint

Anterior maxillary sinus panoramic radiographs

Posterior maxillary sinus panoramic radiographs

Salivary gland panoramic radiographs

Prophile (lateral) cephalometric radiographs

Orthodontic diagnostic photos

\section{D CT SCANS}

Full maxilla and mandible CT scan

Maxilla and maxillary sinus CT scan

Mandible and mandible

Mandible and mandibular canal CT scan

Partial maxillary and mandibular CT scan

TMJ CT scan

CT scan of included teeth

\section{MRI -CT}

Ortho-maxillofacial MRI

Ortho-maxillofacial CT

Examination of the throat using a special protocol for: cavum; oropharynx, oral cavity, tongue, soft palate, salivary glands, larynx and hypopharynx is conducted only at 79-91, Traian Popovici Street, $3^{\text {rd }}$ District,

RO-031422 Bucharest, ROMANIA

Tel: $021-323.00 .00$ | 0731-494.688
The Plevnei Gral Medical Dental Imaging Center provides dental imaging services dedicated to obtaining a quick and correct dental diagnostic in order to plan an adequate and efficient treatement.

Our state-of-the-art equipment provides dentists, implantologists or maxillofacial surgeons with accurate 2D and 3D images of the structures they will work upon, being of real service to the patients, by practically eliminating all major intervention-associated risks, both due to the use of very low radiation doses and the easy and comfortable positioning of the patient.
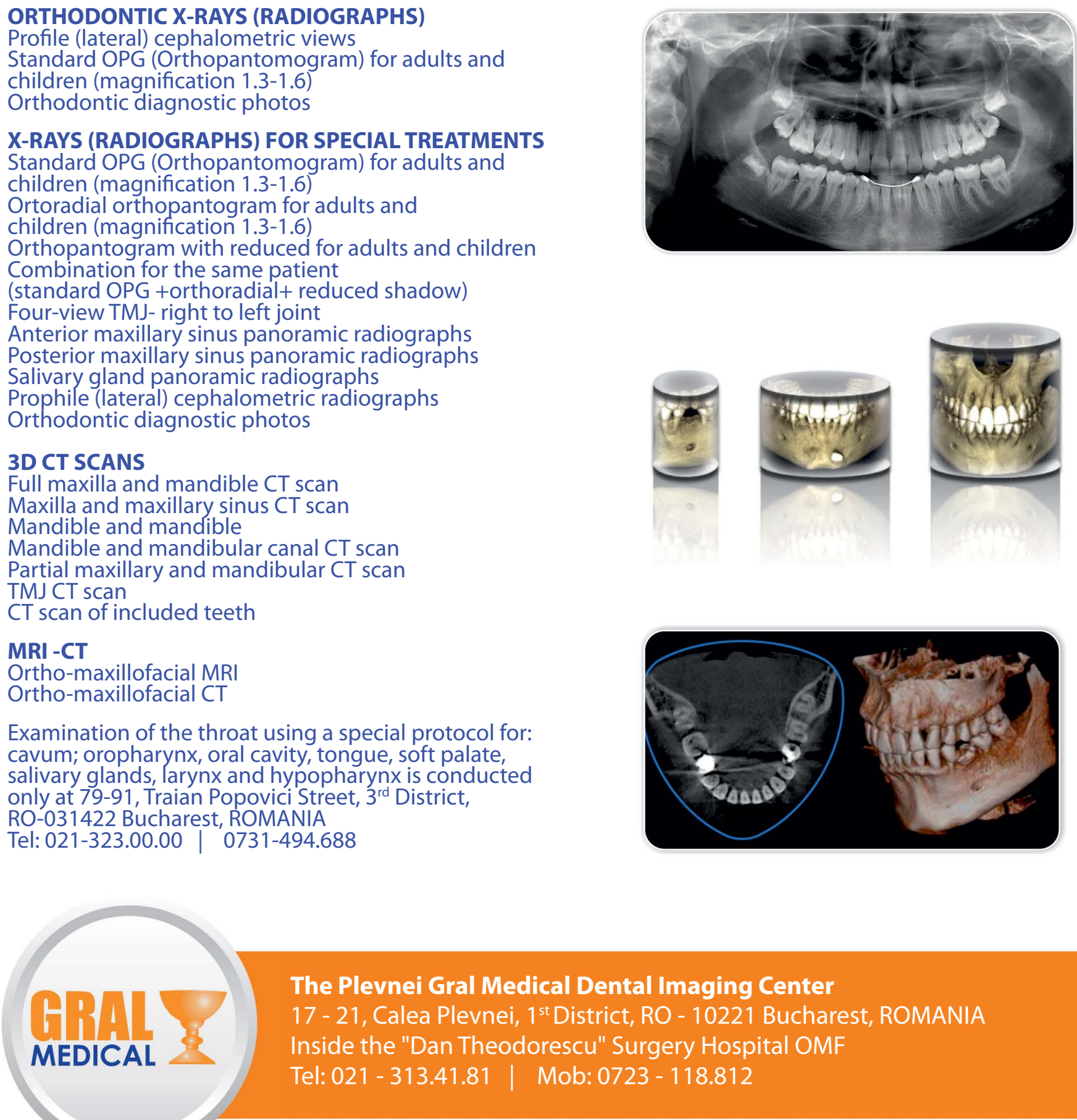


\section{fdic

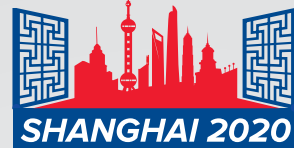 \\ World Dental Congress}

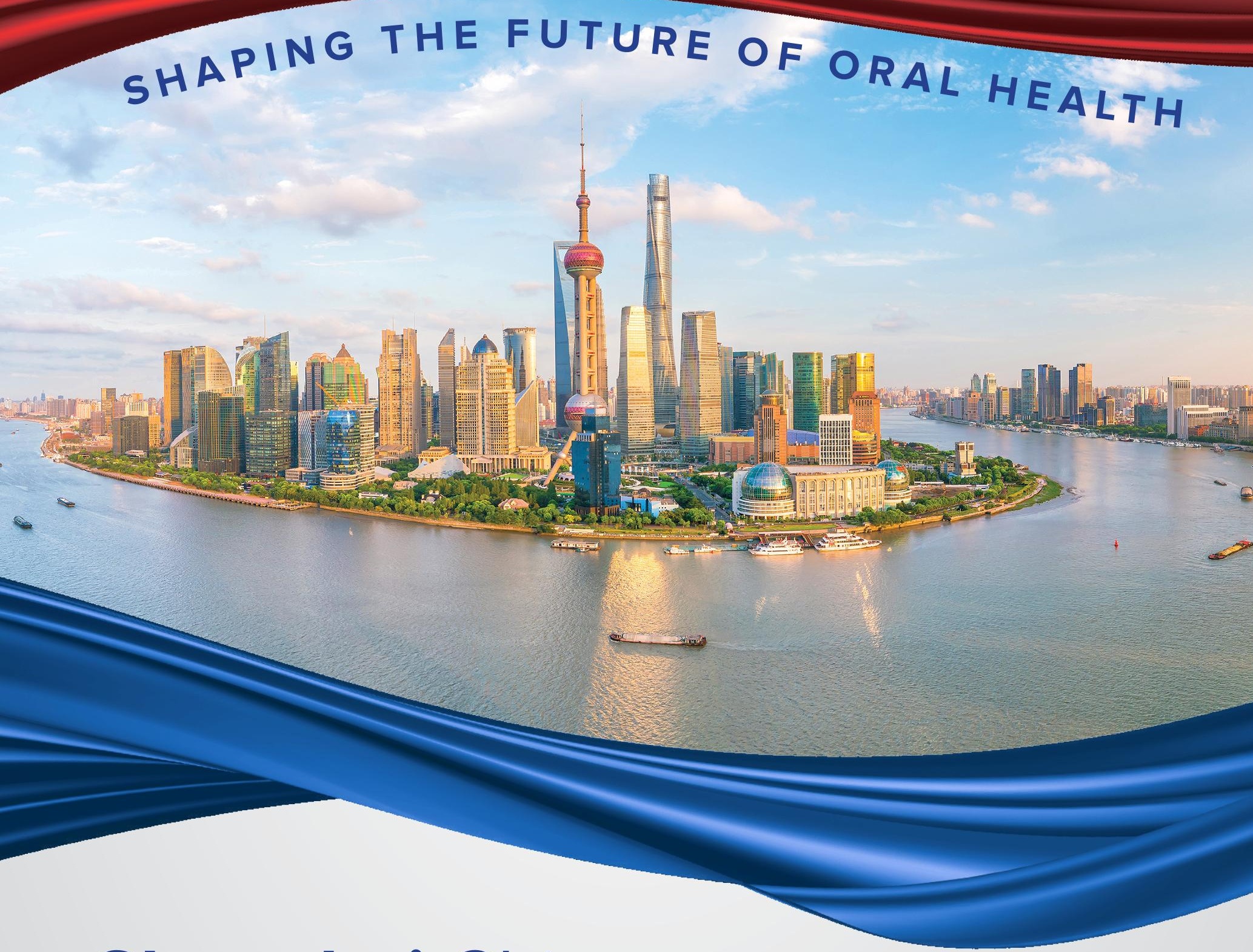

Shanghai China

NATIONAL EXHIBITION AND CONVENTION CENTER

1-4 September 2020
ABSTRACT SUBMISSION DEADLINE

25 March 2020

EARLY-BIRD REGISTRATION DEADLINE

31 May 2020 